
Katharina Habermann (Hg.)

Die Kalenderbriefe des Georg Albrecht Hamberger

This work is licensed under the

Creative Commons License 3.0 "by-nd",

allowing you to download, distribute and print the document in a few copies for private or educational use, given that the document stays unchanged and the creator is mentioned.

You are not allowed to sell copies of the free version.

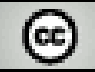

SOMEREIGHISRESERVED 
erschienen im Universitätsverlag Göttingen 2012 


\section{Die Kalenderbriefe des Georg Albrecht Hamberger}

im Kontext der Kalenderreform von 1700

herausgegeben und kommentiert von Katharina Habermann

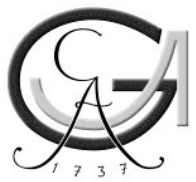

Universitätsverlag Göttingen 2012 


\section{Bibliographische Information der Deutschen Nationalbibliothek}

Die Deutsche Nationalbibliothek verzeichnet diese Publikation in der Deutschen Nationalbibliographie; detaillierte bibliographische Daten sind im Internet über $<$ http://dnb.ddb.de $>$ abrufbar.

\section{Autorenkontakt}

Katharina Habermann

e-mail: habermann@sub.uni-goettingen.de

Dieses Buch ist auch als freie Onlineversion über die Homepage des Verlags sowie über den OPAC der Niedersächsischen Staats- und Universitätsbibliothek (http://www.sub.uni-goettingen.de) erreichbar und darf gelesen, heruntergeladen sowie als Privatkopie ausgedruckt werden. Es gelten die Lizenzbestimmungen der Onlineversion. Es ist nicht gestattet, Kopien oder gedruckte Fassungen der freien Onlineversion zu veräußern.

Satz und Layout: Katharina Habermann Umschlaggestaltung: Franziska Lorenz

Titelabbildungen: Portrait und Siegel Georg Albrecht Hamberger; vollständige Unterschrift des Briefschreibers

J. G. Rabener (Hrg.): Deutsche Acta eruditorum oder Geschichte der Gelehrten, welche den gegenwärtigen Zustand der Literatur in Europa begreiffen.

Bd. 4, Leipzig 1715 [Frontispiz]

Exemplar: Niedersächsische Staats- und Universitätsbibliothek Göttingen

(C) 2012 Universitätsverlag Göttingen

http://univerlag.uni-goettingen.de

ISBN: 978-3-86395-094-1 
Das Verhältnis einer Epoche zur Vergangenheit beruht zu einem wesentlichen Bestandteil auf ihrem Verhältnis zu den Medien des kulturellen Gedächtnisses.

Aleida Assmann 


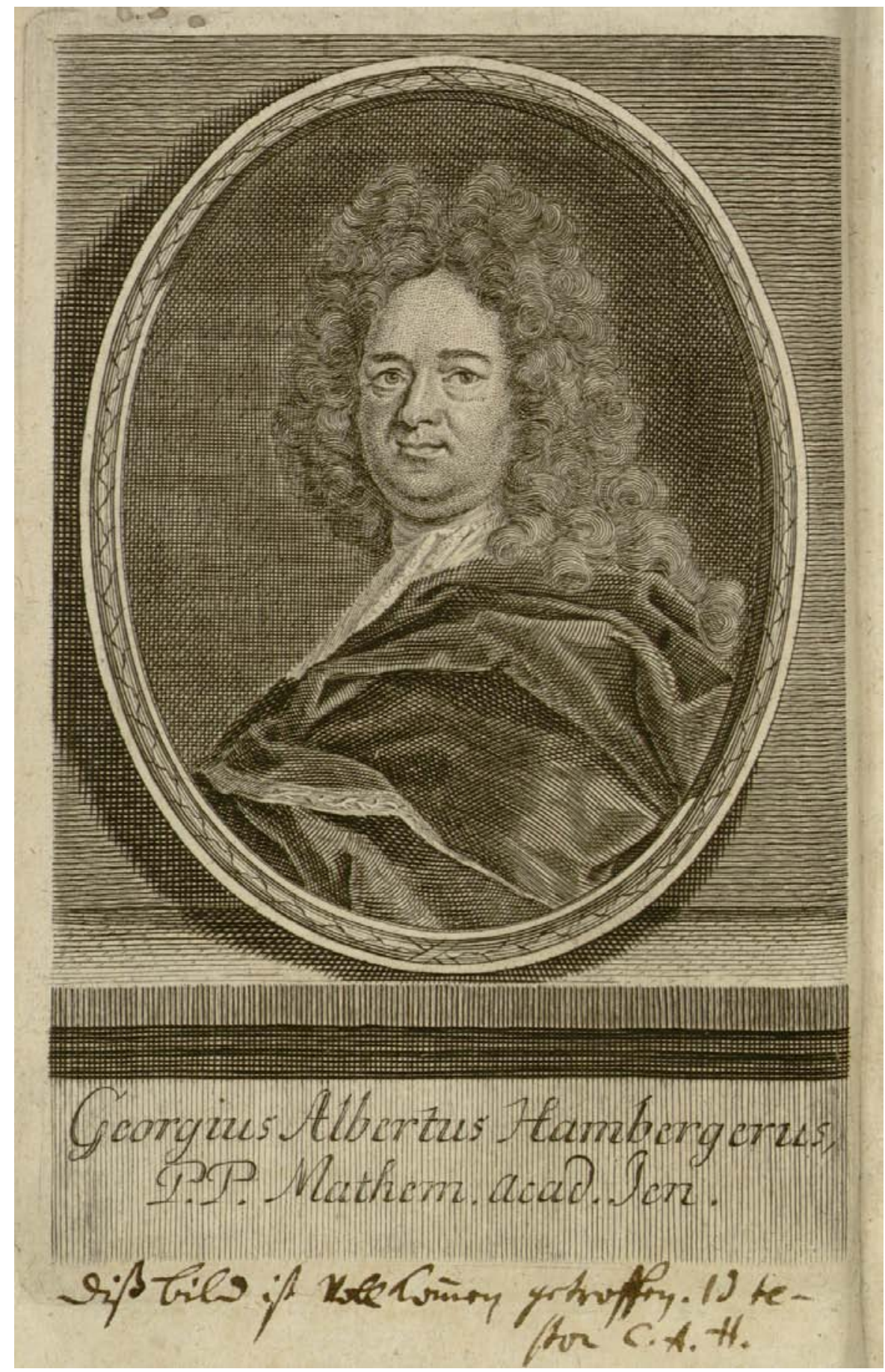




\section{Inhaltsverzeichnis}

Vorwort . . . . . . . . . . . . . . . . . . . . . . . . . . 9

Editionskriterien ....................... . . 13

\begin{tabular}{lll}
\hline 1 & Einführung & 17
\end{tabular}

Prolog . . . . . . . . . . . . . . . . . . 17

Die Rolle Erhard Weigels bei der Kalenderreform . . . . . . . . . . 18

Die Osterfestrechnung . . . . . . . . . . . . . . . . . . 21

Wer war Georg Albrecht Hamberger?. . . . . . . . . . . . . 26

$\begin{array}{lll}2 & \text { Briefe und Schriften } & 39\end{array}$

Chronologisches Verzeichnis der Briefe und Schriften . . . . . . . . 42

$3 \quad$ Ergänzende historische Veröffentlichungen 121

Conclusum vom 23. September 1699 . . . . . . . . . . . . . . 122

Conclusum vom 10.|20. Januar 1700 . . . . . . . . . . . . 123

Des ,Triumviri` Unvorgreiffliches Bedencken . . . . . . . . . . . . 124

Zum Unterschied zw. Verbessertem und Gregorianischem Kalender 136

4 Anhang 143

Symbole . . . . . . . . . . . . . . . . . . . . . . 143

Abkürzungen und Worterläuterungen . . . . . . . . . . . . . 143

Personenverzeichnis . . . . . . . . . . . . . . . . . 159 
Abbildungsnachweis

\begin{tabular}{ll}
\hline Literaturverzeichnis & 169
\end{tabular}

$\begin{array}{ll}\text { Register } & 189\end{array}$ 


\section{Vorwort}

Ein Konvolut, das unter der Signatur Cod. Ms. Philos. 60 an der Niedersächsischen Staats- und Universitätsbibliothek Göttingen aufbewahrt wird, enthält umfangreiches Material aus dem Nachlass des Regensburger Mathematikers Johannes Meyer (1651-1719), welches im Kontext der Kalenderreform von 1700 von historischem Interesse ist.

In der Manuskriptsammlung befinden sich insbesondere neunzehn an Johannes Meyer adressierte Briefe des Jenaer Mathematikers Georg Albrecht Hamberger (1662-1716) und zwei weitere Schriftstücke von dessen Hand. Diese Manuskripte aus den Jahren 1699 und 1700 stehen im Zusammenhang mit Aktivitäten der Beteiligten im Zuge der Kalenderreform von 1700, der Herausgabe von Kalendern sowie der Berechnung unseres Osterdatums. Bis auf den ersten Brief, welcher auszugsweise bereits in biographischen Arbeiten über den Jenaer Mathematiker, Astronomen, Philosophen und Pädagogen Erhard Weigel zitiert wurde, werden diese „Kalenderbriefe“ Hambergers in der hiermit vorgelegten Edition erstmals veröffentlicht und so vollständig zugänglich gemacht. Sie liefern einen repräsentativen Querschnitt zum politischen Ringen um die Kalenderreform des Jahres 1700 und stellen trotz der zu diesem Thema publizierten Materialfülle eine weitere Bereicherung der Quellenlage dar. Diese Unterlagen illustrieren nicht nur sehr anschaulich das historisch bekannte Geschehen, sondern bergen darüber hinaus auch Einiges an neuen und zum Teil überraschenden Erkenntnissen.

Der Verfasser der genannten Briefe und Schriften, der Astronom, Mathematiker, Physiker und Kalenderschreiber Georg Albrecht Hamberger wurde im Jahr 1662 geboren. Im Jahr 2012 jährt sich sein Geburtstag demnach zum 350sten Mal. Dieses Jubiläum dient als Anlass, mit einer kommentierten Herausgabe seiner Schriftstücke aus obigem Konvolut an diesen heute weitgehend unbekannten Mathematiker zu erinnern.

Als Mathematikerin mit den Studiennebenfächern Informatik und Physik wage ich mich mit dieser Briefedition auf für mich völlig neues Terrain. Bei der inhaltlichen Erschließung der Briefe habe ich mich so an den Briefen entlang gearbeitet, wie ich es von der Auseinandersetzung mit mathematischen Fachtexten gewohnt bin. Ergebnis dieser Bemühungen, den Inhalt der Briefe zu erfassen und zu verstehen, sind meine erläuternden Kommentare, die ich jedem der Briefe nachgestellt habe. In meiner Arbeitsmethode halte 
ich mich bei der Art und Weise der Literaturverweise ebenfalls an das, was ich aus dem mir vertrauten mathematischen Umfeld gewohnt bin. Im Unterschied zu bei Historikern üblichen Fußnoten, verweise ich im laufenden Text mit Hilfe eckiger Klammern auf die entsprechenden Quellen.

Meine Absicht ist es, mit dieser Briefedition bisher unveröffentlichtes Material für die Wissenschaftgeschichte zur Verfügung zu stellen. Parallel zur Kalenderdebatte etwa sind durch alle Briefe hindurch die Bemühungen um das von Erhard Weigel angestrebte Collegium Artis Consultorum sichtbar. Über dieses Collegium ist bisher nur wenig bekannt und an verschiedenen Stellen wird in diesem Zusammenhang auf das Konvolut Cod. Ms. Philos. 60 als wichtige noch auszuwertende Quelle verwiesen, so beispielsweise in der Edition der Korrespondenz des Astronomen und Kalendermachers Gottfried Kirch (1639-1710) [94, Seite XXv], in [166, Seite 2] oder auch [25, Seite 39]. Die hier bearbeiteten Briefe sind somit auch ein erster Schritt, dieses Material zugänglicher zu machen. Daneben enthalten die Briefe reizvolle Details aus der Welt eines Gelehrten zum Ende des 17. Jahrhunderts. Nicht zuletzt übte auf mich der Kontext des Werdens unseres Kalenders eine ganz besondere Faszination aus, wirkt doch das historische Ringen um die Kalenderreform bis in unser alltägliches Leben heute hinein.

Zur Person des Briefschreibers Georg Albrecht Hamberger habe ich für eine biographische Skizze ausschließlich das zusammenzutragen versucht, was bereits publiziert an verschiedensten Stellen aufzufinden war. Für eine fundierte wissenschaftshistorische Einordnung wären weitere Untersuchungen notwendig. Dazu gehört neben einer gründlichen Analyse seiner mathematischen Arbeiten beispielsweise auch das Studium von Archivmaterial, welches an der Universität Jena vorhanden ist.

Ohne die hilfreiche Unterstützung von Wissenschaftshistorikern und WeigelForschern, Kollegen und meiner Familie wäre diese Briefedition nicht möglich gewesen. Ihnen allen möchte ich an dieser Stelle ganz herzlich danken. Zu Dank verpflichtet bin ich den Organisatoren des 6. WeigelKolloquiums, welches am 10. Dezember 2011 in Jena stattfand, Professor Olaf Breidbach, Leiter des Ernst-Haeckel-Hauses in Jena, und Dr. KlausDieter Herbst, Vorsitzender der Erhard-Weigel-Gesellschaft. Sie gaben mir die Möglichkeit, dieses Editionsvorhaben erstmals öffentlich vorzustellen. Den Teilnehmern dieses Kolloquiums danke ich für das Interesse, welches sie meinem Projekt entgegenbrachten. Dr. Thomas Behme, Dr. Klaus-Dieter 
Herbst und Stefan Kratochwil von der Erhard-Weigel-Gesellschaft in Jena haben großzügig und geduldig meine zahlreichen Fragen beantwortet. Dr. Thomas Behme hat mir mit seinen prägnanten klaren Erläuterungen zu Weigels Philosophie von der Zeit und dem daraus resultierenden Versuch eines mathematischen Gottesbeweises außerordentlich weitergeholfen. Dr. KlausDieter Herbst teilte mit mir seine Erkenntnisse über das Verhältnis zwischen Gottfried Kirch und Ulrich Junius. Seine Edition der Korrespondenz des Astronomen und Kalendermachers Gottfried Kirch (1639-1710) 94 war für mich eine sehr wertvolle Quelle zum historischen Kontext der hier vorgestellten Briefe Georg Albrecht Hambergers. Stefan Kratochwil verdanke ich insbesondere die Information, dass Erhard Weigels Assistent Johann Heinrich Hoffmann (1669-1716) ein Enkel des früheren Jenaer Mathematikprofessors Heinrich Hofmann (1576-1652) war, dessen Nachfolge Erhard Weigel im Jahr 1653 antrat, und den Hinweis auf das Zitat einer entsprechenden schriftlichen Bemerkung Weigels in [93].

Professor Wenchao Li, Arbeitsstellenleiter der Leibniz-Edition Potsdam und Inhaber der Leibniz-Stiftungsprofessur der Leibniz Universität Hannover, danke ich für sein Interesse an dieser Kalenderbrief-Edition und den Hinweis auf eine Stellungnahme von Gottfried Wilhelm Leibniz „über einige Vorschläge Erhard Weigels" [129, Seite $741 \mathrm{ff}$.].

Besonderer Dank gilt Thony Christie für einen wunderbaren Tag zur Geschichte der Astronomie in Nürnberg, einschließlich der Besichtigung der erhaltenen Hälfte eines Weigelschen heraldischen Himmelsglobus am Germanischen Nationalmuseum, dazu eine eingehende und lebendige Schilderung der Gregorianischen Kalenderreform und der Rolle von Christopher Clavius sowie den wertvollen Hinweis auf die Wetterbeobachtungen Tycho Brahes. Im Sommer 2012 hatte ich die einzigartige Gelegenheit den Weigelschen heraldischen Himmelsglobus von Greenwich zu bewundern. Ich danke Sarah Kmosena vom National Maritime Museum in Greenwich ganz herzlich für die entgegenkommende Betreuung. Thank you so much! Kurz vor der Fertigstellung des Manuskripts erhielt ich noch von Dr. Ernst Böhme, Leiter des Städtischen Museums Göttingen, den Hinweis, dass der Göttinger Weigel-Globus bis Ende 2012 in der Sonderausstellung „Das Geschichtskabinett“ des Museums präsentiert wird. Herzlichen Dank auch dafür!

Ich habe sehr viel Unterstützung und Hilfe durch meine Kolleginnen und Kollegen an der Niedersächsischen Staats- und Universitätsbibliothek 
Göttingen erfahren. Stellvertretend für die freundliche Betreuung durch die Kollegen im „Altbau“ seien Dr. Christian Fieseler, Bärbel Mund, Dr. Helmut Rohlfing und Brunhilde Sobiech genannt. Christine Bethge und Bernd Laubenstein waren zur Stelle, um mir beim Verständnis einiger lateinischer Passagen behilflich zu sein - Fehler in den schriftlichen Übersetzungen habe allein ich zu verantworten. Dr. Wilfried Enderle hat mir unter anderem beim Entziffern einzelner schwierig zu entschlüsselnder Textstellen geholfen. Ganz besonders danke ich ihm für die Durchsicht einer früheren Fassung dieses Manuskripts. Margo Bargheer, Franziska Lorenz und Jutta Pabst vom Göttinger Universitätsverlag danke ich für ihre großzügige Unterstützung und dafür, dass sie sich für dieses Projekt begeistern konnten. Ich danke meinem Kollegen Dr. Norbert Pfurr, der mit Herzblut seine Sondersammelgebiete betreut, sodass ich keinerlei Mangel an benötigter Fachliteratur leiden musste. Insbesondere das zur Astronomie und ihrer Geschichte waren für mich besonders wichtig. Eine großartige Hilfe bei der Recherche nach betreffenden historischen Schriften war das Verzeichnis der im deutschen Sprachraum erschienenen Drucke des 17. Jahrhunderts unter www.vd17.de. In diesem Verzeichnis wird mit Förderung durch die Deutsche Forschungsgemeinschaft eine retrospektive Nationalbibliographie für den Zeitraum von 1601 bis 1700 erstellt, welche alle deutschsprachigen Titel und alle im historischen deutschen Sprachgebiet gedruckten und verlegten Werke aus diesem Zeitraum umfassen soll.

Professor Ilka Agricola von der Universität Marburg danke ich für ihr Interesse an der Thematik und für einen wichtigen Motivationsschub während der kritischen letzten Phase der technischen Fertigstellung des Manuskripts. Nicht zuletzt geht auch ein ganz, ganz herzliches Dankeschön an meine Familie, ohne die ich mich diesen „Kalenderbriefen“ nicht mit der notwendigen Intensität hätte zuwenden können.

Göttingen, im November 2012

Katharina Habermann 


\section{Editionskriterien}

Bei den im Cod. Ms. Philos. 60 vorhandenen Briefen Georg Albrecht Hambergers handelt es sich um Briefe, die hauptsächlich in der zum Ende des siebzehnten Jahrhunderts als Schreibschrift in Briefen gebräuchlichen deutschen Kurrentschrift geschrieben sind. Da das Lateinische verbreitete Wissenschaftssprache war, finden sich in den Briefen bisweilen lateinische Begriffe oder ganze lateinische Passagen. Die Gelehrten verfassten ihre Korrespondenzen und Publikationen meist der Zeit entsprechend lateinisch. Dass das Deutsche in der Bildung nur eine untergeordnete Rolle spielte, äußerte sich insbesondere in einem uneinheitlichen Gebrauch der deutschen Sprache.

Für diese Edition wurden sämtliche Briefe vollständig und ungekürzt transkribiert. Da Briefe für gewöhnlich ein hohes Maß an Authentizität aufweisen, erfolgt die Wiedergabe der Texte wort- und buchstabengetreu. Bezüglich der Groß- und Kleinschreibung gelten dabei die folgenden Grundsätze. Prinzipiell wurde die Groß- und Kleinschreibung der Vorlage übernommen. Als einzige Ausnahme wurde im Interesse einer besseren Lesbarkeit für deutsche Substantive die Großschreibung gewählt. Bei lateinischen Worten und Passagen wurde grundsätzlich der Groß- und Kleinschreibung des Originals gefolgt. Die Wechsel der Schriftart zwischen dem Deutschen und den lateinischen Passagen werden dadurch kenntlich gemacht, dass die lateinischen Begriffe serifenlos als sans serif gesetzt werden.

Eigentümlichkeiten in der Rechtschreibung wurden durchgängig beibehalten, da aufgrund des damaligen Gebrauchs der deutschen Sprache nicht zweifelsfrei entschieden werden kann, ob es sich überhaupt um orthographische Fehler oder um orthographische Eigenarten des Briefschreibers handelt oder ob uns das Ganze heute lediglich als fehlerhaft erscheint. So wird das Wort kan von Hamberger stets mit einem ,n` geschrieben, während könnte in seinen Briefen stets mit doppeltem , $n^{6}$ geschrieben wird. Häufig begegnet uns in den Briefen auch das Wort mögte, welches der Aussprache gemäß heute als möchte geschrieben werden müsste, siehe [153, Seite 271]. Da sich trotz Hambergers deutlicher Handschrift die Interpunktion nicht immer eindeutig entziffern ließ, wurden in Zweifelsfällen geringfügige Eingriffe in die Zeichensetzung vorgenommen. Dabei wurde versucht, sich an der Intention des Autors zu orientieren.

Verkürzungen wurden stillschweigend aufgelöst, so zum Beispiel der waage- 
rechte Verdopplungsstrich über dem , $\mathrm{m}^{\prime}$ oder das Kürzel für die lateinische Wortendung -us. Punkte über dem , $\mathrm{y}^{6}$, beispielsweise bei den Worten se oder be $\ddot{y}$ werden nicht mit angegeben. Das als Abkürzung benutzte über die untere Schriftlinie hinaus verlängerte kleine,$l^{\natural}$ wird durch das Sonderzeichen $\ell$ wiedergegeben und nicht weiter übersetzt, beispielsweise "dienst $\ell$ Dank" für „dienstschuldigen Dank“. Die historischen Abkürzungen ,thlr" für Taler, ,gl' für Gulden und ,d` für Pfennige werden als solche wiedergegeben und nicht aufgelöst. Astronomische Zeichen, wie zum Beispiel $\odot$ für die Sonne, werden im Verzeichnis der Symbole auf Seite 143 entschlüsselt. Korrekturen, Ergänzungen, Streichungen und Einschübe, die der Briefschreiber selbst vorgenommen hat, wurden übernommen, ohne die ursprüngliche Variante kenntlich zu machen. Es wurde nicht versucht, das Originallayout der Briefe wiederzugeben. Bei Grußformeln, Orts- und Datumsangaben wurde die Anordnung gemäß der Vorlage nachempfunden. Zeilenumbrüche und größere Abstände innerhalb einer Textzeile der Vorlage werden nicht kenntlich gemacht. Seitenwechsel in den Briefen werden durch neue Absätze und die zugehöhrige Blattzählung umgesetzt. Bei der Blattzählung der Briefe wird neben der vorangestellten Nummerierung in eckigen Klammern durchgängig die recto-Seite, das heißt die Vorderseite, mit einen zusätzlichen $r$ sowie die verso-Seite, also die Rückseite, mit einem $v$ kenntlich gemacht, zum Beispiel [426v] für die Rückseite von Blatt Nr. 426.

In einigen Fällen sind in der vorliegenden Sammlung neben den Briefen auch die Papierbögen erhalten, die gefaltet als Briefkuvert gedient haben und mit der in französisch abgefassten Anschrift des Empfängers sowie meist auch mit dem Siegel des Absenders versehen sind. Briefkuverts, die vorhanden sind, werden ebenfalls wiedergegeben. Ein einziger Brief, und zwar der vom 14. Oktober 1699, weist geringe Papierschäden auf. Dem Inhalt nach zu urteilen, ist der Brief vor dem Absenden noch einmal geöffnet worden, um das zweite Postskriptum zu ergänzen, und dann so wieder geschlossen worden, dass beim Öffnen durch den Empfänger an dieser Stelle das Papier punktuell Schaden genommen hat. Bei den wenigen fehlenden Textstellen wurde eine denkbare Interpretation ergänzt und in eckige Klammern [...] gesetzt, Seite 72. Einige Briefe enthalten Notizen des Empfängers. Diese nachträglichen Zusätze von einer anderen Hand wurden ebenfalls übertragen und werden durch einen expliziten Vermerk in eckigen Klammern angezeigt.

Die Wiedergabe der Briefe erfolgt in ihrer chronologischen Reihenfolge in separaten Abschnitten, die jeweils mit dem entsprechen Datum des Briefes 
überschrieben sind. Jeder der Briefe ist innerhalb seines Abschnitts mit einem unmittelbar nachfolgenden Kommentar versehen.

Alle in den Briefen genannten und eindeutig identifizierbaren Personen werden im Personenregister ab Seite 159 verzeichnet. Die Personen werden dabei mit kurzen Informationen zur Biographie vorgestellt, soweit es im Kontext der Briefe erforderlich scheint. Dass dabei keine Vollständigkeit angestrebt werden kann, versteht sich von selbst, sind doch die biographischen Quellen zu einzelnen Personen zum Teil sehr umfangreich. Grundsätzlich lassen sich alle gemachten Angaben zu den Personen in den im Literaturverzeichnis aufgelisteten Nachweisen auffinden, auf Einzelnachweise wird aus Platzgründen verzichtet. Die von Hamberger benutzten Abkürzungen P., D. und M. stehen für die akademischen Titel Professor, Doktor und Magister, also nicht für abgekürzte Vornamen. In den Briefen benutzte weitere Abkürzungen sowie lateinische Worte und Phrasen wurden weitestgehend und möglichst vollständig in das Verzeichnis der Abkürzungen und Worterläuterungen ab Seite 143 aufgenommen. Da sich diese Edition nicht nur an eine geschulte Leserschaft, sondern auch an interessierte Laien richtet, wurden dabei lateinische Worte, deren Bedeutung nicht aus dem Zusammenhang hervorgeht, übersetzt, sowie veraltete und untergegangene Worte erläutert. Die Angaben basieren in der Regel auf dem Deutschen Wörterbuch von Jacob und Wilhelm Grimm [55]. Auf einzelne Quellenangaben bei den Worterläuterungen wird auch hier aus Platzgründen verzichtet. Es wurde versucht, längere lateinische Textpassagen und Sätze jeweils in den einzelnen den Briefen nachgestellten Kommentaren zu übersetzten.

Sämtliche Datumsangaben erfolgen entsprechend der für den Briefschreiber gültigen Zeitrechnung. Danach bezieht sich die Datierung bis zur Realisierung der Kalenderreform von 1700, das heißt, bis einschließlich Februar 1700, auf den Julianischen Kalender, während sich alle Datierungen ab März 1700 nach dem sogenannten „Verbesserten“ Kalender richten. An der Einführung des Verbesserten Kalenders im Jahre 1700 war der Briefautor Georg Albrecht Hamberger maßgeblich beteiligt und genau darum dreht sich alles in den mit dieser Edition vorgelegten „Kalenderbriefen“. 



\section{1}

\section{Einführung}

\section{Prolog}

Mit einer päpstlichen Verfügung, der Bulle „Inter gravissimas“ [2, wurde im Jahr 1582 der schließlich nach Papst Gregor XIII. (1502-1585) benannte Gregorianische Kalender eingeführt. In Deutschland wurde dieser neue Kalender anfangs jedoch nur von den katholisch regierten Ländern übernommen. Die protestantischen lehnten ihn grundsätzlich - weil vom Papst angeordnet - ab. Das führte zum Paradoxon einer doppelten Kalenderführung in Deutschland während des gesamten 17. Jahrhunderts. Die katholischen Regionen benutzten den Gregorianischen Kalender, während man in den protestantischen Territorien noch nach Julianischem Kalender lebte. Für die Zeit, während der beide Kalender nebeneinander galten, ist bei der Datierung beispielsweise von Briefen die Konfession des Verfassers zu beachten. Häufig wurde bei offiziellen Dokumenten das Datum mit einem Zusatz gekennzeichnet, zum Beispiel „st.v." bei alter Zeitrechnung, oder eine doppelte Datumsschreibweise verwandt, bei der man Tage und gegebenenfalls auch Monate als Bruch darstellte.

Das Problem der doppelten Kalenderführung wurde während dieser Zeit immer wieder sowohl seitens der Kirche als auch durch die Wissenschaft thematisiert und leidenschaftlich diskutiert. Als ausführliche Darstellung dazu 
sei auf das Buch zur Gregorianischen Kalenderreform von Dirk Steinmetz hingewiesen [172].

Nachdem die Spaltung der Zeitrechnung und des Kalenderwesens in Deutschland über ein Jahrhundert angedauert hatte, wurde die Kalenderreform letztendlich mit einem Beschluss der evangelischen Reichstände auf dem Immerwährenden Reichstag in Regensburg von den protestantischen Ländern in Deutschland im September 1699 angenommen und im Jahr 1700 umgesetzt. Diese Kalenderreform, so wie sie schließlich realisiert worden ist, ist sehr eng mit dem Namen Erhard Weigel verknüpft, siehe damalige Zeitdokumente wie zum Beispiel [200, Band 5, Spalten 236 und 238], oder "Proclama des verbesserten Calenders" in [14, Seiten 10-27]. Leider ist diese Verbindung heute überhaupt nicht mehr im öffentlichen Bewusstsein verankert.

\section{Die Rolle Erhard Weigels bei der Kalenderreform}

Erhard Weigel (1625-1699) stammte aus der oberpfälzischen Stadt Weiden, studierte von 1647 bis 1650 an der Leipziger Universität und war dort anschließend als Privatgelehrter tätig. 1653 erhielt er einen Ruf an die Universität Jena, wo er bis zu seinem Tod 1699 als Astronom und Mathematiker wirkte. Schon seit 1652 befasste er sich immer wieder mit dem Problem der unterschiedlichen Kalendersysteme. So fand am 24. Januar 1652 an der Universität Leipzig unter seinem Vorsitz eine Disputation zu diesem Thema statt [179]. Mit dem Respondenten Christoph Vogel wurde die Arbeit „De Tempore in genere“ erörtert. Im Jahr 1664 kam Weigels „Bürgerlicher Zeitspiegel" heraus, in dem er unter anderem den in Deutschland praktizierten „Kalender-Unfug" kritisierte [180]. Gegenstand seiner Kritik war neben der doppelten Kalenderführung die verbreitete Gepflogenheit, Kalender stets zusammen mit einem wahrsagerischen Teil, den sogenannten Prognostiken, zu publizieren. Diese Prognostiken enthielten sowohl meteorologische Vorhersagen für das folgende Jahr als auch Prophezeiungen mit Orientierungshilfen in wichtigen alltäglichen Lebensfragen der Menschen. Weigel, der sich neben der Erteilung von Nachhilfeunterricht mit Schreibarbeiten im Dienste eines Astrologen und mit dem Erstellen von Horoskopen 
die Finanzierung seines Studiums erarbeitet hatte, wusste, wovon er sprach. Der „Zeitspiegel“, eine gut 120 Seiten umfassende Schrift, erschien zeitlich geschickt platziert, da im Frühjahr 1664 auf dem Immerwährenden Reichstag in Regensburg die von allen Seiten als inzwischen dringend notwendig erachtete Kalenderreform behandelt wurde. Weigel versuchte, das Thema Kalenderreform für den Regensburger Reichstag auch noch auf einer anderen Ebene vorzubereiten. Dazu traf er sich in Leipzig mit Professoren der sächsischen Universitäten Wittenberg und Leipzig, um über den „KalenderUnfug“ zu beraten'1. Dies waren der Mathematiker Christoph Nothnagel (1607-1666) und der Theologe Aegidius Strauch (1632-1682) von der Universität Wittenberg sowie der Mathematiker Johannes Kühn (1619-1676) von der Universität Leipzig, siehe [184, Seite 9], zu Johannes Kühn auch siehe [34]. Diese Drei wandten sich dann an ihre jeweiligen Landesherren, „Worauf Gnädigster Befehl ergangen, an die beyderseits zu Regenspurg anwesenden Chur- und Fürstl. Herren Gesandten, daß, wenn der von dem Calender handlende vierdte Punkt der Kayserl. Reichs-Tags-Proposition vorkommen würde, dieser Vorschlag in Consideration gezogen werden solte" [184, Seite 9]. Die protestantische Seite lehnte die Übernahme des Gregorianischen Kalenders jedoch ab. Das Protokoll des Reichstags konstatierte dazu am 2.|12. April 1664 in der Kalendersache die Uneinigkeit darüber, ob es sich in dieser Angelegenheit um eine weltliche oder religiöse Frage handele, vgl. [157. Seite 177], man also überhaupt dafür zuständig sei oder nicht. Doch Weigel verlor Zeitrechnung und Kalenderproblematik nicht aus den Augen.

Mehrere Jahre später, 1677 erschien Weigels kurze Einführung in die Zeitmesstechnik [183] und 1681 soll er einen weiteren, gleichwohl erfolglosen, politischen Vorstoß für die Kalenderreform unternommen haben. Angeblich hat er Sachsen von seinen Plänen zur Kalenderreform erneut soweit überzeugen können, dass der von November 1681 bis März 1682 tagende Sächsische Landtag 1681/82 beschlossen haben soll, die Kalendersache wieder auf die Agenda des Regensburger Reichstags zu bringen, siehe [84. Folgt man jedoch Weigel selbst, zum Beispiel [184, Seite 10], scheint es auf der genannten Landtagssitzung hingegen nicht um Weigels Vorschläge zur Kalenderreform, sondern um seine pädagogischen Reformideen gegangen zu sein.

Nachdem Georg Albrecht Hamberger im Jahr 1694 zunächst als außerordentlicher und im Jahr darauf als ordentlicher Professor die Nachfolge Er-

\footnotetext{
${ }^{1}$ Schaper schreibt in [158, dieses Treffen habe 1667 stattgefunden. Das kann aber nicht sein, da Nothnagel bereits 1666 verstorben war.
} 
hard Weigels in Jena angetreten hatte, konnte Weigel seine Kräfte konzentrieren und sich mit wesentlich höherer Intensität seiner Bestrebungen zur Kalenderreform annehmen. In den Jahren 1696 und 1697 reiste Weigel zum Beispiel nach Dänemark und Schweden, um für die Zustimmung der dortigen Höfe zu werben. Außerdem unterbreitete er 1697 dem Immerwährenden Reichstag in Regensburg seinen Vorschlag für einen „Verbesserten Reichskalender", nun verknüpft mit einen Plan zur Schaffung eines sogenannten Collegium Artis Consultorum, dem auch die Aufsicht über das Kalenderwesen in Deutschland übertragen werden sollte. Letzteres war von Weigel in gewissem Sinne als Akademie und Patentanstalt gedacht, sollte durch ein Kalendermonopol finanziert werden und ist auch im Zusammenhang mit der Gründung der Berliner Akademie durch seinen Schüler Gottfried Wilhelm Leibniz (1646-1716) im Jahr 1700 von Interesse'2. Neben seinen inhaltlich auf die notwendige Kalenderreform fokussierten Bestrebungen und der institutionalisierten Begleitung durch das angestrebte Collegium Artis Consultorum setzte Weigel enorme Kosten und Personal ein, um bei den politischen Entscheidungsträgern für seine Vorhaben zu werben. An Fürstenhöfen versuchte Weigel mit seinen heraldischen Himmelsgloben sowie bei europäischen Königen und am Wiener Kaiserhof mit überdimensionalen Riesengloben, seinen sogenannten Pancosmen, die Aufmerksamkeit und politische Unterstützung der Herrscherhäuser zu gewinner ${ }^{3}$, Die letzten Jahre waren insbesondere von terminlichen Feinjustierungen und in der politisch-religösen Diskussion von der Abgrenzung zum Gregorianischen Kalender geprägt. So hatte Weigel in seinem Vorschlag von 1697 noch empfohlen, die 10 Tage zwischen dem 18. und 29. November 1699 auszulassen. Zwei Jahre später legte er den besagten Termin für den Kalenderwechsel wenige Tage vor, dem 15. November sollte der 26. November 1699 folgen. Eine Erklärung für diese Änderung lieferte Weigel selbst, indem er es als kanonisch darstellte, den Kalender alten „Stylus“ bis einschließlich 15. November, dem Namenstag Kaiser Leopolds I., gelten zu lassen und mit dem darauffolgenden Tag den Wechsel zu vollziehen, siehe [188. Dass Weigel so auf einen Kalenderwechsel im Jahr 1699 drängte, lag auch an der Tatsache, dass die Differenz zwischen Julianischem und Gregorianischen Kalender im

\footnotetext{
${ }^{2}$ Der junge Erhard Weigel begegnete Leibniz' Vater, dem Juristen und Professor Friedrich Leibnütz, bereits während seiner Studienzeit an der Leipziger Universität und Gottfried Wilhelm Leibniz studierte 1663 bei Weigel in Jena.

${ }^{3} \mathrm{Zu}$ den heraldischen Himmelsgloben und Pancosmen siehe auch ab Seite 46.
} 
Februar 1700 auf 11 Tage anwuchs 4 ,

Leider konnte Weigel den Erfolg seines Engagements nicht mehr selbst miterleben. Auf seiner Rückreise vom Immerwährenden Reichstag in Regensburg, wo er Ende Februar 1699 in Sachen Kalenderreform zu tun hatte, erkrankte er so ernst, dass er nach kurzer Krankheit am 21. März 1699 in Jena verstarb, vgl. dazu auch den ersten Brief Hambergers vom 25. März 1699 ab Seite 43 . Was aber mögen seine Beweggründe für diesen beeindruckenden persönlichen Einsatz für die Kalenderreform gewesen sein? Lassen wir ihn dazu selbst zu Wort kommen: „Denn die Professores Academici sind von dem Publico ... dazu bestellt, daß jeder das, was seiner function gemäß, zu des gemeinen Wesens Nutz anbringen, und, wann irgendwo ein Fehler eingeschlichen, solchen unmaßgeblich anzudeuten sich bemühen soll" [184, Seite 9].

\section{Die Osterfestrechnung}

Grundsätzlich besteht ein Kalender aus zweierlei Komponenten. Zum einen finden wir hierin als formale Struktur die Einteilung eines Sonnenjahrs in Monate, Wochen und Tage. Auf diese Weise wird jedem Tag eine eindeutig bestimmte Datumsangabe gemäß Tag, Monat und Jahr zugeordnet. Zum anderen ist die Platzierung der Feiertage im Gefüge der Tageseinteilung ein erforderlicher Bestandteil jedes Kalenders. Dabei wird zwischen unbeweglichen Feiertagen, die in jedem Jahr auf das gleiche Datum fallen, und beweglichen Feiertagen, die von Jahr zu Jahr auf unterschiedliche Kalendertage fallen können, unterschieden. Unbewegliche gesetzliche Feiertage in Deutschland gemäß Gregorianischem Kalender, der offizielle Grundlage unserer Zeitrechnung ist, sind beispielsweise Neujahr, der 1. Mai oder Weihnachten. Beispiele für bewegliche Feiertage sind Ostern, Christi Himmelfahrt, Pfingsten oder der Buß- und Bettag. Dabei sind bis auf den Buß- und

\footnotetext{
${ }^{4}$ Da 1700 im Julianischen Kalender ein Schaltjahr im Gregorianischen Kalender jedoch ein Gemeinjahr ist, entsprach der 18. Febrauar 1700 im Julianischen Kalender dem 28. Februar Gregorianisch, der 19. Febrauar aber dem 1. März. Bis zum 18. Febrauar 1700 nach Julianischem Kalender betrug die Differenz zwischen dem Julianischen und dem Gregorianischen Kalender 10 Tage, am darauffolgenden Tag erhöhte sie sich auf 11 Tage.
} 
Bettag, welcher als Feiertag der evangelischen Kirche am Mittwoch vor dem 23. November gefeiert wird, alle beweglichen bundeseinheitlich gesetzlichen Feiertage vom Datum des Osterfestes abhängig. Da das Osterfest um den Tod und die Auferstehung Jesu Christi eines der ältesten und wichtigsten Feste des Christentums und von zentraler Bedeutung für den christlichen Glauben ist, wollen Christen dieses Fest auch zum richtigen Zeitpunkt feiern.

Wir alle kennen die Darstellung, dass der Überlieferung zufolge Ostersonntag der erste Sonntag nach dem Frühlingsvollmond ist. Dabei bezeichnet man als Frühlingsvollmond den ersten Vollmond, der im Frühling, also nach dem Frühlingsanfang, stattfindet. Frühlingsanfang ist astronomisch gesehen der Tag im März, an welchem Tag und Nacht gleich lang sind. Angesichts ebenjener Festlegung des astronomischen Frühlingsanfangs heißt dieser Zeitpunkt auch Frühlings-Tag-und-Nacht-Gleiche beziehungsweise Frühlings-Äquinoktium, seinem lateinischen Ursprung nach. Der astronomische Frühlingsanfang kann auf einen der drei Tage 19., 20. oder 21. März fallen. Der entsprechende Tag ist stets in unseren Kalendern als Frühlingsanfang gekennzeichnet. Demzufolge scheint die Bestimmung des Ostertermins eine klare Angelegenheit zu sein. Dank der Astronomie und ihrer präzisen Beobachtungsdaten kann man genaue Vorhersagen darüber machen, wann Frühlingsanfang ist, kann den ersten darauf folgenden Vollmond bestimmen und somit auch den Ostertermin. Dennoch scheint das Ganze nicht so einfach zu sein, wie es sich aus naturwissenschaftlicher Sicht darstellt.

Von seinem Ursprung her steht das christliche Osterfest sowohl inhaltlich als auch zeitlich in sehr enger Beziehung zum jüdischen Passahfest. Dieses Fest wird ein Woche lang gefeiert und beginnt am 15. Nisan, dem fünfzehnten Tag des jüdischen Mondmonats, der mit dem ersten Sichtbarwerden der Mondsichel nach dem Neumond, der auf die Frühlings-Tag-und-NachtGleiche folgt, beginnt. Den Auftakt zum Passahfest bildet der Vorabend am 14. Nisan, dem Tag auf den wegen des Monatsbeginns zu Neumond ein Vollmond fällt. Bezugspunkt ist dabei Jerusalem. Außerdem kann dieser Tag auf jeden beliebigen Wochentag fallen, während die Auferstehung Jesu Christi nach biblischer Überlieferung auf einen Sonntagmorgen fällt.

Auf Grund der territorialen Ausdehnung des Römischen Reiches und der Heterogenität der christlichen Gemeinden in allen Regionen dieses Reiches war die Festlegung des Ostertermins sehr uneinheitlich geregelt. Um über 
den Termin dieses Festes einen Konsens zu finden, wurde die Festlegung des Osterdatums auf die Agenda des ersten Konzils von Nicäa gesetzt. Dieses Konzil war eine Bischofskonferenz, welche vom römischen Kaiser Konstantin I. im Jahr 325 in die kleine Stadt Nicäa einberufen wurde und Grundfragen des christlichen Glaubens behandelte. Obwohl keine Akten oder Protokolle zu den Beschlüssen dieses Konzils erhalten sind, soll es in Sachen Ostertermin festgelegt haben, dass der 21. März (per definitionem) der Tag der Frühlings-Tag-und-Nacht-Gleiche ist und dass Ostern am ersten Sonntag nach dem Vollmond zu feiern ist, der auf diesen festgesetzten Termin der Frühlings-Tag-und-Nacht-Gleiche folgt. Anderen Darstellung zufolge habe das Konzil lediglich geboten, dass das Osterfest am Sonntag nach dem jüdischen Passahfest gefeiert werden solle, siehe beispielsweise [64]. Auf jeden Fall sollte aus religiösen Gründen vermieden werden, dass Ostern mit dem Passahfest zeitlich zusammenfällt. Hauptsächliches Resultat dürfte zumindest die Forderung nach einem einheitlichen Ostertermin für alle Christen gewesen sein. Der darin ausgedrückte Wunsch nach Einheit hat noch heute große Bedeutung, denn einen einheitlichen Ostertermin aller Christen gibt es bis heute nicht. Vielmehr wurde nach dem Konzil von Nicäa versucht, für die Festlegung des Osterdatums formale Rechenvorschriften zu entwickeln. Zum einen wollte man vom jüdischen Passahfest unabhängig werden, zum anderen waren exakte astronomische Vorhersagen des Frühlings-Äquinoktiums sowie der Vollmonde zur damaligen Zeit unmöglich. Mit einer Festlegung des Frühlings-Äquinoktiums auf den 21. März und gewisser vereinfachender Annahmen an die Bewegung des Mondes, wie zum Beispiel der Beschreibung der Mondbewegung als Bewegung auf einer kreisförmigen Bahn, hatte man schließlich die Mondphasen für neunzehn Jahre berechnet. Dabei wird von einem neunzehnjährigen Mondzyklus ausgegangen, wonach jede Mondphase nach jeweils neunzehn Jahren wieder auf das gleiche Datum fällt. Einmal darauf festgelegt und dann jeweils nach Ablauf dieser Zeitspanne von neunzehn Jahren wieder von vorn beginnend, richtete man sich in der Folge nach den so einmal fixierten Datumsangaben für das Osterfest. Auf diese Weise fiel Ostern nach jeweils neunzehn Jahren immer wieder auf denselben Termin - völlig unabhängig vom tatsächlichen astronomischen Geschehen. Dieser 19-Jahre-Zyklus zusammen mit dem seit 45 v. Chr. gültigen Julianischen Kalender bestimmte schließlich bis in das sechzehnte Jahrhundert hinein das Osterdatum sowie die davon abhängenden Festtage, vgl. auch Seite 138 . 
Schaut man sich den Julianischen Kalender genauer an und vergleicht die darin angesetzte Länge eines Kalenderjahrs mit der Länge eines Sonnenjahres, wird man gewahr, dass ein Julianisches Kalenderjahr etwa $11 \mathrm{Mi}-$ nuten länger als das dem wahren astronomischen Sonnenlauf entsprechende Sonnenjahr ist. Über einen Zeitraum von eintausend Jahren summiert sich diese Differenz bereits zu fast acht Tagen auf, sodass schon im vierzehnten Jahrhundert Reformbestrebungen einsetzten, die jedoch erst mit der Gregorianischen Kalenderreform von 1582 ihren Abschluss fanden. Als primärer Beweggrund für die Einführung des neuen Kalenders kann angesehen werden, dass man das Osterfest zum ,richtigen' Zeitpunkt feiern wollte. Mit der Einführung des Gregorianischen Kalenders wurde zudem die Berechnung des Osterdatums präzisiert. Prinzipiell wird in dieser verbesserten Osterfestrechnung ebenfalls nach einem zyklischen Schema vorgegangen, welches auf Berechnungen zur Bewegung des Mondes basiert. Dieser Zyklus hat ebenfalls eine Länge von neunzehn Jahren, wird allerdings zu bestimmten Zeitpunkten korrigiert. Auf diese Weise werden frühere Abweichungen auf ein historisches Minimum reduziert. Dieses neue zyklische Berechnungsschema nähert die tatsächliche Bewegung des Mondes bereits außerordentlich gut an und ist auch heute noch die Berechnungsgrundlage für das Osterdatum in unserem Kalender. Doch die Annahmen, die dabei über die Bewegung des Mondes gemacht werden, sind Vereinfachungen, die immer wieder zu Abweichungen vom tatsächlichen astronomischen Lauf des Mondes führen können. Auch wenn diese Abweichungen sehr selten auftreten, war bereits bei der Einführung des Gregorianischen Kalenders mit seiner verbesserten Osterfestrechnung bekannt, dass derartige Abweichungen möglich sind und sich auch wirklich ereignen.

Derartige Abweichungen des Osterdatums im Kalender vom astronomisch eigentlich korrekten Datum werden als Osterparadoxien bezeichnet. Osterparadoxien können insbesondere immer dann auftreten, wenn Frühlingsanfang und Frühlingsvollmond nahe beieinander liegen. Das letzte Osterparadoxon fand im Jahr 2000 statt, das nächste steht uns für das Jahr 2019 ins Haus. Laut zyklischer Berechnung gemäß der Osterregel des Gregorianischen Kalenders ist Ostersonntag am 21. April 2019, während astronomisch korrekt der 24. März 2019 der erste Sonntag nach dem Frühlingsvollmond ist und so der astronomisch, wahre' Ostersonntag wäre. Auf Grund dieser möglichen und immer wieder auftretenden Differenzen war die Osterfestrechnung in der Diskussion um die Einführung des Gregorianischen Kalen- 
ders von entscheidender Bedeutung.

Bei der von den protestantisch regierten Ländern verkündeten grundsätzlichen Ablehnung des vom Papst angeordneten neuen Kalenders muss man auch die kurz zuvor mit Luthers Thesenanschlag 1517 begonnene Reformation mit in Erwägung ziehen. Im Zuge ständiger akademischer und theologischer Kontroversen hatte sich Ende des siebzehnten Jahrhunderts schließlich Erhard Weigel sowohl auf wissenschaftlichem als auch politischem Parkett dafür eingesetzt, dass endlich auch die Protestanten in Deutschland einen neuen Kalender übernehmen und die absurde und für das wirtschaftliche Leben auch hinderliche doppelte Kalenderführung ein Ende finden möge. Die tiefen Gräben zwischen Katholiken und Protestanten verhinderten jedoch eine einfache Übernahme des Gregorianischen Kalenders. Der neue Kalender der Protestanten durfte also nicht allzu Gregorianisch ,aussehen' - was er bei der Anpassung an den Lauf der Sonne bezüglich der Tageszählung im Kalendarium natürlich tat. Daher wollte man sich zumindest in der Osterfestrechnung deutlich von den Katholiken abgrenzen und das Osterdatum in Übereinstimmung mit dem tatsächlichen astronomischen Gegebenheiten, das heißt nach dem sogenannten "Calculo Astronomico“, bestimmen. Die Protestanten unter den Naturwissenschaftlern glaubten sogar, mit einer astronomisch korrekten Bestimmung des Osterdatums bessere Christen zu sein. Sie gingen ferner soweit, dass sie annahmen, die astronomischen Fakten würden sogar den Papst davon überzeugen können, die mit dem Gregorianischen Kalender verknüpfte formal rechnerische, durch eine auf astronomischen Beobachtungsdaten basierende Bestimmung des Osterfestes abzulösen. Die Kalenderreform der protestantischen Territorien in Deutschland wurde im Jahr 1700 genau zu dem Zeitpunkt realisiert, als die Differenz zwischen Julianischem und Gregorianischem Kalender von 10 auf 11 Tage angewachsen war. Die Protestanten nannten ihren neuen Kalender "Verbesserten" Kalender, da sie darin tatsächlich von einer astronomischen Osterfestrechnung, basierend auf den Rudolfinischen Tafeln [118] von Johannes Kepler, Gebrauch machten. Sie hatten somit nicht den Gregorianischen Kalender übernommen, sondern im Jahr 1700 den Verbesserten Kalender eingeführt. Der Hauptunterschied zwischen beiden Kalendern bestand also in der Bestimmung des Osterdatums.

In den Jahren 1724 und 1744 fiel Ostern nach katholischer und evangelischer Berechnung auf zwei verschiedene Termine, was dazu führte, dass die evangelischen und katholischen Christen in Deutschland zu unterschiedlichen 
Terminen Ostern feierten. 1778 drohte Ostern wieder auf zwei verschiedene Termine zu fallen. Auf Veranlassung Friedrichs II. (1712-1786) ist daher am 13. Dezember 1775 vom Corpus Evangelicorum die astronomische Osterfestrechnung abgeschafft und de facto der Gregorianische Kalender endgültig auch mit seiner Osterfestrechnung - übernommen worden, für das betreffende Conclusum siehe [101, Seite 41].

Abschließend sei angemerkt, dass der "Astronomische Calculus" heute durchaus noch im Gespräch ist. So wurde zum Beispiel im Jahr 1997 auf einer Konferenz des Ökumenischen Rates der Kirchen im syrischen Aleppo ein Vorschlag erarbeitet, wonach Ostersonntag der Sonntag nach dem ersten Frühlingsvollmond ist und dass zur Berechnung der Frühlings-Tagund-Nacht-Gleiche sowie des Frühlingsvollmonds tatsächlich exakte astronomische Daten auf der Basis des Meridians von Jerusalem herangezogen werden [218, 219]. Doch auch dieser Versuch, einen einheitlichen Termin für das Osterfest zu schaffen, ist bis heute nicht von Erfolg gekrönt.

\section{Wer war Georg Albrecht Hamberger?}

Es gibt einige frühere Gelehrtenlexika, die mit Geburts- und Sterbedaten, einigen wichtigen Stationen seines akademischen Lebens und mit seinen $\mathrm{Pu}-$ blikationen Auskunft geben können, trotzdem scheint Georg Albrecht Hamberger gegenwärtig weitestgehend unbekannt zu sein.

Geburt und Herkunftsfamilie. Georg Albrecht Hamberger ist das achte von insgesamt zehn Kindern des aus Breitenau stammenden evangelischen Pfarrers Georg Ludwig Hamberger (1622-1689) und seiner Frau Barbara Cöler (1624-1689), einer Pfarrerstochter aus Ansbach. Er wurde am 26. November 1662 (nach Julianischem Kalender) im mittelfränkischen Beyerberg geboren. Gemäß heute gültigem Gregorianischen Kalender entspricht sein Geburtsdatum dem 6. Dezember 1662. Hambergers Geburtsort Beyerberg ist heute ein Ortsteil der Gemeinde Ehingen im Landkreis Ansbach. Seine Großeltern waren väterlicherseits Georg Albrecht Hamberger (1596-1677), nach dem er getauft worden ist, Sohn von Georg Hamberger und Barbara Aubelin, und Ursula Rabus (1601-1671), Tochter von Ludwig Rabus (1572- 
1648) und Anna Christina Öfelein (†1638), sowie mütterlicherseits Johann Philipp Cöler (1592-1638), Sohn von Caspar Cöler (1547-1613) und Barbara Wenner, und Agnes Laelius, Tochter von Lorenz Laelius (1572-1634) und Apollonia Hertel.

Der aus Dinkelsbühl stammende Tübinger Medizinprofessor Georg Hamberger (1536-1599) soll ein Cousin des gleichnamigen Urgroßvaters sein, vgl. [164] und für ein Portrait siehe [211].

Von den neun Geschwistern Georg Albrecht Hambergers sind drei bereits im frühen Kindesalter verstorben. Ihre Namen waren Georg Philipp, Johann Friedrich und Maria Salome. Die anderen sechs Geschwister waren zum einen Maria Catharina, die später mit dem Weigel-Schüler und Rektor der Fürstenschule Heilsbronn Johann Friedrich Krebs (1651-1721) verheiratet war, Georg Ludwig Hamberger (1652-1723), später Theologe, Dechant und Stiftsprediger im fränkischen Feuchtwangen und ab 1679 mit Maria Sophia Hußwedel (1659-1738), Tochter eines Ansbacher Kammerrates, verheiratet, sowie Maria Sibylla, die den Windsheimer Stadtpfarrer und Diakon Johann Michael Rücker (1653-1712) ehelichte. Über die drei Brüder Georg Friedrich, Hans Philipp und Hans Georg Hamberger (†1738) weiß man, außer dass Georg Friedrich nach seinem Studium als Hofmeister und Reisebegleiter junger Adliger ein erhebliches Vermögen erlangte und dass Hans Georg Bierbrauer und Bürgermeister in Fürth war, wohl nicht sehr viel. Insgesamt sei an dieser Stelle auf [58] verwiesen.

In Hambergers Herkunftsfamilie gab es zahlreiche Pfarrersfamilien, sodass man mit etwas Glück in der einschlägigen Literatur einige Auskünfte über deren Familienverhältnisse erhalten kann, siehe zum Beispiel [168]. Familiengeschichtlich ist vielleicht noch denkwürdig, dass seine Urgroßeltern Caspar Cöler und Barbara Wenner Obereltern, das heißt Vorfahren sieben Generationen zurück, von Johann Wolfgang Goethe waren. Goethes familiäre Herkunft ist mittlerweile auch mit aller möglichen Akribie untersucht worden, siehe zum Beispiel [58] oder [221]. Zahlreiche Familienmitglieder und Verwandte Hambergers haben studiert und lassen sich in den Matrikeln der damaligen Universitäten nachweisen, so zum Beispiel in [107 für die Universität Jena oder in [173] für die Universität Altdorf. Insgesamt ist die Quellenlage zur Familie von Georg Albrecht Hamberger recht umfangreich und es lassen sich viele Familienmitglieder sowie zahlreiche Querverbindungen zu Gelehrtenfamilien in der fränkisch-thüringischen Region in historischen 
Dokumenten und Darstellungen entdecken, siehe auch [162] oder [57].

Schüler der Fürstenschule Heilsbronn. Kindheit und erste Schuljahre verbrachte Hamberger vermutlich unspektakulär im heimatlichen Beyerberg. Als erste belegte Schulbildung ist sein Besuch der Fürstenschule Heilsbronn ab 1677 nachgewiesen. Die Fürstenschule Heilsbronn war aus der ehemaligen Klosterschule des 1578 im Zuge der Säkularisation und Durchsetzung der Reformation aufgelösten Klosters Heilsbronn hervorgegangen [110].

Interessant ist die Tatsache, dass aus Hambergers Familie einige Namen von Familienmitgliedern im Zusammenhang mit der Fürstenschule Heilsbronn auftauchen. So kann man auf der Liste der ersten fünfzig Schüler bei Wiedereröffnung der Fürstenschule nach dem Dreißigjährigen Krieg im Jahr 1655 den Onkel Philipp Albrecht Cöler $(* 1638)$ aus Crailsheim, ein Bruder von Hambergers Mutter Barbara Cöler, und einen Cousin des Vaters, Johann Ludwig Rabus (*1641), Sohn des gleichnamigen Bruders Johann Ludwig Rabus der Großmutter Ursula Rabus, entdecken. Beide kommen auch auf einer Schülerliste aus dem Jahr 1658 vor, auf welcher zudem ein Johann Wenner $(* 1642)$ aus Crailsheim auffällt [110]. Vielleicht ist dieser Johann Wenner ebenfalls ein - wenn auch entfernterer - Verwandter, da Hamberger eine Urgroßmutter namens Barbara Wenner hat.

Nicht nur im Kreise der Fürstenkollegschüler auch bei den Lehrkräften der Schule sind Familienmitglieder Hambergers anzutreffen. Schon vor dem Dreißigjährigen Krieg war sein Urgroßvater Lorenz Laelius (1572-1634) von 1603 bis 1606 Rektor in Heilsbronn [58, 110]. Nach dem Dreißigjährigen Krieg hatte zur Wiedereröffnung 1655 der Onkel Martin Clemens Cöler (1629-1691), ebenfalls ein Bruder von Hambergers Mutter, das Amt des Konrektors übertragen bekommen. Es sind also zu dieser Zeit gleichzeitig zwei Brüder von Hambergers Mutter, der eine als Konrektor und der andere als Schüler, am Fürstenkolleg nachweisbar. Im Jahr 1658 wurde Martin Clemens Cöler das Amt des Rektors übertragen, 1675 übernahm er die höher gestellte Position des Predigers. Das Amt des Rektors wurde 1675 dem aus Jena neu berufenen Johann Friedrich Krebs (1651-1721), ein Student von Erhard Weigel, übertragen. Als Martin Clemens Cöler schließlich im Jahr 1691 verstarb, übernahm Johann Friedrich Krebs das Amt als Prediger [45, 110]. Im Jahr 1676, das heißt, ein Jahr nachdem Johann Friedrich Krebs nach Heilsbronn gekommen war und ein Jahr bevor Hamberger dort 
als Schüler aufgenommen wurde, hatte Hambergers älteste Schwester Maria Catharina den neuen Rektor geehelicht. Die Hochzeit zwischen Maria Catharina Hamberger und Johann Friedrich Krebs fand am 11. Juli 1676 in Heilsbronn statt. Aus dieser Ehe gingen vier Söhne und zwei Töchter hervor. Maria Catharina starb 1684 oder 1685 in Heilsbronn [58, 168]. Während der Zeit als Hamberger Schüler des Fürstenkollegs war, waren also ein Onkel als Prediger und ein Schwager als Rektor an der Schule tätig.

An der Fürstenschule Heilsbronn wurden neben den alten Sprachen besonders Musik, Poesie und Mathematik unterrichtet. Außerdem wurde an dieser Schule zu seiner Zeit der Unterricht in Französisch und Italienisch eingeführt. Anschauliche Informationen zum Lernen und Leben an der Fürstenschule Heilsbronn findet man unter anderem in [110, so zum Beispiel, dass die Schüler eine ihnen zur Verfügung gestellte Schultracht zu tragen hatten, dass sie ihre Kammern sauber zu halten hatten, dass während der Studierzeiten keiner seine Mitschüler durch Singen, Poltern oder Ähnliches stören durfte oder dass den Schülern im Interesse der Gesundheit täglich sowohl mittags als auch abends Suppe, Gemüse und Fleisch oder Fisch gereicht werden sollte. Aber auch von Disziplinlosigkeiten, Ausschreitungen, Delikten, Trunk und Spiel, nächtlichen Ausschweifungen auf der Straße und Schlägereien ist die Rede.

Studium an der Universität Altdorf. Im Sommer vor seinem zwanzigsten Geburtstag, am 24. Juli 1682 immatrikulierte Hamberger sich unter der Ordnungsnummer 12093 an der Universität Altdorf. In Altdorf hatte bereits knapp vierzig Jahr zuvor sein Vater Georg Ludwig Hamberger studiert (Immatrikulation im Mai 1644), nachdem dieser 1642 bereits als Student in Straßburg eingeschrieben war [173]. Einer der Professoren Hambergers an der Universität Altdorf war der Astronom und Mathematiker Johann Christoph Sturm (1635-1703). Johann Christoph Sturm wurde im mittelfränkischen Hilpoltstein geboren und hatte von 1656 bis 1662 in Jena studiert, wo er insbesondere Weigels Vorlesungen besuchte. Im Jahr 1657 verteidigte er in Jena unter dem Vorsitz Weigels seine Disputation „Astronomiae pars sphaerica methodo Euclidea conscripta“, vgl. [47, Seite 27]. Zwischenzeitlich, nämlich ab Oktober 1660, war Sturm für etwa ein Jahr an der Universität Leiden. Im Jahr 1664 trat er eine Pfarrstelle in Deiningen an, bevor er schließlich im Jahr 1669 an die Universität Altdorf berufen wurde. Sturm gehörte mit zu den ersten Professoren, die Experimentalvorlesungen abhielten. So hat Hamberger im Jahr 1683 selbst an diesem Collegium expe- 
rimentale Sturms teilnehmen können. Aus diesem Collegium resultierte auch Sturms Lehrbuch [176], welches an vielen Orten als Vorlage zur Einrichtung von Experimentalveranstaltungen diente.

Studium und Wirken an der Universität Jena. Zwei Jahre nach Studienbeginn in Altdorf ging Hamberger nach Jena und schrieb sich am 26. April 1684 in die Matrikel der Universität Jena ein. Aus dieser Matrikel geht auch hervor, dass Hamberger noch im gleichen Jahr seinen Magisterabschluss gemacht hat. Das in [200, 57] und [58] genannte Jahr 1689 kann für den Magisterabschluss nicht korrekt sein, da für die Jahre 1686, 1687 und 1688 bereits Disputationen unter Hambergers Vorsitz nachgewiesen sind, vgl. [74, 81] und [78].

Beinahe gleichzeitig zu Hamberger - lediglich um ein Jahr versetzt, begegnet uns in Heilsbronn, Altdorf und Jena ein Cousin Hambergers, Johann Achatius Cöler (1663-1713), Sohn des Heilsbronner Konrektors Martin Clemens Cöler. Dieser ist ein Jahr jünger als Hamberger, war ebenfalls Schüler der Heilsbronner Fürstenschule, immatrikulierte sich im Mai 1683 in Altdorf und 1685 in Jena. Hier hat auch er noch im Jahr 1685 die Magisterwürde erlangt. Wie Hamberger war er Student bei Erhard Weigel und Adjunkt an der Philosophischen Fakultät der Universität Jena, bevor er schließlich 1688 Mathematikprofessor am Gymnasium in Coburg wurde [58].

Ebenso findet man bezüglich der Daten Hambergers weiterer akademischer Laufbahn an der Universität Jena in den schon nur spärlich vorhanden Informationen widersprüchliche Angaben. Am zuverlässigsten dürften die Informationen in der Darstellung [202] von Zeumer sein. Dieses Werk scheint zum einen die früheste vorhandene gedruckte Quelle zu sein und ist zum anderen noch zu Lebzeiten Hambergers, nämlich im Jahr 1711 erschienen. Stärkstes Argument für Zeumer ist zudem die Tatsache, dass seine Angaben alle mit den Publikationsdaten entsprechender Disputationen unter Hambergers Vorsitz sowie den darin jeweils aufgeführten Titulaturen konform gehen. Einzig mit Bezug auf Zeumer ergibt sich demnach ein stimmiges Bild. In [58] wird zwar auf diese Diskrepanzen aufmerksam gemacht, jedoch ausgerechnet Zeumer korrigiert.

Der nächste Schritt in seiner akademischer Laufbahn, Hambergers Ernennung zum Adjunctus numerum (,Adjunkt der Zahlen`), nach heutigem Verständnis ein Assistent oder wissenschaftlicher Mitarbeiter, an der Philosophischen Fakultät wird in [200] und [57] mit 1694, von Zeumer [202] 
dagegen mit 1688 angegeben. Die Angabe Zeumers wird davon unterstützt, dass es im Dezember 1688 eine Disputation „pro loco in eadem obtinendo“ unter Hambergers Vorsitz gegeben hat, und zwar zu Hambergers Schrift [78. Dabei spricht die Formel „pro loco in eadem obtinendo“ dafür, dass Hamberger diese Disputation zum Erhalt einer Stelle an der Universität abgehalten hat. Derartige Pro-Loco-Disputationen waren Voraussetzung für weitere akademische Beförderungen und werden oft den heutigen Dissertationen gleichgestellt. Im Unterschied zum heute üblichen Verständnis von der Verteidigung (,Disputation') einer, vom Kandidaten selbst verfassten, eigenen Doktorarbeit (,Dissertation') zur Erlangung eines akademischen Doktortitels sind Disputationen im hier interessierenden historischen Kontext jedoch akademische Übungen für die noch im Studium befindlichen Studenten, in denen diese sich jeweils als Respondenten zur Verteidigung der Thesen und Lehrsätze des Vorsitzenden (,Präses') zur Verfügung zu stellen hatten. Dazu wurden noch ein oder mehrere Opponenten bestellt, die den Kandidaten mit ihren Entgegnungen herausforderten und so einer Prüfung unterzogen. Für den vorsitzenden Präses dieser Disputationen waren diese Rituale Gegenstand ihrer Lehrtätigkeit beziehungsweise dienten am Beginn einer akademischen Laufbahn des Nachweises der Befähigung zur Lehre, wie die hier genannte Pro-Loco-Disputation. Respondent bei Hambergers 1688er Pro-Loco-Disputation war der nur ein dreiviertel Jahr jüngere aus Herford stammende Conrad Philipp Redeker. Redeker wurde am 22. August 1663 als Sohn eines Wegemeisters geboren, besuchte das Gymnasium in seinem Geburtsort Herford und ging zum Studium an die Universität Jena, wo er sich am 11. April 1687 immatrikulierte. Von 1697 bis zum seinem Tod am 6. November 1737 war er Pfarrer an der Marien-Kirche in Blasheim, siehe [20, Nr.4961]. Fortan findet man auf Titelblättern von Disputationen unter Hambergers Vorsitz aus den Jahren 1689, 1690 und 1692 seine Titulatur (zum Teil unterschiedlich abgekürzt) mit „Amplissimæ Facult. Philos. Adiuncto" angegeben, so bei [70, 73] und [67].

Bekanntlich auf Empfehlung Erhard Weigels, der von 1653 bis 1699 an der Universität in Jena wirkte, wurde Hamberger 1694 außerordentlicher Professor der Mathematik 202. Die im gleichen Jahr veröffentlichte Schrift „Programma De Meritis Germanorum In Mathesin" 61] weist ihn unmissverständlich als „Mathemat. Profess. Publ. Extraordinar. In Academia lenensi“ aus. Das in [57] und [200] genannte Jahr 1696 für die außerordentliche Professur kann daher ebenfalls nicht korrekt sein. Schließlich nennt auch 
Poggendorf in [146] das Jahr 1694 im Zusammenhang mit der Übernahme einer Professur, obgleich nicht weiter spezifiziert wird ob es sich dabei um eine außerordentliche oder um eine ordentliche Professur handelte.

Nähere Auskünfte zur Disputation von 1694 erhalten wir aus der „eigenen Lebensbeschreibung " des aus dem fränkischen Lentersheim stammenden Respondenten Johann Ludwig Hocker (1670-1746). Zur Disputation von Hambergers Schrift „De Usu Matheseos In Theologia“ berichtete er [104, Seite 13]:

\begin{abstract}
Den 19. Sept. An. 1694 habe bie nadh dem nod) vorbandenen eí

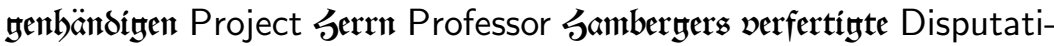
on de Usu Matheseos In Theologia unter féinem Præsidio gebalten, und 3u Opponenten Serrn Simmermann, einen alten Academicum von kie

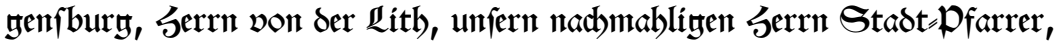
und Jerrn Köhler, bernadb Decanum ju Sdbwabad), gebabt. 2ldbt $\mathbb{C}_{a y g e}$ darauf, den 27. Ejusd., babe, nadb ausgeftandenem yewöbnlícben Exami-

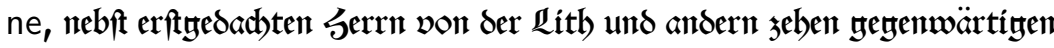
Candidaten, von meinem Hospite, కerrn Prof. Weigelio, den Gradum Magisterii gratis bekommen.
\end{abstract}

Mit dem alten Academicus Zimmermann aus Regensburg ist allem Anschein nach der Prediger und Konsistorialassessor Daniel Zimmermann (16391703) gemeint. Dieser hatte in Wittenberg studiert und wurde 1665 in Regensburg ordiniert, siehe zum Beispiel [126] und [209]. Der genannte Herr von der Lith ist der Theologe Johann Wilhelm von der Lith (1678-1733), „1693 bezog er, dem Studium der Theologie sich widmend, die Universität Jena, wo er sich fleißig im Disputieren übte und 1694 die Magisterwürde erhielt" [35, Seite 329]. Johann Wilhelm von der Lith ist ein Sohn des Weigelschülers Heinrich von der Lith (1648-1682) und wirkte wie Hocker selbst später in Ansbach [192]. Der genannte Herr Köhler war Georg Nicolaus Köhler (1673-1742), der von 1691 bis 1696 an der Universität Jena „Philosophie und Theologie, orientalische und neuere Sprachen" studierte, siehe [45, Seite 62], [109] und [168].

Knopf weist in [119] ebenfalls darauf hin, dass die Angaben in [57] nicht korrekt sein können und bezieht sich auf die Vorlesungsverzeichnisse der Universität Jena aus den Wintersemestern 1694/95 und 1695/96. Im ersten wird Hamberger als außerordentlicher im zweiten als ordentlicher Professor 
aufgeführt. Hamberger übernahm also allem Anschein nach im Jahr 1695 die ordentliche Professur für Mathematik und damit die Nachfolge Erhard Weigels. Zwei Disputationen aus dem Jahr 1696 unter Hambergers Vorsitz bestätigen ihn mit seinen Titulaturen „Mathematum Professoris Publici In Academia lenensi“ in [80] und „Mathem. Profess. Ordinarii In Academia lenensi“ in 68] als ordentlichen Professor. Weigel wurde in dem betreffenden Jahr 70 Jahre alt und soll Hamberger seinen Lehrstuhl selbst überlassen haben. Zuvor hatte er sich in einem Brief an den Herzog in Weimar ausdrücklich dafür ausgesprochen, dass sein Fach an Hamberger übertragen wird, „weil dergleichen Subjekte, als Er ist, in ganz Teutschland auff Universitet, die ordentlichen Professoren ausgenommen, nicht mehr zu finden seien“, zitiert nach [119, Seite 74]. Allerdings kann wohl aus Briefen Erhard Weigels auch geschlossen werden, dass die Übergabe seines Lehrstuhls bezüglich finanzieller Angelegenheiten wohl nicht ganz reibungslos erfolgte, vgl. [169, Seite 8] und [125]. Zumindest konnte Weigel von da an seine Kräfte auf sein letztes Großprojekt, die Umsetzung einer Kalenderreform in den protestantischen Territorien Deutschlands sowie darüber hinaus in den protestantisch regierten Ländern Nordeuropas, konzentrieren und sich mit wesentlich höherer Intensität als schon zuvor seinen Bestrebungen zu dieser Kalenderreform widmen.

Für das Jahr 1698 wird Hamberger als Dekan der Philosophischen Fakultät [79] sowie ab 1697 als Inspektor der Alumnen genannt [202, 77, 82] und 62]. Alumni waren Stipendiaten, denen Unterkunft, Kleidung und Verpflegung gewährt wurde und die auf diese Weise mit finanzieller Unterstützung des Fürsten an der Universität studieren konnten. Im Gegenzug mussten sie sich dafür verpflichten, nach Abschluss des Studiums zum Beispiel an Schulen oder Kirchen in den Dienst des Landesherren zu treten und durften ohne ausdrückliche landesfürstliche Erlaubnis keine Anstellung außer Landes annehmen. Dem Inspektor der Alumnen oblag die tägliche Aufsicht über die Alumni. Er wachte über ihre Disziplin und Studienleistungen, erteilte ihnen Unterricht und beriet sie in allen Dingen des universitären und außeruniversitären Lebens. Die Aufgabe des Inspector Alumnorum hatte zuvor Weigel etwa 45 Jahre lang wahrgenommen. Im Jahr 1705 erhielt Hamberger schließlich zu seiner Professur für Mathematik auch die für Physik [202].

Wie schon zuvor Erhard Weigel ist Hamberger auch mit einem weiteren Ausbau in die Baugeschichte des Torgebäudes des Collegium Jenense eingegangen. Bald nach seiner Ankunft in Jena hatte Weigel das Torgebäude 
seinerzeit 1655 aufstocken lassen und mit einer Beobachtungsplattform versehen, die mit vier Türmen in den Ecken geschmückt war, siehe [160, Seite $278 \mathrm{f}$.] und [47, Seite $26 \mathrm{f}$.]. Für eine Abbildung sei zum Beispiel auf [199, Seite 274] verwiesen. Im Jahr 1697 ließ Hamberger das Dach des Collegium Jenense für sich zu einem Observatorium ausbauen. Dazu wurden die von Weigel errichteten vier Türmchen entfernt und in der Mitte ein großer achteckiger hölzerner Turm mit einem üppigen Barockdach aufgestellt, siehe 40, Seite 200] und [119, Abbildung zu Seite 66].

Hamberger ist in seinem Wirken neben seinen wissenschaftlichen Leistungen besonders als akademischer Lehrer zu würdigen. Wie schon Erhard Weigel vor ihm, verfügte offenbar auch Hamberger über pädagogische Fertigkeiten, mit denen er seine Studenten begeistern konnte. Hamberger ist „vornemlich seiner Deutlichkeit wegen bey seinen Zuhörern sehr beliebt gewesen“ und „seine ... Disputationes sind gar wohl ausgearbeitet." [200, Spalte 332]. Für seine Vorlesungen und physikalischen Übungen, in denen er Studenten experimentieren ließ, nutzte er eine ansehnliche Instrumentensammlung, die bereits Weigel zusammengetragen hatte. Hamberger pflegte diese Sammlung und erweiterte sie [115, Seite 15]. In den Biographien mehrerer Persönlichkeiten wird er als Magnet genannt, der Studenten nach Jena zog, so zum Beispiel bei Ulrich Junius (1670-1726) [203], Johann Kaspar Wetzel (1691-1755) [207, Johann Leonhard Rost (1688-1727) [205], Johann Konrad Schwarz (1676-1747) [206], Melchior Gottlieb Minor (1693-1748) [204] oder Albert Daniel Mercklein (1694-1752) [44. Prominentester Schüler Hambergers ist indes der Philosoph Christian Freiherr von Wolff. In seiner „eigenen Lebensbeschreibung" schrieb Wolff: „Nach Jena brachte mich insonderheit die Begierde die Mathesin und Physicam von dem H. Prof. Hambergern zu erlernen" [198, Seite 120]. Mit Wolff wollte die 1732/34 neu errichtete Universität in Göttingen den „gefeiertsten Philosophen der Gründungszeit" gewinnen, was allerdings nicht gelang, siehe [32, Seite 96]. Zeugnis über Hambergers Einfluss als akademischer Lehrer legen außerdem die zahlreichen unter seinem Vorsitz abgehaltenen Disputationen an der Universität Jena ab. Insgesamt sind im Verzeichnis der Drucke des 17. Jahrhunderts für den Zeitraum von 1686 bis 1699 zwölf derartige Schriften nachgewiesen. Weitere Disputationen für den Zeitraum nach 1700 findet man im Katalog der Thüringer Universitäts- und Landesbibliothek Jena. Alle diese Disputationen sind hier im Literaturverzeichnis ab Seite 175 aufgelistet.

Mathematikgeschichtlich hat man bisher fast keine Notiz von Hamberger 
genommen. Lediglich der Heidelberger Mathematikhistoriker Moritz Cantor (1829-1920) erwähnt in seinen „Vorlesungen über die Geschichte der Mathematik“ Hambergers Publikationen [61] und [75] als Schriften, „deren Titel beanspruchen dürfen hier genannt zu werden", siehe [27, Seite 4]. Bekannt scheint außerdem zu sein, dass Hamberger die Infinitesimalrechnung nach Gottfried Wilhelm Leibniz in das universitäre Lehrprogramm aufnahm [115, Seite 15].

Familie. Das Familienleben Hambergers war eng mit seiner akademischen Karriere an der Universität Jena verknüpft. Nachdem er im Jahr 1694 außerordentlicher Professor wurde, heiratete Hamberger im darauf folgenden Jahr am 8. April 1695 in Altdorf die zwanzigjährige Sophia Katharina Spitz (geboren am 23. Dezember 1674 in Jena, verstorben am 18. März 1754 in Jena), älteste Enkelin Erhard Weigels . Diese war zwar in Jena geboren und aufgewachsen, im Alter von zehn Jahren 1685 jedoch mit ihren Eltern und bis dahin drei Geschwistern nach Altdorf gezogen. Ihr Vater, der Jurist Felix Spitz hatte 1685 einen Ruf an die dortige Universität erhalten [162, 58. Hamberger könnte seiner zukünftigen Ehefrau demnach bereits als Student nach seiner Ankunft in Jena im Hause Weigels begegnet sein, als diese noch ein neunjähriges Mädchen war.

Hambergers Schwiegermutter Anna Katharina Weigel (geboren am 27. Juni 1654 in Jena, verstorben am 22. Dezember 1710 in Altdorf) war das einzig überlebende Kind Erhard Weigels, siehe zum Beispiel [58]. Weigels Ehefrau Elisabeth Beyer hatte ihm zwar im Sommer 1657 noch eine zweite Tochter, Anna Elisabetha, geboren, diese ist jedoch bereits im Alter von nur knapp zwei Wochen verstorben [8]. Georg Albrecht Hambergers Schwiegervater Felix Spitz (geboren am 1. Dezember 1641 in Ronneburg, verstorben am 13. Januar 1717 in Altdorf) war Professor der Rechtswissenschaften an der Universität Altdorf [38].

Hambergers Ehe mit Sophia Katharina Spitz war mit zehn Kindern gesegnet, sieben Töchtern und drei Söhnen, von denen jedoch fünf im Kindesalter starben [58. Die älteste Tochter, Anna Catharina Hamberger (1696-1767) war mit dem Theologen Johann David Beyer (1681-1752) verheiratet und Tochter Anna Dorothea Hamberger (1702-1774) mit dem Juristen Adolph Friedrich Kuhle (1698-1767). Eine weitere Tochter, Clara Elisabetha Hamberger (1705-1774) ehelichte den aus Remda bei Rudolstadt stammenden akademischen Amtmann der Jenaer Universität Christoph Friedrich Reich- 
ardt (1695-1763). Reichardt verwaltete das zur Universität Jena gehörige Gut Remda, dessen Einkünfte der Besoldung der Professoren dienten. Ein Sohn Clara Elisabethas mit Christoph Friedrich Reichardt war der spätere Professor der Rechte an der Universität Jena, Beisitzer des Schöppenstuhls und sächsisch-gothaischer geheimer Justizrat Johann August Reichardt (1741-1808) [58, 57]. Die jüngste überlebende Tochter war Susanna Hedwig Hamberger (1707-1791). Sie war mit dem Theologen Heinrich Michael Gnüge (1702-1782) vermählt. Von den drei Söhnen Georg Albrecht Hambergers und seiner Frau Sophia Katharina überlebte nur Georg Erhard Hamberger (1697-1755), dessen Taufpate der Urgroßvater Erhard Weigel war. Georg Erhard Hamberger wurde später an der Universität Jena Professor der Mathematik, Physik und Medizin. Er vermählte sich mit der Tochter des Mediziners Johann Adolph Wedel, Sophia Margaretha. Gemeinsam mit seinem Schwiegervater hatte er im Jahr 1734 einen Ruf an die in Göttingen gerade neu gegründetet Universität erhalten. Hier hatte man für beide bereits „die beyden an die Universitätskirche stoßenden, und ... nicht lange vorher erbauten Häuser ... bestimmt" [141, Seite 129 f.]. Ein Ausreiseverbot des Herzogs Ernst August I. von Sachsen-Weimar verhinderte 1735 jedoch den Weggang beider von Jena [210, 119]. Stattdessen übernahm Johann Wilhelm Albrecht (1703-1736) aus Erfurt die medizinischen Fächer in Göttingen. Nach dessen Tod nur ein Jahr später wurde Albrecht von Haller (1708-1777) berufen, mit welchem Georg Erhard Hamberger später einige erbitterte akademische Auseinandersetzungen führte [22, 83]. Eine ausführliche Lebensbeschreibung Georg Erhard Hambergers hat sein Schwiegersohn Johann Christian Blasche (1718-1792) verfasst [22].

Georg Albrecht Hamberger verstarb an einer fiebrigen Krankheit am 13. Februar 1716 (nach dem zu diesem Zeitpunkt für ihn geltenden Verbesserten Kalender) in der Universitätsstadt Jena. In [60] finden wir den folgenden Text seiner von Christian Gottfried Rose (1685-1749), Pfarrer in Lehesten im thüringisch-fränkischen Schiefergebirge, verfassten Grabinschrift [60, Seite $439 \mathrm{f}$.$] :$

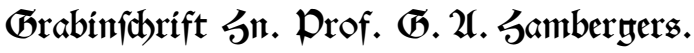

Iena war ebedeffen Iain

das ift: ein üppiges feld voll Trauben,

jetzt if Jain ein Rain,

weldbes Ealte Leíd)mam lieffert, 
und $\mathfrak{W}_{\text {ein in }} \mathfrak{W}_{\text {einen }}$ verwandelt.

Diel frifthe SBlumen verweldẹ,

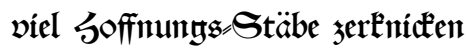
und betrüben íbr $\mathfrak{D}_{\text {aterland. }}$

Die $\mathbb{C}_{a}$ tbeder Felbpt verlafien íbre Lebrer,

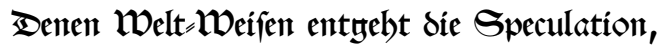
denen 2lertsten daf Laboriren, denen Iuriften wird ein Todes ג Irtheil geiprodhen, und behertyten Cheologis das Maul geftopfft.

Don foldben lebbaften Gelebrten bleiben die Trauer/2Bilder, idh meyne ibre Wittwen, übrig.

Wie viel Elagende Miara-Sdbweftern beweinen nidbt das berübmte Iena.

Jet3t legt abermal im Saal 2 (thben der welt berübmte

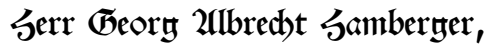
Professor Mathemat. und Physices, feinen Cirdel nieder.

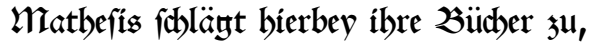
gefellet fiid) jur betrïbten Saline, und beweinet íbren $\mathfrak{E u c l i d e s . ~}$

Iena verliert einen frommen Gelebrten.

Sein Cirdel mablete ibm die Kewigleit vor, weldbem fo wol 2 lnfang alf Sinde feblet.

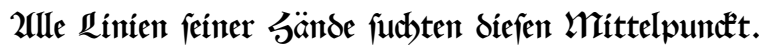

Daf find audb bie beften Geometrä, weldbe aufmefien Ë̈nnen die Jöhe, Breite und Tieffe göttlidher $\mathfrak{w}_{\text {eisheit. }}$

Iena verliert einen gelebrten $\mathfrak{L} e \mathfrak{b r e r}$, daf Ringweyde def Ratur:Cörpers, die verdectte Geheimnifie, und waf dunctele Rätzel fabienen, war feinen 2lugen offenbar.

Und dif ift Kein $\mathfrak{W}$ under, denn $\mathfrak{w}_{\text {eigels }}$ Geift rubete auf ibn zwéefältíg. 
Dodb Jena, bemme deine Thränen, Seine verlaffene Wittwen find Kleinodien GOttes.

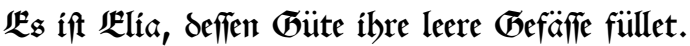

Wittwen/కäufer ruben auf drey Seulen, nemlid) (Gebet, Glauben und 3uverfitht.

Diefé neugeborne frau Wittwe

wird diefés gleídbfals erfabren.

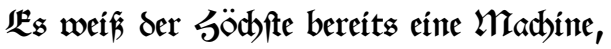
mit weldher er fie bededen will jur böfen కeit.

Wir bingegen wifien, dẩ diefes 2 lrdbimedes Cirdel mur turbirt, nidbt aber ganty und gar ruiniert.

Sein Kubm ift 2lfronomifthen Sternen gleid), weldbe in Sundeler Radbt fhimmern:

drum ift er nidbt verdectit, der $\mathbb{T}_{\text {raum }}$ des Todes deft ínn mur.

Lefer, willft du mebr won ibm wiffen, fo wiffe diefes:

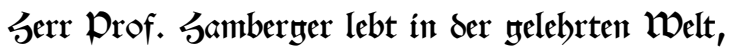
Srum Eonte er in Jena nidbt ferben, und weil er in Sdbriften fid jedermann zeigt, fo wirft du íbn im Grabe vergebens fublen.

Seine Frau Sophia Katharina überlebte ihn um 38 Jahre. An der Herzogin Anna Amalia Bibliothek in Weimar wurden die Leichenpredigt für sie und mehrere Leichengedichte ihrer Kinder und Schwiegerkinder aufbewahrt. Diese Materialien werden bedauerlicherweise im Katalog der Bibliothek als Verlust aufgelistet, vermutlich fielen sie alle dem verheerenden Bibliotheksbrand im Jahr 2004 zum Opfer.

Georg Albrecht Hamberger lebte mit seiner Familie in Weigels berühmtem "Wunderhaus“, der Weigeliana Domus. Dieses Haus wurde von Weigel zwischen 1667 und 1670 erbaut und mit zahlreichen technischen Attraktionen ausgestattet 194. Daher zählt es noch heute, obwohl 1898 abgerissen, zu den so genannten „Sieben Wundern Jenas“. 


\section{2}

\section{Briefe und Schriften}

Nach Weigels Tod übernahm es Georg Albrecht Hamberger als sein Nachfolger an der Universität Jena gemeinsam mit zwei weiteren Schülern Weigels, dem Mathematiker Johannes Meyer in Regensburg und dem Altdorfer Mathematiker und Astronomen Johann Christoph Sturm (1635-1703), die Kalenderreform zu einem erfolgreichen Abschluss zu führen. Leibniz, der Weigels Gedanken aufgriff und in Berlin in seinem Sinne in die Tat umsetzte, bezeichnete dieses Trio in seinen Briefen als ,Triumviri‘ in Sachen Kalenderreform und brachte dessen Aktivitäten großes Interesse entgegen, siehe [130, Seite 310, Fußnote 12]. Ein Ergebnis dieser Kooperation zwischen Hamberger, Meyer und Sturm war auch die gemeinsam verfasste Schrift „Unvorgreiffliches Bedencken wegen vorhabender völliger Calender-Verbesserung " [76, welche bei den ergänzenden historischen Veröffentlichungen ab Seite 124 im Anhang mit abgedruckt ist.

Die im vorliegenden Band wiedergegebenen Briefe Georg Albrecht Hambergers einschließlich zweier Schriftstücke von seiner Hand aus dem Konvolut Cod.Ms. Philos. 60 wurden im Zeitraum von März 1699 bis Juni 1700 verfasst. Sie richteten sich alle an Johannes Meyer in Regensburg. Meyer stammte aus dem böhmischen Graslitz, heute Kraslice, studierte ab 1676 bei Weigel in Jena und ging 1685 als Professor an das evangelische Gymnasium nach Regensburg [6, 107, 159, 201]. Er war in Regensburg zugleich Vertreter Weigels am Immerwährenden Reichstag und Weigel führte ihn of- 
fenbar in der Funktion eines „Collegii Secretarius" als Mitglied des von ihm geplanten Collegium Artis Consultorum, vgl. Cod. Ms. Philos. 60, Blatt 239.

Für eine erste und grobe Orientierung zur Einordnung der Briefe in den Kontext der historischen Ereignisse und im Zusammenhang mit der Kalenderreform von 1700 seien als historische Momente die folgenden geschichtlichen Daten genannt, auf die zum Teil auch in den Briefen Bezug genommen wird:

21. März 1699 Erhard Weigel verstirbt nach kurzer Krankheit in Jena.

25. März 1699 Erhard Weigel wird in Jena unter großer öffentlicher Anteilnahme bestattet.

19. Mai 1699 Gottfried Wilhelm Leibniz bittet seinen Korrespondenzpartner Johann Andreas Schmidt anlässlich dessen Reise nach Jena, im Nachlass Erhard Weigels nach Unterlagen zu den Plänen für das Collegium Artis Consultorum zu suchen.

23. September 1699 Das Corpus Evangelicorum der vereinigten evangelischen Reichsstände Deutschlands beschließt in Regensburg die Annahme des Verbesserten Kalenders, das heißt der Kalenderreform von 1700, wonach auf den 18. Februar 1700 direkt der 1. März 1700 folgt.

8. November 1699 Der in Leipzig ansässige Verleger und Buchhändler Thomas Fritsch erhält vom sächsischen Kurfürsten ein Kalenderprivileg für das Kurfürstentum Sachsen.

26. November 1699 Der Beschluss des Corpus Evangelicorum vom 23. September 1699 wird öffentlich bekannt gegeben.

10. Januar 1700 Das Corpus Evangelicorum beschließt in Regensburg, dass die Rudolfinischen Tafeln Johannes Keplers als Grundlage für die astronomische Bestimmung des Osterdatums dienen sollen.

Januar 1700 Gottfried Wilhelm Leibniz beginnt, ein intensives Interesse an der ,Kalendersache' zu entwickeln.

1. März 1700 In den evangelischen Ländern Deutschlands tritt der Verbesserte Kalender in Kraft. Die Tage vom 19. bis 29. Februar 1700 wurden ausgelassen. 
März 1700 Gottfried Wilhelm Leibniz entfaltet intensive Aktivitäten zur Gründung einer wissenschaftlichen Sozietät in Berlin und hat seinen „Kalendereinfall‘, wonach die geplante Akademie ihre Finanzierung über ein Monopol auf die Herausgabe und den Verkauf von Kalendern für das Kurfürstentum Brandenburg selbst aufbringen soll. Kurfürst Friedrich III. von Brandenburg gibt sein Einverständnis zum Bau eines Observatoriums und zur Gründung einer Akademie in Berlin.

März 1700 Der Große Nordische Krieg um die Vorherrschaft im Ostseeraum beginnt.

10. April 1700 Der Herzog von Sachsen-Eisenach erteilt Georg Albrecht Hamberger ein Privileg zur Herausgabe eines Kalenders.

19. April 1700 Gottfried Kirch reist als zukünftiger Astronom der in Gründung befindlichen Berliner Akademie nach Berlin.

ab 10. Mai 1700 Gottfried Wilhelm Leibniz hält sich zur Konstituierung der Akademie in Berlin auf.

10. Mai 1700 Kurfürst Friedrich III. von Brandenburg erlässt das Kalenderedikt, welches der neuen Akademie das Kalendermonopol für Brandenburg erteilt.

Mai 1700 Im „Monatlichen Staats-Spiegel“ erscheinen die letzten „Gedancken über die Notwenigkeit" des Collegium Artis Consultorum.

12. Juli 1700 Gottfried Wilhelm Leibniz wird zum Präsidenten der Brandenburgischen Sozietät der Wissenschaften zu Berlin berufen.

29. Juli 1700 Der Herzog von Sachsen-Weimar erteilt Georg Albrecht Hamberger ein Privileg zur Herausgabe eines Kalenders.

16. November 1700 Staatsvertrag zwischen Kaiser Leopold I. und dem Kurfürst Friedrich III. von Brandenburg. Friedrich III. wird damit zukünftiger König in Preußen.

18. Januar 1701 Krönung des Kurfürsten Friedrich III. zum König.

1701 Georg Albrecht Hamberger gibt, mit dem Jahr 1701 beginnend, eine eigene Kalenderreihe heraus. Überliefert sind allerdings nur die Kalender aus den Jahren 1701 und 1704. 
Chronologisches Verzeichnis der Briefe und Schriften

Brief vom 25. März 1699 . . . . . . . . . . . . . . . 43

Erster Brief vom 1. Mai 1699 . . . . . . . . . . . . . . . . 48

Zweiter Brief vom 1. Mai 1699 . . . . . . . . . . . . . 5 51

Brief vom 4. Juni 1699 . . . . . . . . . . . . . . . . . 552

Erster Brief von Juli 1699 . . . . . . . . . . . . . . . . . 59

Brief vom 27. Juli $1699 \ldots \ldots$

Brief vom 6. August 1699 . . . . . . . . . . . . . . 64 64

Brief vom 28. September 1699 . . . . . . . . . . . . . . . 67

Brief vom 14. Oktober 1699 . . . . . . . . . . . . . . 71

Brief vom 18. November 1699 . . . . . . . . . . . . . . . . 75

Brief vom 25. November 1699 . . . . . . . . . . . . . . . 81

Brief vom 8. Dezember 1699 . . . . . . . . . . . . . . 89

Brief vom 11. Dezember 1699 . . . . . . . . . . . . . . 93

Brief vom 29. Dezember 1699 . . . . . . . . . . . . . . 95

Denkschrift zum Conclusum vom 10.|20. Januar 1700. . . . . . . . 99

Extract Fürstliches Rescript an den Abgesandten Fabricius . . . . 101

Brief vom 12. Februar 1700 . . . . . . . . . . . . . . . 102

Brief vom 1. März 1700 . . . . . . . . . . . . . . . . . . 105

Brief vom 8. März 1700 . . . . . . . . . . . . . . . . . . 110

Brief vom 1. Juni 1700 . . . . . . . . . . . . . . . . . . 113

Brief vom 12. Juni 1700 . . . . . . . . . . . . . . . 116 


\section{Brief vom 25. März 1699}

\section{Cod. Ms. Philos. 60 , Blatt $495 \& 496$}

[495r] Wohledler, Großachtbar und Hochgelahrter, Insonders hochgeehrter H Professor, und hochgeschätzter Gönner.

Demselben muß leider! berichten daß dem Höchsten Gott gefallen meinen H GroßSchwiegerVatter, Hn Rath Weigelium, nach einer kurzen Krankheit auß dieser Welt ab und zu sich zufordernt. Denn nach dem Er auf der letzten Zurückreiße von Regenspurg, durch den Thüringer Wald Lebensgefahr, wegen ungemein tiefen Schnees, außgestanden, und sich sonder Zweifel sehr erkältet, ist Er zwar noch glücklich hier ankommen, und sich auch 10 Tag wohl befunden. aber den 5ten Martii muste Er zweymal hefftig sich erbrechen, darauf Ihn große Mattigkeit nebst einer Hitze überfallen, und, ungeachtet aller von H D Wedeln dagegen verordneten Arzneyen, dermassen entkräfftet, daß Ihm schon den 3ten Tag darauf nicht nur das gehen und essen, sondern auch das reden schwehr fiel, und es immer schiene als ob Er halb schlief. Da er nun wegen Eckel u. großer Schwachheit nichts Solides essen, auch letzlich nichts mehr trincken konnte, hat Ihm die Hitze die Lebenskräffte völlig verzehret, daß Er endlich den 21ten früh nach 3 Uhr als ein Liecht verloschen und sanfft und seelig verschieden. Gott hat Ihm die Gnade gethan und des Verstandes, Gesichtes u. Gehöres Gebrauch unverruckt biß an den letzten Athem erhalten, auch den geringsten Schmertzen nicht fielen lassen; wie Er denn über nichts als Mattigkeit geklaget, welche Ihm febris continua, daran Er, der Medicorum Meinung nach, laborirt, verursachet. Bene fit beatis manibus. Nun bedaure ich nebst dem großen Verlust unserer Familie auch insonderheit, daß das große, von Ihm so lange Jahr mit unglaublicher Mühe u. Kosten getriebene, und nun fast zum Stand gebrachte Werk, der ZeitVereinigung, samt der Anrichtung eines Collegii Artis Consultorum, durch seinen Tod ins Stecken gerathen wonicht gar liegen bleiben möchte; weil niemand so viele Kosten darauf wenden wird, um die Potentzen mit beständigem anhalten endlich zu einem Schluß zu bringen. Jedoch weil mein hochgeehrter $\mathrm{H}$ Professor biß anhero durch sonderbahre kluge conduite diese Sach in Abwesenheit des seel. Hn Weigelii so glücklich zu tractiren gewust, so will ich mir doch noch einige Hoffnung machen daß es wegen der Zeitvereinigung noch zu einem glücklichen Schluß kommen möge. Wie ich den Mhg Hn Professorem sowohl des publici als unsers lieben seel. Vatters wegen dienst $\ell$. will gebetten haben die Sach ferner nach aller 
Möglichkeit zu treiben, daß Teutschland seiner so großen Bemühung genießen können. Kan ich selbsten etwas gutes in der Sach beytragen werde ich mich alle Zeit willig dazufinden lassen; wie ich denn auch an Hn P. Sturm nicht zweifeln daß Er gleichfals seine Symbolam nach Möglichkeit conferiren werde. Aus dem von Gotha an den seel. Hn Weigelium abgelassenen guten Schreiben habe gesehen daß man auf des Hn

[495v] Reihers Vorschlag und dessen censur des Weigelianischen, einige reflexion machen wolle. Es hat aber nicht nur die letzten der seel. Mann in seinem unterthänigsten Antwortschreiben gründlich abgelehnet, sondern auch Mhg H des ersten Mängel deutlich gezeiget. Da ich Ihn zu sehen bekommen habe ich allso bald darum annotirt, daß er ao 1693 würklich wider des Concilium Nicænum angestossen daß man sich allso ins künfftige desto weniger darauf verlassen kan. Ich glaube daß der seel. H Weigelius seine Anmerkungen jedoch tecto nomine werde communicirt, weil man sich nicht gern in Streit einlässet. Aber mit dem Collegio Artis Consultorum halte ich es fast vor desperat. Jedennoch aber wenn die Protestirende Stände den Weigelianischen Vorschlag der Zeitvereinigung annoch belieben und haben wollen daß allen Fehlern in Zukunfft recht vorgebauet werde, so müsten sie sich billig auch wegen Aufrichtung u. salarirung eines solchen Collegii resolviren. Nicht minder bin ich sehr bekümmert ob der $\mathrm{H}$ von Schad zu Wien sich noch weiter bemühen werde den kostbaren Pancosmos u. prächtige Sphæram etwan am Keyserl. Hoff, gegen den vom seel. Hn Weigelio Ihm versprochenen partem proportionalem des pretii, anzubringen oder ob wir selbigen wider mit großen Kosten müssen herauf schaffen? Weil mir wissend daß Mhg H Professor mit dem Hern von Schad in vertraulicher Bekantschafft stehen, so will dienst $\ell$. gebetten haben mir dero Gedanken hochgeneigt zu eröffnen was hirbey zu thun? Ob ich sofort an Ihn schreibe u. nebst notificirung des Todesfalls bitte sich die Sach ferner bestens lassen angelegen seyn, oder ob man es noch ein Zeit lang lässet anstehen. Womit nebst Empfehlung Göttlicher Gnaden verharre

Meines hochgeehrtisten Hn Professoris u. großen Gönners ergebenster Diener

Raptim

G A Hamberger

Jena d 25ten Martz 1699

ipso exequiarum die

Das patent $u$. Leichcarmina werde etwan morgen an meinen Hn Schwieger Vatter zuschicken, der nicht ermangeln wird selbige zu communiciren. 


\author{
A Monsieur \\ Monsieur Jean Majer, Professeur Publique tres_renommé \\ Cito \\ Franco Nurnberg, Regenspourg
}

\title{
Kommentar
}

Zunächst sei daran erinnert, dass Georg Albrecht Hamberger mit Sophia Katharina Spitz, einer Enkelin Erhard Weigels, verheiratet und sein Schwiegervater der Altdorfer Professor Felix Spitz, der Erhard Weigels Tochter Anna Katharina ehelichte, war.

Der unsere Sammlung eröffnende Brief ist auf den 25. März 1699 datiert. An genau diesen Tag wurde Erhard Weigel, der vier Tage zuvor verstorben war, unter großer Anteilnahme durch die Öffentlichkeit in Jena bestattet. Am Ende des Briefes wird darauf mit dem lateinischen „ipso exequiarum die“ hingewiesen. Die Farbe des Siegellacks enthält dazu eine Mitteilung, die über die funktionale Aufgabe des Siegels, den Brief zu verschließen, hinausgeht. Dieser und - bis auf den letzten Brief - alle weiteren Briefe in dieser Sammlung, deren Siegel erhalten ist, sind mit Trauersiegellack (schwarz) gesiegelt, der verwendet wurde, um in der Trauerzeit Briefe etc. $\mathrm{zu}$ versiegeln.

Der erste hiermit vollständig vorliegende Brief scheint der einzige der im Konvolut Cod.Ms. Philos. 60 vorhandenen Hambergerbriefe zu sein, welcher bereits Erwähnung in der Sekundärliteratur gefunden hat, und das auch bloß auszugsweise, siehe [158, Seite 137]1, [162, Seite 24] und [58, Seite 91]. Alle drei Zitate weichen, wenn auch nur in kleineren Variationen, sowohl voneinander als auch im Wortlaut vom Original ab. Interessant ist, dass alle drei Autoren lediglich aus dem ersten, dem privat-biographischen Teil des Briefes zitieren, in dem über die letzten Lebenstage Weigels berichtet wird. Weigel reiste im Februar 1699 nach Regensburg und hatte dort am Immerwährenden Reichstag in Sachen Kalenderreform zu verhandeln. Er kam am 23. Februar 1699 in Regensburg an, reiste jedoch vorzeitig - vermutlich noch am selben Tag - wieder ab und legte auf seiner Rückreise zudem nicht, wie sonst wohl üblich, einen Zwischenhalt bei dem ihm befreundeten Astronomen Georg Christoph Eimmart (1638-1705) in Nürnberg ein, vgl. [158. Auf seiner schwierigen Rückreise, insbesondere durch tiefen Schnee im Thüringer Wald, soll Weigel sich erkältet haben. Nachdem er in Jena angekommen war, erkrankte er am 5. März 1699 so schwer, dass er schließlich am 21. März 1699 verstarb. Am

\footnotetext{
${ }^{1}$ In [158] wird der Brief mit einem falschen Sterbedatum zitiert.
} 
6. März 1699 hatte er noch einen - vermutlich seinen letzten - Brief an Georg Christoph Eimmart geschrieben [187].

Bemerkenswert erscheint mir an Hambergers erstem Brief die Tatsache, dass er nach der Mitteilung zu Weigels Tod umgehend auf das weitere Verfahren in Sachen Kalenderreform zu sprechen kommt und seiner Sorge Ausdruck verleiht, die bis dahin gemachten Fortschritte könnten nun zum Erliegen kommen. Er bietet sofort an, sich selbst in dieser Angelegenheit zu engagieren. Außerdem bringt er am Ende des Briefes bereits Johann Christoph Sturm, den Dritten im Bunde des ,Triumviri‘ mit ins Spiel.

Sodann erwähnt Hamberger einen Vorschlag zur Kalenderreform, der von dem Kieler Mathematiker Samuel Reyher in Regensburg eingereicht worden war. Allem Anschein nach war Weigel gebeten worden, zu Reyhers Vorschlag Stellung zu nehmen, und hat Hamberger den Inhalt dieser Stellungnahme gekannt. Reyher schlug insbesondere vor, als Grundlage des neuen Kalenders eine von ihm als wahre Jahreslänge angenommene Größe von $365 \frac{7}{29}$ Tagen zu wählen sowie recht komplizierte Regeln für die Einfügung von Schalttagen anzuwenden, ,durch welche die einmal zur Richtigkeit gebrachte Zeit, so lange die Welt stehet, unverrückt, und also, daß sie mit des Concilii Nicæni, wie auch des Pabstes Gregorii XIII. Anordnung einstimme, beybehalten werden kan“ [149, Seite 4]. Zu Regensburg war im Juni 1699 ohne Nennung eines Autors eine Erwiderung auf Reyhers Kalendervorschlag gedruckt worden [4. Hierin wurden sowohl die Reyhersche Jahreslänge als auch seine Schaltregeln im Detail diskutiert. Möglicherweise handelt es sich dabei um die von Hamberger genannte Weigelsche Entgegnung, die dann „tecto nomine“, also ,mit verheimlichtem Namen` publiziert wurde. Zu Reyhers Aktivitäten im Zuge der Kalenderreform vgl. auch [193. Ferner weist Hamberger darauf hin, dass Reyhers Kalenderansatz für das Jahr 1693 bei der Festlegung des Osterdatums zu einem falschen Resultat geführt hätte. Tatsächlich gab es im Jahr 1693 ein sogenanntes Osterparadoxon. Nach dem Gregorianischen Kalender fand 1693 die Frühlings-Tagund-Nacht-Gleiche am 19. März statt, Vollmond war am 22. März, während der sogenannte Kirchenvollmond, das heißt der Vollmond, der laut zyklischer Berechnung gemäß des Gregorianischen Kalenders nach dem oder am 21. März stattfindet, auf Samstag den 21. März datiert war. Ostersonntag war demnach der 22. März. Astronomisch ist jedoch erst der 29. März der Sonntag nach dem ersten Frühlingsvollmond gewesen.

Außerdem enthält dieser Brief eine interessante Information zu einem von Weigels sogenannten Pancosmen. Dass Weigel dem Kaiser, Kaiser Leopold I., einen seiner heraldischen Himmelsgloben nach Wien geschickt hatte, können wir bei Weigel selbst nachlesen: „Ihro Kayserl. Majestät ein Silbern mit Demant versetztes Exemplar Heraldischer Himmel-Globen, zur Censur und Prob, in aller Unterthänigkeit mit offerirt ist worden“, siehe [185, §. 20]. Über einen von Weigel an den Kaiserlichen Hof nach Wien gesandten Pancosmos war jedoch in der Weigelforschung 
bisher nichts bekannt, vgl. beispielsweise die Arbeiten [120, 121] und 124, Stefan Kratochwils. Folglich ist auch der Verbleib dieses Pancosmos offen. Die von Weigel als Pancosmos bezeichneten begehbaren Himmelsgloben sind von eigenem Interesse, da sie als Vorläufer heutiger Planetarien gelten. Noch als junger Professor war Weigel 1659 mit dem Neubau des Jenaer Stadtschlosses beauftragt worden. Als Oberbaudirektor ließ er 1661 zum Abschluss der Arbeiten auf dem Dach des Schlosses einen ersten übergroßen Globus errichten. Der Durchmesser dieses Globus betrug etwa 5,5 Meter. Wegen seines großen Gewichts wurde der Globus 1692 wieder abmontiert 160. Im Jahr 1670 publizierte Weigel zwei Schriften, 181 und [182, in denen er den von ihm vorgestellten Pancosmos, ein Globus von mehr als drei Metern Durchmesser in dem mehrere Personen Platz fanden, als „neue Art der Himmels- und Erd-Kugel" beschreibt [182, Titelseite]. Bekannt ist, dass Weigel sowohl zu Lehrzwecken als auch in seinen späteren Jahren zum Zwecke der Werbung für seine Bemühungen zur Kalenderreform an europäischen Herrscherhäusern derartige Riesengloben anfertigen ließ, während er die deutschen Fürstenhäuser mit heraldischen Himmelsgloben bedachte, auf denen er die bekannten antiken Sternbilder durch die Wappen europäischer Fürsten ersetzte. Neben der Werbung für seine Kalenderreformbestrebungen verband er mit diesen Globen den expliziten Wunsch, „dass künfftig Fried auf Erden in Europa werden werde“, siehe 138. Nachgewiesen ist, dass Weigel im Jahr 1696 dem dänischen König Christian V. (1646-1699) einen Pancosmos überreichte, vgl. [138] und [160, Seite 283]. In der Schrift über diesen König Christian V. überbrachten Pancosmos finden wir außerdem eine vollständige Gegenüberstellung der alten und neuen von Weigel eingeführten heraldischen Sternbilder einschließlich der zugehörigen Herrscherhäuser 138. Da zum Verbleib von Weigels Pancosmen nichts bekannt ist, weiß man auch nichts Genaueres über deren Aufbau und Funktionsweise. Von den heraldischen Himmelsgloben Weigels sind derzeit 17 Stück mit ihrem heutigen Standort bekannt2] siehe [213]. Ein Globus im heutigen Wien ist nicht darunter. Ob einer der bekannten Globen der nach Wien gesandte Globus ist, ist eine offene Frage. Vielleicht ließe sich mit weiteren Nachforschungen etwas über den Verbleib des Wiener heraldischen Himmelglobus in Erfahrung bringen.

Hambergers Daten scheinen noch in einem völlig am Rande liegenden Punkt von Interesse zu sein. Wenn er schreibt, dass Weigel sich noch 10 Tage „wohl befunden“ hat, muss Weigel Regensburg nicht nur am 23. Februar bereits wieder verlassen haben, sondern auch spätestens am 24. Februar im Laufe des Tages in Jena eingetroffen sein. Das hieße aber, dass Weigel sehr eilig, ununterbrochen und die Nacht durch unterwegs gewesen sein muss. Nach [148] beträgt die Reiseroute zwischen Regensburg und Jena über Nürnberg entlang der alten Heeresstraße, welche durch den Thüringer Wald führt, vierzig Meilen. Gewöhnliche Postkutschen, riesige Gefährte die häufig steckenblieben oder umkippten, waren Ende des siebzehnten Jahrhun-

\footnotetext{
${ }^{2}$ Einer dieser 17 heraldischen Himmelsgloben befindet sich im Göttinger Stadtmuseum.
} 
derts wohl mit einer Geschwindigkeit von etwa einer Stunde und bei schlechtem Wetter oder gar Schnee bestimmt anderthalb bis zwei Stunden pro Meile unterwegs. Das ergäbe auf der genannten Strecke eine Reisezeit in der Größenordnung von vierzig bis achtzig Stunden, Weigels Reise hätte so also mindestens zwei Tage gedauert. Aus seinem oben genanntem Brief [187] an Eimmart wissen wir aber, dass er mit einer eigenen und offenbar wesentlich schnelleren Kutsche unterwegs war. Er schrieb am 6. März 1699 nämlich „Bin unlängst über Sulzbach zu Nürnberg durch das neue Thor eingefahren ... wollte ich gleich nach Jena weiterfahren. Hab stracks meinen Wagen transferieren lassen“, zitiert nach [162, Seite 23].

Das im Brief verwendete Wort carmina ist in diesem Kontext als Oberbegriff für Gedichte zu verstehen. Im Bereich der Gelegenheitsdichtungen unterschied man nach entsprechenden Anlässen zum Beispiel anlässlich von Beerdigungen ,Leichcarmina“ oder zu Hochzeiten ,Hochzeitscarmina“.

Bei dem genannten Arzt Dr. Wedel handelt es sich aller Wahrscheinlichkeit nach um den zu diesem Zeitpunkt 53jährigen Mediziner Georg Wolfgang Wedel (1645-1721), welcher ab 1673 den Lehrstuhl für Medizin an der Universität Jena inne hatte. Theoretisch könnte auch einer seiner Söhne Ernst Heinrich (1671-1709) oder Johann Adolph Wedel (1675-1747) in Frage kommen. Beide waren ebenfalls Mediziner, standen jedoch im Jahr 1699 erst am Beginn ihrer akademischen Laufbahn.

\section{Erster Brief vom 1. Mai 1699}

\section{Cod. Ms. Philos. 60, Blatt $451 \& 452$}

[451r] Wohledler Großachtbar u. Hochgelahrter, Insonders großg $\ell$ hochgeehrter H Professor und Patron.

Nebst dienst $\ell$. Danksagung vor die Christ $\ell$. condolenz und Gegenanwünschung alles Seegens von Gott vor denselben u. dessen ganzes werthes Hauß, berichte, daß mich die fröliche Zeitung, wie nemlich zu der Calendervereinigung u. Collegio Artis Consult: die Hoffnung noch nicht auß, sondern durch MhgHn Professoris kluge conduite die Wohlgesinnten Hhn Abgesanten noch bey ihrer guten Meinung verharren sehr erfreut und weil dieselbe von mir eine Erklärung verlanget die Sie dörfften vorweisen, so kommt selbige hirbey. Aber all mein Hoffen habe zu gleicher Zeit 4 fürst $\ell$ Befehl, nemlich von Weimar, Eisenach, Gotha u. Coburg in sehr gnädigen terminis erhalten als worinn nicht nur des seel. Hn Weigelii Vorschlag approbirt u. gelobet, sondern auch mir befohlen wird selbigen nach allem Vermögen helffen außzuführen. Von Weimar u. Eisenach ist mir gar injurgirt, daß ich mich auf 
bedörffens Fall gar persönlich nach Regenspurg begeben u. bey der Reichsversamlung mit einem unterthänigsten Memorial einkommen solle. Es haben meine gute Herren deswegen auch an Ihre Hhn Abgesandten rescribirt, wie denn das Fürst $\ell$. Weimarische hirbey in originali kommt, welches nebst meinem Schreiben, darinn ich mich Ihm entpfehle und um guten Rath bitte was zu thun seye, bestens zu insinuiren bitte. Wegen der in Wien stehenden Sachen erwarte mit Verlangen Hn D. Schadens Antwort. An Hn Zimmermann kommt hirbey das verlangte Schreibn in ganz glimpflichen terminis. Solte Er sich weiter sperren wegen der Zahlung, so will ich auf gut Befinden noch ein andres schicken und darinn gedenken daß ich mir auf bedürffenden Fall commendatitias an E. HochEdlen Rath zu Regenspurg von hiesiger universität wolte geben lassen. Wegen des gethanen Vorschusses wird mein $\mathrm{H}$ Schwieger Vatter die restitution mit allem Dank so willig als schuldig thun. Die Polemica werden MhgHn Professori viel Mühe machen. Ich zweifele nicht, wann noch

[451v] länger mit der end $\ell$ resolution vertagen wird daß noch mehr ungereimte Vorschläge werden ans Tagesliecht kommen. Und ist nur schad daß man so viel Zeit mit der refutation verderben muß. Gleichwol ists nöthig. $\mathrm{H}$ Reiher hat nun auch beykommenden Bogen drucken lassen. Er ist aber eine bloße Beziehung auf des Calend: novum Tiedii darauf schon geantwortet ward. In Gotha wird noch reflexion darauf gemacht, $u$. ist mir befohlen mit Hn D. Reihern deswegen mich in correspondenz einzulassen. Ich gedenke aber ehestens selbst nach Gotha zu reisen und mündliche remonstation zu thun $\mathrm{u}$. zu suchen die Sache in einen andern Stand zu setzen. Womit nebst Empfehlung Göttlicher Gnaden $\mathrm{u}$. Erwartung fernerer freund $\ell$. u. fordersamter communication dessen was passirt, verharre

Meines hochgeehrten Hn Professoris u. Patrons ergebenster Diener

Raptim d. 1. Maji 1699

G A Hamberger

P.S. Wegen Kürze der Zeit u. vieler Geschäffte war mir dißmal ohnmöglich wegen des Aufsatzes zum Collegio Artis Cons: zu antworten. Soll aber nechstens geschehen. 


\section{Franco Nurnberg, á Regenspourg avec un paquet}

\section{Kommentar}

Im Zusammenhang mit dem Kalenderreformvorschlag von Samuel Reyher aus Kiel, vgl. Seite 46, erwähnt Hamberger in diesem Brief noch explizit den in Kiel publizierten ,neuen Kalender، 177] von Joachim Tiede, der in enger Beziehung zu Reyhers Vorschlag zu sehen ist. Mit der zu dem Zeitpunkt, als Hamberger diesen Brief schrieb, bereits in Druck befindlichen und bereits erwähnten anonym publizierten Entgegnung [4] scheint dieser Vorschlag für Hamberger im Prinzip vom Tisch. Hamberger befürchtet aber, dass bei weiterer Verzögerung der anstehenden Reform noch mehr ausgefallene oder gar groteske Entwürfe für die Kalenderreform auftauchen könnten, deren Beantwortung jeweils viel Mühe machen würde.

Die Anschrift Meyers in Regensburg trägt den Vermerk „avec un paquet“, also ,mit einem Paket‘. Tatsächlich erwähnt Hamberger in seinem Brief mehrere Papiere, die er in der Anlage mitschickt. Er nennt im Einzelnen

○ eine von ihm verfasste Stellungnahme zur Kalenderreform an die Abgesandten des Immerwährenden Reichstags in Regensburg,

- ein Schreiben des Fürsten von Weimar an den Weimarischen Regensburger Abgesandten (im Original),

○ einen weiteren Brief von seiner Hand, der zusammen mit dem fürstlichen Schreiben an den Weimarischen Abgesandten übergeben werden soll,

- ein Schreiben bezüglich einer Zahlung, die ein gewisser Herr Zimmermann allem Anschein noch zu leisten hat, sowie

○ einen Druck Samuel Reyhers den „neuen Kalender“ von Joachim Tiede betreffend.

Abgesandter des Herzogs von Sachsen-Weimar und des Herzogs von SachsenEisenach am Immerwährenden Reichstag in Regensburg war zu der Zeit der Weimarische Rat Georg Philipp Fabricius (1632-1709). Bei dem genannten Herrn Zimmermann aus Regensburg handelt es sich vermutlich ebenfalls um den Regensburger Prediger und Konsistorialassessor Daniel Zimmermann, welcher auf Seite 32 bereits im Zusammenhang mit Hambergers Disputation „De Usu Matheseos In Theologia“ 75. genannt worden ist.

Die oben aufgelisteten Dokumente befinden sich anscheinend nicht in dem vorliegenden Konvolut Cod. Ms. Philos. 60, auch nicht als Abschrift. Die ausführliche Beschreibung der Dokumente dieser Sammlung in [143] gibt dazu zumindest keinen Anhaltspunkt. Dahingegen befindet sich im Konvolut noch der folgende ebenfalls auf den 1. Mai 1699 datierte Brief Hambergers an Meyer. 


\section{Zweiter Brief vom 1. Mai 1699}

Cod. Ms. Philos. 60, Blatt 494

[494r] Wohledler, Großachtbar und Hochgelahrter, Insonders großgl. hochgeehrter H Professor, und Patron.

Ich zweifele nicht es werde der Todesfall des nunmehr seeligen Hn Weigelii seinem zu Regenspurg wohl angebrachten, und schon weit avancirten unmaßgebigen Vorschlag, wegen der Calender-Vereinigung und des Collegii Artis Consultorum, einen harten Stoß gegeben haben, weil einige leicht hetten können in die Gedanken kommen, als ob mit diesem hochberühmten und hoch meritirten Mann auch das ganze Werk abgestorben, und nun niemand seye der seine Gedanken recht inne habe, und solche außführen könne oder wolle. Allein, wie dem publico eines so nützlichen Mannes Leben Ihm aber die Freude wohl wäre zu gönnen und $\mathrm{zu}$ wünschen gewesen, daß Er die Früchte von seiner so großen Bemühung, die Ihn einen zimlichen Theil seines Vermögens und letzlich, so zureden, gar das Leben gekostet: So ist doch im Gegentheil gewiß und bekant, daß der seel. Mann diese so wichtige Anschläge niemaln allein auf seine Hörner zu nehmen gedacht, noch selbige auf seine eigene caprice oder auf eine tiefgesuchte von Ihm erst außzuführende, nun aber mit Ihm verstorbene Speculation, sondern auf so deutliche und männiglich bekante, als leicht practicable principia gegründet, sodaß die berühmten Mathematici mit denen er hierinn communicirt, und die sich auch guten theils schrifftlich zu Außführung des Hauptwerks anheischig gemacht, capabel genug sind wann nur das publicum autorität $\mathrm{u}$. Willen dazu gibt, das Werk mit der Hilffe Gottes zum Stande zu bringen. Dahero denn hoffe daß die vortreffl. Hhn Abgesanten der Protestirenden Stände zu Regenspurg, ein so nützliches Werck, zu dessen Anrichtung wohl in 100 Jahren sich keine so gute Gelegenheit zeigen dörffte, nicht werden liegen las-

[494v] sen. Dieses kan zum wenigsten Mhg Hn versichern, daß meine gute Herren, die Durch $\ell$ Herren Herzogen zu Sachsen Coburg, Weimar, Eisenach und Gotha mir expresse durch gute Befehle aufgetragen, daß ich mir die Außführung der vom seel. Hn Weigelio, als meinem GroßSchwiegerVatter, vorgeschlagenen Zeitvereinigung best möglichst soll lassen angelegen seyn. Zudem sind Sie auch an Dero Hhn Abgesandten zu Regenspurg gut rescribirt, diese Sache ferner zu treiben und mich mit Ihrem noto zu secundiren. Darum ich denn so willig als schuldig bin alles was mir möglich hiezu beyzutragen, 
und, wo es nöthig, gar eine Reiß nach Regenspurg zu thun. Dahero dann dienst $\ell$ will gebetten haben, mich ehrstens zu berichten, in was terminis die Sache vorjetzo stehe, und was ich gutes beytragen könne. Solche mir dißfalls erzeigte Freundschafft werde mit allen Gegendiensten zu erwidern niemaln ermangeln als der ich nebst Empfehlung Göttlicher Gnaden verharre

Meines Hochgeehrten Hn Professoris u. Patrons ergebenster Diener

Jena d 1 Maji 1699 Georg Albrecht Hamberger

\section{Kommentar}

Dieser Brief wirbt für die Fortsetzung der Bemühungen des verstorbenen Erhard Weigel um die Kalenderreform und die Einrichtung des Collegium Artis Consultorum. Er hat einen wesentlich offizielleren Charakter als die anderen Briefe Hambergers an Meyer. Es macht den Eindruck, als sei dieses Schreiben ausdrücklich dazu bestimmt gewesen, auch anderen Personen vorgelegt zu werden, obwohl es sich in Anrede und Schlussformel explizit an den Empfänger Johannes Meyer richtet. Für den offiziellen Charakter spricht auch, dass dies der einzige Brief ist, den Hamberger mit seinem vollem Namen, das heißt auch mit ausgeschriebenen Vornamen, unterschreibt. Da der Brief in den Unterlagen Meyers verblieben ist, dürfte es keine der im vorigen Brief genannten Beilagen sein, die an andere Personen übergeben werden sollten.

\section{Brief vom 4. Juni 1699}

Cod. Ms. Philos. 60, Blatt $106 \& 107$

[106r] Wohledler, Insonders hochgeehrtister Herr und Patron.

Desselben beede geehrtiste vom 10ten und 24ten Maji sind mir nun so viel angenehmer gewesen, weil auß selbigen, wie auch des Hn Abgesandten Fabritii Schreiben, erfreylich ersehen, daß die CalenderSache in einem erwünschten Stand stehe und allso unnöthig sey deswegen eine kostbare Reiß anzustellen, welche mir nicht nur durch einen expressen guten Befehl injungirt, sondern auch von einem meiner größten Patronen durch mehr als 4 Brief gerathen wurde; daß ich dahero, zu Vermeidung Fürst $\ell$. Ungnade, mich in unterthänigster Antwort damals erkläret. Wo der H Abges: Fabritius, der 
von gegenwärtigem der Sache Zustand, die beste Nachricht hette, solche vor nützlich und nöthig erachtete, daß ich mich ungesaumt auf den Weg machen wolte. Und weil ich vernommen daß jetzt hochgedachter $\mathrm{H}$ Abgesandter in gleichen terminis an die HochFürst $\ell$. Höffe geschrieben, und allso in diesem Stück mir selbst das Wort geredet, so bitte Demselben deswegen, wie auch wegen der sehr obliganten Zuschrifft, ohnschwehr in meinem nahmen gehorsamsten Dank zu sagen und zu ferneren hohen affection bestens zu recommendiren. Anbey remittire den wohlgefaßten Auffsatz wegen des Collegii Artis Consultorum, bey welchem dieses hauptsächlich wünschen mögte, daß die Nutzbarkeiten des Collegii voran stünden, dem Lectori eine gute opinion von selbigem zu machen und dadurch zu dessen constituirung und salarirung desto mehr anzureitzen. Und wann die CalenderSache erst völlig adjustirt ist, wird selbige eines der wichtigsten momentorum geben, weil ohne das Collegium die projectirte völlige correction der Calender nicht wohl wird zu erhalten seyn. Weil auch der Aufsatz doch noch nicht gedruckt wird, so will, wann mir bey mehrer muße noch etwas importantes einfallen solte, schon deswegen schleunig communiciren. Wann sonst gemeldet worden daß die Hhn Evangelicos Legatos am meisten torquiren der Vorwurf der Catholicorum daß diese Enderung eine bloße accessio zu Ihnen sey. 1) Wann schon alles war wäre so sehe nicht was Ihnen der Vorwurf mehr schaden könnte als denen Holländern und Engeländern, welche beede nationes, meines behalts, das Calendarium Gregor: observiren. Allein 2) diese Sorg ist ganz nicht nöthig wann die Hhn Protestanten nur selbsten die Calenderreformation völlig nach unseres see $\ell$. Vatters Vorschlag wollen einrichten. Denn weil der cyclus Gregorianus notorisch zuweilen in der Festrechnung fehlet, hat der see $\ell$ : Mann vorgeschlagen daß ein hirzu bestelltes Collegium die Guarantie leisten solle, damit Er nicht contra Canones anstosse. Das heist aber in der that einen astronomischen an statt eines cyclici calculi vorschlagen (massen die guarantie bloß durch den calculum astronomicum kan geleistet werden) diesen aber haben ja die Catholici nicht. Kämen sie nun schon mit uns in der Festrechnung

[106v] überein, so lang ihr cyclus nicht fehlet, so kan man ja deswegen nicht sagen daß wir zu ihnen übergetretten, sondern wir hetten dennoch einen total diversen calculum. 3) Ja die Hhn Protestanten haben auf diese maße Gelegenheit große Ehr zu erwerben und die Hhn Catholiquen zu veranlassen, daß sie zu ihnen übertreten müsten. Denn als diese $\bar{a}$ o 1693 in den Bann kamen, hat man damals in offentliche Zeitung gesetzet, daß der Pabst auf 
eine neue reformation bedacht wäre. Und zweifele ich gar nicht, wann solche casus mehr kommen, daß es Ihm ernst seyn werde. zumaln nunmehro der Vorwurf dazu käme, daß die Protestanten den Ostertermin besser treffen als Er. Er mag es aber angreiffen wie Er will, und entweder einen bessern cyclum fingiren (der doch nicht beständig seyn kan) oder auch den Astron: calculum introduciren, so kan Er ohnmöglich anderst als zu uns tretten. Und glaube ich es werde der casus, da nemlich unser u. ihr Ostern um 8 Tag differiren über ein oder 2 mal nicht sich ereignen, so werden die Hhn Catholi die Enderung belieben. wolten die Hhn Protestanten aber selbsten kein Collegium so die guaratie über sich nehme, belieben, auch nicht leiden daß zuweilen in der Festrechnung zwischen uns und denen Cathol. sich um 8 Tag eine discrepanz euserte, biß nemlich der Pabst auf gute Vorstellung sich auch enderte, sondern wolte warten biß sich die ganze Christenheit deswegen verglichen, so wäre dieses am Ende des see . Hn Weigelii Vorschlag nicht zu imputiren: sie könnten sich aber meines Erachtens genug wider allen Vorwurf schützen daß sie dieses proprio motu, Catholicis requidem hoc postulantibus, auf andere Art, zu anderer Zeit und auß andern Ursachen thäten, als solches ehemaln die Hhn Catholici gethan. Ich meines Orts wolte lieber daß der Astronomische calculus placitirt würde. zumaln solches nicht nur Hn P. Sturms sondern auch Hn Weigelii Meinung in effectu gewesen, als oben gewiesen. Und werden wir anderst von denen vielen verdrüßlichen Vorwürffen der adversariorum so sich biß anhero in scriptis opponirt, nicht loß werden, wann schon das ganze Röm. Reich autoritate publico den neuen Stylum introducirt. Jedoch MhgH Professor wird am besten wissen ob die Protestantische Stände dazu leicht zu disponiren seyn oder nicht. Wäre es nicht und solten dahero neue difficultäten sich hervor thun die wohl die ganze soweit gebrachte conciliation über einen Hauffen werfen, so hielte ich davor man lasse, die völlige conciliation oder viel mehr die völlige Annehmung des neuen styli in principio conciliationis vor sich, in Gottes Nahmen gehen. Wann das Collegium Artis Consultorum zu Stand kommt, wird sich schon Mittel u. Weg zeigen die errores mit der Zeit conjureta manu zu heben. Und drückt uns am Ende der Bann, darein man indessen zuweilen verfiele, nicht so sehr als die catholicos. Ja die teutsche Wahrheit zu sagen, das Concilium Nicænum hat in certo casu eine impossibilität gebotten, u. kan uns allso nicht obligiren. Aber hievon mag jeziger Zeit noch nicht viel sagen; es wird sich mit der Zeit und Gelegenheit schon eusern. Inzwischen verhoffe ehestens Dero Gedanken und wohin der meisten Protestanten inclination gehe zu vernehmen. 
[107r] Belangend ferner die bißherigen antagonisten, so wird sich wohl der von Hoff, oder vielmehr der Pfarherr von Lobenstein H M. Körber sich weiter nicht melden, sondern künfftig fleissiger auf seine Predigt studiren. H D. Reihers Vorschlag ist nicht nur unpracticabel, sondern sein u. Hn Tiede cyclus ist auch falsch und setzt e.o. 1693 den terminum Paschalem oder das plenilunium paschale auf einen Sonnabend da es doch vermöge der Ephemeridum auf den Sonntag gefallen; dahero man nach seinem cyclo damals müssen in Bann kommen. Von denen Hhn Spleißen hat mir jüngst ein passagier von Schaffhausen, so sie sehr wohl kennet, gesagt daß sie incapabel wären ihres Hn Vatters, der in der Schul daselbst Rector gewesen, invention außzuführen, welches mich die überschriebene neue exceptiones völlig convinciren. Sie können sich nur zu Rom melden. Dieser Tagen ist mir gedruckt zu Gesicht kommen, was ein Leipziger Student, H Ulrich Juni, wider des See $\ell$. Hn Weigelii Calender-Vereinigung geschrieben, samt MhgHn Professoris responsion und seiner neuen exception. Man mögte Ihm wohl auß 2 Sam: 2.v. 21 antworten. Er ist zwar sonst mein discipul u. ist im calculiren wohl versirt, wie sein Tractätgen de Mircurio in Sole viso außweiset, dahero ich Ihn auch bey dem see $\ell$. Hn Vatter so weit recommendirt, daß Er Ihn versichern lassen Er solte auch mit in das Collegiam gezogen werden. Weiß nun nicht wer Ihn muß aufgereitzet haben. Sein ganzes Schreiben kommt darauf an daß Er sich einbildet man recommendire bloß die Einführung des Calend: Gregor: Seines argumente Minor damit Er solches zu behaupten suchet in seiner exception, ist durch alle membra falsch. So begehet Er auch lauter Lufftstreich wann Er die observationes privatorum hochzuheben suchet. Ich will suchen ob ich Ihn durch zuschreiben auf bessern Gedanken bringen könne. Seine Sorg daß der Pabst wenn wir mit Ihm einig, eine neue reformation vornehmen u. uns allso vexiren dörffte, ist ganz überflüssig weil ja ohne dem nach des See $\ell$. Hn Vatters Vorschlag der neue Stylus nur mit condition daß man Ihn mit der zeit völlig corrigiren wolle, angenommen wird. Hiernebst kommen auch die Zimmermännischen Schuldzettul in originali wider zurück, nebst einer kurzen Beantwortung seiner dubiorum. Das 4te der jüngere $\mathrm{H}$ Zimmerman mit eigener Hand beantwortet weil es Ihn insonderheit angehet. Ich habe zur Zeit angestanden die Sache vor den Hn Rectorem zu bringen, theils weil der ältere H Zimmermann nicht in loco ist, theils weil es ohne ihre Beschimpfung nicht abgehet, theils auch weil ich hoffe ihr $\mathrm{H}$ Vatter soll sich nun begreiffen. Sonsten kan es noch alle mal geschehen wann ich auch schon die original obligationen nicht in Händen habe. Der Zettul Lit: A. (welchen wohl 
zu conserviren bitte,) wird Ihm hoffentlich ganz auß dem Traum helffen.

[107v] Ich glaube der gute Mann sey nider opinion gestanden des jüngern Hn Sohns Schuldzettul von 37 thlr. 14 gl 9 d. welchen Er nur auf seines Hn Vatters Verlangen und zu seiner justification besonders aufgesetzet, sey à parte zu bezahlen. Allein selbige Schuld ist unter denen 42 thlr $13 \mathrm{gl} 9 \mathrm{~d}$ welche der ältere H Sohn allein unterschrieben, mit begiffen (wie wohl es die Hhn Söhne selbst nicht gewust). Solte ich es in meinem letzten Schreiben selbst mit angesetzet haben so ich nicht mehr weiß, so wäre es auß Übereilung unversehens geschehen. Bestehet allso die ganze Schuld auß 42 thlrn $13 \mathrm{gl} 9 \mathrm{~d}$ so dem see $\ell$. Hn Weigelio, 4 thlrn so mir und 25 thlrn so der Magd gehörig; zusamm 71 thlr $13 \mathrm{gl} 9 \mathrm{~d}$ welche Schuld sich noch wird abtragen lassen. Endlich sind wir nicht wenig bekümmert wegen Hn D Schaden weil Er einen silbern Globum und eine kostbare Sphæram ohne deshalben von sich gestelter obligation, in Handen hat, und nun nicht antwortet. Meine Fr. SchwiegerMutter, welche schon einige Wochen hier ist, lässet nebst dienst $\ell$. Empfehlung angelegentlichst bitten, ob mein hochgeehrter $\mathrm{H}$ Professor ihr die besondere Freundschafft erweisen und nur oblique wolle nachfragen lassen ob Er beede Stücke noch habe; so wolten wir Hn Hoffmann hinab schicken der sie nebst dem Pancosmo, so noch in der Mauth stehet, wider herauf schaffen solle, weil doch schwerlich einige Hoffnung verhanden daß selbige mögen an Mann gebracht werden. Mit dem Collegio Artis Consultorum dörffte es wohl am besten gehen wann selbiges vom gesamten Reich nach Wien recommentirt würde zumaln Ihr Kays: Majestet selbiges schon allergnädigst placitirt, und allso das Werk nur beym Reich zu treyben ist. Auf solche Weiße hette ein so odiose Person in dieser Sach weiter nichts zu thun. Schließlichen berichte daß der H Abgesandte Fabritius den Hn Hoffmann in sehr nachdrücklichen terminis recommendirt auch MhgHn Professoris memorial mit überschicket. Und weil mein Gutachten darüber verlanget worden, habe ich mit Hn Hoffmann selbst darauß communicirt, und seine Qualitäten nebst der ganzen Sach aufs das beste schrifftlich recommentirt, wie Er, den ich das Schreiben lesen lassen, es selbsten vor gut befunden. den Außgang muß man hier nechst erwarten. Womit nebst Empfehlung Göttlicher Gnaden verharre Meines hochgeehrtisten Herrn u. Patrons

Jena d 4 Junii ergebenster Diener 1699.

G A Hamberger

Wann man einen verstreuten studiosum oder Kauffmann in Wien hette, könnte man am eesten erfahren ob vorgedachte Sachen bey H D. Schaden 
noch vorhanden seyn.

Empfang den $\frac{10}{20}$ Junij. [offenbar eine Notiz des Empfängers]

\section{Kommentar}

Hamberger hatte sich im zweiten Brief vom 1.5.1699 ausdrücklich angeboten, auch mit Bezug auf die darin erwähnten Anordnungen seiner Landesherren, bei Bedarf zur Unterstützung der Kalenderreformbestrebungen eine Reise nach Regensburg zum Immerwährenden Reichstag zu unternehmen, vgl. Seite 52. In diesem Brief kommt zum Ausdruck, dass Hamberger der schriftlichen Lage der Dinge nach zu der Einschätzung kommt, die Kalendersache entwickle sich gemäß der Intentionen Weigels und des Trios Hamberger, Meyer und Sturm. Insbesondere scheint er darauf zu vertrauen, die Argumente für das angestrebte Collegium Artis Consultorum seien bereits ausreichend überzeugend dargestellt, um das Collegium politisch auch tatsächlich durchbringen zu können.

Hamberger erwähnt in diesem Brief Christian Körber, Pfarrer und Diakon im vogtländischen Lobenstein [28, Seite 550]. Körber soll als Verfasser eines Lichtenbrunner immerwährenden Bauernkalenders bekannt geworden sein und sich damit auch als Gegner des Aberglaubens einen Namen gemacht haben. Im Jöcherschen Gelehrtenlexikon heißt es dazu: „Er ist auch Verf. des Lichtenbrunner immerwährenden Baurenkalenders, der ein Beweiß ist, daß er zu den edeln Männern gehörte die den Aberglauben auszurotten bemühet waren" [109, Spalte 680], vgl. auch [39, Seite 129].

Der genannte Rektor am Gymnasium von Schaffhausen in der Schweiz war Stephan Spleiß (1623-1693) [137]. Zwei seiner Söhne, David Spleiß (1659-1716) und Johann Jacob Spleiß (1655-1728), studierten und waren wie ihr Vater Lehrer am Schaffhausener Gymnasium, siehe [156, Seite 133 f.] und [175, Seite 281]. Erwähnt sei noch ein weiterer Sohn von Stephan Spleiß, nämlich Johannes Spleiß. Dieser war Buchbinder und der Mathematiker Thomas Spleiß (1705-1775) war ein Sohn dieses Buchbinders, vgl. [59, Seite 7] und [56].

Von Stephan Spleiß findet man eine Schrift über seine Beobachtungen des großen Kometen von 1664 [171]. Außerdem soll er Kalender herausgegeben haben. Zu einer etwaigen Erfindung des bereits 1693 Verstorbenen gibt es lediglich die von den beiden Söhnen David und Johann Jacob Spleiß im Jahr 1699 publizierte kleine Schrift „Kurzer Bericht von einer newen Erfindung“ [170, in welcher die Autoren zwar vollmundig verkünden, dass ihr Vater eine neue, einfache und allgemeingültige Rechenmethode zur Vereinigung von Julianischem und Gregorianischem Kalender sowie vornehmlich zur Osterfestrechnung gefunden habe, geben aber in dieser Schrift keinerlei Details zu dieser Methode an. Vielmehr lesen wir dort: 


\begin{abstract}
Dífe Invention haben bey íbren Ganden, def́ Inventoris und Auctoris bin derlafifene Jerben, und bier underidhribene Söbne, weldbe, bey erfolgender execution, nodh fernere Gandanlegung verbeiffen und denen Begebrenden, fonderlidh Mathematicis, und difes Studii $\mathfrak{L i e b h a b e r n , ~ f o ~ v i l ~ f i d ~ t h u n ~ l a f f e t , ~}$ mit gebübrender Erläuterung, wo nötbíg, aufwarten werden.
\end{abstract}

Die betreffende „Erfindung“ beziehungsweise Rechenvorschrift soll zudem in den Jahren 1694 und 1697 bereits dem Kaiser mitgeteilt worden sein, vgl. dazu insgesamt auch [197, Seite 262 f., Fußnote 4].

Der Leipziger Student, den Hamberger hier erstmals nennt, ist Ulrich Junius (16701726). Junius stammte aus dem schwäbischen Ulm, hatte 1693 sein Studium der Mathematik und Theologie in Jena begonnen und ging im Sommer 1697 nach Leipzig, wo er 1700 seinen Magister erwarb. In seinem ersten Brief an Gottfried Kirch, mit welchem er als Student kurz nach seiner Ankunft in Leipzig eine intensive Korrespondenz aufnahm, beklagte er sich darüber, dass er ursprünglich zum Studium nach Jena gegangen war, um Erhard Weigel zu hören, dieser dagegen bloß auf Reisen war. Außerdem begründete er darin seinen Wechsel nach Leipzig damit, dass er in Jena die Anleitung durch einen Lehrer - als Gegenstück zum Selbststudium aus Büchern - vermisste, vgl. den Brief Nr. 578 der Korrespondenz Gottfried Kirchs [94, Band 2, Seite 233 f.] und Anmerkung 5 dazu [94, Band 3, Seite 435]. Junius hatte 1699, noch als Student, in Leipzig ein „Unpartheyisches Bedencken“ zu Weigels Kalenderreformvorschlag drucken lassen [113. Die darin enthaltenen „eines unbenandten Authoris Anmerckungen" stammen offenbar von Hambergers Korrespondenzpartner Johannes Meyer, siehe auch [94, Band 3, Seite 468]. Über dieses „Unpartheyische Bedencken“ berichtete Junius Ende April 1699 sehr ausführlich an Kirch, vgl. den Brief Nr. 657 [94, Band 2, Seite 310 f.] und die Anmerkungen [94, Band 3, Seite 467 ff.]. Insbesondere lesen wir in diesem Brief von Junius:

Hierauß siehet mein HochgeEhrter h $\ell$. GeVatter, daß ich innerhalb 8. tagen wegen meines Calendersbedencken werde von $\mathrm{h} \ell$. Prof. Meyer angegriffen werden, darauff ich mich von Herzen freue, und es ex tempore wieder antworten will. ... Mein Calenderbedencken will ich nicht drucken lassen, biß ich vorher sehe, wie starck ich angegrieffen werde: vielleicht ändere ich es sodann, und gedencke $\mathrm{h} \ell$. Weigelij am besten.

Folglich hatte Junius im Mai 1699 innerhalb eines Monats auf sein „Bedencken“ eine schriftliche Erwiderung von Meyer erhalten, darauf wiederum eine eigene Entgegnung verfasst und das Ganze drucken lassen, sodass Hamberger bereits Anfang Juni 1699 davon Kenntnis haben konnte. Hamberger bezeichnet Junius als seinen Schüler und verweist auf eine Bibelstelle im zweiten Buch Samuel. Im zweiten Kapitel geht es dort um den Bruderkrieg zwischen dem Königreich Israel und dem Königreich Juda. Der erfahrene und bewährte Feldherr Abner, Heerführer König Sauls, wird in einem Wettlauf von dem jungen und ungestümen Asahel verfolgt. In 
Vers 21 spricht Abner zu Asahel „Geh nach rechts oder links und pack dir einen von den jungen Leuten. Dem kannst du die Rüstung abnehmen." [136]. Ungeachtet der Aufforderung Abners, sich einen anderen Gegner zu suchen, lässt Asahel sich nicht aufhalten und wird schließlich von Abner getötet.

In diesem Brief an Meyer verleiht Hamberger wieder seiner Sorge um den Verbleib der von Weigel nach Wien gesandten astronomischen Geräte Ausdruck, explizit auch im Namen seiner Schwiegermutter, Weigels Tochter Anna Katharina.

Außerdem nennt Hamberger erstmalig den Astronomen Johann Heinrich Hoffmann (1669-1716). Hoffmann war ein Schüler Erhard Weigels, bis zu dessen Tod sein Assistent und hatte Weigel insbesondere auf dessen Reisen nach Dänemark und Schweden begleitet. Offenbar bemühte Hamberger sich um eine berufliche Perspektive für Hoffmann.

Die am 1. Mai 1699, vgl. Seite 49 f., angesprochene ausstehende Zahlung von Herrn Zimmermann in Regensburg wird in diesem Schreiben mit einer genauen Auflistung von Schulden spezifiziert. In diesem Zusammenhang werden zum einen zwei Söhne Zimmermanns, die sich beide offenbar in Jena aufhalten, sowie zum anderen eine Magd erwähnt. Eine Durchsicht der Matrikel der Universität Jena für den Zeitraum von 1652 bis 1723 liefert genau zwei relevante Einträge. Danach hat sich am 28. Dezember 1688 ein aus Regensburg stammender Daniel Zimmermann und am 1. Dezember 1694 ein ebenfalls aus Regensburg stammender Christian Zimmermann an der Universität Jena eingeschrieben [107]. Der genannte Christian Zimmermann ist gemäß [46, Seite 248] tatsächlich ein Sohn des Regensburger Predigers Daniel Zimmermann und mit Sicherheit Respondent der juristischen Disputation [165] aus dem Jahr 1699. Außerdem ist nach Lage der Dinge seinem älteren Bruder Daniel Zimmermann die Disputation [43] zuzuschreiben, die im Jahr 1691 mit diesem als Respondenten an der Universität Jena abgehalten wurde. Im Verzeichnis der Drucke des 17. Jahrhunderts wird als Respondent jedoch der Vater Daniel Zimmermann genannt, welcher zu dieser Zeit längst in Regensburg wirkte.

\section{Erster Brief von Juli 1699}

\section{Cod. Ms. Philos. 60, Blatt 449}

[449r] Wohledler, großg $\ell$ hochgeehrtister H und Patron.

Desselben beede werthiste Schreiben vom 28 ten Junii u. 6 ten Julii, sind mir nebst denen Beyschlüssen behändiget. Hoffe auch daß das meinige heut 8 Tag abgelassene, nicht minder indessen werde eingelauffen seyn, darauf ich mich dann, zumaln was die prognostica angehet, welche ich, als ein Stück so 
Gottes Ehre touchirt, u. viele 1000 Leuth zum Aberglauben verleitet, bey künfftiger publication des neuen Calenders gern autoritate publica mögte abgeschafft wissen, will bezogen haben, und wird solches nun mehro so viel mehr zu urgiren seyn, weil nach eingelangten Schwedischen consens sonderzweifel bald zur publication wird geschritten werden. Daß H P. Sturm schlechte Neigung zeiget das Collegium zu befördern, wundert mich, zumal Er sich bey Lebzeiten des see $\ell$. Hn Weigelii eigenhändig als ein künfftig membrum Collegii aufgeschrieben, wie MhgHn Professori sonderzweifel nicht unbekant. Ich glaube aber der larguer komme nur daher weil Er noch an der possibilität zweifelt. Allein wann es denen Protestirenden Ständen Ernst ist mit der reformation des Calenders, werden sie sich nicht wohl entbrechen können die curam temporum gewissen personis publicis aufzutragen u. ihnen eine genugsame Ergötzung deswegen zu gönnen, weil sonst wann sich einige des calculi Unterfangen so sein nicht mächtig, leicht confusiones enstehen könnten. Wann es aber so weit kommt u. sich allso einiger fundus zum collegio zeiget, denke ich nicht daß man die übrigen Nutzbarkeiten, so weit größer, sind, solte gar hinten ansetzen. Es würde sich auch leicht ein Haupt zeigen, der inventis et meritis illustris ist, u. der ganzen Sach einen guten splendeam gebe. Zu Wien möchte die Sach am eesten gehoben werden, wann die wohl gesinnte Stände das Werk Ihro Kays $\ell$ : Majestät selbst recommendirten. Ob aber solches zu hoffen wird MhgH Professor besser wissen als ich. Mit Hn Schaden als einer persona odiosa wird wohl wenig außzurichten. Und dörffte, wo die Standte das Werck nicht selbst am Keys $\ell$. Hoff anbringen, dieses wohl der schwerste Stein seyn, wie nemlich Ihro Keys $\ell$ : Maj: zu constituirung des Collegii zu bewegen. Daß H Zimmermann endlich abgetragen was der see $\ell \mathrm{H}$ Vatter Weigelius an Ihn zu prætendiren gehabt, war mir sehr lieb zu vernehmen. Sage auch so wohl in meiner Fr. Schwieger Mutter nahmen als vor mich sehr dient $\ell$ Dank vor dißfalls gehabte viele u. große Bemühung. Mein hochgeehrter H Professor wolle nun so gütig seyn und das seinige, davon ehemaln gedacht worden, nebst schuldigster Danksagung vor den Vorschuß u. gütiges Nachwarten, hievon zurück behalten und den Rest dahin senden wo mein $\mathrm{H}$ Schwieger Vatter deswegen Anzeige thun wird dem ich dieses billig nebst der Art zu quittiren überlasse. Maria Schumännin sendet hiebey eine neue specification. Hoffe allso daß dißfalls auch die dubia werden gehoben seyn und endlich der völlige Abtrag geschehen wann ich verarhmen werde daß mein H Schwieger Vatter die Quittung vor die Magd von sich zu stellen bedenken tragen, soll selbige von hier auß 
übersandt werden. Das Geld könnte etwan mit guter Gelegenheit übermachet werden. H Hoffmann, der sich gehorsamst recommendiren lässet ist im Werk, nachzuschlagen wie offt die Gregoriani Ostern

[449v] mit denen Juden halten, und soll die specification über 8 tag folgen. Selbiger wird an hiesigen Hoff, auß mir wohlbekannten Umständen schwehrlich etwas anders als ein Stipendium zu hoffen haben. Aber in Weimar dörffte es eher gehen wann zumaln der H GR von Linker darinn Patronus seyn wolte, dem ich deswegen ehester Tagen aufwarten u. Hn Hoffmann bestens recommendiren will. Sein anderer Bruder ist vor einigen wochen von hier über Hall nach Berlin gereiset daselbst seine fortun zu suchen. Der jüngste Bruder aber ist ein Balbiergesell in Nürnberg, wird allso der durch Regenspurg ohnlängst gegangene wohl keiner von der familie seyn. Womit nebst Empfehlung Göttlicher Gnaden verharre.

Meines großg $\ell$ hochgeehrtisten Hn u. Patrons ergebenster Diener

Jena d Julii 1699

G A Hamberger

P.S. Die J. Weigelin ligt schon etliche Tage fest an ihres see $\ell$. Hn Bruders Krankheit darnieder u. dörffte menschlichem Ansehen nach schwehrlich wider davon kommen. Die Beylage an den Hn Abgesandten Fabricium betrifft bloß die Abschaffung der prophezeyungen davon oben gedacht. Bitte die Sach bestens zu secundiren.

\section{Kommentar}

Am Beginn des Briefes wird auf ein vor acht Tagen abgesandtes Schreiben Bezug genommen. Ein solcher Brief hätte auf einen Tag Ende Juni oder Anfang Juli 1699 datiert sein müssen, da Hamberger sich in diesem Brief bereits für ein Schreiben vom 6. Juli bedankt. Ein Brief passenden Datums ist in der Sammlung jedoch nicht vorhanden. Der vorliegende Brief ist aller Wahrscheinlichkeit nach am 19. oder 20. Juli 1699 geschrieben worden. Am Ende des Briefes wird nämlich angekündigt, dass mit dem nächsten Schreiben in einer Woche Spezifikationen Johann Heinrich Hoffmanns darüber mitgeschickt werden sollen, wann das Osterfest nach dem Gregorianischen Kalender mit dem jüdischen Passahfest zusammenfällt. Dies erfolgte tatsächlich mit dem nachfolgenden Brief vom 27. Juli 1699, siehe ab Seite 63.

Wie schon in der Einführung erwähnt, war Weigel 1696 und 1697 in Stockholm, um neben Dänemark auch die schwedische Krone für die Kalenderreform zu gewinnen. Weigel hatte für die Notwendigkeit der Kalendervereinheitlichung nicht 
nur die protestantischen deutschen Territorien im Auge sondern auch die anderen protestantischen Staaten Europas. Er war für diese Reise mit einem ausdrücklich befürwortenden Empfehlungsschreiben des dänischen Königs, datiert auf den 8 . August 1696, ausgestattet, um auch das Einverständnis Schwedens „zu seinem der gantzen Christenheit so ersprießlichen Werck zu erbitten und einzuhohlen", siehe [3] in [132, Seite 752 f.] oder [105, Seite 11]. Bekanntlich war Weigel auf seiner Reise in Stockholm nicht so erfolgreich wie in Dänemark. Doch im Kontext der fortgeschrittenen Bemühungen im Jahr 1699 versuchten die evangelischen Stände nochmals, Schweden für die Kalenderreform zu gewinnen [11, Seite 31]:

Damit aber auch Ih. Königl. Majest. von Schweden/ als ein mächtiger Potentat selbiger Religion, und ein so considerabler Reichs-Stand diser Veränderung wenigstens in dero Teutschen Provintzen accediren möchten/ dörffte an Dieselbe deßhalber geschrieben/ und das Vorhaben zur Conformität bestens recommendiret werden.

Als Resultat des Dreißigjährigen Krieges besaß Schweden die Herrschaft über Schwedisch-Pommern, bestehend aus Vorpommern und Rügen, der Stadt Stettin sowie der Odermündungen. Da Schweden dieses Territorium lediglich als sogenanntes ewiges Reichslehen erhalten hatte, das heißt es wurde Namen der pommerschen Herzöge verwaltet, blieb Schwedisch-Pommern Teil des Heiligen Römischen Reiches. Das genannte Schreiben an den schwedischen König trägt das Datum 7.|17. Mai 1699 und ist im „Monatlichen Staats-Spiegel" von Juli 1699 abgedruckt worden [12, Seiten 27-30]. Offenbar erwartete Hamberger, dass binnen kurzem ein Antwortschreiben mit der Stellungnahme Schwedischer Mathematiker zur Kalenderreform vorliegt, und geht davon aus, dass, sobald dies der Fall ist, umgehend zur Beschlussfassung über die Kalenderreform geschritten wird. In diesem Zusammenhang drängt er wiederholt auf die Abschaffung des bereits mehrfach erwähnten "Kalender-Unfugs".

In diesem Brief deutet sich erstmals ein äußerst substanzieller Aspekt im Zusammenhang mit dem politischen Ringen um die Kalenderreform an. Bisher war man immer bemüht, dass es zu einem kaiserliches Dekret zur Annahme eines für alle deutschen Territorien geltenden gemeinsamen neuen Kalenders kommt. Über ein solches Dekret des Kaisers wäre auch das angestrebte Collegium Artis Consultorum in seiner Aufgabenstellung endgültig autorisiert worden und hätte mit dem gebotenen Privileg in der Kalendersache ausgestattet werden können. Zwar hatte der Kaiser am 27. Juli 1697 ein Dekret bezüglich der Einrichtung des Collegium Artis Consultorum erlassen, vgl. [42, Seite 211] sowie zum Wortlaut [132, Seite $748 \mathrm{f}$.$] ,$ aber dieses Collegium befand sich bei Weigels Tod in der Konstituierungsphase und hatte seine Arbeit noch gar nicht aufgenommen. Bekanntlich gab es keinen kaiserlichen Erlass zu einem neuen Kalender für das gesamte Reich, 1700 wurde von den protestantischen Ländern lediglich der Verbesserte Kalender eingeführt. Siehe auch den Kommentar zum Brief vom 18. November 1699 auf Seite 79. 
In den Bemühungen um die berufliche Perspektive für Johann Heinrich Hoffmann konnte Hamberger die Unterstützung eines einflussreichen Politikers am Weimarer Hof gewinnen, nämlich die des Geheimen Rates Nikolaus Christoph von Lyncker (1643-1726). Von Lyncker hatte 1659 in Jena studiert und war zu einem der bedeutendsten Juristen seiner Zeit avanciert 37, 145.

Im Postskriptum des Briefes wird Weigels Schwester Margareta erwähnt [162, Seite 20]. Sie war sieben Jahre älter als ihr Bruder und unverheiratet geblieben, daher im Brief die Abkürzung ,J.' für Jungfer. Vermutlich hatte sie Erhard Weigel in Jena den Haushalt geführt [36, Seite 16].

\section{Brief vom 27. Juli 1699}

Cod. Ms. Philos. 60, Blatt 433 \& 434

[433r] Wohledler, Hochgeehrtister Herr und Patron.

Hierbey kommen die vom Hn Hoffmann aufgesuchten Jahr in welchen die Hhn Catholici ihre Ostern mit denen Juden zugleich halten. Im instehenden Seculo hat sich derg $\ell$ nicht finden wollen. Jetzt gedachtem Hn Hoffmann habe ich heut eine unterthänigste Sapplique an den Weimarischen u. hiesigen Hoff aufgesetzet, damit die gute zu seinem besten gefaste resolution nicht möchte in Vergessenheit gerathen, habe auch an hiesigen Hoff verstanden, wann der $\mathrm{H}$ Abgesandte Fabritius sich seinetwegen mit einer recommendation nochmal bemühen solte (so zur Zeit noch nicht geschehen seyn mag) daß wohl ein extraordinar subsidium vor Ihn zu hoffen wäre. Weil sonst des Chur Hannov. Hn Residenten zu Wien Bruder H M. Erasmi morgen von hier über Prag nach Wien zu reisen gedenket, so hab ich Ihm commission gegeben bey Hn D. Schaaden nach zufragen wann seine Geschäfte ließen daß der silberne Globus u. Sphæram von

[433v] Ihm könnten abgeholet werden, welches Er auch über sich genommen. Dafern Er nur antworten und die Brief etwa an Mhg Hn Professorem addressieren solte; so will dienst $\ell$ gebetten haben sich solchen bestens recommendirt seyn zu lassen damit ich sie bald erhalte. Ubrigens habe jüngst gegen den Hn Abgesandten Fabricium u. vieleicht auch gegen Mhg Hn eines Tractätleins vom Calenderunfug gedacht, welches ich anbey schicke u. solches auch dem Hn Abgesandten nebst meiner gehorsamsten recomendation vorzuzeigen bitte. Schließlich beziehe mich auf meine letzte 2 Schreiben $u$. 
verharre unter Göttlichem Schutz

Jena d 27 Julii

Meines Hochgeehrten Hn Professoris und Patrons

1699

ergebenster Diener

[434v]

G A Hamberger

\begin{abstract}
A Monsieur
Monsieur Jean Majer, Professeur és Mathematiques tres_celebre

avec un paquet, á Regensbourg
\end{abstract}

\title{
Kommentar
}

Wir erfahren in diesem kurzen Brief insbesondere etwas über den Stand der Bemühungen um die weitere berufliche Perspektive für den früheren Assistenten Erhard Weigels, Johann Heinrich Hoffmann. Dieser hatte im Zusammenhang mit der Diskussion um die Festlegung des Ostertermins die Jahre herausgesucht, in welchen das Osterfest nach dem Gregorianischen Kalender mit dem jüdischen Passahfest zusammenfällt, wie im vorherigen Brief angekündigt. Die von Weigel nach Wien gesandten Instrumente, insbesondere Globus und Pancosmos, sollen nun offenbar von dort wieder abgeholt werden. Dazu hofft man auf die Unterstützung durch den Bruder des Gesandten des Kurfürsten von Hannover am Wiener Hof, Daniel Erasmus von Huldenberg. Dieser ,Bruder des Erasmus“ („Bruder Erasmi“) wird auf dem Weg nach Wien Station in Jena machen. Schließlich scheint man dazu außerdem noch auf eine Antwort des besagten Herrn Schad aus Wien zu warten, wann es diesem zeitlich am besten passen würde. Als Anlage wurde offenbar ein Text Hambergers über den sogenannten „Kalender-Unfug“, also Wahrsagerei und Wetterprognostiken, mitgeschickt, vgl. Seite 18

\section{Brief vom 6. August 1699}

Cod. Ms. Philos. 60, Blatt $437 \& 438$

[437r] Wohledler, Insonders großg $\ell$ Hochgeehrter Herr u. Patron

Ich habe zwar erst vor 3 Tagen über Eisenach ein Schreiben lassen abgehen welches hoffentlich franco eingelaufen seyn wird. Weil aber Zeiger dieses $\mathrm{H}$ M. Erasmi, des Chur Hannov $\ell$. Residenten in Wien H Bruder, seinen Weg 
über Regenspurg nach Wien zu nehmen gesonnen, habe ich zugleich berichten wollen daß ich Dero werthistes, so vor 3 Tagen annoch desiderirt, nun auch erhalten. Hoffe mein Hgh $\ell$ Professor werde das seinige von dem Zimmermannischen Geld erst abgezogen haben, wie jüngst gebetten, und nur den Rest meinem Hn Schw.Vatter zugesandt haben. Ich hoffe daß jetzt gedachter mein $\mathrm{H}$ Vatter etwa $\mathrm{Hn}$ M. Erasmi einige commission wegen der instrumenten in Wien mitgeben werde. Meine Meinung gehet dahin, weil $\mathrm{H}$ Schad den Preiß der instrumenten nicht mehr wissen will selbigen zu berichten $\mathrm{u}$. sich zu offeriren daß H Hoffmann hinab kommen u. den Pancosmum aptiren soll wann man erst versuchet wäre, daß Ihn jemand um honetten preiß haben wolte. Außerdem halte ich es nicht vor rathsam, weil mir die

[437v] Sach gar gefährlich zu seyn scheinet. Und halte ich daß man so den Pancosmum eher wider erhalten könne, weil sie Ihn doch nur vor alt Kupfer gebrauchen können. Daß die mathematici Suecici suchen werden nur gloriolam mit einem neuen Vorschlag zu erwerben zweifele ich ganz nicht, aber wohl ob sie was besonders werden zu wegen bringen. Ihre bißherigen Scripta geben mir keine Hoffnung dazu will selbsten gebetten haben zu urgiren daß wir ihnen in tempore begegnen konnen.

Vale et salve milliens

T.T.

Raptim d 6. Aug 1699

G A Hamberger

[438v]
A Monsieur
Monsieur Jean Majer, Professeur és Mathematiques tres_renommé Par Amy, á Regensbourg

\section{Kommentar}

Der zweite Satz des Brieftextes sowie die Notiz „Par Amy“, das heißt ,durch einen Freund', bei der Adressierung des Briefes weisen darauf hin, dass dieser Brief durch den namentlich nicht weiter genannten Bruder des Hannoverschen Gesandten Daniel Erasmus von Huldenberg an den Empfänger Johannes Meyer übergeben worden ist.

Auch in diesem Brief geht es um die weitere Verfahrensweise bezüglich der Instrumente in Wien. Für den Fall, dass jemand die Geräte für einen angemessenen Preis kaufen wollte, würde Johann Heinrich Hoffmann sogar nach Wien reisen, um sie 
entsprechend herzurichten. Möglicherweise ist gemeint, dass er die Apparaturen bei einem Käufer aufbauen würde.

Hamberger macht außerdem eine Bemerkung über zu erwartende Vorschläge der schwedischen Mathematiker zur Kalenderreform. Tatsächlich kam von den schwedischen Mathematikern ein Vorschlag mit komplizierten Schaltregelungen. Hambergers Einschätzung nach schien diesem Vorschlag wohl auch der wirkliche Wille zur Reform zu fehlen. Schließlich hatte das protestantische Schweden die Kalenderreform im Jahr 1700 nicht mitgetragen. Allerdings führte die schwedische Provinz Schwedisch-Pommern mit den anderen protestantischen Territorien Deutschlands im Jahr 1700 den Verbesserten Kalender ein [172, Seite 409 f.].

In Schweden selbst wurde ab 1700 ein verwirrender kalenderreformtechnischer Sonderweg versucht, der schließlich scheiterte. Aus Angst, mit einem einmaligen Schritt zum Überspringen der überzähligen zehn beziehungsweise elf Tage der Bevölkerung den Eindruck vermitteln zu müssen, man würde ihr wertvolle Lebenszeit nehmen, sollte nämlich der Übergang zum neuen Kalender schrittweise und über mehrere Jahre verteilt erfolgen. Eine Idee bestand darin, erstens im Februar 1700 den Schalttag ${ }^{3}$ zweitens im November 1700 eine ganze Woche und schließlich in den folgenden drei Schaltjahren 1704, 1708 und 1712 jeweils den Schalttag wegfallen zu lassen, siehe dazu [9] oder [1]. Damit hätte der Wechsel erst bis 1712 abgeschlossen werden können. Anderen Darstellungen zufolge soll Schweden geplant haben, beginnend mit 1700 und in den folgenden zehn Schaltjahren jeweils den Schalttag zu überspringen, siehe 90] und 217. Damit hätte die Umstellung erst im Jahr 1740 abgeschlossen werden können. Tatsächlich hatte Schweden von seiner Reform lediglich die Streichung des Schalttages im Jahr 1700 realisiert und begann ab März 1700 mit einem Kalender zu operieren, der in seiner Datierung zum Kalender alten Stils einem Tag und zum Kalender neuen Stils zehn Tage Differenz aufwies. Das dürfte sich insbesondere international im Handel oder in den politischen Beziehungen zum Ausland als völlig unzweckmäßig erwiesen haben. Ob die Reformpläne - möglicherweise auch im Zusammenhang mit dem Großen Nordischen Krieg um die Vorherrschaft im Ostseeraum, der im März 1700 begann - ausgesetzt wurden oder ob der ursprüngliche Plan am Ende völlig in Vergessenheit geriet, sei dahingestellt. Zumindest kehrte Schweden im Jahr 1712 auf Veranlassung des schwedischen Königs Karl XII. (1682-1718) zum alten Julianischen Kalender zurück. Dazu wurde nicht nur der Schalttag am 29. Februar beibehalten, sondern auch noch ein zusätzlicher Tag, ein historisch einmaliger 30. Februar, eingefügt. Auf diese Weise war vom 1. März 1700 bis zum 30. Februar 1712 als historische Kuriosität der Schwedische Kalender in Gebrauch, bevor Schweden erst im Jahr 1753 den neuen Kalender endgültig übernahm, dem 17. Februar folgte der 1. März 1753.

\footnotetext{
${ }^{3}$ Das Jahr 1700 ist bezüglich des Julianischen Kalenders ein Schaltjahr bezüglich des Gregorinischen Kalenders jedoch nicht.
} 


\section{Brief vom 28. September 1699}

Cod. Ms. Philos. 60, Blatt $439 \& 440$

[439r] Wohledler, großg $\ell$ hochgeehrter H und Patron.

Hierbey kommt der vom Hn Hoffmann verlangter massen quoad mathematica politica et Ecclesiastica elaborirte Calender. Was das Nebenwerk betrifft, so ist freylich unsres see $\ell$. Hn Vatters Meinung gewesen daß zuförderst die Existentia Numinis ex doctrina de tempore darinn deutlich solte gewiesen $\mathrm{u}$. allso der Grund zur Tugend geleget, und hierauf eine mathematische Anweisung zur Tugend beygefüget werden, welches Er darum so viel mehr gewünschet, damit, wann solche Calender unter dem Namen des ganzen Collegii publicirt würden, diese so nützliche doctrin desto mehren applausum fünden mögten. Und ist es nicht ohne daß, wie MhgH gemeldet, u. auch der seel Mann selbst im Wiener: Tugendspiegel dargethan, in der blosen arithmetic sehr viel Tugend vorthel stecken. Ich bin ehe dessen in einer besondren disputation de methodo acquirendi virtutum auf eben diese materie gerathen $u$. bin dieses klärlich darzuthun bemühet gewesen. Man könnte allso dieses wohl ein Jahr oder etliche versuchen. Solte es denen Leuthen nicht ad pala-

[439v] tum seyn, wann man, zumal viele Jahr nach einander materiam maxime seriam tractirte, könnte nicht schaden wann andere nützliche materien mit eingemenget würden, wie denn der see $\ell \mathrm{H}$ Weigelius intentionirt gewesen jedes mal etwa eine schöne Kunstinvention mit beydrucken zu lassen. Wegen der Witterung waren seine Gedanken, daß man, wo ja Wetter verlangt würde, des vorigen Jahrs Witterung anstatt der zukünftigen hinein setzen solte, so könnten Gelehrte die Calender als ephemerides meteorogicas gebrauchen u. großen Nutzen darauß ziehen. Wie Er denn diese seine Meinung in einen Calender so nach Pommern hier verfertiget wurde, drucken lassen. Ich habe auch letzt an den Hn Abgesandten Fabritium, dem ich mich gehorsamst recommendiren und vor jüngstes geneigtes Zuschreiben bedanken lasse, derg $\ell$ gemeldet. Stelle es aber zu reiferer Überlegung ob man das Wetter, ohne welches zwar kein Kalender bey dem gemeinen Mann was gilt, gar außlassen wolle, u. selbiges Feld mit Tugendsprüchen anfüllen. H Fabritius hat wegen Hn Hoffmanns nochmaln an beeden Fürst $\ell$. Höffe geschrieben u. ich habe Hn Hoffmann vermocht daß er die Sach zu treiben an jedem Hoff bey einem patrono mit seinem Calculo Eclipseolune futuræ aufwarten solte, so Er auch gethan, u. ich hab es mit Schreiben secundirt, auch von Eise- 
[440r] nach die Vertröstung erhalten, so bald der H Herzog von der Hirschjagt, damit Er sich nun einige Wochen divertirt, daß man suchen wolte, auch hoffte, die Sach zum Stand zu bringen. Von Weimar aber ist mir geschrieben worden man habe Hn Hoffmanns supplique nebst des Hn Abgesandten recommendation der Cammer übergeben solches dem Hn zur resolution vorzutragen. Er hat den calculum auch dem Hn Geh. Rath Linker offerirt, der ihn angesehen, aber wider zurück gegeben. Weiß nicht ob der H Fabritius an Ihn geschrieben habe. Die Eclipsin $\odot$ hat sowohl H Hoffmann als ich, jeder á parte, und so viel der ungemeine Zulauf gelitten, ganz genau observirt. Meiner observation ist hier gewesen Initium $9^{\mathrm{h}} 3^{\prime} 29^{\prime \prime}$ Medium $10^{\mathrm{h}} 21^{\prime} 4^{\prime \prime}$ Finis $11^{\mathrm{h}}$ $38^{\prime} 39^{\prime \prime}$ Duratio tota $2^{\mathrm{h}} 35^{\prime} 10^{\prime \prime}$ Obscuratio maxima 10 digit : 50 min: Hat allso Hn Hoffmanns auf hiesigen meridianum gerichtete calculus quoad durationem wohl zu getroffen, aber in dem principio um 8 minuta $u$. in der magnitudine um 33 minuta gefehlet, so jedoch nicht so wohl Ihm als der imperfectioni tabularum zuzuschreiben. Die remarquen über Hn D. Reihers Calender habe ich unter des Hn Weigelii Sachen gefunden. Die Antwort darauf ist hier wider abgeholet worden $u$. wird sich nun bald weisen wo sie werde gedruckt [440v] werden. Mich verlangt sonderlich die Ingolstättische censur, davon MhgH Professor ehemaln gedacht zu sehen. Womit ich nebst Empfehlung Göttlicher Gnaden verharre

Raptim

Meines Hochgeehrtisten Hn Professoris

Jena d 28 Sept. 1699 ergebenster Diener G A Hamberger

P.S. Gleich bei Schließung dieses wird mir von Weimar das König $\ell$ schwedische Antwort schreiben nebst selbiger mathematicorum judicio gesandt. Dieses ist so beschaffen, wie ich es vermuthet, Sie musten doch auch was sagen. Ich will morgen nach Hoff darauf antworten, und bey nechster Post auch meine Gedanken überschreiben. Nun ist es hohe Zeit das Collegium artis Consultorum zu urgiren, wozu dieses judiciam succicum gute gelegenheit gibt, $\mathrm{u}$. dan dadurch allen ihren dubiis oder desideriis auf einmal geholffen werden sole.

\section{Kommentar}

Mit der Existentia Numinis ex doctrina de tempore, der Existenz Gottes aus der Lehre von der Zeit, wird auf einen Versuch Erhard Weigels Bezug genommen, einen mathematischen Gottesbeweis zu erbringen. Seine Gedankengänge dazu hatte Weigel 
beispielsweise in seinem ebenfalls in diesem Brief genannten Werk „Wienerischer Tugend-Spiegel" [191 dargelegt. Dazu sei erläutert, dass der Begriff der Zeit in Weigels Philosophie eine zentrale Rolle spielt. Darin ist sicher auch einer der Beweggründe für seinen immens hohen Einsatz für die „Zeit-Vereinigung“, also die Kalenderreform, zu sehen. Weigel versteht unter der Zeit die sich stets ändernde Wirklichkeit der Dinge dieser Welt [191, Seite 19] und damit ein ständiges Werden und Vergehen, das nur eine außerhalb dieses Prozesses stehende göttliche Macht bewirken kann. Ausgehend von dieser seiner These, dass Gott „die Zeit macht und continuirt" [191, Seite 36], entwickelt Weigel sein Bildungsideal von der Erziehung zur "Tugend" und sieht insbesondere in den mathematisch-naturwissenschaftlichen Fächern das Potential, dieses Ideal erlangen zu können. Weigel empfiehlt in seinen Darlegungen zur Pädagogik beispielsweise eine frühe und intensive mathematische Förderung in den damaligen Trivialschulen sowie spielerisches Lernen von Mathematik bereits im Rahmen der frühkindlichen Erziehung.

Weigel beginnt in seiner umfassenden Abhandlung des „Wienerischen TugendSpiegels" mit einer Bestandsaufnahme zur Lage des Mathematikunterrichts an öffentlichen Schulen und schreibt dazu: „Es sind viel hundert Jahr bißhero verflossen, in welchen die zur Kunst und Tugend-Ubung in den Schulen von Natur gewidmeten Mathematischen Wissenschaften (die vor Alters so genannten Artes Liberales, Arithmetica, Geometria, Astronomia, Musica) so sehr verabsaumet worden, daß an vielen Orten auch diejenigen, die da studiren sollen, nicht einmal das Einmal-Eins zu lernen einige Gelegenheit gefunden." [191, Widmung]. Diese Krise, in der sich sowohl schulischer Mathematikunterricht als auch Mathematik in ihrer öffentlichen Akzeptanz befanden, wurde von Weigel an verschiedensten Stellen und bei unterschiedlichsten Gelegenheiten thematisiert, siehe dazu zum Beispiel auch sein Manuskript [189.

Ein Paradigma, welches sich wie ein roter Faden durch Weigels Lebenswerk zieht, ist seine Auslegung der Beziehung zwischen Theorie und Praxis. Er misst den „Wert verantwortlicher Tätigkeit am Nutzen ..., den sie für das Gemeinwohl erbringt", siehe [123, Seite 19]. Dieser Auffassung folgend können wir sein Nachdenken über die Philosophie der Zeit und sein Wirken für die Kalenderreform als zwei Seiten ein und derselben Medaille deuten. Auch seine 1691 vorgebrachte Kritik an Leibniz, dass dieser seinen Verstand und seine Intelligenz nur mangelhaft für die Entwicklung von dem Allgemeinwohl dienenden Anwendungen gebraucht, kann man unter diesem Aspekt sehen, vgl. neben [123, Seite 19] beispielsweise auch [144, Seite 163]. Sich auf diesen Leitgedanken stützend hat Weigel auch folgerichtig nicht nur theoretische Abhandlungen zu pädagogischen Entwürfen vorgelegt, sondern selbst eigene Schulexperimente in einer eigens dafür in seinem Hause eingerichteten Kunst- und Tugendschule durchgeführt, siehe [123, Seite 9]. Darüberhinaus haben Weigels Ideen zur Pädagogik durch seine zahlreichen Schüler und deren Wirken nennenswerte Verbreitung gefunden, vgl. dazu die eigenständigen und umfangreichen Darstellungen [159, 162] und [178]. Hambergers Ausführungen nach zu urteilen, hatte 
sich Weigel aber offenbar gewünscht, dass auch die theoretischen Grundlagen seines pädagogischen Konzeptes mit der Veröffentlichung in einem Massenmedium wie den Kalendern einen noch größeren Bekanntheitsgrad erlangen möchten. Obwohl Weigels pädagogische Konzepte und Reformmodelle den am ausführlichsten erschlossenen Bereich seines Schaffens darstellen, gibt es auch heute noch Forschungsdefizite zu seinen pädagogischen Anschauungen und Ansätzen. Hierzu sei an dieser Stelle nur auf noch nicht näher erschlossenes handschriftliches Archivmaterial, beispielsweise auf die Brief- und Manuskriptsammlung „Acta des Mathematici Weigels Scripta et inventiones Mathematicas, wie auch aufgerichtete Kunst \& Tugend-Schule betr. 1658. bis 1694." im Thüringischen Hauptstaatsarchiv Weimar, verwiesen.

Hamberger erwähnt eine Disputation über die Methode des Erwerbs der Tugend („disputation de methodo acquirendi virtutum“), in welcher er ebenfalls die von Weigel verfolgte Idee von der Erziehung zur „Tugend“ ausführte. Gemeint ist allem Anschein nach die Disputation [73] von Veit Benedict Heuber unter Hambergers Vorsitz.

Hamberger spricht in diesem Brief außerdem die Möglichkeit der Publikation von Wetteraufzeichnungen an. Dies sollte im sogenannten "Nebenwerk" erfolgen, also in dem einen Kalender damals üblicherweise ergänzenden Teil und anstelle der früheren Prognostiken, vgl. auch Seite 18, Da es verbreitet war, in den Kalendern Vorhersagen über das Wetter mit abzudrucken, sollten nach Hambergers Vorschlag dieser Gewohnheit folgend wohl Wetterangaben gemacht werden, diese sollten sich jedoch aus Wetterbeobachtungsdaten des Vorjahres speisen. Hamberger ist dieser Idee, die gemäß seinen Ausführungen in diesem Brief auch auf Weigel zurückgeht, in seinen eigenen Kalendern später selbst gefolgt. Zu Hamberger als Kalenderschreiber verweisen wir auf den Kommentar zu seinem Brief vom 18. November 1699, ab Seite 79 .

Bei der genannten Sonnenfinsternis geht es um die vom 13. September 1699 (nach Julianischem Kalender), die in damaligen historischen Quellen auch als „große Sonnenfinsternis" beschrieben wurde, siehe beispielsweise [167, Seite 87f.]. Das uns auch heute noch beeindruckende Schauspiel einer Sonnenfinsternis war damals ein überaus spektakuläres Ereignis. Über die heute eher skurril anmutenden aber auf einem tief verwurzelten Aberglauben begründeten Vorbereitungen der Bevölkerung auf eine Sonnenfinsternis, nämlich auf die im August 1654, gibt uns heute das Hausbuch des Apothekers Michael Walburger lebendige Auskunft [87]. Erst 300 Jahre später fand am 11. August 1999 wieder eine in Europa sichtbare totale Sonnenfinsternis mit ähnlichem Verlauf wie 1699 statt.

In dem Brief wird nochmals die Entgegnung Weigels auf den Kalendervorschlag Samuel Reyhers erwähnt. Dazu sei auf den Kommentar zum Brief vom 25. März 1699 auf Seite 46 hingewiesen.

Zu den Details der Kalenderreform in Schweden sei an die Ausführungen im Kom- 
mentar zum Brief vom 6. August 1699, Seite 66, erinnert. Mit dem genannten Antwortschreiben könnte möglicherweise die in den Conclusen des Corpus Evangelicorum [157] publizierte Abhandlung [7] vom 19. August 1699 gemeint sein, zumindest aber ein Text, der dem Inhalt nach mit diesem konform geht. Außerdem sei das „Bedencken einiger Schwedischer Mathematicorum" [1 erwähnt. Auch in der Auseinandersetzung mit den schwedischen Entgegnungen sieht Hamberger ein Argument für die Notwendigkeit eines Collegium Artis Consultorum.

\title{
Brief vom 14. Oktober 1699
}

\author{
Cod. Ms. Philos. 60, Blatt $435 \& 436$
}

[435r] Wohledler, Hochgeehrtister H Professor u. Patron.

Ich habe albereit in 2 unterschiedlichen Schreiben meine dubia wegen künftiger Oster Feyer communicirt. Nach diesem habe in Maestlini Examine Calend: Greg: p. 44. gelesen daß dieser schon dem Clavio vorgeworfen, man würde $\overline{a o}$ 1700 Ostern nach seinen cyclis 8 Tag zu spät halten. Clavius antwortete aber darauf, es fiele zwar das Plenilunium auf d 3ten April, weil es aber erst post Solis occasum geschehe, würde es nothwendig dem folgenden Tag attribuirt. So schreibt er auch p. 117 Elenchi sui: Adscribimus plenilunium, quod post meridiem evenit, sequenti diei, ex doctrina omnium, qui de computo scripserunt. Solchem nach wäre der 4 te April als dies $\odot$ doch pro die Plenilunii zu achten u. allso Ostern auf $8 \mathrm{Tag}$ zu differiren. Wie ich denn auch in des Hn Kirchii schon herauß gegebenen Calender gesehen, daß die Juden ihre Ostern auf d 4ten April halten, den wenn das plenilunium nachmittag fällt so schlachten sie selbigen Abend noch das Osterlam u. halten folgenden Tag Ostern. Fället es aber auf einen Vormittag schlachten sie selbiges den Tag vorhero. Wofern wir allso dem Rigori calculi Astronomici nachgehen u. künfftiges Jahr Ostern d 4ten April halten wolten concurrirten wir mit denen Juden. Und weiß ich nicht ob uns schützte, wann

[435v] wir mit Clavio wolten sagen, es wäre nur verbotten den Tag Ostern zu halten, wann die Juden ihr Lamm schlachten nicht aber wann sie folgenden Tages die solennität begehen. Zum wenigsten wolten unsere eigene Leuth die excusation Ihm damals nicht gelten lassen. Scheinet also das beste expediens zu seyn, wir lassen künfftiges Jahr Ostern noch in seinem Lauf und thun als 
wann der aufgetragene calculus erst $\bar{a}$ o 1701 angehen solte. Inzwischen verlanget mich sehr sowohl MhgHn Professoris als auch Hn P. Sturms Meinung hievon zu vernehmen, weil man sich doch etwas gewisses einmüthig wird entschließen müssen. Es zeiget aber auch dieser casus wie nöthig es sey ein Collegium mathematicum zu ordnen, die uniformität im calculo zu erhalten. Mir sind noch viel mehr dubia bekant deren collegialischen decision nöthig. Womit nebst Empfehlung Göttlicher Gnaden verharre.

Meines Hochgeehrtisten Hn Professoris u. Patrons ergebenster Diener G A Hamberger

Jena d 14 Oct 1699

P.S. Es hat mir mein H socer copiam conclusi in der Calender Sache communicirt, darauß ersehen daß man mit Abschaffung der Warsagereyen nicht gern daran will. Solten aber die Mathematici künfftig darauf bedacht seyn, so ist kein ander Mittel als daß ein Collegium constituirt u. Ihm das monopolium im Calendermachen oder doch censiren gegeben werde. Es wird sich auch sonst nicht wohl ein subsistent Mittel ohne ander Leuth Schaden u. ohne Aufwand des publici dazu finden. MhgH wird nach beywohnender sonderbahren prudenz die Sach schon nachdrücklich verzustellen wissen. Einen dient $\ell$ Gruß vom Hn M. Teuber, der auch das Collegium bestens recommendirt.

[436r] P.S. Als dieses Schreiben allbereit geschlossen erhalte MhgHn Prof. geehrtes von 7bten Sept: über Eisenach, darauß mit Verwunderung ersehen daß bey der letzten Versamlung unseres seel. Vatters Hn Weigelii gute intention so viel habe leiden müssen. Weil mir aber dieses dunckle Wort so will um eine Erleiterung dienst $\ell$. gebetten haben. Insonders aber wundert mich, daß die sich der Sach nicht angenommen, von denen man es am meisten vermuthen sollen. Ich kan versichern, daß in denen an mich ergangenen guten rescripten des seel. Mannes Vorschlags mit ungemein gnädigen terminis gedacht, $u$. außdrücklich befohlen worden dahin nach Vermögen zu trachten, daß Er zum Stand komme, wie [ih]nen in gleichen terminis nach Regenspurg rescribirt [wor]den. [So]fern MhgHn einige Unkosten verursachen, daß ich [diesen] Brief zu desto schleunigerer Bestellung auf die geschwinde Post gegeben, so bitte dienst $\ell$. um Vergebung. Ich habe wegen Wichtigkeit der Sache u. da periculum in mora auf die Eisenach $\ell$. Gelegenheit nicht warten können. 
[436v]

\author{
A Monsieur \\ Monsieur Jean Majer, Professeur en Philosophie tres_renommé \\ Cito \\ Franche jusqu'á Nürnberg, á Regensbourg
}

\title{
Kommentar
}

In der Diskussion um die Festlegung des Osterdatums in Übereinstimmung mit den Vorgaben des Konzils von Nicäa wird zu Beginn des Briefes auf den Theologen, Mathematiker und Astronomen Michael Mästlin Bezug genommen. Mästlin war bei Erscheinen der Päpstlichen Bulle „Inter gravissimas“ vom 24. Februar 1582 zur Verordnung der Kalenderreform des Jahres 1582 Professor an der Heidelberger Universität, bevor er im darauf folgenden Jahr 1583 nach Tübingen wechselte. Von seinem protestantischen Heidelberger Landesherren Ludwig VI., Pfalzgraf bei Rhein und Kurfürst von der Pfalz, wurde er um eine Stellungnahme zur vom Papst verfügten Kalenderreform gebeten [85, Seite 38]. Mästlin legte eine umfangreiche Bewertung vor und gewann mit seiner klaren Polemik gegen den neuen Kalender in dieser Angelegenheit großen Einfluss. Sein Gutachten avancierte gar zu einem zentralen Dokument im schriftlichen Meinungsaustausch zwischen den protestantischen Fürsten. Grundsätzlich war man sich darüber einig, dass der aus dem Rhythmus geratene Kalender wieder mit dem tatsächlichen Sonnenlauf in Einklang gebracht werden müsse. Deshalb ging es in der Auseinandersetzung auch weniger um astronomische Fragen, vielmehr wurden theologische Aspekte der Reform als inakzeptabel beanstandet. Hier fokussierte man sich insbesondere auf die korrekte Festlegung des Osterdatums und auf die als unabdingbar erachtete Forderung, dass das christliche Osterfest nicht mit dem jüdischen Passahfest zusammenfallen dürfe. Zur bestimmenden Rolle Michael Mästlins in der Kalenderpolemik sei auf die ausführliche Darstellung [85] in 21] verwiesen. Bei dem in Hambergers Brief erwähnten Text Mästlins handelt es sich allem Anschein nach um die Streitschrift 139. Auf der von Hamberger zitierten Seite 44 heißt es dort nämlich „Cuiusmodi paschata erunt anno.1629.1693.1700.\&c." und konkreter zum Jahr 1700 auf Seite 45 „Ita anno 1700. Aureus numerus erit 10. epacta ix.terminus paschalis. 4. Apr. Litera Domin: C. hinc pascha die 11. Apr. Sed verus terminus est die 3. Apr. vnde pascha asse deberet die 4. eiusdem." Weiterhin ist mit dem Elenchus des Christopher Clavius die Schrift [155] gemeint. Dort findet sich am Ende von Seite 117 tatsächlich die von Hamberger angeführte lateinische Textstelle.

Am Rande sei noch angemerkt, dass das Exemplar des Mästlin-Werkes [139], welches sich im Bestand der Niedersächsischen Staats- und Universitätsbibliothek 
Göttingen befindet, auf dem Titelblatt den folgenden handschriftlichen Provenienzvermerk trägt

Joh : Hen : Hoffmannus

Henrici Nepos, Jena

Anno Christi 1695.

Offenbar stammt dieses Buch aus der Handbibliothek von Weigels Assistenten Johann Heinrich Hoffmann, der in Hambergers Briefen bereits mehrere Male Erwähnung gefunden hat. In der zweiten Zeile dieser Notiz finden wir einen Hinweis darauf, dass Johann Heinrich Hoffmann ein Enkel des früheren Jenaer Mathematikprofessors Heinrich Hofmann ist, auf dessen Lehrstuhl Erhard Weigel als Nachfolger berufen wurde. Tatsächlich erwähnt Weigel in einem "Memorial“ von 1688 zwei „zwei junge Laboranten“ und bezeichnet sie als „des vorigen Mathematici Enenckeln gleiches Nahmens", also Enkel seines Vorgängers, vgl. 93, Seite 62 und Seite 63, Fußnote 23].

Interessant an Hambergers Ausführungen ist, dass er wegen der genannten Probleme mit dem Osterdatum vorschlägt, für das Osterfest im Jahr 1700 einfach noch wie bisher zu verfahren und der astronomischen Osterfestrechnung erst ab $1701 \mathrm{zu}$ folgen. Im „Monatlichen Staatsspiegel“ von November 1699 finden wir eine Abhandlung von Johannes Meyer [13, Seite $46 \mathrm{ff}$.], in welcher für die öffentliche Diskussion ausführlich Argumente zur Beibehaltung des Ostertermins am 11. April 1700 vorgebracht werden, obwohl Ostersonntag nach dem astronomischen Calculus auf den 4. April 1700 fallen würde. Meyer schreibt insbesondere [13, Seite 46]:

So fraget sichs/ ob Vermög der neuen Verordnung/ der Ostertag de 1700. Jahrs auf den 4. Aprilis müste angesetzt werden? oder ob selbiger auf den hernach folgenden Sonntag/ nemlich den 11. Aprilis in denen bereits gedruckten Calenderen recht angeordnet sey?

Entscheidendes inhaltliches Argument ist, dass zur Vermeidung des Zusammentreffens von Ostern mit dem Passahfest die Christen gemäß dem Konzil von Nicäa „ihr Oster-Fest nothwendig auf den andern Sonntag verschieben müssen“ [13, Seite 48]. Außerdem spielten ökonomische Gründe eine Rolle, waren doch bereits zahlreiche Kalender gedruckt und in den Handel gebracht worden, in denen das Osterdatum nach zyklischer Rechnung bereits auf den 11. April 1700 gesetzt worden war, vgl. [13, Seite 50].

Außerdem spricht Hamberger von nun an bei dem angestrebten Collegium überhaupt nicht mehr vom Collegium Artis Consultorum. Hier nennt er es erstmals Collegium Mathematicum. In späteren Briefen wird er, wenn nicht einfach vom Collegium die Rede ist, noch die Begriffe Collegium Mathematici oder manchmal auch Collegium Astronomici verwenden. 
Der im ersten Postskriptum genannte Herr Teuber ist Gottfried Teuber (16561731), ebenfalls ein Student und Assistent Erhard Weigels sowie späterer Pfarrer in Theissen und Zeitz, welcher Kupferstich- und Holzschnittillustrationen zu Weigel-Schriften angefertigt hatte und später mit Gottfried Wilhelm Leibniz an der Weiterentwicklung von dessen Rechenmaschine arbeitete. In 93 findet sich ein ausführlicher Bericht über Teuber und seine Arbeiten für Weigel.

Im zweiten Postskriptum geht es allem Anschein nach um den Erhalt der Mitteilung über die Beschlüsse des Corpus Evangelicorum zur Kalenderreform vom 23. September 1699. Da dieser Brief Hambergers auf den 14. Oktober datiert ist, ist das von ihm genannte Datum des empfangenen Schreibens, der 7. September, vermutlich ein Schreibfehler und das Schreiben, welches er von Meyer erhalten hat und welches hier gemeint ist, stammt eigentlich vom 7. Oktober. Hambergers erste unmittelbare Reaktion auf das Conclusum des Corpus Evangelicorum (zum Wortlaut siehe Anhang, Seite 122 drückt deutlich die Enttäuschung darüber aus, dass mit den gefassten Beschlüssen die von Erhard Weigel eingebrachten Vorschläge nur zu einem geringen Teil umgesetzt worden sind. Ernüchterung dürfte sich insbesondere darüber breit gemacht haben, dass das angestrebte Collegium Artis Consultorum in den Beschlüssen keinerlei Rolle spielte.

\section{Brief vom 18. November 1699}

Cod. Ms. Philos. 60, Blatt $424 \& 425$

[424r] Wohledler, Hochgeehrtister Herr und Patron.

In meinem letzten habe gemeldet daß Dero werthes vom 1sten Octob: darinn die dubia wider Hn Hoffmanns Calender monirt worden, mir nicht zu Handen kommen. Nachdem es aber endlich vorgestern noch zu recht kommen, hab ich folgendes am Calender desiderirt gefunden 1) soll er nicht der Evange sondern der verbesserte heisen, 2) soll nicht stehen Festnahmen sondern nur der Monathstage. 3) die Catholizi sollen ihre Tage à part haben. 4) sehe man nicht gern daß wir mit den Catholischen einerley Sonntagsbuchstaben bekommen, u. würde dahero gefragt, ob wir nicht an stat $\mathcal{C}$ könnten $\mathcal{D}$ setzen oder gar das $\mathcal{G}$ behalten. Nun hab ich zwar wegen überhäuffter Geschäffte nicht Zeit gehabt Hn Hoffmanns Calender genau zu censiren ehe er überschickt worden, doch hatte ich was wichtiges daran notirt darum er ihn wider umschreiben müssen, weiß aber nicht mehr was es gewesen. Auf die dubia aber antworte kürzlich allso: Ad 1 et 2) der Titul ist damals noch nicht 
bekant gewesen, kan nach belieben geendert werden. Ad 3) wird vieleicht den Verstand haben, daß dem Gregorianischen auch besondere Zahlen sollen zugeeignet werden, ob sie sehen mit denen unsern übereinkommen, welches auch leicht geschehen kann. Ad 4) Ich halte davon man solle den Sonntags[424v] buchstaben gar außlassen, weil Er bloß zum behuff des cyclici calculi insonderheit zu leichterm Gebrauch des aurei numeri, erfunden worden, der aber nunmehr ganz abgeschafft. Finde auch daß H Kirch in seinem so genannten Himmels-Calender gleichfals keine literas Dominicales setzet. Wann wir sie ferner brauchen wolten, müsten wir nothwendig auch einen neuen cyclum Paschalem machen, so doch wider die gefaste resolution lauftet. So könnten wir zwar dieses Jahr 1700 den literam $\mathcal{G}$ fortführen, weil der erste Monath selbigen hat; es würde uns aber wenig helffen, weil wir doch alle folgende Jahr nothwendig einerley literas Dominicales mit denen Catholicis behalten müsten, mussen der erste Januarius, den wir nunmehr zugleich haben jedes Jahr $\mathcal{A}$ heisen muß in beeden Calendern, dahero denn auch alle übrige Tag einerley Buchstaben haben müsten. Wolten wir aber gar einen cyclum Solarem machen, darinn, wider die bißherige observant aller Welt, der erste Tag des Jahres nicht $\mathcal{A}$ hieße, machten wir uns nicht nur viele vergebliche Mühe, sondern es würde an außlachen bey denen Catholicis nicht fehlen, weil wir keine gnugsame Ursachen können allegiren. Was sonst wegen des tituls, Verlags, Drucks, u. ingredientien des Calenders gesetzet worden, lasse ich mir alles gefallen den Nahmen eines Collegii darauf zu setzen, ehe eines constituirt, halte auß vielen Ursachen vor bedencklich. Dem

[425r] Vernehmen nach ist ein Schema Calendarii zu Regenspurg gedruckt. Bitte mit nechster Gelegenheit um ein exemplar. Möchte auch gern wissen wie H Sturm mit denen Hhn Endern tractirt hat oder was er pro labore bekommt? Zu Gotha und Langensalza ist schon ein neuer Calender gedruckt, habe aber noch keinen gesehen. Dörffte es dahero noch hart halten, daß die Calender censur nur gewissen mit einander communicirenden Personen aufgetragen werden, welches doch zu Vermeitung aller confusion höchstnöthig. Das größte impediment eines solchen Collegii Mathematici, wie unser seel. H Vatter vorgeschlagen, dörffte seyn, daß nicht Keysl. Majestet, sondern die Protestirende Stände selbst, auß habender hoher Macht, die Calender Reformation publicirt. So haben auch die Herren so vom seel. Hn Weigelio als Collegæ angesprochen worden noch niemaln ein gemeinschafftlich consilium gefaßt, so viel mir wissend, welches doch fast nöthig, wann nähere Hoffnung dazu anscheinet. Außer dem thut man freylich so viel 
möglich. und wird MhgH schon ferner dafür arbeiten daß unsere viele Mühe nicht vergebens gewesen, davor wir sonders obligat seyn werden. Ich werde hier auch wegen eines Calenders stark angesprochen. Habe mich aber auß vielen Ursachen noch nicht resolvirt. Wann ich es noch thun solte, würde ich gar kein Wetter hinein setzen, um zu sehen wie es die Leuth aufnehmen. Es wird aber schwerlich was daraus.

Vale et porro fave T.T.

Jena d 18 Nov 1699

G A Hamberger

\section{Kommentar}

Der sogenannte Sonntagsbuchstabe (lateinisch ,littera dominicalis') markiert den ersten Sonntag eines Kalenderjahrs. Er wurde eingeführt, um zu vorgegebenem Datum eines beliebigen Jahres den zugehöhrigen Wochentag bestimmen zu können. Fällt der erste Sonntag auf den 1. Januar, so lautet der Sonntagsbuchstabe $\mathcal{A}$, für den 2. Januar $\mathcal{B}$ usw. bis zum 7. Januar mit $\mathcal{G}$ als Sonntagsbuchstaben.

Das Jahr 1700 begann nach dem Julianischen Kalender an einem Montag während es nach dem Gregorianischen Kalender an einem Freitag begann. Der erste Sonntag

\begin{tabular}{|c|c|c|c|c|}
\hline $\begin{array}{l}\text { Sonntags- } \\
\text { buchstabe }\end{array}$ & $\begin{array}{r}\text { Julianischer } \\
\text { Kalender }\end{array}$ & & $\begin{array}{r}\text { Gregorianischer } \\
\text { Kalender }\end{array}$ & $\begin{array}{l}\text { Sonntags- } \\
\text { buchstabe }\end{array}$ \\
\hline & 22. Dezember 1699 & Freitag & 1. Januar 1700 & \multirow{13}{*}{$\mathcal{C}$} \\
\hline & 23. Dezember 1699 & Samstag & 2. Januar 1700 & \\
\hline & 24. Dezember 1699 & Sonntag & 3. Januar 1700 & \\
\hline & 25. Dezember 1699 & Montag & 4. Januar 1700 & \\
\hline & & & & \\
\hline & 30. Dezember 1699 & Samstag & 9. Januar 1700 & \\
\hline & 31. Dezember 1699 & Sonntag & 10. Januar 1700 & \\
\hline \multirow{6}{*}{$\mathcal{G}$} & 1. Januar 1700 & Montag & 11. Januar 1700 & \\
\hline & & & & \\
\hline & 6. Januar 1700 & Samstag & 16. Januar 1700 & \\
\hline & 7. Januar 1700 & Sonntag & 17. Januar 1700 & \\
\hline & 8. Januar 1700 & Montag & 18. Januar 1700 & \\
\hline & & $\vdots$ & & \\
\hline
\end{tabular}

Wochentage zum Jahreswechsel 1699/1700 und Sonntagsbuchstaben für 1700 
des Jahres 1700 war also im Julianischen Kalender der 7. Januar und im Gregorianischen Kalender der 3. Januar. Als Sonntagsbuchstaben für das Jahr 1700 haben wir demnach für den Julianischen Kalender das $\mathcal{G}$ und für den Gregorianischen Kalender das $\mathcal{C}$. Der Vollständigkeit halber sei angemerkt, dass für Schaltjahre zwei Sonntagsbuchstaben angegeben werden müssen. Da das Jahr 1700 bezüglich des Julianischen Kalenders ein Schaltjahr ist, gilt der Sonntagsbuchstabe $\mathcal{G}$ nur bis zum Schalttag, für die Zeit nach dem Schalttag bis zum Jahresende hat das Jahr noch ein $\mathcal{F}$ als zweiten Sonntagsbuchstaben.

Traditionell wurde der aktuelle Sonntagsbuchstabe in den für jedes Jahr neu gedruckten Kalendern im Vorspann zum eigentlichen Kalendarium neben anderen Kalenderdaten (zum Beispiel neben der Goldenen Zahl, welche die Position eines Kalenderjahrs innerhalb des neunzehnjährigen Mondzyklus kennzeichnet, oder der Epakte, einer zur zyklischen Osterfestrechnung notwendigen Kennzahl des Mondes) und neben der Erklärung im Kalender benutzter Symbole (zum Beispiel für die Sonne, für Mondphasen, Planeten oder Sternzeichen) als großer und meist rot gedruckter Buchstabe angegeben, siehe beispielsweise [18, Seite 3] oder [26, Seite 3]. Heute finden wir den Sonntagsbuchstaben in unseren Kalendern in der Regel nicht mehr. In astronomischen Jahrbüchern für das Fachpublikum oder für eine an der Astronomie interessierte breitere Leserschaft, wie zum Beispiel dem bekannten „Kosmos Himmelsjahr“ [10, wird der Sonntagsbuchstabe dagegen auch heute immer noch angegeben.

Da Kalender mit ihrer jährlichen Erscheinungsweise zu den verbreitetsten Druckerzeugnissen gehörten, boten diese den Kalenderautoren - so auch Johann Christoph Sturm - immer eine Gelegenheit, das eigene Einkommen aufzubessern. Leider wurde seitens der Verleger anscheinend kein Unterschied zwischen ,liederlichen' Kalenderschreibern und sorgfältigen Kalenderautoren gemacht: „Kein Kalenderverleger sei ... bereit, eine aufwendige Neuberechnung solcher Daten zu honorieren, da ihm ein ,liederlicher Calender" ebenso viel Geld bringe" [140, Seite 239]. Sturm hat über viele Jahre und mit mehreren Verlegern Kalender herausgegeben und dabei hohe Qualitätsmaßstäbe an sich selbst angelegt, was ihm ,viel ,Mühe und große Beschwerden' brachte" [140, Seite 229]. Die letzten zehn Jahre hat er schließlich mit dem Verlag der über mehrere Generationen etablierten Nürnberger Buchhändlerund Buchdruckerfamilie Endter zusammengearbeitet und diesem Verlag neben seinen eigenen Kalendern auch astronomische Unterlagen für die übrige Kalenderproduktion zur Verfügung gestellt. Dafür und für eine weitere ausführliche Darstellung des Engagements von Johann Christoph Sturm als Kalendermacher sei auf den Beitrag [140] in [48] verwiesen. Nach dem Tode Erhard Weigels 1699 war es daher naheliegend, Sturm in die gemeinsamen Bemühungen Hambergers und Meyers um die Kalenderreform von 1700 einzubeziehen.

Für die Orte Gotha und Langensalza lassen sich derzeit leider keine Nachweise von Kalenderdrucken für das Jahr 1700 aufspüren. Mit Publikationsort Gotha finden 
wir im Verzeichnis der Drucke des 17. Jahrhunderts für die Jahre 1672 und 1676 die „Historischen Schreib- und Hauß-Calender"von Petrus Aventinus [18, 19. Für den Druckort Langensalza ist in dem genannten Portal lediglich ein „GeschichtsCalender" von Ernst Dieterich Butterfladen (vermutlich ein Pseudonym) aus dem Jahr 1690 nachgewiesen 26. Darüber hinaus nennt Klaus-Dieter Herbst für 1690 einen Kalender von Jodocus Arnisaeus mit Druckort Langensalza 95, Seiten 69 und 176] und mit Erscheinungsort Gotha für 1699 einen „Thüringer Zeit- Geschichtund Schreib-Calender" von Albert Talander (Pseudonym von August Bohse) [95, Seiten 154 und 192].

Hamberger kommt in diesem Brief explizit auf den wesentlichen Punkt zu sprechen, der letztendlich gegen eine tatsächliche Etablierung des Collegium Artis Consultorum sprach, auf welches Weigel hingearbeitet hatte. Die Kalenderreform wurde allein durch die protestantischen Stände für die evangelischen Länder Deutschlands beschlossen und nicht, wie ursprünglich angestrebt, durch die Autorität des Kaisers als neuer und für alle verbindlicher Kalender im gesamten Reich verkündet. So haben lediglich die evangelischen Länder ihren Verbesserten Kalender eingeführt, was keinerlei Änderung für die Anwendung des Gregorianischen Kalenders bei den Katholiken bedeutete. Ohne die Annahme eines einheitlichen Kalenders für alle deutschen Territorien und ohne Proklamierung eines Kalendermonopols, welches die Finanzierung des Collegiums hätte sichern sollen, sah man sich seitens der Beführworter weder mit den notwendigen Privilegien und Befugnissen noch mit den notwendigen Mitteln ausgestattet, um die Arbeit aufnehmen zu können. Zudem war das Collegium trotz der formalen Bewilligung durch den Kaiser vom 27. Juli 1697, vgl. [42, Seite 211], und der weitreichenden Vorarbeiten Weigels offenbar überhaupt noch nicht zusammengetreten.

Obwohl er am Ende des Briefes schreibt „Ich werde hier auch wegen eines Calenders stark angesprochen. ... Es wird aber schwerlich was daraus." ist Hamberger in der Zukunft dann auch selbst als Kalenderschreiber in Erscheinung getreten. Für das Jahr 1700 ist von ihm zwar noch kein Kalender überliefert, aber dank der Arbeiten von Klaus-Dieter Herbst im Rahmen eines Forschungsprojektes zu historischen Kalenderdrucken sind heute zwei Kalender Hambergers nachgewiesen, einer für das Jahr 1701 63] und der andere für das Jahr 1704 65]. Darüber hinaus gibt es in der Beilage zu Cod. Ms. Philos. 60 die handschriftliche Notiz eines unbekannten Bearbeiters mit dem Hinweis „Hambergers verbesserter und neuer und vom Aberglauben gereinigter Kalender von 1702. Jena“ (Beilage, Blatt 8). Nach Einführung des Verbesserten Kalenders in den protestantischen Territorien Deutschlands wurde Hamberger im April und Juli 1700 mit Kalenderprivilegien seiner Dienstherren, der Herzöge zu Sachsen-Weimar und Sachsen-Eisenach bedacht, siehe 63]. Hamberger wandte sich - auch ganz im Sinne Erhard Weigels - gegen den sogenannten "Kalender-Unfug", die Astrologie in den Kalendern, und bekennt bereits mit der Wahl des Titels „... von allem Aberglauben gereinigter Calender ... " seiner Kalenderreihe gegen den verbreiteten Aberglauben Farbe. In der Ergänzung „Ver- 
schiedener zum Calender gehöriger Sachen " 64] zu seinem Kalender für das Jahr 1701, die Hamberger dem Kalender anstelle der gewohnten Prognostiken beifügte, schilderte er den Lesern neben Angaben zu Finsternissen, zum Planetenlauf, zu den Jahreszeiten und der Witterung ausführlich den Unterschied zwischen dem Verbessertem und dem Gregorianischen Calender, siehe ab Seite 136 hier im Anhang. Immerhin war Hamberger selbst maßgeblich in die politischen Bemühungen um die Einführung des Verbesserten Kalenders involviert, wovon seine hier vorliegenden Briefe an Meyer Zeugnis ablegen. Hambergers oben genannte Ergänzung, die Kalenderbeigabe 64 ist eine durchaus anspruchsvolle Darstellung und erschien in einem gängigen Massenmedium der damaligen Zeit. Dies stützt die These, dass die Schreibkalender der Frühen Neuzeit auch als Medium der wissenschaftlichen Kommunikation unter Gelehrten fungiert haben, vgl. zum Beispiel [96, 97] oder 95, Seite 42]. In seinen Ausführungen über das Wetter behandelte Hamberger die Frage „Woher überhaupt die Witterung, dadurch die vier Jahrs-Zeiten unterschieden werden, entstehe?" 64]. Seine Idee, dass man aufgrund der Nichtvorhersagbarkeit des Wetters anstelle astrologisch motivierter Wettervorhersagen Aufzeichnungen von tatsächlichen Wetterbeobachtungen in den Kalendern abdruckt, geht - der Äußerungen in seinem Brief an Meyer vom 28. September 1699, vgl. Seite 67, nach - auch auf Weigel zurück und dieser Idee ist er in seiner eigenen Kalenderreihe dann offenbar selbst gefolgt. Dokumentiert ist, dass Hamberger über mindestens eine Dekade meteorologische Messungen vorgenommen und aufgezeichnet hat. So hatte beispielsweise sein Schüler Christian Wolff nachweislich Kenntnis von diesen Messungen und Daten. Leider konnten Hambergers Aufzeichnungen meteorologischer Messdaten bisher lediglich in seinem überlieferten Kalender 65 für das Jahr 1704 aufgefunden werden. Im Anhang dieses Kalenders für 1704 wird eine sechs Seiten umfassende Messreihe für das Jahr 1702 dargeboten, die in [98, Seiten 221-226] vollständig wiedergegeben wird. Siehe insgesamt hierzu 98, und die Referenzen darin. Alles in allem gebührt Georg Albrecht Hamberger demnach ebenfalls ein Platz in der Geschichte der Meteorologie während der frühen Aufklärungszeit. Im Sinne einer ideengeschichtlich korrekten Einordnung sei noch angemerkt, dass die Idee der Wetterbeobachtungen und der Aufzeichnung von Wetterbeobachtungsdaten nicht neu war. Zum Beispiel ist bekannt, dass auch schon Tycho Brahe mit seinen Assistenten umfangreiche Wetterbeobachtungen durchführte und von 1582 bis 1597, also über einen Zeitraum von fünfzehn Jahren, ein detailliertes Wettertagebuch geführt hat 24. Nach [98, Seite 217] gibt es für Deutschland insbesondere Aufzeichnungen von Samuel Reyher für den Zeitraum 1679 bis 1713, von Gottfried Kirch ab 1700 sowie von Gottfried Wilhelm Leibniz für die Jahre 1677 bis 1679. Neu scheint dagegen die Idee zu sein, die protokollierten Wetterbeobachtungen in einem Kalender zu publizieren und damit insbesondere den verbreiteten astrologisch angelegten meteorologischen Vorhersagen aufklärerisch entgegenwirken zu wollen. $\mathrm{Zu}$ Hamberger als Kalenderschreiber siehe auch [98, Seite $217 \mathrm{ff}$.$] .$ 


\section{Brief vom 25. November 1699}

Cod. Ms. Philos. 60, Blatt $93 \& 94$

[93r]

Jena d 25 Nov. 1699

recept 9 Dec [offenbar eine Notiz des Empfängers]

WohlEdler, Insonders Hochgeehrtister Herr u. Patron.

Desselben beede geehrtiste vom 16ten u. 20ten currentis sind mir d 23ten u. 24ten ejusdem wohl behändiget. Sage zuförderst dienstschuld $\ell$. Dank vor habende fernere Sorgfalt daß die Calender Reformation völlig zur perfection kommen u. unsere Mühe nicht umsonst seyn möge. Gott gebe ferner Gnad u. Seegen dazu. Ich wolte freylich wünschen näher zu seyen daß die communication geschwinder geschehen könnte, es lässet sich aber nicht endern. Nun aber auf die überschriebene Punckt, so viel in Eil geschehen kan u. meine überhauffte Geschäffte zulassen, zu antworten: So beruhet der dem Corpori Evangelico übergebene Vorschlag hauptsächlich auf dem 8ten u. 9ten Punckt, darüber ich mit permission meine gedanken eröffnen will.

Ad 8) Hette wünschen mögen daß, ad evitandam invidiam, unser keiner mit Nahmen im Aufsatz gedacht (u. solches nur hier u. dar mündlich geschehen wäre) u. mehrere Collegæ wären angegeben worden, ungefähr in folgenden general terminis: Solte das Werck zuförderst denen aufgetragen werden so bißher einige Jahr wegen des Calenderwesens in communication gestanden, nebst andern so im calculiren $\mathrm{u}$. observiren sich hervor gethan, und von jenen dazu solten invitirt werden. Und zwar auß folgenden Ursachen: 1) damit nicht, wann die Sach an die Höffe gedeiet, die hier und dar steckende Mathematici, solche zu hintertreiben suchen und doch den effectum zu vernichten, wann sie keine Hoffnung haben auch mit considerirt zu werden, dazu es ihnen an speciosis argumentis nicht fehlen wird, denn es ist res plena invidiæ. 2) damit das Collegium und ihre Arbeit mehr autorität habe, wann mehr membra sind. 3) damit man denen mißruffenden das Maul stopfen, wann sie auch was participiren 4) damit man mehr calculanten habe, denn unser $\mathrm{H}$ Hoffmann macht nun die erste Prob, ist etwas zaghafft, $u$. ist der lapsus ohne dem facilis. 5) weil H Kirch und andere so bißhero calculirt sich schwehrlich dörfften nehmen lassen seine Calender ferner selbst zu calculiren, und sich eher mit seinem Junio in öffentlichen Schrifften wider unsern calculum legen, und uns zu prostituiren suchen solten, zumal wann sie hören (so doch bald außkommen wird) daß H Hoffmann den calculum führet, immassen H Kirch 
eine solche fiduciam von sich hat, daß Er auch die Tabulas Rudolfinas in einem $u$. andren zu corrigiren sucht, wie wohl nun etlich mal mit schlechtem success. Solche Leuthe könnten mit ins Collegium genommen werden. 6) weil auch das observiren mehr Leuth u. Augen erfordert, indem wir in unsern officiis ohne dem sehr occupirt sind. 7) damit auch endlich weniger Betrug $u$. Unterschleif von denen Verlegern könnte vorgenommen werden wann unsere Collegæ hier und dar zerstreit sind.

Ad 9. ejus dem n. 1) der Calculus kan, zu Vermeidung vieler Irrthümer, so in observiren vorgehen, auf Kosten des Collegii zwar gedruckt, aber nicht divulgirt werden, (zu dem End man den Buchdrucker beeidigen könnte, daß Er oder seine Gesellen kein exemplar wolten weggeben) sondern ad n. 2) Jedweder Calenderverleger solte gehalten seyn, weil Er doch sonst bißhero den Calender einem Verfasser bezahlen müssen, so viel exemplar dieses Calculi von dem Collegio um billigen Preiß an sich zu kauffen als vielerley Gattung Calender Er zu drucken gedenkt. Diesen calculum mögte er denn ungeendert nachdrucken, nichts von prognosticis einmischen, (NB denn wir müssen hier auf die Ehre Gottes sehen, damit Seegen dabey sey)

[93v] und bloß nützliche historien und andere erbauliche Dinge mit anhengen und damit diesem allen desto gewisser nach gelebet $u$. alle confusion vermieden werde, solte jedes Orts Obrigkeit dem Censoriordinario anbefehlen, keinen Calender zu censiren, wo der Verleger nicht ein exemplar des calculi vorzeigte, so von Mhgh $\ell$. oder dem cassirer des Collegii mit Nahmen unterschrieben u. seinem Petschafft bezeichnet wäre, mit vermelden wenn, und zu was Gattung des Calenders solch exemplar gegeben worden. Man könnte auch nachmals ein oder anderm Calender Verleger die Nahmen derjenigen so vom Collegio ein exemplar des calculi ansich gelöset, communiciren, damit, wann sich auf Messen oder sonst einer zeigt der keinen Fug hat, sie selbigen die exemplar könnten lassen wegnehmen, so sie gern thun würden weil es ihr interesse ist. Damit aber das pretium davor die Verleger die exemplaria vom Collegio verkauffen erklecklich wäre, so viel Mühe u. Kosten als auf das calculiren, observiren, reisen, correspondiren pp gehen in etwas zu compensiren, könnte von dem Hochlöb $\ell$. Corpore Evangelico der Preiß eines Calenders um ein gewisses weniges erhöhet, und solchen Überschuß von denen Verlegern, über das honorarium so sie sonst denen Calenderaußschreibern zu geben gewohnt, dem Collegio bezahlt werden. deswegen sie allemal bey Erhandlung eines exemplars des calculi bey ihrem guten Gewissen u. bey Verlust ihres privilegii zu melden hetten wie viel exemplaria sie aufzulegen gesonnen als 
wonach übers Jahr, wann sie ein neu Exemplar des calculi an sich zu handlen gesonnen, die Zählung geschehen müste. Dieses sind meine wenige und unmaßgebende Gedanken wegen des Vorschlags so im besten aufzunehmen u. mich dero Meinung wider wissen zu lassen bitte. Wann die Cameralbedienten in cassiren $u$. das Geld an die universal cassa liefern solten, siehet es etwas weitlauffig $\mathrm{u}$. gefehrlich damit auß $\mathrm{u}$. befahre ich mich das Werk habe nicht lang Bestand $u$. dörfften wir gar wenig bekommen. Ich weiß wie es bey Hoff hergehet. Bekommen wir aber das Geld immediate von denen Verlegern, so ist es sicherer. Müssen sie es doch mit ihren bißherigen Verfassern ebenso halten. Sie können uns schon finden und das Geld schicken weil man genug sichere Posten hat. H D. Schmidt hat ehedessen einen Calender nach Stargard in Pommern hier gemacht. Es hat kein Mensch ein privilegium Calender zu calculiren, so kan uns das corpus Evangelicum solches wohl geben u. uns privilegiren. Was sonst die andren Punckt betrifft darüber Antwort verlangt worden, so bleib ich 1) bey meiner Meinung die ich jüngst wegen des Otagsbuchstaben überschrieben daß man selbigen außlassen soll. 2) H Hoffmann wird in beykommenden wegen seines differenten calculi Antwort geben. Er hat freylich dieses Jahr dem argolo müssen folgen. Ob H Sturm selbst calculirt, weiß ich nicht, zweifele aber, weil Er nicht Zeit hat. Hn Kirchs calculus differirt vom Hn Sturm so viel, als dieser vom Hn Hoffmann, da sie doch auf einen meridianum calculirt. 3) Die Stund u. Minuten der aspecten kan man leicht haben, weil selbige in denen Ephemeridibus stehen $u$. nur ad loci meridianum dörffen applicirt werden, halte es aber weder nöthig noch rathsam. Denn wer solche minutien verlangt oder nöthig hat, kaufft sich ohnedis die Ephemerides. So trifft es auch ob imperfectionem Tabularum so genau nicht ein, und haben darnach unsre Neider nur so viel mehr Gelegenheit uns zu sugilliren mit der perfection unserer Calender. Genug ists wann Stund $\mathrm{u}$. Minuten in phasibus $\mathcal{D}$ beygesetzt werden.

[94r] 4) Im calculo könnte man sich anfangs der Tabularum Rudolfinarum bedienen weil sie doch die gelaufigsten sind, $u$. in den meisten planeten zur Zeit am besten zutreffen. doch könnte nebenher auch der calculus nach andren Tabulis versucht werden, (welches leicht geschehen kan wann wir mehr als einen calculatorem haben) da dann die mit Fleiß hier nebst angestellte observationes leicht zeigen werden welchen man in Zukunfft am meisten folgen u. ob man bey einerley Tabulis durch alle Planeten bleiben solle, welches das gesamte Collegium nachmals determiniren wird. 5) Im calculo braucht man den meridianum nach dem die Tabulæ gerichtet, aber in der application 
ad determinationem Festorum muß man sich wegen eines andren unanimiter vergleichen, sonst dörfte die exemtio Canonum Concilii Nicæri öffters eine impossibilität nach sich ziehen, davon unten n. 9. 6) Quantitas anni $\odot$ et $\mathcal{D}$ muß so groß interim angenommen werden, als die Tabulæ, die man zum fundament des calculi setzet, haben wollen. Denn wenn schon solche quantitas in denen minutiis nicht accurat ist, so gibt doch solches in dem jährlichen calculo keinen notablen errorem, wann man nur keine cyclos darauf bauet, als in welchen der error multiplicativne wächset $u$. sensibel wird, weil man nicht mehr endert, dahingegen wir uns vorbehalten, nach befinden der observationum zu endern. In dem Ende nicht rathsam scheinet, die Ephimerides auf lange Jahr vorauß zu calculiren, sondern nur auf wenige, oder nur von Jahr zu Jahr, die man nach der Zeit könnte zusammen drucken damit sie sich nicht verliehren. 7) Es müssen aber die Ephemerides wie bißhero also auch kunfftig den motum verum exhibiren. 8) Ein Vollmond ist nach dem æquinoctio gefällig zu achten, wann Er auch schon in ipsum æquinoctii diem, aber doch etliche stunden nach dem æquinoctio fiele. Solte sich aber ein casus ereignen da das æquinoctium u. Plenilunium einander so nahe tretten, daß man propter imperfectionem Tabularum Astronomicarum, nicht gewiß vorhero wissen könnte, ob das plenilunium vor oder nach dem æquinoctio fiele, meinte ich, salvo meliori judicio, man könnte denen Tabulis u. calculo grad nach gehen, wann sie auch schon fehlen solten, weil mans doch nicht besser machen kan $\mathrm{u}$. man sich dem periculo errandi exponiren muß, man mache es auch wie man wolle. Jedoch weil es nie grandius peccatum gefelten wird 4 Wochen zu bald als 4 Wochen zu spat Ostern zu halten, könnte ich es auch leiden wann man auf solchen Fall 4 Wochen wartete. Wenn der calculus dem Collegio aufgetragen wird, ists nicht Noth alles in antecessum außzumachen. Wir haben Zeit genug dazu, weil solche casus gar rar sind. Detur casus et da bitur Responsio, collatis interea mutatis consiliis et pluribus observationibus. 9) was das letzte dubium betrifft, wie weit nemlich das Plenilunium Paschale vor dem die Paschali hergehen müsse? So muß man zu forderst sich wegen eines gewissen meridiani vergleichen, wo anderst verlangt wird das wir des Concilii Decretis gemeß Ostern auf einen Tag halten sollen; weil es sich zutragen kan, daß einem das Plenilunium auf den Sonntag dem anderen auf den Sonnabend, oder einem Vormit- dem andern Nachmittag falle. Wann aber das ganze Werk principaliter auf die Juden angesehen, daß man mit ihnen nicht gern concurriren will: die Juden aber, sie seyen wo sie wollen, es allso halten, daß sie sich nach dem meridiano Hierosolymitano richten $\mathrm{u}$. 
wann daselbst das plenilunium e.o. auf Sonnabend nachmittag fället sie auf den Abend agnum Paschalem schlachten u. allso auf den Sonntag ihre Ostern halten; hingegen wann es vormittag einfällt solches den Abend vorher thun u. allso am Sonnabend Ostern halten

[94v] So könnten wir wohl am sichersten den concursam cum Judæis vermeiden wann wir uns nach eben diesem meridiano richteten, wie auch H D. Ludolf wie wohl ex alia causa, vorgeschlagen, u. allso wann zu Jerusalem das Plenilunium auf einen Sonnabend nachmittag eintritt, wir 8 Tag warteten, wo es sich aber vormittag ereignete, strack folgenden tags Ostern hielten. Wolte man aber gar einen meridianum zwischen Japan u. Americam setzen, wie unser see $\ell \mathrm{H}$ Vatter (meines behalts, denn ich hab jetzt nicht Zeit nach zuschlagen) ehemaln in seinem Zeitspiegel vorgeschlagen, u. nach selbigem die Plenilunia Paschalia censiren, könnten wir dem concursum cum Judæis vieleicht noch gewisser excitiren $u$. dörffte man allso dem universaliter statuiren daß man den nechsten Sonntag nach dem Plenilunio solte Ostern halten, wann es auch gleich nur ein Stund zuvor gewesen wäre. Dieses sind nun meine unmaßgeb $\ell$. Gedanken über denen überschriebenen punctis $u$. dubiis. Bitte dabey dienst $\ell$ mir dero eigene, ingleichen, wann es nicht allzu viel Mühe macht, auch Hn P. Sturms Meinung zu communiciren, wo wir in ein $u$. andrem differenter opinion seyn, um einen gemeinsamen Schluß zu fassen. Doch meinte ich man müste die Sach so fern behutsam tractiren damit nicht, wann wir das meiste debattirt $u$. was confusion erregen könnte abgethan, man nachmals meinen mögte, es wäre nun kein Collegium mehr nöthig. Allein man wird nicht auß der Sach kommen, wo man nicht gewissen Personen in Verfertigung des astronomici das monopolium gibt. Der neue Calender so zu Langensalza gedruckt worden, hat die Vorerinnerung nicht, wie befohlen worden, vordrucken lassen, vom Mertz an biß zu End hat Er nur eine einzige columnam gesetzt und denn neuen Calender gar außgelassen, oder viel mehr auf selbigen den Titul des verbesserten gesetzet, $u$. alle festa Papisten roth drucken lassen, übrigens den Sonntagsbuchstab $\mathcal{G}$ behalten $u$. vom Wetter $\mathrm{u}$. Zustand davon so in jedem Monath geboten worden, mehr gelogen als jemand anders. MhgH Professor wird solche Sachen wohl wissen zu nützen, um die Nothwendigkeit des Collegii desto nachdrücklicher vorzustellen $\mathrm{H}$ Junius hat nichts neues wider den Calender lassen drucken, sondern es ist nur dem ReichsConcluso u. judicio Mathematicorum Suecicorum auch sein unpartheisches Bedencken samt MhgHn Professoris Antwort, u. seiner exception, beydruckt worden. Würd allso nicht nöthig seyn daß ich 
es schicke. Ist am Ende das wichtigste von MhgHn gründlich abgelehnet, u. seine exceptiones von so großer importanz nicht. Ich dörffte bald resolviren an Ihn, als meinen discipulum, der ehedessen öffters mit mir correspondirt, zu schreiben u. Ihm Hoffnung machen daß Er im Collegio auch eine employe haben solle als ich Ihm schon vor 2 Jahren als er seinen Mercurium herauß gegeben, auf expresse order des see $\ell$ Hn Vatters gethan. Ich dencke auch durch Ihn Hn Kirchen zurück zu halten, zumal dieser noch nichts wider dero Calender reformation drucken lassen, außer daß er etwas weniges in seinen Calender gesetzt. H Junius soll in seinen vorhabenden Ephemeridibus nicht einerley sondern vielerley tabulas e.o. Rudolfinas, Philolaicas, Britannicas, adhibiren wollen. Ich kan aber nichts zuverläßiges davon berichten. Wann ich des Kirchii lamentationes in copia haben konnte, wäre es mir sehr lieb. vor die überschickte Antwort darauf sage schuldigsten Dank. Auß selbiger sehe daß sich seine ganze Sorge auf die ignoratiam dessen was in Regenspurg passirt, geändert. Mein H Socer wird sonderzweifel indessen die verlangte general Quittung über sendet haben. Sage nochmaln dienst $\ell$ Dank vor große Bemühung. Mit Wien muß man freylich warten, biß Hn D. Schadens promesscen wahr werdt, u. der Frühling herann rücket. Bitte sich den Einschluß lassen befohlen seyn.

Vale et porro fave.

T.T.

G. A. Hamberger

P.S. H P. Ludolf hat sich gegen meinen vornehmen Mann gerühmet daß die Calenderreformation ganz nach seinem Vorschlag eingerichtet sey. Ich hab bloß geantwortet, es wäre mir sehr lieb daß Er die opinion hette. Wundert mich allso daß Er nun post festam noch einmal mit seinem Vorschlag aufgezogen kommt. Das dubium mit Ostern haben hier schon viel gereget $\mathrm{u}$. war die præcantio bey denen Hhn Gesandten sehr nöthig.

\section{Kommentar}

Nachdem im September 1699 das Corpus Evangelicorum die Annahme des Verbesserten Kalenders für die protestantischen deutschen Länder und den Kalenderwechsel für Februar/März 1700 beschlossen hatte, bemühten sich Hamberger, Sturm und Meyer weiter um die Etablierung des Collegiums, insbesondere um den zweiten Punkt des Conclusums vom 23. September 1699, vgl. Seite 122, zur astronomischen Bestimmung des Osterdatums gewährleisten zu können. Offenbar lag dem Corpus Evangelicorum dafür ebenfalls ein konkreter Resolutionsentwurf 
vor. Dabei könnte es sich um den Text handeln, der unter der Überschrift „Die Calender-Verbesserung recht zu stabiliren, wird folgendes erfordert" siebzehn konkrete Punkte benennt, siehe [105, Seite $130 \mathrm{ff}$.$] . Darin heißt es [105, Seite 1314$

(7.) Die Membra Collegii können aus denen Professoribus und andern Mathematicis von denen Kreyss-Ständen vorgeschlagen, und aus denen vorgeschlagenen ein certus numerus von einem gesamtlichen Hochlöblichen Corpore Evangelico in Collegium adoptirt werden. Dieser Numerus darf sich anfangs nicht so gar weitlæufftig erstrecken, wegen des noch ungewissen Unterhaltungs-Mittels: Massen die zu Collegis erwehlte gleichwohl von allen und jeden Stænden eines Hochlöblichen Corporis Evangelici erwehlet werden, allen und jeden obligirt sind, vor alle und jede arbeiten. Und ist daher gantz kein Bedencken zu machen, ob schon nicht jeder Stand seinen Mann im Collegio hat.

(8.) Dieses Collegii Amt und Occupation ist.

1. Durch fleissige observationes die Tabulas Astronomicas und Hypotheses zu perfectioniren.

2. Ephemerides zu calculiren, und jæhrlich den Calculum, wie er im Calender kommen soll, einzurichten.

3. Die Mathematische Künste und Wissenschaften je længer je mehr zu excoliren.

(9.) Den Fonds zu dotirung des Collegii muss der Calender selbst verschaffen, ohne die geringste Beschwerung einiger Cammer auch einiger Menschen, und ohne Schaden der priviligirten Verleger.

Hamberger spricht sich dafür aus, dass in einem entsprechenden Beschluss die Mitglieder des Collegiums noch nicht explizit benannt werden, und erläutert seine Gründe dafür. Seiner Meinung nach sollten individuelle Befindlichkeiten zurückgestellt und ganz im Sinne der Sache entschieden und gearbeitet werden. Außerdem sollten die anstehenden umfänglichen und arbeitsintensiven Aufgaben auf viele Schultern verteilt werden. Zudem erläutert Hamberger mit Blick auf den Druck der Kalender und die Verleger Einzelheiten der Durchführung des angestrebten Kalendermonopols. Siehe auch die mit Beispielrechnungen unterlegten Ausführungen dazu in der gemeinsamen Abhandlung [76] Hambergers, Sturms und Meyers, die bei den historischen Quellen in dieser Briefedition ab Seite 124 mit abgedruckt ist.

Weiterhin macht Hamberger konkrete Vorschläge zur Gestaltung der Kalender. Insbesondere verlangt Hamberger von dem Massenmedium Kalender keine detaillierten astronomischen Daten, sondern hält es für ausreichend, wenn die Mondphasen

\footnotetext{
${ }^{4}$ Hamberger bezieht sich explizit auf Punkte in der Nummerierung. Diese ist vermutlich bis zur endgültigen Version noch geändert worden.
} 
aufgeführt werden. Offenbar arbeitete Johann Heinrich Hoffmann an einem Kalenderentwurf, aller Wahrscheinlichkeit nach an der Vorlage des Collegiums. Aus Gründen, die Hamberger nicht weiter spezifiziert, musste Hoffmann dabei für den neuesten Kalender den Tabellen des italienischen Astronomen Andrea Argoli (15701657) folgen, die dieser 1667 in Padua publiziert hatte [16].

Bei der Bestimmung des Osterdatums kommt nach Meinung Hambergers für den Fall, dass Frühlingsanfang und Vollmond sehr nahe beieinander liegen, das Collegium mit ins Spiel. Diese Situation tritt jedoch nur sehr selten ein, sodass das Collegium genügend Zeit zu astronomischen Beobachtungen und gemeinsamen Beratungen hat. Hamberger schreibt dazu „Detur casus et dabitur Responsio, collatis interea mutatis consiliis et pluribus observationibus" (Seite 84 , Übersetzung: Die Antwort wird auf den Fall gegeben werden, nach einer Änderung von Plänen und einer Reihe von Beobachtungen).

Bei einer astronomischen Bestimmung des Osterfestes ist es im Zusammenhang mit der Abgrenzung der Christen gegen das jüdische Passahfest erforderlich, sowohl einen ausgezeichneten Bezugsmeridian für die zugrunde zu legenden astronomischen Beobachtungen festzulegen als auch eine Datumsgrenze zu definieren, bezüglich welcher die Wochentage bei der Festrechnung zu zählen sind. Hamberger verweist in diesem Zusammenhang auf Weigels "Zeit-Spiegel“. Weigel hatte darin offenbar zu diesem Zweck bereits die Einführung einer Datumsgrenze vorgeschlagen: „Da dann meines unmaßgeblichen Erachtens am sichersten seyn würde, hierzu einen Meridian-Strich zu erwehlen, welcher mitten durch das mare Pacificum zwischen der Mexicanischen und Japonischen Cüste durchstreichet, und die alte Welt gegen Morgen von der neuen scheidet." siehe [180, Seite 106]. Die Notwendigkeit einer Datumsgrenze gewann mit der Seefahrt, insbesondere nach der ersten Weltumsegelung durch Ferdinand Magellan (1480-1521) praktische Bedeutung. In der Folge gab es in der ersten Hälfte des siebzehnten Jahrhunderts verschiedene Vorschläge zur Definition einer kalendarischen Datumsgrenze. Es kann also davon ausgegangen werden, dass Weigel diese Problematik kannte. Die Rudolfinischen Tafeln geben die astronomischen Daten, aus denen sich die für das Osterdatum relevanten Daten der Frühlings-Tag-und-Nacht-Gleiche und des Frühlingsvollmondes ergeben, bezüglich des Meridians von Uraniborg an. Da der Meridian von Jerusalem jedoch als solch ein Meridian für das jüdische Passahfest dient, sollte dieser Meridian ebenfalls als Bezugsmeridian für die Berechnung des christlichen Osterfestes herangezogen werden. Nur so ließe sich vermeiden, dass Ostern mit dem Passahfest zusammenfällt.

Übrigens ergab sich die heute international vereinbarte Lage der Datumsgrenze nahe des 180. Längengrades im Pazifischen Ozean aus der Festlegung des Nullmeridians in Greenwich. Der 180. Längengrad wurde in Symmetrie zu diesem Nullmeridian als Datumsgrenze gewählt, verläuft hauptsächlich durch die Gewässer des Pazifischen Ozeans und betrifft relativ dünn besiedeltes Gebiet. Die Wahl des Me- 
ridians von Greenwich als Nullmeridian erfolgte aber erst auf einer internationalen Konferenz im Jahr 1884, also 220 Jahre nach Erscheinen von Weigels „Zeit-Spiegel“.

Hamberger nennt den bereits im vorherigen Brief erwähnten Kalender aus Langensalza als schlechtes Beispiel eines Verbesserten Kalenders. Dieser Kalender eignete sich somit als willkommenes Argument für die Notwendigkeit des Collegiums. Wie bereits in den Kommentaren auf Seite 79 konstatiert, ist für den Druckort Langensalza bisher jedoch kein Nachweis eines Kalenders für das Jahr 1700 zu finden.

Am Ende geht Hamberger noch einmal, vgl. Seite 58 auf die Publikation der Schrift 113 von Ulrich Junius ein, misst ihr aber nicht allzu viel Bedeutung bei und kündigt an, Junius in Anerkennung seines Talentes als konstruktiven Mitarbeiter in die Aktivitäten des geplanten Collegiums einbeziehen zu wollen. Junius hatte 1697 zwei Schriften zur bevorstehenden Merkurpassage vor der Sonne vom 24. Oktober 1697 publiziert [111, 112. Da ihm als Student der Druck einer derartigen Schrift nicht erlaubt gewesen wäre, hatte er diese mittels eines Kunstgriffs zum Druck befördert, vgl. dazu seinen Brief an Gottfried Kirch vom 12. Oktober 1697, Brief Nr. 583 [94, Band 2, Seite 242]. Offenbar hatte Hamberger Kenntnis von Junius Plänen, Ephemeriden, also Positionstabellen von Sonne, Mond, Planeten, Kometen oder Fixsternen, zu publizieren, in denen dieser sich der Beobachtungsdaten verschiedener Astronomen bedienen wollte, vgl. dazu die ausführlicheren Kommentare zu den Briefen vom 11. Dezember 1699 ab Seite 94 und vom 12. Juni 1700 ab Seite 119.

\section{Brief vom 8. Dezember 1699}

Cod. Ms. Philos. 60, Blatt $447 \& 448$

[447r] Wohledler, großg $\ell$. hochgeehrtister H u. Patron.

Ich habe heut 8 Tag durch die geschwinde Post weitlauffig auf die vorgelegte Fragen, die dotirung u. fundirung des Collegii Astronomici, wie auch den calculum astronomicum betreffend, geantwortet, zugleich 4 leere Bogen papier mit Unterzeichnung meines Nahmens, begehrter massen überschicket. Hoffe es solle alles wohl $u$. zu rechter Zeit überliefert seyn. Nachdem habe auch MhgHn 4 tes Schreiben vom 27 Nov: wohl erhalten, u. darauß sehr gern ersehen daß H P. Sturm, was den calculum astronom. betrifft ganz mit mir im Hauptwerk einig. den 6 ten Punckt hab ich etwas umständlicher beantwortet $u$. werden seine Wort: auf welchen Tag, Stund $\underline{u}$. Minute nach dem æquinoctio ein Vollmond einfält, $\underline{\text { so }}$ trifft auf den selben Tag der Juden 
Ostern; die resctriction sonder zweifel leiden, daß solches zu verstehen, wann der Vollmond nach ihrem calculo (der den motum mediam supponirt) noch Vormittag fällt, den sonst ist auf den Abend erst tempus mactandi agnum Paschalem u. allso den folgenden Tag Ostern. Zugleichem leidet es eine restriction wann das plenilunium auf seriam 2. 4. oder 6 fällt, auf welchen casum sie Ostern auf folgenden Tag verschieben; wie beedes auß Ricciolo, Calvisio $\mathrm{u}$. andern welche der Juden Calendarium recens gar deutlich beschrieben, zu ersehen. Allein diese letzte restrictio gehet præsentem casum, da die Frag ist, was zu thun sey, wann das Plenilunium auf einen Sonnabend fället, nicht an.

[447v] Wegen des casus wann das plenilunium dem æquinoctio so nahe kommet, daß man nicht ohnfehlbar vorhero sagen könnte, welches motu utriusque sideris vero, zuerst fiel (quod siarguam certe rarissime accidet) wolte ich noch gedenken, daß man auch in diesem Fall auf die Juden, auf die doch das ganze Werk principaliter angesehen, regardiren könnte, so daß wann sie solches plenilunium vorbey giengen, wir derg $\ell$. thäten. doch halte ich es nicht vor nothwendig daß wir in præsenti alles decidiren u. etwa gar solten drucken lassen, damit unsre Neider nicht neue ansam carpendi bekommen, sondern wenn einem Collegio die direction anvertraut wird, kan dato casu schon eine resolution gefasset werden die zulänglich. Ob wir sonst denen Juden vi Canonum nachzugeben schuldig, wann die Juden im calculo fehlten und u. allso per errorem mit uns zugleich Ostern hielten, stelle ich dahin. Meinte aber nicht daß uns die Pontificii was vorzuwerfen hetten, wann wir schon nicht wichen denn wenn sie bißhero mit denen Juden concurrirt ist das vitium nicht bey denen Juden sondern bey ihnen gewesen. Sonsten wolle MhgH sich nicht irren lassen daß zu 2 malen der Zeit gedacht da die Juden das Osterlam schlachten. Denn ich weiß gar wohl daß solches nach der Zerstörung Jerusalem nicht mehr geschehen. Habe aber das tempus mactandi agnum u. den Ostertag (quæ nunquam Judæicum a vespera diem incipientium Christianarum tn. salt. Germanorum computar duratione in diversos dies cadunt,) mit Fleiß wollen distinguiren, weil Ricciolus, zu defendirung des Calend: Gregoriani, fingert es wäre denen Christen durch Conc: Nic: nur verbotten den Tag Ostern zu halten, da das Lamm geschlachtet

[448r] wird. Daß H P. Sturm auf den andren Punckt von Einrichtung des interims Collegii noch nicht geantwortet, wundert mich. Ich will etwa morgen selbst an Ihn schreiben $\mathrm{u}$. Ihn animiren. Mag vieleicht sich wegen der dotirung so bald nicht resolviren können. Welches freylich ein schwehrer Punckt wann alles so eingerichtet werden soll daß es Bestand habe u. uns nachmaln 
nicht die intraden unter allerhand Unterschleif entstehen. Ob meine Gedanken zureichen überlasse ich billig ihrer freien Beurtheilung. Denn mann darf hier niemand was zu lieb approbiren. Was sonst MhgH über Hn P. Sturms Beantwortung des 6 ten Punckts sich vor ein dubiam concipirt, als ob nemlich dieses Jahr 1699 das plenilunium auf den $\frac{4}{14}$ Aprilius falle, u. doch die Juden nach Hn Kirchii calculo Ostern erst d $\frac{5}{15}$ hielten; wird nur ein Übersehen seyn. Denn sie halten Ostern zwar im 15ten Nisan, aber diß ist der $\frac{4}{14}$ Aprilis wie Hn Kirchii Calender klar weiset. Sonsten ist freylich nöthig das wegen eines Collegii bald eine resolution gefasset werde damit uns nicht alle pässe verrennet werden. H Fritsch Buchführer zu Leipzig hat sich das monopolium im Calender Verlag durch ganz Chursachsen außgebracht. Andere dörfften wohl derg $\ell$ thun wann wir endlich nichts prætendiren als das Astronomicum, so mag Verleger seyn wer da will, u. wenn deren nicht allzu viel sind können wir uns eher an ihnen erholen als wann wir selbst nicht wissen wo sie alle stecken. Hierbey kommt auch die verlangte Quittung wegen Maria Schumännin. Bitte sie aber noch einige Tage zurück

[448v] zu halten weil ich hoffe mein H Schwieger Vatter dem ich außfühlich vergangenen Mondtag geschrieben, werde selbst noch eine schicken, da man als denn die meinige nur zerreisen kan. Sein Zweifel, als ob die Magd nur 20 thlr zu fordern ist auß einem Zettul entstanden darinn MhgH ehemaln nach Hn Zimmermanns Angeben die Schulden specificirt. u. hab ich mich anfangs selbst nicht recht darein finden können. Weil aber nun wohl daß die vom ältren Hn Zimmermann aufgesetzte specification auf 25 thler lautet. womit nebst Empfehlung Göttlicher Gnaden verharre.

Meines hochgeehrtisten Hn Prof. u. Patrons ergebenster Diener

Jena d 8 Dec: 1699

G A Hamberger

\section{Kommentar}

Hamberger diskutiert in diesem Brief Details zum Verhältnis zwischen dem christlichen Oster- und dem jüdischen Passahfest. Er erinnert daran, dass im jüdischen Kalender ein Tag von einem Abend zum nächsten Abend gerechnet wird und demnach für die deutschen Christen auf verschiedene Tage fällt. Insbesondere weist er auf Giovanni Battista Riccioli hin. Nach dessen Verteidigung des Gregorianischen Kalenders dürfe Ostern gemäß des Konzils von Nicäa lediglich nicht auf den Tag fallen, an welchem Juden, deren Tag am Abend beginnt, das Osterlamm schlach- 
teten. Vermutlich ist an dieser Stelle Ricciolis Schrift „Chronologiae reformatae" [151] gemeint. Hamberger benutzt im Brief die doppelte Datumsschreibweise, bei der die Tage bezüglich des alten und des neuen Kalenderstils mit ihrer Differenz von zehn Tagen als Bruch dargestellt werden.

Außerdem drängt Hamberger auf eine Entscheidung zur Etablierung des Collegiums und spricht schließlich ein lokales Kalendermonopol für das Kurfürstentum Sachsen an. Der sächsische Kurfürst Friedrich August I. hatte nämlich am 8. November 1699 - also gut vier Wochen bevor Hamberger diesen Brief verfasst hatte - dem Leipziger Verleger Thomas Fritsch (1666-1726) ein Monopol zur Herausgabe von Kalendern erteilt [5] und damit absolutes Neuland beschritten. Dieses Kalenderprivileg garantierte Thomas Fritsch das alleinige Recht, Kalender für Kursachsen zu drucken, sie zu verlegen und zu verkaufen. Es untersagte strikt jegliche Konkurrenz durch andere Kalenderverleger und Kalenderhändler. Verfasser der bei Fritsch gedruckten Kalender war der in Leipzig studierende Ulrich Junius, vgl. auch Hambergers Briefe vom 29. Dezember 1699, Seite 96, und vom 12. Februar 1700, Seite 108. Diese Autorschaft geht zudem zweifelsfrei aus der Korrespondenz hervor, die Ulrich Junius mit Gottfried Kirch führte, siehe hier insbesondere die Briefe Nr. 710 94. Band 2, Seite 375 f.] und Nr. 712 [94, Band 2, Seite 379 f.]. Am 9. Dezember 1699 hatte Junius an Kirch geschrieben, siehe [94, Band 2, Seite 375 f.]:

Fritsch will einen in Leipzig haben, der ihm alle discurse nach Seinen kopff einrichte, alle correctionen auff sich nehme, und in summa zu seinem gefallen lebe, ... so schickte er nach mir, daß ich ihm solchen in besagter zeit machen möchte ... so arbeite ich iezo tag und nacht daran, damit er bis auff den dienstag fertig werde, ... es will aber $\mathrm{h} \ell$ Fritsche wenig pro labore geben, und hatt man eine schreckliche scherrereÿ mit diesem Mann, ... daran ich aber niemahlen gedacht, daß ich auff Universitäten solte einen Calender machen

Von Interesse ist hier auch die Anmerkung 14 zum diesem Brief (Brief Nr. 710). Danach hatte Junius bei seiner Arbeit an dem Kalender für Fritsch Material von Kirch genutzt und „Kirchs Arbeit vor die Seinige herausgegeben“ 94, Band 3, Seite 497], was wahrscheinlich die Ursache für den Bruch in der Freundschaft zwischen Kirch und Junius war. Zu kalendertechnischen Details des von Fritsch veröffentlichten Leipziger Verbesserten Kalenders sei auf [98, Seite $273 \mathrm{ff}$.] verwiesen. 


\section{Brief vom 11. Dezember 1699}

Cod. Ms. Philos. 60, Blatt 450

[450r] Wohledler, großg $\ell$ hochgeehrtister H und Patron.

Ich habe d 9 ten u. 2 ten currentis an Desselben durch die geschwinde Post geschriben, und auf alle mir in etlichen Schreiben vorgelegte puncta umständlich geantwortet, auch 4 Bogen papier, in Gestalt ein charta blanca begehrter massen, beygeleget, und letzlich auch ein Quittung vor Hn Zimerman im Nahmen Mariæ Schumännin überschickt. Hoffe es solle alles wohl behändiget seyn. Heut erhalte ganz unvermutet vom Hn Junio beyliegende Epistolam, darüber Er mein sentiment verlanget, mit vermelden daß Er täglich derg $\ell$ von der Societate Parisina und Londinensi erwarte; darauß zu ersehen, daß Er in motu $\mathcal{\odot}$ Cassinum et Hevelium, in $\mathcal{D}$ Flamstedium, in 4 Ricciolum in $\boldsymbol{\sigma}^{\prime}$ Keplerum, in $\Varangle$ Wingium gebrauchen werde, doch wie Er mir schreibt, cum aliquócorre, et ione. Bin aber dennoch der Meinung es seye besser man behalte durchgehends einerley Tabulas, tentire jedoch, wie jüngst überschrieben, die Sach darneben auch nach andern Tabulis. Denn obschon hirdurch die Arbeit wächset, so können hirdurch nicht nur viele confusiones die bey der andern Art zu besorgen, vermieden werden, sondern es kan auch wann diese Arbeit etliche Jahr continuirt worden solches calculs mit dem eventu desto besser die correctio plenior Tabularum angestellet werden. Die Arbeit aber wird eben nicht unerträglich werden, wann nur mehr als ein calculant ist.

[450v] Inzwischen wird mir dieses Gelegenheit geben von Ihm zu erfahren ob Er allbereit was fertig habe von allen Planeten, denn daß Er würklich Eclipses rechne gedenket Er, wann u. auf wie viel Jahr Er Ephemerides ediren wollen, und ob Er Lust habe sich bey dem Collegiogebrauchen zu lassen. Von welchem allen ich MhgHn so fort Nachricht geben werde damit wir auch unsers Hn Hoffmanns bestes beobachten können. Insonderheit werde ich, nachdem seine Antwort lautet, auch bey Ihm hören ob Er socius laboris leiden könne. Von der Calender Sache und dem so Er darwider geschrieben, hat Er kein Wort im Brief gedacht, doch hat Er des Hn Fritschen privilegium über den Calender, davon neulich gedacht, mit beygeleget, darauß ich ersehen daß selbigem nicht nur das monopolium im Calenderverlag durch Chursachsen und andere dazu gehörige Stiffter $u$. Landen gegeben sondern auch verbotten wird, daß Ihm niemand durch Teilhabung des verssanten, außer des Churfürsten Landen gedruckten Calenders, Schaden zufügen sol- 
te. So zwar viel ist, $u$. soll mich verlangen ob es mit denen Keys $\ell$. andern Buchführern ertheilten privilegiis stehen könne. Womit nebst Empfehlung Göttlicher Gnaden verharre.

Meines hochgeehrten Hn u. Patrons ergebenster Diener

Jena d 11. Dec: 1699.

G A Hamberger

An Hn P. Sturm hab ich vorgestern geschrieben u. Ihn gebetten seine Gedanken wegen des Collegii zu eröffnen. Bitte Ihm etwa auch des Hn Junii Epistel zuzuschicken seine Gedanken darüber zu vernehmen.

\section{Kommentar}

Der zu Beginn genannte Brief vom neunten des gegenwärtigen Monats ist aller Wahrscheinlichkeit nach der auf den 8. Dezember 1699 datierte vorhergehende Brief ab Seite 89. Vermutlich ist er am darauf folgenden Tag abgesandt worden. Einen Brief vom ersten oder zweiten Dezember 1699 gibt es in der Sammlung leider nicht.

Aus diesem Brief hier geht hervor, dass Ulrich Junius für die Herausgabe seiner geplanten Ephemeriden [114] auf die Beobachtungsergebnisse verschiedener anerkannter zeitgenössischer Astronomen zurückgreifen wollte. Für die Sonne $(\boldsymbol{\odot})$ sollten es dabei die Daten von Giovanni Domenico Cassini (1625-1712) sein, die dieser in ausdauernder und präziser Observationstätigkeit gesammelt hatte. Die im Jahr 1668 von ihm herausgegebenen Tafeln über die Jupitermonde [29] brachten Cassini 1669 eine Berufung als Direktor der Sternwarte der neugegründeten Pariser Akademie der Wissenschaften ein. Ursprünglich waren seine Beobachtungen auf die Sonne gerichtet, erst mit der Verfügbarkeit leistungsstärkerer Teleskope wandte er sich der Planeten- und Jupitermondbeobachtung zu [208]. In der Position des Direktors der Pariser Sternwarte wurde er 1699 offenkundig von Ulrich Junius um ein Urteil zu den geplanten Ephemeriden gebeten. Außerdem wollte Junius für die Sonnendaten die Resultate des Danziger Astronomen Johannes Hevelius (1611-1687) heranziehen. Hevelius beobachtete die Sonne von 1652 bis 1679 sehr eingehend und publizierte seine Beobachtungsergebnisse 1679 in einem kurzen, leicht zu übersehenden Kapitel im zweiten Band seiner „Machinc Coelestis“, vgl. [106, Seite 21] und siehe [102]. Für den Mond (D) sollten die 1673 in den „Lunares Numeri" [41] publizierten Beobachtungsdaten des britischen Astronomen John Flamsteed (1646-1719) genutzt werden. Flamsteed, dessen Ergebnisse durch bemerkenswert hohe Genauigkeit bestachen, war 1675 zum ersten Astronomer Royal, also zum ersten Direktor des Royal Observatory in Greenwich ernannt worden. Seine Mondbeobachtungen galten als die exaktesten jener Zeit. Auf einer Bildungsreise im Jahr 1706 lernte Junius Flamsteed persönlich kennen. Beide sollen von da an einen regelmäßigen Briefwechsel geführt haben. In Sachen Jupiter (4) wollte 
Junius offenbar dem italienischen Jesuiten Giovanni Battista Riccioli (1598-1671) das wissenschaftliche Vertrauen schenken. Dieser hatte bei seinen astronomischen Beobachtungen bereits die Schatten der Jupitermonde auf der Planetenoberfläche des Jupiters entdeckt und seine Jupiterbeobachtungen 1665 in der „Astronomice reformatce " 150] publiziert. Außerdem beabsichtigte Junius für seine Tabellen die Resultate Johannes Keplers (1571-1630) zum Mars ( $\left.\mathbf{O}^{\prime}\right)$ zu verwenden. Bekanntlich hatte Kepler die nach ihm benannten Gesetze zu den Planetenbewegungen auf der Basis seines Studiums der Umlaufbahn des Mars aufgestellt. Die ersten beiden Bewegungsgesetze veröffentlichte er 1609 in seiner „Astronomia Nova“ [116, das dritte 1619 in seinen „Fünf Büchern zur Harmonik der Welt“, der „Harmonices mundi libri $V^{\text {" }}$ 117. Schließlich sollten in Junius Ephemeridenwerk für Merkur (§) die Beobachtungsergebnisse des britischen Astronomen Vincent Wing (16191668) verwertet werden. Wing publizierte von 1652 bis 1671, das heißt über einen Zeitraum von zwanzig Jahren, Ephemeriden, die von John Flamsteed als die genauesten bezeichnet wurden, die zu jener Zeit zur Verfügung standen, vgl. zum Beispiel Wings 1652 in erster und 1669 in zweiter Auflage erschienene „Astronomia Britannica" [196].

\section{Brief vom 29. Dezember 1699}

Cod. Ms. Philos. 60, Blatt $422 \& 423$

[422r] Wohledler, Hochgeehrtister H u. Patron.

Von meinem Hn Schwiegervatter habe gestern Hn M. Erasmi letzteres Schreiben wohl erhalten, darauß ersehen daß H D. Schad nunmehr die gemachte große Hoffnung, die instrumenta mathematica bey Sn Majestet dem Röm. König wohl anzubringen, nun selbst fallen lassen, und hingegen neue Vertröstung gebe, daß der Land Marschall H Graf von Braun selbige vor die Land Ständ $\ell$. Academie, als deren Director Er ist, erkauffen werden, so die Zeit lehren wird. Weil inzwischen H M. Erasmi auf Ostern von Wien abreiset, so scheinet fast rathsam, wann es in solcher Zeit kein Ernst wird, dahin zu trachten, wie man sie, die instrumenta, zu sichren Handen bekommen, weil solches nach seiner Abreiß schwehrlich ohne große Kosten dörfte zu erhalten seyn. Sonsten verlanget mich sehr zu vernehmen, ob das unterth $\ell$. memorial bey dem Corpore Evangelico, in der Calender Sache communi nomine eingegegeben, $u$. was dießfals, wie auch wegen des versprochenen Honorarii zu hoffen? Nicht minder ob ein Calender in Nürnberg gedruckt worden. H Fritsch in Leipzig hat von dem seinigen vor ganz Chur Sachsen priviligirten 
Calender 600000 exemplaria auflegen lassen. Wenn das Collegium Astronomicum noch solte zum Stand kommen u. selbigem von einem jeden exemplar nur 3d bezahlt würden, betrüge es schon über 6000 thler, darauß zu schließen, daß von allen Calendern so in denen gesamten Evange $\ell$. Landen gedruckt ward, vor das Collegium

[422v] wohl 40 biß 50000 thler außfallen solten, wann kein Betrug bey vorgieng; welcher so viel weniger zu befahren wann auch in andern Chur $u$. Fürst $\ell$. Landen der Calenderverlag einer einzigen Person, oder, wo es noch nicht occupirt, gar dem Collegio gegeben würde. Der autor des Chursäch $\ell$. Calenders ist, der Schreibart u. allen andren Umständen nach, H Junius. Er gedenket darinn unter andren daß die Tabulæ Rudolfinæ nach des Hn Cassini observation das æquinoctium vernum um 3 Stund zu früh $u$. das autumn: $3 \mathrm{St}$ zu spät ansetzten, welches mit der Zeit große confusion im Calenderwesen machen könnte auf den Fall wann das Plenilun: Paschale dem æquinoctio nahe tretten, und man auf falsche tabulas bauete. Es hat aber keine Gefahr wann nur ein Collegium angeordnet wird. Auf sein neuliches Zuschreiben davon ich jüngst gedacht $u$. seine gedruckte epistel mit beygelegt, $u$. bitten, hab ich Ihm geantwortet; obwohl geständlich, daß die Tabulæ Rudolfinæ in ein und andern Stück nicht mehr perfect zutreffen, so hielte ich dennoch vor rathsam daß die Ephemerides durchgehend nach denen selbigen elaborirt, aber zur probi latere gesetzt würde wie die phænomena coeli nach denen Tabulis die in ein $u$. andern Planeten vor perfecter gerhalten werden, sich weisen solten und zwar darum weil 1) geständlich daß auch von denen andern Tabellen keine omni exceptione major sey; und man sonst, wann auch selbige nicht dem coetu nicht völlig zusammentreffen, nachmals immer ein Zweifel stehen müste ob nicht die TabulæRudolf. näher zur Wahrheit getretten wären 2) man auf solche weiße, wann viele Jahr nach einander fleisige u. Collegialische observationes angestellet würden, und mit solchen Ephemeridibus conferirt würden, so viel eher zu einer vollkommnen correctione Tabularum

[423r] gelangen könnte, $u$. die Teutschen, so a renatis literis nun über 200 Jahr in dem Ruhm gestanden, daß sie die besten Tabulas u. Ephemerides gehabt, nicht nun erst, non fine opprobrio ihr altes Lob fallen lassen u. mit fremden Augen sehen dörften pp Ich habe aber noch bißher von Ihm keine Antwort erhalten. Ich sehe indessen noch zur Zeit gar nicht warum der Cassini es allein außmachen und dem Hevelio vorgezogen werden solte, nach dessen calculo aber die Rudolfinæ des æquinoct: vernum nur um eine halbe Stund zu früh ansetzen. So trifft auch des Hn Wurzelbauers observatio proxi- 
mi æquinoctii autumnalis, cum ejusdem observatione cassiniana nicht überein. Und glaube allso nicht daß wir annoch Ursach haben von unserer einmal gefaßten und letzt überschriebenen Meinung abzuweichen, zumal es dem Röm. Reich scheinet etwas schimpflich sey, daß es in defecta eigener mathematicorum solte auf fremde eben noch ungewiße u. undemonstrierte Tabulas bauen. H D. Ludolf zu Erfurt hat eine Schrifft verfertigt zu behaupten daß das neue Seculum mit künftigen Januario anfange, darin er sich anfangs sehr freuet daß die Calender Reformation so wohl nach seinem Vorschlag einge-

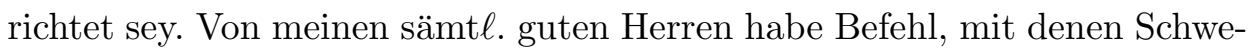
dischen Mathematicis dem Reichs Schluß gemeß, wegen ihres Vorschlags zu communiciren, auch dahin zu trachten wie das Wahrsagen könne abgeschafft werden, u. davon, als auch wie sonst das ganze Werk völlig zu perfection zu bringen unterthänigsten Bericht zu thun. Selbiger

[423v] aber wird nach dem zwischen uns concertirten Vorschlag eingerichtet werden. Vor einigen Wochen ist in hiesiger Zeitung gedruckt worden, daß MhgH einen Vorschlag wegen eines Collegii Mathematici gethan, u. zu dessen dotation den Calender angegeben (auf Art u. Weiß wie sie mir selbst überschrieben) es wäre aber das letzte von denen meisten vor unzulänglich erachtet $u$. viel mehr davon gehalten werden, daß die Stände selbst einen Zuschuß thun solten. Und weil sich auch viele gelüsten lassen wider die beliebte Calender reformation zu schreiben, als würde solches beginnen Reichswegen scharf verbotten werden. Möchte wohl wissen was hieran sey, ingleichen ob meine Schreiben darinn auf alle mir überschriebene punctte geantwortet, alle zu recht kommen seyn. Womit nebst Anwünschung alles Seegens von Gott zu dem bevorstehenden neuen Jahr, verharre

Meines hochgeehrtigsten Hn u. Patron ergebenster Diener G A Hamberger

Jena d 29 Dec: 1699

Von Hn P. Sturm habe auf mein Zuschreiben darinn ich Ihn gebetten sich des vorseyenden Collegii mathematici mit anzunehmen, habe noch keine Antwort erhalten.

accepi d 6 Jenner 1700 [offenbar eine Notiz des Empfängers]

\section{Kommentar}

Nachdem es zu Anfang des Briefes wieder um den Verbleib der von Weigel an den Kaiserlichen Hof in Wien gesandten astronomischen Instrumente geht, insbe- 
sondere des sogenannten Pancosmos, diskutiert Hamberger mögliche Einnahmen aus dem erhofften Kalenderprivileg. Die Abkürzung , d' (als kleines d in Kurrentschrift) steht für Pfennig. Der Kurs zwischen Pfennigen und Talern war damals im Thüringer Raum in etwa der, dass 1 Taler umgerechnet 288 Pfennigen entsprach, siehe 222. Drei Pfennige pro Kalender mit einer Stückzahl von 600000 Kalendern würden demnach 1800000 Pfennige einbringen, was durch 288 geteilt genau 6250 Taler ergibt. Die Anzahl der evangelischen Länder im damaligen Deutschland scheint mit maximal acht angesetzt zu sein, vgl. dazu die Liste der Vertreter protestantischer Territorien im Vorspann zum Conclusum vom 23. September 1699 im sogenannten „Schema Sigillantium“ [157, Seite 180]. Offenbar werden als evangelische Länder neben den beiden großen Kurfürstentümern Sachsen und Brandenburg nur größere Territorien, wie beispielsweise die Landgrafschaft Hessen-Kassel oder die Fürstentümer Braunschweig-Wolfenbüttel und Anhalt, ohne die freien Reichsstädte in Betracht gezogen. Ohne Betrug und andere Verminderungen wären also maximal 6250 Taler mit acht zu multiplizieren, was 50000 Taler als maximal erzielbaren Ertrag ausmacht. Neben Hambergers Rechnungen findet sich als Randnotiz des Empfängers der Vermerk „F. vom ex: 1d 2500“. Allem Anschein nach hat Meyer in Regensburg Hambergers Berechnungen in eine für ihn geltende Währung umgerechnet. Wenn man nämlich pro Kalender eine Abgabe von einem Pfennig ansetzt, dann würde man mit einem für das damalige Bayern gültigen Umrechnungskurs von 240 Pfennigen für 1 Gulden, siehe [212], aus 600000 Pfennigen 2500 Gulden erhalten. Die Abkürzungen für Gulden lauten ,fl.' beziehungsweise ,F.' und haben ihren Ursprung in dem Wort Florin.

Weiterhin diskutiert Hamberger das Problem, welche astronomischen Tabellen für die Festsetzung des Osterdatums heranzuziehen seien. Trotz der bereits bekannten Ungenauigkeiten der Rudolfinischen Tafeln plädiert er dafür, diese bis zum Vorliegen korrekter Daten durchgehend und einheitlich von allen verwenden zu lassen.

Die erwähnte Schrift des Erfurter Mathematikers Hiob Ludolf betrifft die auch zum jüngsten Jahrtausendwechsel 2000/2001 neu aufgelegte Streitfrage, wann ein neues Jahrtausend beginnt. Bei Hiob Ludolf lautet sie „Ob 1700. oder 1701. für das erste Jahr des zukünfftigen Seculi zu halten sey?“ 134].

Schließlich macht Hamberger einen Kommentar zu einer Zeitungsmeldung, die Finanzierung des Collegium Artis Consultorum über Einnahmen aus dem Kalender betreffend. Damit ist ein Beitrag Johannes Meyers im "Monatlichen Staats-Spiegel" von November 1699 gemeint, siehe [13, Seite 50 f.]. Der „Monatliche Staats-Spiegel“ war eine politische Monatszeitschrift, die nur wenige Wochen nach Ablauf des jeweiligen Monats erschien, für den die betreffende Ausgabe abgefasst war. Zum einen wurden Dokumente, beispielsweise des Immerwährenden Reichstages in Regensburg, veröffentlicht und zum anderen das politische Geschehen in ganz Europa kommentiert. 


\section{Denkschrift}

\section{zum Conclusum vom 10.|20. Januar 1700}

Cod. Ms. Philos. 60, Blatt 426

[vermutlich Februar 1700]

[426r] Daß zu Regenspurg d $\frac{10}{20}$ Jan. a. c. vom Hochlöb $\ell$. Corpore Evangelico gemachte conclusum, daß in Zukunfft der calculus durch alle Evange $\ell$. Lande nach denen Tabulis Rudolphinis solle eingerichtet werden, biß durch der Mathematicorum Fleiß bessere elaborirt würden, so an jener statt könnten substituirt werden, ist ganz wohl bedächtlich auch zum Ruhm der teutschen nation abgefaßet. Wofern aber dadurch der heilsame Zweck, nemlich eine durchgehend beständige conformität und Richtigkeit in denen Evange $\ell$. Calendern erhalten, und nicht ein so löb $\ell$. conclusum in denen Hauptstücken ohne einigen effect seyn sollen, will höchstnöthig scheinen daß auch unverzüglich das zu dessen Außführung hinlängliche Mittel, nemlich ein Collegium Mathematicum beliebet werde. Denn wann die darinn anbefohlene Verbesserung der Tabularum Rudolphinarum (die freylich gar nöthig ist wann der calculus Astronomicus mit der Zeit eher fehl seyn soll) würklich mit erwünschter finess vor die Hand genommen werden soll, so muß fast unumgänglich ein Collegium Mathematicum angerichtet werden, somit zusamm gesetzen Fleiß und conferirung vieler an unterschiedlichen Orthen und zu unterschiedlicher Zeit mit möglichster accuratesse angestelter, und ein ganzes seculum, oder so lang es nöthig wird erachtet werden, continuirter observationum, dieses wichtige Werk zum erwünschten effect bringen; müssen das menschliche Leben so kurz, die Arbeit so schwehr, der Hindernisse so viel, die nöthige Behutsamkeit so groß $\mathrm{u}$. hingegen der lapsus so leicht ist, daß man es auf einiges einigen Mannes Fleiß nicht so, wohl kan ankommen lassen. So ist auch der Aufwand auf richtige zum observiren gehöriger Instrumenta u. Observatoria so groß, daß nun in 100 Jahren, nemlich von den Zeiten Tychonis, auß dessen Observat. die Tabul. Rudolph. entsprungen, der über sein großes Adeliches Vermögen auch die ansehnliche Keyser $\ell$. und König $\ell$. Besoldungen darauf gewendet, sich in Teutschland niemand, als Johann Hevelius, Bürgermeister zu Danzig, der gleichfals durch große König $\ell$. pensionen dazu animirt worden, finden wollen, der sich dieser Arbeit unterzogen, ungeachtet es an guten aufgeweckten Köpfen die dem Werk gewachsen nicht fehlet.

[426v] Nicht minder wann wir in mehr erwehntes Concluso gleichfals löb $\ell$. befohlen, die OsterVollmond und übrige Festordnung nach denen Rudol- 
phinischen Tabulis sollen außgerechnet werden; Hingegen gar wenige von denen welche bißhero Calender zu verfertigen gepflogen capabel sind den calculum nach denen Tabulis richtig zu führen, so daß auch wohl in großen Landen u. Fürstenthümern nicht einer anzutreffen seyn möchte, noch wenigere wegen anderer Amtsgeschäffte Muße haben, eine solche langwürige saure Arbeit über sich zu nehmen, die allerwenigsten aber Lust dazu haben, weil die Verleger bißhero, da die meisten die Calender nur auß denen nun geenderten cyclis u. Ephemeridibus außgeschrieben, ein solch Spott Geld vor die Arbeit zu geben, gewohnt, daß man dabey unmöglich zu recht kommen kan: Dahero aber, und weil auf diese Stund noch keine Ephemerides vorhanden darnach sich Unwissende in etwan richten könnten, ja dienige, welche in solcher Arbeit, so lang es Ihnen gefället $u$. biß sie etwan heut oder morgen ein officium publicum bekommen, begriffen, selbige mit Fleiß so spat wollen drucken lassen, daß sie kein Calendermacher wird gebrauchen können; und doch auf anstehende Ostern schon der Anfang mit Druckung der Calender vors künfftige Jahr gemacht wird, gar große confusion $u$. folglich illusion der Catholischen zu befahren stehet: So will sich diesem vorzubiegen $u$. das heilsame conclusum auch in diesem Stück zu exequiren kein füglicher Mittel zeigen, als die schleunige Bestellung eines Collegii Mathematici, so den calculum richtig und beständig führe und anderen damit diene. Zu geschweigen, daß, wann der Ostervollmond auf einen Sonnabend oder dem Æquinoctio allzu nahe fället, sich casus ereignen können die schwerlich vermieden werden mag, daß nicht die Protestanten in dem Oster u. anderen Festen im ersten Fall um 8 Tag, im letzten wohl gar 4 Wochen von ein ander differiren solten, wo fernernhin männiglich vergönnet wird obschon nach einerley tabulis jedoch nach eigenem Gutdünken und ohne Direction eines Collegii so hierinn, was zu thun decidiren kan, Kalender zu machen. Welche Fehler so viel öffter kommen müssen, wann die calculanten, wie gar leicht geschehen kan, errorem calculi begehen, $u$. weil sie zu obstruirt seyn $u$. ein ander nicht können, auch nicht mit einander communiciren können. Lebe dannenhero der unterth $\ell$. Zuversicht, es werde das hochlöb $\ell$. Corpus Evangelicum, um auf einmal alles was immer mehr in Verbesserung der ZeitRechnung ferner desiderirt werden kan, zu heben u. selbige zu dessen unsterblichen Ruhm bey der Nachwelt in einen solchen Stand zu setzen daß zu ewigen Zeiten niemaln der geringste Fehl so zu verführen in menschlichen Kräfften stehet, begangen werden kan. Nichthin auch die Künste gleich wie in andern benachbarten Königreichen zu unaußsprechlichen Nutzen der Teutschen nation 
mehrers empor zu heben sich gut gefallen lassen ein Collegium Mathematicum nach dem unmaßgebigen $u$. keinem Menschen beschwehrlichen Vorschlag so unlängst zu Regenspurg gedruckt eingegeben worden, anzuordnen, welches in der ZeitRechnung das Directorium führet.

\section{Kommentar}

Nach dem Beschluss des Corpus Evangelicorum vom 23. September 1699 wurde im Januar 1700 eine präzisierte Durchführungsbestimmung die Osterfestrechnung betreffend erlassen. Während das Conclusum vom 23. September 1699 diesbezüglich lediglich festlegte, dass diese nach dem „Calculo Astronomico“, also nach astronomischer Berechnung, durchgeführt werden solle, wurde im Conclusum vom 10.|20. Januar 1700 expliziert, als astronomische Datengrundlage die Rudolfinischen Tafeln [118, zu verwenden, vgl. den Wortlaut des Conclusums im Anhang Seite 123. Die Frage, nach welchem "Calculo Astronomico" das Osterdatum bestimmt werden sollte, war unter Astronomen offenbar strittig, da Ende des siebzehnten Jahrhunderts in den Rudolfinischen Tafeln, die bei Erscheinen 1627 eine bis dahin unübertroffenen Präzision vorweisen konnten, Abweichungen vom tatsächlichen Himmelsgeschehen erkennbar wurden. Hamberger sieht in dem Gebot zur Erstellung neuer und präziserer astronomischer Tabellen die Notwendigkeit eines einheitlichen und gemeinsamen Vorgehens - im politisch zersplitterten Deutschland seiner Zeit ein um so schwierigeres Unterfangen. Zur Abstimmung einschlägiger Aktivitäten hält er ein koordinierendes Gremium für unentbehrlich und plädiert zu diesem Zweck abermals für die Einrichtung des von Weigel vorgeschlagenen Collegiums.

\section{Extract eines Fürstlichen Rescripts an den Abgesandten Fabricius vom 1. Februar 1700}

Cod. Ms. Philos. 60, Blatt 453

[453r]

d. 1 Febr: 1700

Extract des Fürst $\ell$. Rescripts an den Hn Gesandten Fabricium zu Regenspurg

Eure an uns sub dato d 25 Jan: a.c. abgelassene relation begreifft unterschiedliche puncta, darauf ihr instruirt zu seyn unterthänigst verlanget. Hierauf lassen wir vor uns und, euch unverhalten daß wir das von einigen mathematicis erstattete unvorgreifliche Bedenken wegen der Calenderverbesserung, und 
das von dem corpore Evangelico gemachte conclusam vor wohl bedächtig außgearbeitet und angeordnet finden und weil die Feststellung künfftiger richtiger $\mathrm{u}$. beständiger Außrechnung des calculi astronomici vornemlich auf ein der Sache genau erfarnes u. fleisiges Collegium Astronomicum, wozu anfänglich ein oder 2 habile subjecta auß jedem ReichsCreiße erwehlet $u$. bestellet werden könnten, beruhet; So wollet Ihr bey anderweitiger hierüber vorgehenden deliberation unsern auf obgedachtes Gutachten gerichteten Beyfall eröfnen und zugleich dahin antragen daß mehr auf die Förderung des der ganzen Evange $\ell$. Christenheit zustehenden boni publici als auf ein und des andern gewinnsüchtigen Calendermachers privatinteresse zu sehen sey. Ihr habt euch hirbey des von

[453v] unserm Mathematico zu Jena P. Hamberger an uns gehorsamst eingeschickten weitern Bedenkens und Vorschlags sub A et B zu bedienen und zu sehen ob das Calenderwesen nach demselbigen einzurichten. Und lassen wir uns gefallen was die majora zur Ergötzlichkeit vor die von P. Sturm zu Altdorf, P. Majer zu Regenspurg und jetztgenanten P. Hamberger zu Jena, wegen der Zeit hero aufgehabten und nach ferner continuirenden Mühe u. Arbeit vor gut befunden und auf die vota legen werden; massen an unsers Orths Beytrag nichts ermangeln soll.

\section{Kommentar}

Diese Abschrift einer brieflichen Instruktion des Herzogs von Sachsen-Weimar oder des Herzogs von Sachsen-Eisenach an den Abgesandten am Regensburger Reichstag Georg Philipp Fabricius, der allem Anschein nach eine Anfrage Fabricius vorausgegangen war, schickte Hamberger höchstwahrscheinlich im folgenden Brief mit. Dort wird zumindest ein derartiges ,Rescript` explizit als Anlage erwähnt.

\section{Brief vom 12. Februar 1700}

Cod. Ms. Philos. 60, Blatt $441 \& 442$

[441r]

recept. 17 febr. [offenbar eine Notiz des Empfängers]

Wohledler, Hochgeehrtister H u. Patron.

Die Beylage weiset was vor ein gutes Rescript ich an den Hn Fabricium außgewürket; Es wird ehest derg $\ell$ auch an den Hn Gothaischen Abgesandten 
ergehen, daß ich allso nicht zweifele Sie werden sich nunmehr der stabilirung des Collegii mit Nachdruck annehmen, auch wegen der Ergötzlichkeit sich der instruction gemeß erklären. Ich werde Ihnen nechstens zu dem End selbst mit einem Briefgen aufwarten. Meine 2 Bedenken deren im Rescript gedacht wird, sind von mir expresse gut verlanget. Das eine ist auf das d $\frac{10}{20}$ Jan: $\mathrm{zu}$ Regenspurg abgefaßte Conclusum gerichtet, da ich gewiesen daß zu dessen execution die Anordnung eines Collegii Mathematici höchst nöthig. In dem andren so ich schon am neuen Jahr eingegeben, hab ich gesetzet alles was ferner bey der Calender-Reformation zu bedenken komme auf diese 3 Punkt an. 1) wie der calculus Astronomicus in Richtigkeit $u$. Einigkeit zu erhalten. 2) wie der fernere Überschuß des Julianischen $\odot$ Jahrs zu vermeiden. 3) wie dem abusui astrologiæ judiciariæ zu steuern. darauf ich geantwortet, das erste könnte am leichtesten geschehen durch Anordnung eines Collegii Mathematici

[441v] dessen Nothwendig-, Nützlich- u. Leichtigkeit ich gezeiget und mich auf unser zu Regenspurg eingegebenes Bedenken bezogen. Das andere wäre nicht nöthig vor jetzo strack zu entscheiden $u$. würde sicherer seyn wo man wartete biß durch des Collegii Fleiß die tabulæ emendirt würden. das dritte könnte am leichtesten erhalten werden wann künfftig nicht männiglichen erlaubet wäre Calender zu machen $\mathrm{u}$. zu verlegen sondern jeder Herr in seinem Landes einem einzigen es auftrüge der davor stehen könnte u. müste. Ich hab nicht nöthig erachtet die copeyen bey zu legen weil wir im Hauptwerk einig und man selbige auch bey dem Hn Abgesandten leicht wird haben können. Sonsten darf ich nicht wohl hoffen daß sich meine gute Herren soweit wegen des Collegii interessiren solten daß Sie deswegen an andere Potentaten schreiben. So will es sich auch nicht schicken daß ich selbst an den Hn von Fuchs solte schreiben. Ich habe aber an den Hn D. Müller, Probst zu Magdeburg, den extract unsres Bedenkens geschickt, und gebetten weil Er bey dem Hn von Fuchs sehrwohl stehet, selbigen an Ihn zu schicken $u$. bestens zu recommendiren. Er ist mein guter Freund $u$. der mathematic besonders gewogen. Zweifele nicht er werde es thun. Gott wird Mittel zeigen daß auch dieser Stein auß dem Weg geraumet werde.

[442r] An Hn D. Schmid habe sowohl den Extract als nachmals das gedruckte exemplar geschickt. Auf jenes hat er geantwortet Er wolle die Sach aufs beste recommendiren u. was Er vor Antwort von Hoff erhalten, sofort berichten, ist aber noch nicht geschehen. Wegen der membrorum Collegii wird es sich auch geben wann nur erstlich res ipsa beliebet u. decretirt worden. Wegen 
dessen, was wegen des Wetters in unserem Bedenken gedacht worden, wird man ja fleißig vigiliren müssen, daß nicht etwan in das künfftige conclusum eine formul mit eingerücket werde, dadurch es das ansehen gewinne als ob das Wetter prognosticiren durch ein Reichsdecret probirt würde. denn sonst hetten die Astrologi gewonnen weil sie sagen: si planeta mutant aerem, mutant etiam humores corporis, et consequenter temperamenta ingenio, mores actiones inclinationes et facta hominum. Womit nebst Empfehlung Göttlicher Gnaden verharre

Jena d 12 Febr 1700

Meines hochgeehrtisten Hn u. Patrons ergebenster Diener G A Hamberger

\section{Kommentar}

Hamberger versuchte offenbar weitere Kontakte für die Bemühungen zur Einrichtung des Collegiums zu mobilisieren. Bei dem genannten Doktor Müller in Magdeburg handelt es sich um den Theologen Philipp Müller (1640-1713), der an der Universität Jena studierte und als Professor wirkte, bevor er 1680 als Probst des Klosters Unser lieben Frauen nach Magdeburg ging. Über diesen hoffte Hamberger, den einflussreichen brandenburgisch-preußischen Staatsminister Paul von Fuchs (1640-1704) für die Bemühungen um das Collegium zu gewinnen. Außerdem hatte Hamberger sich an einen Herrn Schmidt gewandt, der seine Unterstützung zusagte. Vermutlich handelt es sich dabei um Johann Andreas Schmidt in Helmstedt, der in engem Briefkontakt zu Leibniz stand.

Hamberger spricht sich zudem für die Notwendigkeit einer Verordnung gegen die Astrologie, insbesondere gegen die astrologisch begründeten Wetterprognostiken aus, und zitiert die Astrologen mit „Si planeta mutant aerem, mutant etiam humores corporis, et consequenter temperamenta ingenio mores actiones inclinationes et facta hominum." (Seite 104 Übersetzung: Wenn sich die Planeten verändern, dann wandelt sich die Luft und sogar die Flüssigkeiten des Körpers, und folglich auch die Mischung aus Talent, Wille, Handlungen, Neigungen und Taten des Menschen.) 


\section{Brief vom 1. März 1700}

Cod. Ms. Philos. 60, Blatt 443, 444, $445 \& 446$

[443r] Wohledler Vest und Hochgelahrter, Hochgeehrtister H und Patron.

Desselben geehrtes vom 7ten Febr: ist mir d 13 ejusdem wohl nebst denen Beylagen behändiget. Die rationes Collegiam suadentes sind ganz gut, u. hab ich die meisten derselben allbereit bey dem ersten Empfang des d $\frac{10}{20}$ Jan: gemachten Conclusi sowohl an meine gute Herren als auch Hn D. Schmidten überschrieben, von dem ich vorgestern Antwort erhalten, daß Er selbige allso bald an die Braunschw. Höffe übersendet u. guten effect hoffe. Vorjetzo, meinte ich, könnte efficacissime das letzte conclusum d $\frac{10}{20}$ Jan: urgirt werden, als welches sine effectu seyn wird wo kein Collegium angerichtet wird. Was ich deswegen auf guten Befehl ad Ser ${ }^{\text {mus }}$ meos gelangen lassen weiset die Beylage. Man könnte auch wohl anbringen daß die jenige welche durch eingegebene Schedas die Anordnung eines Collegii dissuadirten u. hingegen die Freylassung des calculi urgirten, dabey es ihrem eigenen Geständnis nach annehmliche (wie sie es jetzo nennten) varietäten geben würde, allem Ansehen nach theils auß Neid theils aus andren motiven es suchten dahin zu bringen daß bey erfolgter confusion man uns durch ganz Teutschland als unbedachtsame Angeber des calculi Astronomici accusiren $u$. in des gesamten Corporis Evangelici Ungnade stürzen, mithin durch dieses Kunststück das schon gemachte löb $\ell$. conclusum wider aufheben mögte. Da wir doch vor der ganzen Welt excusirt seyn würden, wo man auf Seiten des corporis Evangelici das Werk nicht außführen wolte wie unmaßgebig vorgeschlagen. Auf die monirten dubia ist gleichfals ganz wohl geantwortet. In genere wäre dabey zu notiren daß sie ganz nicht concludiren was sie sollen, daß man nemlich einen computum cycliam annehmen

[443v] müsse. Denn das Concil. Nic: hat nicht nur befohlen daß man auf einen Tag soll Ostern halten, sondern auch daß man den concursum cum Judæis vermeiden $\mathrm{u}$. zu dem End das Plenilunium genau determiniren soll. Ob man nun schon mit denen cyclis das erste erhält, so wird doch in denen andren beeden Stücken gar offt gefehlet $u$. allso nicht von etlichen sondern von der ganzen Kirch Ostern unrecht gefeyert. Wolte man aber sagen die Kirch habe Macht zu statuiren daß man cyclice rechnen soll $u$. wäre allso nachmals genug wann der computist nicht contra cyclum impingirte, so sehe ich nicht warum sowohl die Evangelici als catholici eine Reformation vorgenommen. 
Sie hetten es allso immer bey denen alten cyclis können bleiben lassen. Das 3 tium dubium ist von dem see $\ell$. Hn Weigelio in seinem Zeit Spiegel stattlich untersuchet $\mathrm{u}$. durch Setzung eines Meridiani zwischen Asiam u. Americam ein Mittel vorgeschlagen worden selbigem zu begegnen. Ich meinte aber, weil man der Juden Ostern vermeiden soll, diese aber, sie mögen in der Welt wohnen wo sie wollen sich nach dem Meridiano Hierosol: allso richten, daß wann das Plenilunium juxta Merid: Hieros: vormittag fället, sie noch selbigen Tag, wo es aber juxta eundem Merid: nachm. fället, erst folgenden Tag Ostern halten, man thäte am besten wann wir zwar in calculo Ephemeridam, wie billig u. nöthig, den Meridianum Uraniborg: behielten, aber in applicatione ad usum Reipublicæ uns gleichfalls nach dem Meridiano Hieros. richteten, weil wir dadurch nicht nur am leichten der Juden Ostern vermeiden können, sondern auch nicht zu befahren daß in Ewigkeit einige Mensch in der Welt Ostern hielten ante Plenilunium oder wann dieses auf den $\odot$ tag fället, denn von Jerusalem gegen Orient biß ins mare pacificum sind nicht 180 gradus $\mathrm{u}$. kan allso nicht geschehen wann zu Jerus. noch vormittag ist am Sonnabend, daß gegen Orient biß zum mare pacificum es schon Sonntag früh, oder $12 \mathrm{~h}$. mehr wären die aber über dem mara pacifico in America wohnen zehlen ihre Tag u. Stund nicht eher sondern langsamer als die zu Jerusalem, weil die Europaer nicht durch orient sondern durch occident dahin gereiset $u$. sich da gesetzet. Wir haben Ursach mit

[444r] dem Calenderwesen über Europam hinauß zu dencken und genau zu determinieren wann das auf einen Sonnabend gefällige Plenilunium pro Paschali zu achten oder nicht, weil auch der Moscowitter denn verbesserten Calender (so denn Corpori Evangelico nicht wenig Ehr bringt) angenommen, dessen Lande aber sich biß fast an China erstrecken. Die Canones Concilii Nicæni müssen hier einen commodam interpretationem leiden nevideantur obligare ad impossibile. Es ist mit dem Christenthum, so durch die ganze Welt ausgestreuet, eine ganz andere Sach, als mit dem Judenthum, so ehemaln nur in Palestinam eingeschlossen war. Dem Hn Römer sind wir wegen seines honetten Schreibens großen Dank schuldig. Unser see $\ell$. Vatter Weigelius hat dieses Mannes erudition generosität $\mathrm{u}$. Ihm erwiesenen vielen Wohlthaten öffters sehr gerühmet. Er stehet auch in großem Ansehen bey der Societate Parisina, $u$. werden wir seine Freundschafft wohl nützen können. Wer meinte allso man solte Ihm communi nostrum nomine Dank sagen vor contestirte affection. Auf seine quæstion wäre unmaßgeblich zu antworten: Wir wolten zwar lieber die decision dieser wichtigen Frag dem ehest aufzurich- 
tenden Collegio Mathematico überlassen, hetten auch wünschen mögen daß Er uns dißfalls seine eigene Meinung hette wissen lassen, jedoch giengen unsere vorlauffige Gedanken dahin weil die Catholici in denen 6 überschriebenen Jahren das Plenilunium Æquinoctio vicinum pro Paschali halten (wie wohl, wann nach ihrer hypothesi das æquinoctium alle Zeit auf dem 21 Martii civiliter fället, sie wenigstens ao 1704, $1761 \mathrm{u}$. 1780 solches nicht thun solten, oder doch nicht wohl werden laugnen können, daß sie ex propria hypothesi fehlen) und man wegen der unter Ihnen wohnenden Protestanten, u. gleichem wigen der Reichsgeschäffte, u. um sie etwan in Zukunfft desto leichter zu gewinnen, billig darauf zu sehen daß wir in der Festrechnung von Ihnen nicht abweichen, als wo sie in fallibiliter fehlen, daß man lieber das ÆEqui-

[444v] noctium $u$. Plenilunium verum als mediam attendiren solle, obschon nicht zu laugnen, daß jene viel schwerer als diese zu determiniren seyn, u. sich allso das Collegium u. sämt $\ell$. Mathematici in Zukunfft desto mehr anzugreifen hetten um hierinnen eine mehre Gewißheit zu finden. Die Juden lassen in allen 6 specifizirten casibus das plenilunium æquinoctio vicinum fahren $\mathrm{u}$. nehmen das folgende pro Paschali an. Bitte MhgH Professor wolle mich gleichfals großg $\ell$. wissen lassen, ob derselbe, wie auch H P. Sturm, dißfals mit mir gleicher Meinung seyen. Es verlangen viel einen casum zu wissen da unser computus von den Gregorianer ihrem abweiche, damit klar werde daß wir nicht den computum Gregorianum angenommen, als man zu Wien u. anderswo im öffentlichen Druck vorgegeben. Mann muß aber Behutsamkeit brauchen. Es werden schon solche casus genug kommen, wo die Gregorianer nicht auch eine Änderung vornehmen. Uber Hn M. Gauppens Verfahren kan ich mich nicht genug verwundern. Er ist des see $\ell$. Hn Weigelii Inguilinus, convictor, discipulus, Amicus gewesen, auch von Ihm jeder Zeit unter die künfftigen membra Collegii gezehlet worden. So hab auch ich, da vor etwa 4 Monathen wegen einer andren Ursach an Ihn schreiben müssen, des see . Mannes gegen Ihn gehegte gute intention gedacht, davor Er sich gar sehr bedankt und im geringsten nicht erwehnet daß Er animi â Collegio alieni sey, viel mehr aber eine propension dazu bezeiget, $u$. nun opponirt Er sich so heimtückisch. Gegen unsren see $\ell$. Hn Vatter hat Er einsten im Schreiben gemeldet Er hette einen sonderlichen Vortheil erdacht geschwind u. leicht Ephemerides zu calculiren. Darum H Hoffmann Ihn gebetten ihm solchen vorthel, nicht aber die Kunst selbst, zu communiciren, welches Er nun so male fide $u$. sinistre interpretirt. Ich dörffte fast noch einmal in terminis generalibus an Ihn schreiben, ob ich Ihn gewinnen könnte. H P. Sturm aber 
könnte es, als Præceptor, mit größren Nachdruck thun, bitte Ihn deswegen anzuliegen.

[445r] H Junius (so im vorigen Monath Magister worden) ist selbst autor von dem Leipziger Calender. Will Ihm ehesten berichten was zu Regenspurg an selbigem desiderirt werde, damit Er es endere, welches hoffentlich keine difficultät haben wird. Wann Er ferner candide wegen seiner Ephemeridum mit mir communiciren wird, so will ich Ihm schreiben was H Römer davon judicirt, weil Er anxie solche judicia sucht $u$. ich allso glaube Er werde es gar wohl aufnehmen. Der Leipziger Calender ist im Magdeburg $\ell$. bey 50 thlr Straf verbotten, weil im Chursäch $\ell$. gleichfals alle andren Calender prohibirt sind. Vieleicht gibt dieses ein Argument den Magdeb $\ell$. Hn Abgesandten desto eher zu gewinnen daß Er sich gleichfals die stabilirung des Collegii gefallen lasse. Denn wenn dadurch quoad Astronomica nur ein Calender unter denen Protestanten wäre, so fiele das Hauptmotivum warum Chursachsen alle andren Calender will verbotten haben $\mathrm{u}$. wird allso dieses dissidium desto leichter gehoben werden. Mein letztes vom 12 Febr: wird nebst dem extract des von Weimar an den Hn Abgesandten Fabricium abgelassenen guten Rescripts, hoffentlich wohl behändiget seyn. In gleichen terminis ist würcklich auch an den Gothaischen Hn Abgesandten rescribirt. Hoffe allso sie werden sich nun mehr die stabilirung des Collegii lassen angelegen seyn auch wegen der Ergötzlichkeit sich favorabel erklären. Beygehende Schreiben habe deswegen an sie abgehen lassen so wohl zur Danksagung daß sie so favorabel nach Hoff berichten wollen, als auch um selbigen zu animiren sich des Werks ferner eifrig anzunehmen. H Propst Müller zu Magdeburg hat mir geantwortet Er könnte mir wegen der commendation nicht dienen, die Sach müste immediate an den Churfürsten gebracht werden, welches ich aber nicht thun kan. Gott wird schon prospiciren. Ich habe Hn D. Schmit gebetten ob H Leibnitz der große correspondenz hat, was thun

[445v] könnte. Er hat mir aber nicht darauf geantwortet. In Zukunfft bitte allemal zu berichten ob und welche von meinen Schreiben zurecht kommen. Ich hab suspicion daß etliche verlohren gangen, da ich sie doch alle der geschwinden Post aufgebe. Womit nebst Empfehlung Göttlicher Gnaden verharre.

Meines hochgeehrtisten Hn u. Patrons ergebenster Diener 
P.S. Ich habe die von Hn Römer überschriebene casus vom Hn Hoffmann geschwind überlauffen lassen $u$. deswegen die Antwort noch ein paar Tag aufgeschoben. Wie die beyliegende schedula weiset so hat $\mathrm{H}$ Hoffmann fast überall einen Tag weniger als $\mathrm{H}$ Römer, welches daher kommen muß daß $\mathrm{H}$ Römer dies currentes $\mathrm{u}$. hingegen $\mathrm{H}$ Hoffmann completos angesetzt. Nur weiß ich nicht warum sie in den 3 ersten casibus zusammen treffen. Find sich die Ursach noch so will es mit nechster Post berichten. Heut ist H P. Poßner gestorben, $u$. wird Ihm wohl sein Sohn succediren.

Jena d 1 Mertz 1700

[446r] [offenbar Notizen des Empfängers]

1) $\mathrm{V}$ zu bitten um die dubia, ob sie nicht schriftlich zu haben

2) Acht zu haben, wann er sich wohl exponirt hat, ob solche ex tempore zu beantworten sind, oder ob dilation zu bitten und schriftliche Antwort zu praemittiren

3) Die gedruckte Schrift zu praemittiren oder viel mehr eine schriftliche Erörterung

4) Weils important ist, wer auß dem Fall wans schneler kommt, zu bitten, diß vorher mögl mit den andern communicirt wird

\section{Kommentar}

Johannes Gaupp (1667-1738) studierte ab 1685 in Jena und 1690 in Altdorf. Bevor er im Jahr 1693 als Pfarrer in seinen Geburtsort Lindau am Bodensee berufen wurde, unternahm er Studienreisen nach Amsterdam, London und Oxford. Während seines Aufenthaltes in England in den Jahren 1691 und 1692 diente er als Kontaktperson Weigels zur Londoner Royal Society, das heißt über ihn erfolgte Weigels Korrespondenz mit der königlichen Akademie. Nach Publikationen über Sonnenuhren, vgl. [50, 51, 52, und über die Sonnenfinsternis vom 3. Mai 1715 [53] veröffentlichte Gaupp 1724 eine Schrift, in welcher er anlässlich der differierenden Ostertermine für Protestanten und Katholiken im Jahr 1724 ausführlich Grundlagen und Charakteristika des Verbesserten Kalenders schilderte [54. Tatsächlich feierte die evangelische Kirche 1724 eine Woche früher Ostern als die katholische, was in konfessionell gemischten Regionen zu Problemen und Streitigkeiten führte. Neben der Darstellung des Astronomischen Calculus zur Bestimmung des Ostertermins gemäß der Anforderung durch das Konzil von Nicäa diskutierte Gaupp in 
dieser Schrift ausführlich die Konstellationen für die Jahre 1724, 1744, 1778 und 1798, das heißt für alle Fälle, in denen es im achtzehnten Jahrhundert noch zu Osterparadoxien kommen sollte.

Der dänische Astronom und Mathematiker Ole Christensen Rømer (1644-1710) gehörte zu den protestantischen Gelehrten, die sich für die Kalenderreform einsetzten. Er war ab 1681 Professor für Mathematik an der Universität Kopenhagen sowie als königlicher Astronom Direktor der Sternwarte in Kopenhagen. Rømer gilt als wissenschaftlicher Kopf hinter der Kalenderreform von 1700 für Dänemark. Im Januar 1696 wandte er sich mit der Bitte an den dänischen König Christian V., die Bemühungen um die Kalenderreform zu unterstützen [105, Seite 4 f.]. Im Juni 1696 traf Rømer sich mit Erhard Weigel nach dessen Ankunft in Kopenhagen. Christian V. stand den Reformbestrebungen zur Vereinheitlichung der Zeitrechnung sehr aufgeschlossen gegenüber und sekundierte das Unternehmen beispielsweise durch sein Empfehlungsschreiben an den schwedischen König, mit welchem Erhard Weigel für seine Weiterreise nach Schweden ausgestattet worden war, siehe auch Seite62, Außerdem beteiligte Rømer sich im Jahr 1699 intensiv an der Korrespondenz sowie der publizistischen Debatte um die Kalenderreform, vgl. beispielsweise 105, Seite 22, Seite 26 f., Seite $81 \mathrm{ff}$. oder Seite $144 \mathrm{ff}$.]. Von Johannes Meyer gibt es ein auf den 11. Januar 1700 datiertes Sendschreiben in Sachen Kalenderreform an Rømer [105. Seiten 106-109], welches mit Datum vom 27. Januar 1700 von Rømer beantwortet worden war [105, Seiten 120-122]. Möglicherweise bezieht sich Hamberger auf diese Schrift, wenn er meint, dass man Rømer „wegen seines honetten Schreibens großen Dank schuldig“ ist. Dänemark hatte die Kalenderreform übrigens per königlichem Dekret vom 28. November 1699 angenommen und Ende Februar 1700 zeitgleich zu den Protestanten in Deutschland realisiert [154, Seite 243]. Zur Kalendersache stand auch Leibniz mit Rømer in einem regen schriftlichen Meinungsaustausch, siehe [105, Seiten 134-143].

Im Postskriptum meldet Hamberger den Tod Kaspar Posners (1626-1700). Dieser war seit 1656 Professor der Physik in Jena und verstarb am 1. März 1700. Die Nachfolge auf dem Lehrstuhl für Physik wurde tatsächlich von dessen Sohn Johann Kaspar Posner (1673-1718) angetreten [119, Seite $71 \mathrm{ff}$.$] .$

\section{Brief vom 8. März 1700}

Cod. Ms. Philos. 60, Blatt $427 \& 428$

[427r] Wohledler Vest und Hochgelahrter Insonders hochgeehrter H u. Patron Desselben geehrter so vor 6, 4 und 2 Wochen an mich abgelassen worden hab vor 8 und 14 Tagen durch die geschwinde über Gera gehende Leipziger 
Post ausführlich beantwortet; hoffe meine Schreiben sollen indessen wohl behändiget seyn. An Hn M. Erasmi kommt hirbey gleichfals eine resolution, welche schleunig bestellen zu lassen bitte. Hn G.Rath Leibnitz Schreiben ist ganz gut vor uns, und kan dessen monitam (so er besser als wir geben können) zum stattlichen argument dienen, die Nothwendigkeit eines Collegii vorstellig zu machen. Denn weil die Verfertigung neuer Tabularum viele Zeit erfordert, und billig, wo sich indessen, besondere errores Rudolfinarum hervor thun, daß selbige interim vermieden $u$. corrigirt werden, solches aber ohnmöglich eines jeden privati caprice überlassen werden darf, so muß ein Collegium mathematicum angeordnet werden. Womit nebst Empfehlung Göttlicher Gnaden verharre

Meines hochgeehrtisten Hn u. Patrons ergebenster Diener Jena d 8 Mertz 1700

G A Hamberger [428v] Siegel Hambergers (schwarzer Siegellack)
A Monsieur
Monsieur Jean Mejer
Professeur és Mathematiques tres_celebre
á Regenbourg

\section{Kommentar}

Bei den „vor 8 und 14 Tagen“ abgesandten ausführlichen Briefen Hambergers an Meyer handelt es sich allem Anschein nach um die Briefe vom 12. Februar 1700 sowie vom 1. März 1700. Beide Briefe sind im vorliegenden Konvolut vorhanden, haben also offenbar ihren Empfänger erreicht und werden in dieser Edition wiedergegeben, der Brief vom 12. Februar 1700 ab Seite 102 und der Brief vom 1. März $1700 \mathrm{ab}$ Seite 105. Man beachte, dass der Brief vom 12. Februar 1700 am 8. März 1700 genau 14 Tage zurücklag, da aufgrund der Kalenderreform die Tage vom 19. bis 29. Februar 1700 ausgelassen wurden.

Das Schreiben von Gottfried Wilhelm Leibniz, auf welches in diesem Brief Bezug genommen wird, genau zu identifizieren, ist nicht einfach. In seinem Buch „Leibniz und seine Akademie" führt Hans-Stephan Brather aus, siehe [25, Seite 39 f.]:

Leibniz hatte sich bis zur Jahreswende 1699/1700 „wenig mit den astronomisch-chronologischen Hintergründen der Kalenderarbeit befaßt". Etwa seit Januar 1700 entwickelte er plötzlich ein intensives 
Interesse an diesen Fragen. Er machte sich präzise Auszüge aus den einschlägigen Berichten des kurhannoverschen Gesandten am Regensburger Reichstag, verdichtete seine eigene Auffassung in einem Promemoria für die Geheimen Räte in Hannover und nahm einschlägige Korrespondenzen auf.

Das genannte „Promemoria für die Geheimen Räte in Hannover" stammt von Ende Januar 1700 und lässt Leibniz' Auffassungen zum Thema Kalenderreform zu diesem Zeitpunkt erkennen, siehe [131, Seite $17 \mathrm{ff.}$.]. Möglicherweise meint Hamberger genau dieses Memorandum, da Leibniz es auf Ersuchen der Geheimen Räte und bei Kenntnis der aktuellen Diskussion, die ihm kommuniziert wurde, als Gutachten in der Kalendersache abfasste. Nach dem Beschluss des Corpus Evangelicorum vom 23. September 1699 zur Kalenderreform nannte Leibniz darin drei noch zu klärende Fragen. Die erste Frage war die nach dem Ob und Wie des Collegiums. Interessant ist, dass Leibniz hier auch bereits die Bezeichnung "Collegium Mathematicum“ übernommen hatte. Er bezeichnete das Collegium als „eine Löbliche Sach, welche auf alle weise zu befördern, wenn sie nur wohl gefaßet wird“. Leibniz nahm weiter zur Kenntnis, dass das Collegium bereits durch den Kaiser bewilligt worden war, beanstandete jedoch gleichzeitig, dass man , alhier biß dato keine zulängliche Notitiam erlanget" hatte. Die zweite Frage, die Leibniz ansprach, war die nach den astronomisch genauen Daten zur Berechnung des Osterdatums. Nach der Feststellung, „daß sie zu zeiten in etwas streitig“, sprach sich auch Leibniz dafür aus, den Rudolfinischen Tafeln zu folgen „biß andere Tabulae von denen Evangelischen Ständen angenommen" sind. Die Erstellung neuer astronomischer Tabellenwerke benannte er danach ebenfalls ausdrücklich als Aufgabe des zu etablierenden Collegiums. Drittens sah Leibniz ,auch noch einige andere Puncta zu regulieren“, für die er als Beispiel das Gebot bezüglich des jüdischen Passahfestes nannte. Leibniz schloss sein Memorandum mit den Worten „So wäre auch in übrigen wegen Censur der Calender und ander Umbstände ein gewißes concert unter den Evangelischen nicht undienlich, zumahl aber mit vortrefflichen Astronomis, mehr als bißher geschehen seyn mag, zu communiciren nöthig." Alles in Allem müssen sich die Befürworter des Collegiums durch diese Stellungnahme Leibniz' in ihren Argumenten vollauf bestätigt gesehen haben.

Bis März 1700 hatte Leibniz ebenfalls seine Pläne zur Gründung der Berliner Sozietät der Wissenschaften intensiv vorangebracht. Die Konzipierung der Berliner Akademie erfolgte in enger Zusammenarbeit mit dem Berliner Hofprediger Daniel Ernst Jablonski [25]. Auch wenn Leibniz in dem oben zitierten Memorandum geschrieben hat, „keine zulängliche Notitiam“ von den Aktivitäten Erhard Weigels zur Gründung des Collegium Artis Consultorum erhalten zu haben, so müsste er nach der Quellenlage eigentlich Kenntnis davon gehabt haben. Zumindest besagt dies ein Brief von Leibniz an Johann Andreas Schmidt vom 19. Mai 1699, zwei Monate nach Weigels Tod [130, Seite 211 f.]. Leibniz bat Schmidt, der sich im Aufbruch 
zu einer Reise nach Jena befand, in diesem Brief gleich zu Beginn, sorgfältig den Nachlass Weigels zu untersuchen, ob nicht dessen Pläne gefunden werden können, auch wenn diese noch unvollkommen sein mögen. Leibniz hat in dem genannten Brief weiter geschrieben „Collegio Mathematicorum Caesarea autoritate instituendo", das heißt er muss auch von dem kaiserlichen Dekret für das Collegium gewusst haben. Am Ende eines Briefes vom 26. Mai 1699 an Schmidt betonte Leibniz noch einmal sein Interesse an Weigels Plänen für das Collegium und meinte, das Ganze sei eine Angelegenheit von öffentlichem Interesse [130, Seite 242]. Schmidt hatte in Jena diesbezüglich allerdings keinen Erfolg. Nach seiner Rückkehr nach Helmstedt teilte er Leibniz am 29. Juni 1699 mit, dass er bezüglich des Collegiums nicht mehr gefunden habe, als das was bereits darüber publiziert worden ist. Außerdem berichtete Schmidt, dass sich in Jena bereits Weigels Nachfolger Hamberger und in Regensburg Meyer weiter um die Kalenderangelegenheit kümmerten. Der Erfolg werde sich in den nächsten Monaten zeigen. Schmidt konnte Leibniz außerdem darüber informieren, dass das Collegium mit dem Kalender zu tun haben soll und dass in Nürnberg bereits eine Liste mit den geplanten Mitgliedern des Collegiums veröffentlicht worden ist, auf welcher sowohl Leibniz als auch Schmidt („meam tenuitatem" - meine Wenigkeit) genannt werden [130, Seite 310 f.].

\section{Brief vom 1. Juni 1700}

\section{Cod. Ms. Philos. 60, Blatt $431 \& 432$}

[431r] Wohledler, Hochgeehrtister H u. Patron.

Die Beylage, so ich gestern gedruckt von Berlin erhalten, zeiget daß das vorseyende Collegium mathematicum daselbst einen beynache tödlichen Stich bekommen. Denn obwohl des Churfürsten Entschließung sehr generös ist, daß er nicht, wie anderswo geschehen, einigen 100 Thaler wegen, allen profit ein oder andern gewinnsüchtigen Buchführer zuwendet, sondern unsers see $\ell$. Hn Vatters Vorschlag gemeß die mathesin mit ihrer eigenen Arbeit dotirt; so befahre ich mich doch gänzlich, der Churfürst werde nun zu dem universal Collegio mathematico, wie es von uns vorgeschlagen worden, nichts contribuiren, dadurch aber selbigem wenigstens der 4te Theil ihrer intraden entgehen. Jedoch weil dieses particular Collegium so viel besser floriren kan, wann ein universal aufgerichtet werd; denen Churfürst $\ell$. mathematicis auch sowenig an ihren intraden, als andern, so wegen des Calenders privilegirt sind, entgehet, ja selbige viel mehr den Überschuß nach proportion mit zugewießen haben, so will ich doch noch hoffen, daß der Churfürst auch zum universal 
Collegio seinen quotam geben solle, wann es nur einmal Ernst wird u. sich die Stände zu dessen stabilirung entschließen. Ich gedächte auch auf solchen Fall wohl noch ein recommendationschreiben von meinen guten Herren dieser Sach wegen außzuwürken.

[431v] Es sind noch zur Zeit keine membra solchen Collegii angenommen außer Hn Kirchen, der allbereit mit Weib und Kind sich dahin begeben, sonder Zweifel auß Verdruß weil Ihm Hn M. Junius die Calenderarbeit in Leipzig weggenommen, überdieß auch seine Nürnberg $\ell$. Calender durch das Fritschische Privilegium sehr gefeiert worden, da Er sonst dem Vernehmen nach jährlich von seinem Calendermachen biß 350 thle zu fehlen gehabt. $\mathrm{H}$ P. Frank zu Halle hat Ihm sogleiches dazu geholffen. H Leibnitz ist auch nach Berlin beruffen $u$. wird allbereit daselbst angelanget seyn, glaube aber mehr die Leges $u$. Einrichtung des Collegii zu formiren, als daß Er beständig daselbst bleiben solte. Von Hn M. Junio habe gestern auch Brief erhalten, darinn Er versichert, daß Er auf der Messe mit 3 hohen Churf $\ell$. Räthen wegen des Collegii geredet $\mathrm{u}$. sie sehr propensos dazu gefunden, auch Versicherung erhalten daß deswegen fort nach Regenspurg von Dreßden solle rescribirt werden. Werde morgen wider antworten u. bitten daß Er die resolution beschleunigen möge wo Er kan. Nun wird man müssen darauf dringen, daß es mit Außzahlung des Honorarii ernst werde, wir dörfften sonst auch darum kommen. Vor das jüngst überschickte gedruckte monitorium in puncto Collegii sage dienst $\ell$. dank. Gott helffe daß es den gewünschten effect haben möge. So viel auß MfgHn letzten verstanden, hat H M. Erasmi wider an meinen Hn SchwiegerVatter geschrieben, weil dieser aber in seinem vorgestrigen nichts davon wissen will und sich bekümmert erzeiget, daß $\mathrm{H} \mathrm{M}$. Erasmi wegen des empfangenen Wechsels nicht antwortet, so möchte wohl wissen wie die Sachen stehen. H D. Schmid

[432r] von Helmstett ist hier. Habe aber noch nicht mit Ihm reden können. So viel von andren vernehme will Er von dem Collegio zu Berlin nichts wissen, so auch wundern solte da Er doch seinem Angeben nach mit Hn Leibnitz in starker correspondenz stehet. Ich werde morgen oder heute noch suchen mit Ihm zu sprechen, und wann ich was von Ihm erfahre so berichtens würdig, solches bey nechsten Posttag überschreiben. Womit nebst Empfehlung Göttlicher Gnaden verharre.

Jena

Meines hochgeehrtisten Hn u. Patrons

Raptim d 1 Juni 1700 ergebenster Diener G A Hamberger 


\section{Kommentar}

Johann Andreas Schmidt, Weigelschüler und seit 1695 Professor an der Universität in Helmstedt, stand, wie schon auf Seite 104 angemerkt, in engem Briefkontakt mit Leibniz. Leibniz ließ sich von Schmidt ausführlich über die Aktivitäten des Trios Hamberger, Meyer, Sturm zur Kalenderreform und zur Einrichtung des Collegiums Artis Consultorum informieren. Wie in [49] dargestellt, ist diese Korrespondenz sehr asymmetrisch und es ist durchaus denkbar, dass Schmidt Anfang Juni tatsächlich noch keine Kenntnis von Leibniz' Akademieplänen hatte, obwohl diese in ihrer Realisierung bereits weit fortgeschritten waren [25. Im Kontext der aktuellen Entwicklungen in der Kalendersache konnte Leibniz sich bei Schmidt auch über personelle und inhaltliche Angelegenheiten auf den neuesten Stand bringen lassen, ohne seine Pläne ihm gegenüber offenbaren zu müssen. So tauchten bereits am 28. Dezember 1699 die Namen von Kirch und Eimmart in einem Brief Schmidts an Leibniz auf [131, Seite 221] und Leibniz nannte diese beiden dann in seinem Brief vom 26. März 1700 an den Hofprediger Daniel Ernst Jablonski im Zusammenhang mit seinen Akademieplänen als mögliche Kandidaten für die Position des Astronomen am Observatorium der neuen Akademie [25, Seite 70].

In seinem Brief an Jablonski vom 12. März 1700 erwähnt Leibniz seinen ,Kalendereinfall', vgl. [25, Seite 43]:

Höre auch gern, daß mein Einfall wegen des Calenders ingreß gefunden, und Gelegenheit gegeben, die ehmahligen Gedancken von einer Churfürstl. Societät, dadurch gründliche Wissenschaften und gemein nützliche Künste zu verbessern, wieder vorzunehmen.

Gemeint ist damit Leibniz' Idee zur Finanzierung der Berliner Akademie, wonach die geplante Akademie ihre Finanzierung über ein Monopol auf die Herausgabe und den Verkauf von Kalendern für das Kurfürstentum Brandenburg selbst aufbringen sollte.

Zur Klärung der Frage, wieviel Johann Andreas Schmidt tatsächlich von Leibniz' Aktivitäten zur Gründung der Berliner Akademie wusste, wäre eine gesonderte Analyse seines Briefwechsels mit Leibniz notwendig. In einem Brief an Schmidt vom 30. März 1700 bleibt Leibniz nämlich noch recht vage. Darin heißt es, vgl. [131, Seite 498]:

Serenissimus et Potentissimus Elector Brandeburgicus decrevit condere Observatorium, nescio an non res Calendaria contulerit. (Übersetzung: Der mächtige Kurfürst von Brandenburg hat beschlossen, ein Observatorium zu gründen. Ich weiß nicht, ob nicht die Angelegenheit um den Kalender dazu beigetragen hat.) 
Leibniz hielt sich ab dem 10. Mai 1700 zur Konstituierung der Akademie in Berlin auf [25, Seite 83]. Kirch kam bereits am 19. April 1700 für wenige Tage nach Berlin und zog Mitte Juni endgültig um [94, Band 1, Seite LXxxir]. Noch am Tage von Leibniz' Ankunft, also am 10. Mai 1700, erließ der Kurfürst von Brandenburg das Kalenderedikt, welches der neuen Akademie das Kalendermonopol für Brandenburg erteilte, siehe [25, Seiten $83 \mathrm{f}$. und $233 \mathrm{f}$.] sowie zum Wortlaut beispielsweise [15, Seiten 56-63] oder [220. Gottfried Kirch hatte seit 1678 bei der Nürnberger Verlegerfamilie Endter über mehrere Jahre hinweg verschiedenste Kalender (Nürnberger Gerichts-Calender, Schreib-Calender, Christen- Jüden- und Türcken-Kalender) herausgegeben. Nach Studienaufenthalten in Danzig bei Johannes Hevelius und in Königsberg lebte er von 1676 an in Leipzig. Wegen antipietistischer Anfeindungen ging er 1692 in seine Geburtsstadt Guben zurück [94, Band 1, Seite Lxxxi]. Als Pietist war Kirch eng mit dem Hauptvertreter des Pietismus, August Hermann Francke (1663-1727) befreundet, der 1698 in Halle die bis heute bestehenden Franckeschen Stiftungen begründete, siehe [94, Band 3, Seite 813].

In diesem Kontext scheint vielleicht erwähnenswert, dass noch im Mai $1700 \mathrm{im}$ „Monatlichen Staats-Spiegel" ein ausführlicher Text mit „Gedancken über die Nothwendigkeit des Collegii Mathematici“ veröffentlicht worden ist, der mit „Unterthänigste Knechte Liewe Willems Graf und de Voss" und Datum vom 16. März 1700 in Amsterdam unterzeichnet wurde, siehe [11, Seiten 48-64]. Zumindest der erste Unterzeichner ließ sich zweifelsfrei als der Astronom Lieuwe Willemsz Graaf (1652-1704) identifizieren, vgl. [216].

\section{Brief vom 12. Juni 1700}

Cod. Ms. Philos. 60, Blatt $429 \& 430$

[429r] Wohledler, großg $\ell$ hochgeehrtister $\mathrm{H}$ und Patron

Mein letztes darinn von dem zu Berlin aufgerichteten Collegio Mathematico part gegeben, wird hoffentlich wohl behändiget seyn. Inzwischen habe mit Hn D. Schmidten geredet, der mir gesagt daß H Leibnitz zwar gegen Ihn etwas von dem vorseyenden Collegio Scientiarum zu Berlin gedacht, aber nicht dabey erwehnet daß es mit dem Calender etwas würde zu thun bekommen. Ich bathe Ihn, weil unser Zweck dem Berlinischen nicht contrair, Ihnen auch dadurch an ihren intraden kein Heller entgieng sondern selbige vielmehr vermehret würden, zumaln wann einige von Ihnen auch membra in dem Collegio Universali würden, nicht minder sie ihren Scopum, nemlich die Verbesserung der Tabularum und aufnehmen der Künste, als dann erst recht erreichen 
würden, wann in andern Orthen Teutschlandes nach gleichem Zweck gearbeitet, und vertrauliche communication zwischen sämt $\ell$ membris angestellet würde, es durch Hn Leibnitzen als Directorem in die Wege zu richten daß man in Berlin dem Collegio nicht abstehen, sondern ehestens deswegen angenehme resolution nach Regenspurg ergehen; welches H D Schmid zu thun sancte versprochen. Ich fürchte sonst H Kirch, der unserm Collegio niemaln recht gut gewesen, möchte uns einen Verdruß machen.

[429v] H M. Junius ist diese Woche auch hier gewesen, um sich wegen seiner Ephemeridam mit mir zu bereden. Unser Schluß gieng dahin, daß Er erstlich den calculum durchgängig nach denen Tabulis Rudolphinis, befohlenermassen einführen solte, nachmals will Er hinten, gleichsam appendicis loco eben diesen calculum durch die Ricciolianas, Philolaicas, Flamstedii, de La Hire et Cassini - welche beede letzte Ihm viele subsidia gesetzt - Tabulas völlig durchführen, $u$. in der præfation erwehnen, weil vom hochlob $\ell$. Corpore Evangelico befohlenen worden, durch observationes die Tabulas Rudolphinas zu verbessern, so hette Er um die Hhn Observatores einer Arbeit zu überheben und daß man desto leichter sehen könne, wohin man in der Verbesserung sein Absehen richten müsste auch zeigen wollen, wie sich die phenomena nach anderen Tabulis zeigen solten, zur Prob, und um zu sehen welche etwan dem Himmel näher kämen. Ich hab Ihm gerathen anfangs nur ein paar Bogen auf solche Art abzudrucken und sie nach Regenspurg zur Censur denen Hhn Gesandten zu schicken, ob selbige allso anständig wären. Er hatt auch mit Hn Hoffmann geredet u. hab ich gesuchet ob Er etwan dem Hn Hoffmann ein Stück der Arbeit lassen wolten. Er will selbige aber lieber allein haben $\mathrm{u}$. sagt, man könne hernach seinen calculum mit $\mathrm{Hn}$ Hoffmanns seinem conferiren, um desto sicherer wegen eines erroris calculi zu seyn. Darneben gedachte Er es wären Ihm von Dreßden 2 Schemate eines zu Regenspurg gedruckte Calenders zu kommen, sich darnach zu achten. Im einen stünden die Feste H. 3. König, Lichtmeß, Fastnacht, Fronleichnam; im andren aber stünde Offenbahrung, Reinig. Mariæ, Fastnacht und Fronleichnam wä-

[430r] re gar außgelassen, dahero Er zu wissen verlangt wem Er hierinn folgen solle. Weil ich aber selbst nicht weiß ob u. was dißfals von ein Decretum abgefasset worden, so bitte mich dißfalls zu informiren, und mir das richtige Schema, ingleichem einen recht abgefaßten Gregorianischen e.o. den Wienerischen Calender auf dieses oder zukünftiges Jahr mit ehester Gelegenheit zu schicken, zumaln es das Ansehen gewinnet als wolten meine gute Herren 
mir die interims Vertretigung der Calender in ihren Landen anvertrauen, biß das Collegium resolvirt wird. Womit nebst Empfehlung Göttlicher Gnaden verharre

Meines Hochgeehrten Hn Professoris u. Patrons ergebenster Diener G A Hamberger

Jena d 12 Junii 1700

Mein H SchwiegerVatter in Altdorf ist noch immer in Sorgen weil H M. Erasmi wegen des emphangenen Wechsel nichts rescribirt. Hat MfgH einige Nachricht von Ihm so bitte solche Ihm oder mir fordersamt zu communiciren. Obgedachtes Calenders schema bitte mit nechster Post zu senden.
A Monsieur
Monsieur Jean Majer
Mathematicien tres celebre
Franco Nurnberg
á Regensbourg

\section{Kommentar}

Der Brief vom 12.6.1700 schließt die vorliegende Sammlung der im Göttinger Cod. Ms. Philos. 60 vorhandenen Briefe Hambergers ab. Man beachte, dass dieser Brief der einzige der Briefe mit erhaltenem Siegel in dieser Sammlung ist, der mit rotem Siegellack gesiegelt wurde. Die Trauerzeit nach dem Tode Erhard Weigels scheint nun abgeschlossen. Die lange Trauerzeit erklärt sich daraus, dass die Trauerzeit über Eltern allgemein länger war, als die über andere Angehörige. Gemeinhin trauerten Kinder um ihre Eltern ein Jahr lang.

Anfangs geht es in diesem Brief wieder um die Aktivitäten Leibniz' zur Gründung der Berliner Akademie der Wissenschaften. Inzwischen hat Hamberger offenbar mit Johann Andreas Schmidt gesprochen und erstattet nun, wie im letzten Brief angekündigt, von diesem Gespräch Bericht an Johannes Meyer. Es wird betont, dass keine Konkurrenz zu dem von Weigel konzipierten überregionalen Collegium bestünde und dass beide Institutionen eher noch einander in gewisser Weise förderlich sein könnten. Hamberger zeigt sich jedoch überrascht darüber, dass die Berliner Akademie sich aus einem Kalendermonopol (für Brandenburg) finanzieren sollte. Dieser Aspekt schien Schmidt, der Leibniz selbst ausführlich über die Entwicklungen in Regensburg bezüglich der Kalenderreform auf dem Laufenden hielt, nicht 
klar gewesen zu sein. In einem Brief an Leibniz hat Schmidt am 3. Juli 1700 berichtet, dass das ,Triumviri“ noch auf eine Partnerschaft hofft, von der beide Seiten gewinnen können: „Triumviri illi, qui collegium imperiale adhuc urgent aliquod ex societate sperant emolumentum." siehe [131, Seite 743].

Bekanntlich konnte das Collegium Artis Consultorum nach der Gründung der Berliner Akademie tatsächlich nicht mehr etabliert werden. Mit der Veröffentlichung des kurbrandenburgischen Kalenderprivilegs im „Monatlichen Staats-Spiegel" von Juli 1700, siehe [15, Seiten 56-63] und [220], war das Thema zumindest in dieser verbreiteten politischen Monatszeitschrift abgeschlossen. Die Bekanntgabe des brandenburgischen Privilegs wurde hier lediglich noch von dem folgenden anonymen Kommentar begleitet, siehe [15, Seite 63]:

Mit dem gleichmässigen gemeinsamen Vorhaben des Evangelischen Corporis stehet es noch in weitem Felde, und so Löbl. auch die vorgemeldete Chur-Brandenburgische Verordnung an sich ist, so sehr stehet doch zu besorgen, daß ... dadurch ... das allgemeine Reichs-collegium ... stecken bliebe ...

Am Ende dieses letzten Briefes werden inhaltliche Fragen behandelt, die Hamberger mit Ulrich Junius zur Herausgabe von dessen Ephemeriden besprochen hat. Es wurde verabredet, dass Junius sich grundsätzlich nach den Rudolfinischen Tafeln richten und die Daten, welche auf den Tabellen anderer Astronomen basieren, im Anschluss ergänzen sollte. Danach ist Junius im ersten Jahrgang seiner Ephemeriden, die für das Jahr 1701 erschienen sind, tatsächlich verfahren und gab darin zunächst die Daten an, welche auf den Rudolfinischen Tafeln Johannes Keplers basieren. Im Anschluss daran führte er weitere astronomische Tabellen aus, bei denen er sich der Werke von Johannes Hevelius, Giovanni Domenico Cassini, Philippe de La Hire [127, Johann Philipp Wurzelbauer und Gottfried Kirch bediente. Ab 1702 nahm er beispielsweise noch die Tabellen von Vincent Wing und Ismael Boulliau [23] sowie 1703 die von Giovanni Battista Riccioli, Flaminio Mezzavacca und John Wing hinzu. Am Ende der Ephemeriden für das Jahr 1702 druckt Junius zudem die Epistel „Epistola ... de Parallaxi Orbis annui telluris observatâ " von John Flamsteed an John Wallis (1616-1703), datiert vom 20. Dezember 1698, mit ab, während er am Schluss der 1703er Ephemeriden noch Betrachtungen Cassinis zu dem Flamsteed'schen Sendschreiben an Wallis wiedergibt: „Reflexions sur une lettre ... “. Mehr als die drei Jahrgänge von 1701 bis 1703 hat Junius seine Ephemeriden allem Anschein nach nicht herausgegeben [114].

Leibniz hatte offenbar erwartet, dass Junius seine Ephemeriden der in Berlin neu gegründeten Akademie widmet. Auf einer Agendenliste Leibniz' von Juli 1700 erscheint nämlich unter Punkt (40) die Notiz „H. Junii dedication seiner Ephemeridum so er an die Societät thun will“, zitiert nach [25, Seite 119]. Junius hatte seinen Ephemeriden jedoch eine Widmung an Wolfgang Dietrich von Beichlingen (1665- 
1725) vorangestellt, der zu dieser Zeit Staatsminister des sächsischen Kurfürsten in Dresden war, vgl. 25] und siehe [114]. Gottfried Kirch setzt sich in einem Brief vom 25. Oktober 1703 an Ole Christensen Rømer ausführlich mit Junius Ephemeriden auseinander, siehe dazu die kommentierte Edition des Briefes in [92. Zur zeitlichen Einordnung sei an dieser Stelle nochmals daran erinnert, dass die enge Freundschaft zwischen Ulrich Junius und Gottfried Kirch im Jahr 1700 bereits zerbrochen war, vgl. Seite 92 . Kirch hatte Anfang Dezember 1699 seinen letzten Brief an Junius geschrieben, Brief Nr. 708 [94, Band 2, Seite $369 \mathrm{ff}$.$] , Junius seinerseits$ dann noch vier Briefe an Kirch, alle vier im Dezember 1699, Briefe Nr. 710, 711, 712 und 713, 94, Band 2, Seiten 374-384]. In seinem Brief vom 23. Dezember 1699 hatte Junius noch um Verzeihung wegen der unautorisierten Veröffentlichung von Kirchs Beobachtungsergebnissen gebeten: „Solte dem H $\ell$ GeVatter die publication Seiner Observation unangenehm fallen, so bitte ich nochmahlen um verzeihung, es solle nimmermehr geschehen." Brief Nr. 712 [94, Band 2, Seite 380].

Weitere Auskünfte über die Beziehung zwischen Hamberger und Junius könnten Briefe geben, die Hamberger und Junius zwischen März 1698 und Oktober 1700 gewechselt haben und die an der Universitätsbibliothek Leipzig aufbewahrt werden, vgl. [33, Seite 148, Fußnote 95].

$* * *$

Weigels Ideen von einem Collegium Artis Consultorum und dessen Finanzierung über ein Kalenderprivileg fanden mit der Akademiegründung in Berlin durch seinen Schüler Leibniz eine lokale Realisierung. Das ursprüngliche Projekt erwies sich als eine zu dieser Zeit der politischen Zersplitterung Deutschlands unerreichbare Vision. 


\section{3 \\ Ergänzende historische Veröffentlichungen}

In diesem Anhang werden vier historische bereits publizierte Quellen abgedruckt, denen im Kontext dieser Briefedition besondere inhaltliche Bedeutung zukommt. Dies sind zum einen die beiden Beschlüsse des Corpus Evangelicorum der vereinigten evangelischen Reichsstände Deutschlands zur Kalenderreform von 1700, das heißt, das Conclusum vom 23. September 1699 und das Conclusum vom 10.|20. Januar 1700. Zum anderen wurden zwei Texte aufgenommen, an denen Georg Albrecht Hamberger als Mitautor beteiligt war beziehungsweise als Autor wirkte. Dabei handelt es sich um das "Unvorgreiffliche Bedencken“, welches Hamberger, Meyer und Sturm $\mathrm{zu}$ Kalenderreform und Collegium herausgegeben hatten, sowie ein Beitrag Hambergers zum Unterschied zwischen dem Verbesserten und dem Gregorianischen Kalender. 


\section{Conclusum vom 23. September 1699}

Im Wortlaut des Conclusums vom 23. September 1699, also des Beschlusses des Corpus Evangelicorum der vereinigten evangelischen Reichsstände Deutschlands zur Kalenderreform von 1700 folgen wir [157, S. 183-184], siehe auch [88, S. 58].

Conclusum Corporis Evangelicorum vom 23. Sept. 1699.

Die Calender Verbesserung betreffend.

Nachdeme die Calender-Verbesserung bey dem Corpore Evangelico in behörige Deliberation gestellt worden, so hat man einmüthiglich vor gut befunden und geschlossen, daß

1. Die nach dem 18. Febr. st. v. folgende 11. Tag des 1700. Jahrs in denen Calendern auszulassen, und das Matthiæ Fest auf besagten 18. Febr. $\mathrm{zu}$ legen seye.

2. Die Oster-Fest-Rechnung, und was davon dependirt, in Zukunfft weder nach dem, im Julianischen angenommenen Dionysianischen viel weniger Gregorianischen Cyclo, sondern nach dem Calculo Astronomico (wie ehemals zu Zeiten des Concilii Nicæni beschehen) gemacht werde.

3. Die Evangelische Sonn- Fest- und gemeine Wochen und Wercktäg, wie bishero, also jederzeit in eine besondere Columnam gebracht werden, mit darüber gesetzter Inscription: Verbesserter Calender.

4. Allerseits Mathematici Evangelici dahin angewiesen werden, mit denen Königl. Schwedischen, über die von selbigen gethane Vorschläg fleißig zu communiciren, ob, und wie, so wohl gedachte Vorschläg als das gantze Werck vollends zum Stand zu bringen seyn möchte.

5. Denen Mathematicis ebenmäßig aufzugeben, daß selbige darauf gedencken solten, wie künfftighin und mit der Zeit der bissherige abusus der Astrologiæ Judiciariæ aus denen Calendern bleiben könne. Wie nun

6. Diese Calender-Veränderung aus der, denen Evangelischen Ständen des Reichs in Sacris \& Profanis zustehenden hohen Macht und Gewalt, bey dem Corpore Evangelico resolvirt und beschlossen worden, also wäre solches in denen dieser Calender-Veränderung wegen in deren Landen auszufertigenden Publications Edictis insonderheit anzuführen; Und

7. Die Publication dieses Schlusses in allen Evangelischen Landen den letzten Sonntag vor dem Advent dieses 1699. Jahres zu bewerckstelligen. 


\section{Conclusum vom 10.|20. Januar 1700}

Für den Wortlaut dieses Conclusums des Corpus Evangelicorum verweisen wir auf [157, S. 194-195].

Conclusum in Conferentia Evangelicorum den $\frac{10}{20}$. Januar. 1700.

Bis zu Verfertigung anderer- mit dem Himmels-Lauf accurater übereinstimmender Tabularum Astronomicarum, die bisherige Rudolphinische Tabulas Kepleri zum Calculo der Ephemeridum beyzubehalten.

Nachdem zu Verhütung aller Confusion bey dem Calculo des Stand- und Gangs der Planeten, und absonderlich bey der Fest-Rechnung nöthig seyn will, die Mathematicos auf gewisse allgemeine Fundamenta zu weisen, und aber wegen des unter denen Astronomis noch obschwebenden dissensus, welche Tabulæ die allerzuverläßigste und accurateste seyen, am rathsamsten scheinet, die bishero fast durchgehends gebrauchte Rudolphinische Tabulas Kepleri zum Calculo der Ephemeridum und besonders zum computo des OsterVollmonds zu behalten; Also wäre allen Mathematicis zu bedeuten, daß sie stricte dabey bleiben, und nach derselben præceptis ad Meridianum Uranoburgicum die Phænomena cœlestia und zumalen das tempus æquinoctii verni, und dann den wahren Oster-Vollmond in Tag, Stunden und Minuten berechnen, und solchen so lange nachgehen solten, bis durch der Mathematicorum observationes andere mit dem Himmels-Lauff accurater übereinstimmende Tabulæ Astronomicæ verfertiget, von denen Evangelischen Ständen approbiret- und zu substituiren von Selbigen beliebet werden möchten; Welches man also an allerseits gnädigste Herren Principalen Obern und Committenten zu referiren und Dero Verordnung darüber einzuholen, nöthig befunden. 


\section{Des ,Triumviri‘ Unvorgreiffliches Bedencken}

G. A. Hamberger, J. Meyer, J. Ch. Sturm: Unvorgreiffliches Bedencken wegen vorhabender völliger Calender-Verbesserung. Auf gnädige Veranlassung eines Hochlöblichen Corporis Evangelici unterthänig verfasset von einigen Mathematicis. Siehe [105, Seiten 110-120].

Unvorgreiffliches Bedencken wegen vorhabender völliger

Calender-Verbesserung

Auf gnädige Veranlassung eines Hochlöblichen Corporis Evangelici

Unterthänig verfasset von einigen Mathematicis.

Des H. Römischen Reichs Churfürsten, Fürsten und Stände, Evangelischer Religion, bey noch fürwährender Reichs-Versammlung, hochansehnliche Herren Räthe, Bottschaften, und Gesandte

Hoch- und Wohlgebohrne, HochEdelgebohrne, HochEdle, Gestrenge, und Hochgelehrte, Gnädige, Hochgeneigte, Hochgeehrteste Herren.

EUer Excellenz und Gnaden, auch unseren Hochgeneigten und Hochgeehrtesten Herren sagen endsbenannte Professores zuvorderst unterthänig und beflissensten Danck, dass Dieselbe, bey bevorstehender würcklichen Einführung der ohnlængst von einem gesammten Hochlöblichen Corpore Evangelico resolvirten Verbesserung dess Calender-Wesens in denen Evangelischen Provintzen und Stædten dess Heil. Römischen Reichs, unsere gehorsamste unvorgreiffliche Meynung, in ein und andern Stück, so zu völliger Einrichtung dieses wichtigen Wercks erfordert wird, zu eröffnen, gnædig und grossgünstig erlauben wollen.

Gleichwie hiedurch nicht allein Dero ruhmwürdigste Sorge vor das gemeine Beste, sondern auch eine besonders gnædige und wohlmeinende Propension gegen uns sich an den Tag legt: also erfordert unsere Schuldigkeit, in diesem un allen immer möglichen, alle gehorsamste Willigkeit und Beflissenheit vielmehr im Werck als mit Worten zu bezeigen.

Belangend also dasjenige, so über das bereits im Calender-Wesen löblich verordnete, zu Erlangung einer zuverlæssigen Richtigkeit, und dero kræfftigen Handhabung, dissfalls nöthig und nützlich scheint: So kommt das gantze Werck hauptsæchlich auf folgende zwey Stücke an: nemlich, wie und welchergestalt erstlich die beschlossene Astronomische Fest-Rechnung, nach allen ihren Requisitis, auf einen festen Fuss gesetzet, und, nebst übriger Einrichtung dess Calculi beym Calender-Werck, durch alle Evangelische Lande 
im Heil. Römischen Reich, zu allen künfftigen Zeiten, in einer bestændigen, vollkommenen Ubereinstimmung erhalten werden möge. Hiernæchst und vors andere: Was von dem jüngsthin in Vorschlag gekommenen Mittel, darauss dieses Calender-Geschæfft, und die darinn beym Calculo, und andern dahin gehörigen Dingen, Bemühete, die nötige Aufwendungen und Ergötzlichkeit ziehen; mithin auch einige Subsidia zu Excolirung der Mathematischen Künste und Wissenschafften erlangen könnten, zu halten sey; und wie fern die Möglichkeit zulasse, selbiges in die Praxin zu bringen?

Was das erste belangt: so wird vor allen Dingen erfordert (soll anderst in denen Landen der Evangelischen Churfürsten, Fürsten und Stænde eine durchgehends wohl zusammen-treffende Harmonie in denen Calendern seyn und verbleiben, und aus mancherley Fundament dess Calculi nicht eine neue Confusion enstehen) dass man sich gewisser Tabellen vergleiche, welche der Grund dieses Calculi seyn müssen. Und dieweil die Tabulæ Rudolphinæ so lange Jahr her denen Ephemeridibus und Calendern zum Grund der Rechnung gedienet, und durch die ziemlich genaue Zutreffung, mit denen Phænomenis cœlestibus in denen meisten Planeten sich legitimirt haben; so könnte man der Zeit ohne Bedencken solche Tabulas erwæhlen, und die Rechnungen nach denenselben führen. Solchenfalls blieben die Radices oder Epochæ motuum Solis \& Lunæ (das ist, wo Sonn und Mond den ersten Januarii im ersten Jahr Christi gerad um Mittag gestanden, von welchen hernach auf folgende Zeiten fortgerechnet wird) wie sie in denen Tabulis Rudolphinis zu finden sind: ingleichen die darinn gebrauchte Længe dess Sonnen-Jahrs von 365. Tægen, 5. Stunden, 48. Minuten, 57. Secunden: wie nicht weniger die Længe dess Mond-Jahrs, oder seine zwölff Monathen zusamm, nemlich 354. Tæge, 8. Stunden, 48. Minuten, 38. Secunden, 10. Tertien \& c. Ein Mensis Lunaris hielte 29. Tæge, 12. Stunden, 44. Minuten, 3. Secunden, 10. Tertien \& c. Mit welchen Quantitæten viele berühmte Astronomi nostri seculi, als Lansbergius, Wendelinus, Bullialdus, und andere, dergestalt genau übereinstimmen, dass sie kaum in minutis secundis, oder gar tertiis differiren. So bliebe auch der in gedachten Tabulis gebrauchte Meridianus Uranoburgicus beym Calculo; obwohl übrigens in der application ad determinationem Festi Paschalis die Mathematici dess Collegii sich künfftighin unter einander zu vernehmen hætten, damit nicht je zu weilen die Executio Canonum Concilii Nicæni ein Inconveniens nach sich zöge.

Demnach aber seit Tychonis und Kepleri Zeiten, durch den Fleiss der Astronorum, ein und anders noch etwas genauer beobachtet, und durch die Rech- 
nung bestimmt worden; als könnte man, wo zumal der Calculanten mehr wären im Collegio, auch nach andern Tabulis als die Rudolphinæ sind, die Rechnung absonderlich führen. Wie dann, besage der Beylage, bereits sich jemand findet, der Vorhabens ist, aus allerhand Tabulis gleichsam einen electivum Calculum zu versuchen, und nach denen Observationibus und Tabulis verschiedener berühmten Astronomorum des jetzigen zu End gehenden Seculi, nach und nach Ephemerides auszurechnen. Welches Vorhaben, wie es allen Ruhm und möglichen Vorschub verdienet, auch zu dem End dieser Herr Junius, wie auch der alte Herr Kirchius, der nun so lange Jahr mit seiner Ephemeridographia und Observationibus sich um die Astronomie, und das Publicum, wohl verdient gamacht hat, wie ingleichen der in Jena würcklich im Calculo Ephemeridum nach denen Rudolphinis Tabulis jetzo begriffene gute Mathematicus Herr Johann Heinrich Hoffmann, gehorsamsten Fleisses hiemit hoc nomine recommendiret werden; also könnte man doch interim, biss sich der Effecct dieses Conatûs zeigt, und durch die mit höchsten Fleiss anzustellende und zu continuirende Observationes cœlestes die Richtigkeit des Calculi dieser vorhabenden neuen Ephemeridum approbirt wird, es bey denen Tabulis Rudolphinis bewenden lassen, und derselben sich zum Grund der Calender-Rechnung bedienen. Nur wird hiebey dieses gnädig und grossg. in Consideration zu ziehen gehorsamsten Fleisses gebeten, das ob summum in mora periculum, und weil mit dem Druck der Calender aufs Jahr 1701. bald muss angefangen werden, die Resulution, wegen Veranstaltung des Calculi, möglichst beschleunigt, und doch dabey also möge angetragen werden, dass man nicht in die vorige Confusion verfalle, sondern vielmehr alles in eine durchgehende Conformitæt komme.

Solchen Zweck zu erreichen, und damit künfftig alle Calender in allen Evangelischen Reichs-Provintzen und Städten desto gewisser zusammen treffen, und alle Discrepanz im Calculo vermieden bleibe; wird vonnöthen seyn, dass alljährlich ein allgemein Muster eines Calenders, quà partem Mathematicam, aus denen Ephemeridibus extrahirt, und dergestalt verabfasset werde, damit hernach jedweder Verleger solchem Haupt-Muster des Calculi nachgehen, dabey ohne die geringste Aenderung verbleiben, und die sonst gewöhnlicher massen beygedruckte, nützliche und erbauliche Sachen dem Calculo anfügen lassen könne. Welche dem gesammten Evangelischen Wesen hauptnöthige und rühmliche Zusammenstimmung allerdings dieses erfordern will, dass gleich jetzo zu Anfang, vermittelst eines gemeinsamen, vom gesammten Hochlöblichen Corpore Evangelico einmüthig zu fassenden 
Schlusses, die Verordnung, gestellt werde, denen Verlegern aller Orten ernstlich, und bey Verlust ihres Verlags, oder zu erlangenden Privilegii, zu injungiren sey, dass sie von solchen allgemeinen Muster des Calculi nicht allein in keinem Stück abweichen, sondern auch übrigens alle ärgerliche Zothen, ingleichen die Prognostica von Glück- und Unglücks-Fällen (deren VorausVerkündigung nicht den geringsten Grund in denen Principiis Astronomicis, daher sie doch wollen gezogen werden, findet) gäntzlich aus denen Calendern lassen sollen. Was die Witterung belangt: so wäre zwar zu wünschen, dass dieses ungegründete Wesen des Wetter-Prognostici auch aus denen Calendern bleiben mögte. Allein weil der gemeine Mann, ja auch von denen Gelehrten nicht wenige, das Contrarium nur gar zu sehr sich einbilden; so stehet dahin, ob man nicht diejenige, welche in dem Wahn stehen, es könne kein Calender ohne die Witterungs-Anzeige seyn, und giennge demselben ein Essential-Stück ab, wann dieses davon bliebe, auf solcher Meinung lassen, und in einer, an sich selbst weder nützlich noch schädlichen Sach, ferner condescendiren solle. Bevorab, wenn die verstændigen Calendariographi den Ungrund solches Wetter-Prognostici, bey Anführung der Anstronomischen Meynung davon, stetig und getreulich inculciren werden.

Bey solcher löblich gemachten Anstalt, könnte ein Hochpreisslich Corpus Evangelicum in Teutschland sich mit gutem Fug rühmen, dass ihre Calender verbessert seyn; zumahl was den durch alle Evangelische Lande gleichförmig gehenden Calculum belangt. Welcher nicht nur vor jetzo auf das accurateste als möglich eingerichtet würde; sondern es müste das Collegium sich je længer je mehr durch fleissige Observationes dahin bearbeiten, wie die Hypotheses Astronomicæ immer zu verbessern, und hiedurch so Tabulæ als Ephemerides mit der Zeit vollkommener einzurichten seyn möchten. Wie dann eben diese nöthige und mögliche Verbesserung der Tabularum die Ursach ist, warum man noch zur Zeit sich nicht wohl in eine Cyclische Rechnung einlassen, oder auch rathen kan, einen Cyclum, wie gut und wohlzutreffend er auch scheinet, anzunehmen: weil ein Cyclus, wie er einmahl gefasset ist, verbleibt; und wo in denen kleinesten Minutien etwas an denen Revolutionen der Planeten nicht accurat genug bestimmt ist, der Fehler sich immer vermehret, und nach und nach mercklicher wird. Da hingegen der Astronomische Calculus durch fleissige Observationes sich immer verbessern, und nach demselben die Ephemeris je længer je vollkommener sich einrichten läst.

Eben durch diesen Astronomischen Calculum kan auch am allerfüglichsten, 
zu Folge der allbereits publicirten Resolution, die eigentliche Zeit der Ostern bestimmt, und der Oster-Tag in denen Ephemeridibus und dem HauptMuster dess Calculi angesetz werden. Dann wann erstlich auss denen Tabulis gerechnet und bekannt ist, welchen Tag und in welcher Stunde und Minute das Æquinoctium vernum einfællt: fürs andere eben auch auss gedachten Tabulis genau berechnet worden, welchen Tag, Stunde und Minute, nach demselben Æquinoction, ein Vollmond sich ereignet, so trifft auf denselben Tag, wann der Vollmond Vormittage einfællt, der Juden Ostern. Damit wir nun unsere Ostern nicht mit denen Juden halten, so wird der næchste Sonntag darauf für unsern Oster-Tag angesetzt. Solchergestalt können wir den Fehler, den der Gregorianische Calender schon öffters begangen hat, evitiren. Und damit man hierinn desto sicherer gehen möge, wird rathsam seyn, dass auch der Juden ihre Ostern nach ihren eigenen Principiis alljæhrlich aussgerechnet werden, die eigentliche Zeit solcher Jüdischen Ostern dessto gewisser zu erfahren und folglich zu vermeiden. Was aber etwa bey Astronomischer Aussrechnung der Ostern, so wohl wegen obgedachten Meridiani, als wegen dess gantz absonderlichen Casus der nahen Zusammentreffung dess Vollmonds und Æquinoctii, wie auch dess Oster-Vollmonds und OsterTags (welches sich aber selten zutrægt, und daher mit guter Weil von denen Mathematicis mag überlegt werden) zusetzen und ausszumachen ist, kan am füglichsten dem Collegio zu gründlicher Untersuchung überlassen werden. Welches die Erörterung dieses nothwendigen Puncts, auf gepflogene Communication mit andern Astronomis so wohl, als unter sich selbst, sich besten Fleisses wird lassen angelegen seyn, und vigiliren dass der Calculus Astronomicus mit der Intention dess Concilii Nicæni wohl zustimme.

Dieweil nun aus bisshero angeführten leicht zu ermessen ist, dass, im Fall die Aussrechnung und Determinirung dess Æquinoctii, wie auch dess Plenilunii Paschalis, und so dann die Ansetzung der Ostern selbst, davon, bekanter massen, alle Sonn- und beweglichen Festtæge dess gantzen Jahrs dependiren, einem jeden Calculanten, wie bisshero, freygestellt bliebe, es freylich offtmals eine ziemliche Dissonanz unter denen Calendern der Evangelischen setzen, und dahero besorglich alle biss dato geführte gute Consilia und wohlgemeinte Verordnungen, denen Illusionen, sowohl der dem Gregorianischen Calender nachgehenden, als anderer, der Calender-Ænderung und Verbesserung Ungeneigten, sich exponirt sehen würden: Als erfordert die unumgængliche hohe Nothwendigkeit, dass, zu Erlangung einer durchgehenden bstændigen Harmonie, und zu Verhütung aller Inconvenientien 
im Calender-Wesen, die zuverlæssige Einrichtung obvermeldter unentbehrlichen Stücke, wie auch die fleissige Obsicht auf die Observanz der zustellenden guten Verordnung, damit keine neue Unrichtigkeit im Calender-Wesen sich einschleiche, einem Collegio Mathematicorum, das von dem gesammten Hochlöblichen Corpore Evangelico dependire, gnædigst committirt und anvertrauet werde. Und ob schon solch Collegium wegen dess noch zur Zeit ziemlich ungewissen Unterhaltungs-Mittels, Anfangs sich so gar weitlæufftig und auf viele Collegas nicht wohl extendiren læst, ja von wenigen Mathematicis desto bequemer, richtiger und schleuniger alles kan zu Werck gerichtet werden: So wollen jedoch Ends-benannte Professores, damit niemand Anlass nehme, unter allerhand Vorwand, (wie bereits von verschiedenen Orten her dergleichen sich spühren læst) diese zur Ehre GOttes, auch dess gesamten Evangelischen Wesens Wohlstand, und Mathematischer Künste Aufnehmen, abzielende Sache zu hindern, im geringsten nichts darwieder zu rathen sich unterfangen, im Fall etwa die Consilia da hinaus giengen, dass in jedem Reichs-Creyss ein Mathematicus, oder, wo derselbse weitlæufftig ist, zwey, zu solchem negotio bestimmt, und also conjuncto omnium conatu das Werck befördert werden möchte.

Dafern nun solches geschehe, so könnten wegen der Einsammlung der Calender-Gelder, gedachten Mathematicis in eines jedwedern CreysStandes-Land, eine oder etliche Persohnen adjungirt werden, die Nothdurfft dissfalls zu beobachten. Nur erheischt hierbey die mehrberührte, durch alle Evangelische Lande im Reich hochnothwendige Einigkeit im CalenderWesen, dass vor allen Dingen gleich jetzo zu Anfang verhütet werde, damit kein zergliedertes getheiltes Wesen in dem Collegio entstehe, sondern dass alle Mathematici in denen Reichs-Creysen in ein Corpus coalesciren, dero Consilia und Arbeit, mit einmüthigen Unterwinden, allein zu offt berührten Haupt-Zweck der Richtigkeit und Einigkeit im Calculo dirigiren, alle insgesamt von einem Hochlöblichen Corpore Evangelico dependiren, dessen Befehl eintzig nachleben, und alles, nicht zu dieses oder jenes gewinnliebenden Privati profit, sondern zu des gesamten Evangelischen Wesens Ruhm und Ehren, und zu der Mathematischen Künste und Wissenschafften je länger je mehrerer Cultivirung einrichten mögen.

Wann dann aus angeführten zur Genüge erhellet, dass dieses wohl der allerzulänglichste Modus sey, das Calender-Wesen und die Zeit- und FestRechnung, zur völligen Verbesserung zu bringen und darinn zu erhalten: Dabey aber leicht zu erachten, dass die beym Calculo Ephemeridum unaus- 
setzlich anzuwendende blutsaure Müh, zumal aber die Observationes Colestes, als der Grund der Tabularum und Ephemeridum (wegen der vielen Unkosten, so auf die an mehrern Orten aufzurichtende Observatoria, anzuschaffende Instrumenta, und andere Requisita gehen, auf welche Tycho ehedessen, ohne die genossene Königliche und hernach Käyserliche Subsidia, sein gantzes Vermögen gewendet, ja zu deren Excolirung Cassini zu Paris jährlich eine Königliche Liberalitæt von etlich tausend Thalern geneust) ohne einige erkleckliche Aufwendungen nicht füglich, zu des Publici Ruhm und Nutzen, zum Stand zu bringen seyen: Als enstehet nun

Vors andere die Frag: Ob das ohnlängst summarisch berührte ohnmassgebliche Mittel, dass nehmlich keine Cammer einiges Evangelischen ReichsStands einen Kreutzer hiezu beytragen dörffte, sondern dass der Calender selbst die Unkosten abwerffen könne, practicable und hinlänglich sey, vorgelobten Scopum zu erreichen? Auch wie und welcher Gestalt solch expediens ohne der privilegirten Verleger Nachtheil und Schaden, auch ohne einiges Menschen Beschwerde, möge ins Werck gerichtet werden?

Nun ist zwar hoch zu betauren, dass, da ohne dem das edelste Kleinod der Mathesis, die liebe Astronomia (welche von der Welt Anfang her, durch der Astronomorum unermüdeten Fleiss, denen Menschen so herrlichen Nutzen geschafft, und ihrer Vortrefflichkeit wegen vor allen andern Wissenschafften verdiente erhaben und befördert zu werden) sich bisshero in Teutschland durch den überhand genommenen Calender-Missbrauch wegen der eingeflickten unverschämten Wahrsagereyen aufs höchste beschimpfft befunden; Auch noch über diss die Astronomi den von GOtt und Rechtswegen ihrer Profession zustændigen, auch in der ersten Christlichen Kirche, was zumahl den Punckt der Rechnung belangt, ihnen allein überlassenen, Calender und die davon herfliessende Nutzung, welche sie zu der Astronomiæ und übrigen Mathesis Cultur anwenden könten, nunmehr fast durchgehends in fremden Hænden, und zwar also angewendet sehen müssen, dass öffters damit weder GOtt noch Menschen im geringsten gedienet wird.

Allein weil diese durchgehends eingerissene Gewohnheit zu ændern, und denen Scientiis \& artibus Mathematicis solch Emolumentum wiederum zu vindiciren, vielleicht alle Rationes und Persuasiones von der Welt zu schwach seyn werden; als læst doch das veste Vertrauen auf die Æquanimitæt derjenigen, die hierinnen remidiren können, wenigstens dieses Hoffen, dass, wofern denen Calender-Verlegern ihr jus quomodocunque acquisitum nicht allein 
nicht geschmælert, sondern vielmehr erhalten und verbessert wird, das wenige, so etwa daneben vors Collegium und die Excolirung der Mathesis, abfallen kan, ihm wird gegönnet werden.

Demnach nun, bekannter massen, die Calender-Verleger bisshero den Calender einem Verfasser bezahlen müssen, und zwar zum Exempel, einen Calender in 4to mit 12. biss 24. fl. Denen blossen Ausschreibern aber, die selbst nicht calculiren, etwas wenigers vor die Müh zugewendet haben; als könnten, durch einen gemeinsamen Schluss, gedachte Verleger in allen Evangelischen Landen und Orten im Reich dahin angehalten werden, dass jedweder so viel Exemplaria, dess vom Collegio elaborirten Haupt-Musters dess Calculi der Calender, mit etlichen Gulden an sich lesen solte, als vielerley Gattungen Calender er selbiges Jahr zu verlegen gedenckt. Diesen Calculum könnten so dann die Verleger ungeændert nachdrucken, und die Historien, oder andere erbauliche Sachen demselben beyfügen lassen. Den eigentlichen Preiss des Calculi würde ein Hochlöbliches Corpus Evangelicum, nach der Gattung des Calenders zu bestimmen gnædigst belieben, damit solcher Gestalt sich niemand über des Collegii Tax beschwehren dörffte, sondern alles in bester Æquitæt zugienge. Und könnte solches Quantum ungefehr nach folgender proportion eingerichtet werden. Dabey die Verleger besser zu recht kæmen, als wann sie, wie bisshero, dem Verfasser 12. biss 24. fl. vor Ealborirung eines Calenders in Quart zahlen müssen. Nemlich, es könnte etwa gezahlet werden vor einen gantzen Verlag, wenn er auch in etlich tausend Exemplarien bestünde, eines Calenders in Quart 6. fl. in 8vo 5. fl. in 16. 2. fl. in 32. 1.fl. vor einen gantzen Verlag der Kupffer-Calender, der schlechtesten Gattung 3. fl. der Mittlern, da das Exemplar über 3. Batzen kommt, 6. fl. der Besten, da einer über 6. Batzen kommt 9. fl. alles vom gantzen Verlag, wie gedacht, zu verstehen. Damit nun dieser Verordnung nachgelebet würde, so könnte jedes Orts Obrigkeit dem Censori ordinario anbefehlen, keinen Calender eher zu censiren, biss der Verleger ein Exemplar dess offterwehnten Calculi oder Hauptmusters des Calender vorzeigte, welches vom Vorsteher der gemeinen Casse des Collegii, oder der Provincial-Casse, unterschrieben, und sein Petschaft beygedruckt wære, mit Vermelden, wem, und zu was Gattunge dess Calenders, solche Exemplaria gegeben worden. Würde nun ein Verleger sich finden, der etwas heraus gebe, wann es auch, gleich wie die Schreib-Calender, censirens nicht vonnöthen hætte, darauf er den Calculum nicht gelöst hatte, so wære der Verlag verfallen, und könnte er dabey in eine Straff condemnirt werden. 
Dieweil aber das Pretium, vor welches die Verleger die Exemplaria mehrgedachten Calculi vom Collegio erkauffen müsten, lang nicht erklecklich seyn dörffte, so viele Unkosten, als auf das calculiren, observiren, reisen, correspondiren, zumahl aber auf die kostbare, bey dieses Wercks Ausführung unentbehrliche Observationes, und am allermeisten auf excolirung Mathematischer Kunst- und Wissenschafften gehen werden, anzuschaffen; als könnte von oft hocherwehnten Corpore Evangelico der Preiss der Calender, welcher ohne dem, aus Æmulation der Verleger, fast um die Helfte dess ehmaligen Quanti herab gekommen, denen Verlegern so wol als dem Collegio zu lieb, um ein gewisses erhöhet, und von solchen Uberschuss hernach dem Collegio etwas zu theil werden. Desswegen dann die Verleger allemal bey Erhandlung eines Exemplars dess Calculi, nach ihrem guten Gewissen, und bey Verlust dess Verlags, oder auch dess zu erlangenden Privilegii, zu melden hætten, wie viel Exemplaria sie aufzulegen gesonnen seyn, als wornach übers Jahr, wenn sie ein neu Exemplar dess Calculi an sich erhandelten (nach einem billichmæssigen Abschlag, wann ihnen etwa von ein oder anderer Gattung viel Maculatur geblieben) die Zahlung an die Casse geschehen müste.

Belangend die Erhöhung dess Preises, und was etwa davon dem Collegio heimfallen könnte, so verkauffen die Verleger jetziger Zeit aufs allerhöchste

Das Dutzet $\left\{\begin{array}{lr}\text { Schreib-Calender } & 15 \\ \text { Gute Calender in quarto } & 12 \\ \text { Schlechte Cal. in quarto } & 9 \\ \text { Schlechte Tafel-Calender } & 6 \\ \text { Kleine in sedez } & 3 \\ \text { Kleinste in 32. } & 1 \frac{1}{2}\end{array}\right\}$ Batzen: kommt also ein Exemplar vor $\left\{\begin{array}{c}5 \\ 4 \\ 3 \\ 2 \\ 1 \\ \frac{1}{2}\end{array}\right\}$ Kreutzer.

Wann nun der Preiss also erhöhet würde, dass denen Verlegern müste gezahlt werden 


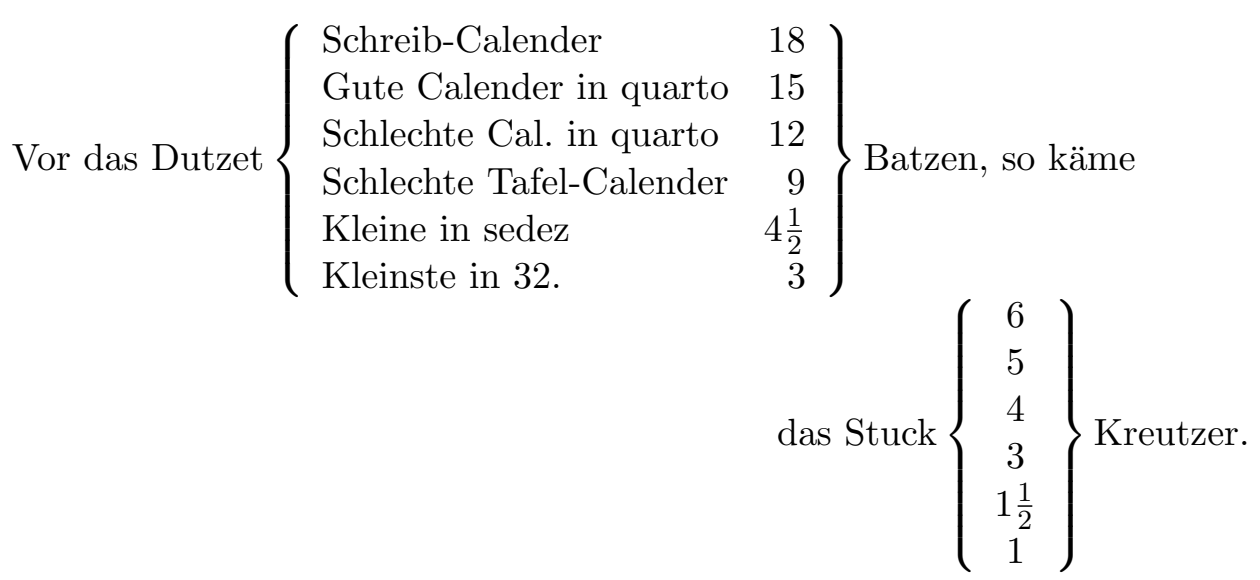

Der Uberschuss am Preiss, trägt über bissherigen Werth, vom jedem hundert der ersten vier Sorten, 1. fl. 40.kr. der lezteren zwey Sorten, 50. kr. Davon deputirte man dem Collegio dort 1. fl. hier $35 \mathrm{kr}$. Bliebe dem Verleger dort 40. kr. hier 15. kr. über bissherigen Profit, von jedem hundert. Von denen übrigen Kupffer-Calendern zahlte der Verleger, von denen, die 12. biss 24. kr. kosten von jedem hundert 2. fl. von denen, die über 24 . kr. kosten 3 . fl. Und dafern jedes Exemplar, jener um 2. kr. dieser um 3. erhöhet würde am Preiss, so bliebe dem Verleger über bissherigen Profit auch noch etwas mehrers.

Uber solches Quantum nun hätte kein Mensch von der Welt Ursach sich zu beschweren. Denn (1.) kämen ja etliche Pfennige oder Kreutzer, die der Kauffer mehr gebe, keinen Menschen beschwerlich an, weils alle Jahr nur einmal kommt. (2.) Kommt den Verlegern nicht allein etwas von dem erhöheten Preiss zu, sondern sie kommen auch mit Erkauffung des Calculi um ein gutes besser zurecht, als wann sie, wie bishero, den Verfasser der Calender contentiren sollten. Was demjenigen zu reichen ist, der die Historien, oder was sie andrucken lassen, ihnen verabfasset, wird so hoch sich nicht belauffen, als was sie vor den Calculum zahlen, das doch vielleicht das Viertel oder Fünfftel dessen, was sie sonst gezahlt, nicht erreichet. Welche Unkosten manche Verleger gar erspahren, indem sie gedachte Historien oder andern Zusatz selbst beyfügen. Wozu noch dieses kommen könte, dass, weil die privilegirte Verleger biss dato von andern sehr sind gehindert worden in dem Genuss ihres Privilegii, die Zahl der Verleger, ihnen zu Liebe, von jedweder hohen Lands- oder Stadts-Obrigkeit, etwas eingezogen, und der Verleger weniger geduldet werden möchten. (3.) Das Collegium Mathematicorum, 
als Urheber dieses Fonds, könte hierdurch nicht nur zu Erbauung der Observatorien, Anschaffung der Astronomischen und anderer Mathematischen kostbaren Instrumènten, zu Büchern und übriger Nothdurfft, wie auch zu Unterhaltung der Correspondenz mit ausländischen Mathematicis, zu Salirung der Membrorum Collegii, dero Assistenten im Calculo Astronomico, observiren, copiren, auch der bey der Cassa und auf Reisen Bemüheten, die nöthige Spesen überkommen; sondern es könte auch durch das in der Cassa restirende, zumal wenn die Sache im Schwung kommt, die Excolirung Artium Mathematicarum auf eine rühmliche, öffentliche Art und Weise, da es bisshero meistens gar unvollkommen von Privatis geschehen müssen, sich in Teutschland, durch einen Vortheil, auf welchen öeine Nation bissher gedacht hat, gleichsam propriis viribus empor schwingen, und manch gutes Ingenium, so wegen Abgang der Mittel, und des Verlags sein Talentum nicht recht zu excoliren vermag, hinkünfftig beym Collegio unterkommen, und dem Vatterland zu Ehren und Nutzen sein von GOtt verliehenes Pfund wohl anwenden. Welches höchstwichtigste Momentum allein verdiente (wann auch gleich des Calenders wegen ein Collegium zu bestellen nicht nöthig wäre) dass dieses unschuldige Mittel, denen Mathematischen Wissenschafften in Teutschland aufzuhelffen, ambabus manibus amplectirt, und auf alle Weise befördert würde: weil solchenfalls ohne jemands Beschwerung dasjenige erreicht wird, was andere Nationes mit grossen Unkosten und noch wæhrenden ungemeinen alljæhrigen Aufwendungen zu erlangen kein Bedencken tragen.

Es hat aber hiebey die Meynung gantz nicht, dass die in die Casse des Collegii gesammlete Calender-Gelder allein nach dem Belieben der Membrorum des Collegii möchten dispensirt und verwendet werden; wie etwa Ubelgesinnete vorgeben: Sondern es bliebe die völlige Disposition solcher Gelder, die Bestimmung der Besoldungen, und Placitirung alles desjenigen, so Publici commodi causa aufzuwenden seyn möchte, allein in dem gnædigsten Willen mehr hocherwehnten gesammten Corporis Evangelici. Zu dessen gütigster Propension die jetzo an Beförderung dieses löblichen Wercks arbeitende, und andere künfftig ins Collegium zu ziehende, ohne dem das veste unterthænigste Vertrauen tragen, dass solcher Fonds vornehmlich zum Aufnehmen mathematischer Kunst- und Wissenschafften zu allen Zeiten werde destinirt verbleiben. Wie dann zu dem Ende die gemeine Cassa, bey noch wæhrenden Reichs-Tag, am füglichsten in Regenspurg aufgerichtet werden könte: Damit alles ex Beneplacito totius Corporis Evangelici angewendet werden mögte. Ob nach dissolvirten Reichs-Convent solche Cassa in Regenspurg 
verbleiben, oder wo sie hin zu verlegen sey, wird sich so dann schon Rath finden.

Gleichwie nun Euer Excellenz und Gnaden, auch unsere Hochgeneigte und Hochgeehrteste Herren, dero hohen Prudentz und Æquanimitæt nach, aus Obangefügten sattsam erkennen werden, dass durch ein solch Collegium Mathematicum Evangelicorum in Imperio Romano Statuum, die ZeitRechnung und das Calender-Wesen am allergewissesten in guter Richtigkeit, durch alle Evangelische Provinzen im Römischen Reich jetzt und zu allen Zeiten mag erhalten, die sonst gewiss zu befahrende Unordnung und Weitlæufftigkeit abgewendet, und benebst die dem Publico höchstnöthige und nützliche Mathematische Künste und Wissenschafften, zu unfehlbahren grossen Ruhm der Teutschen Nation, und absonderlich Eines Hochpreisslichen Corporis Evangelici, herrlich befördert werden könne: das Sustentations-Mittel aber der Mathematicorum und ihrer Asistenten, niemand schædlich, ja dem gemeinen Wesen und Verlegern der Calender selbst (es mögen auch einige, die lieber die Sache in bissheriger Confusion als in guter Richtigkeit sehen möchten, einwenden was sie wollen) profitable ist: Als haben unterschriebene Professores zumal auf Euer Excellenz und Gnaden, auch unserer Hochgneigten und Hochgeehrtesten Herren gnædig und grossgünstige Veranlassung, diese ihre unvorgreiffliche Gedancken, in Unterthænigkeit zu eröffnen, und übrigens, weil zumal wegen Abgang der Ephemeridum summum in mora periculum ist, dieses gantzen wichtigen Wercks schleinige Einrichtung, und nachdrückliche Handhabung, wider diejenige, so etwa aus einem unziemlichen Eigennutz selbiges unter allerhand nichtigen Vorwand zu hemmen, oder zu hintertreiben sich unterfangen möchten, gehorsamsten Fleisses hiemit recommendiren; sich selbst aber, nebsthertzgründlichster Anwünschung alles Göttlichen Seegens und Gedeyens zu Dero, auf des gesammten Evangelischen Wesens Flor und Aufnahm abzielenden, hochwichtigen Consultationen, in beharrliche Gnade und Gunst, mit geziemenden Respect, empfehlen sollen

Euer Excellenz und Gnaden, auch unserer Hochgeneigten Hochgeehrtesten Herren Unterthænige und gehorsamste, auch dienstwilligst und beflissenste

M. Johann. Christoph. Sturm. Mathem. \& Phys. PP. Altdorff.

Georg Albrecht Hamberger, Mathem. Prof. Publ. Jenens Johannes Meyer, Pr. P. Ratisb. 


\title{
Zum Unterschied zwischen Verbessertem und Gregorianischem Kalender
}

\author{
G. A. Hamberger: Gründliche Entscheidung der Frage: Ob und was vor ein Un- \\ terscheid zwischen dem Verbesserten und Gregorianischen Calender sey? Siehe [64, \\ Seiten 8-13]
}

Nachdem des H. Röm. Reichs Churfürsten, Fürsten und Stände aus hochwichtigen Ursachen, und krafft der Ihnen in Sacris und Politicis zustehenden hohen Gewalt, die so lang vorgewesene Reformation der Zeit-Rechnung zum erwünschten Schluß gebracht, und auf des nunmehro in GOtt ruhenden grossen Mathematici, Herrn Erhardi Weigelii, der durch seinen unermüdeten Fleiß diese wichtige und von denen meisten vor desperat gehaltene Sache rege gemacht, gethane unterthänigste und unmaßgebige Vorschläge so viel gnädigste reflexion gemacht, daß das Hauptwerck gäntzlich darnach eingerichtet worden; so höret man, nachdem verwichenes Jahr der verbesserte Calender würcklich introducirt und männiglichen vor Augen geleget worden, daß nunmehro so wohl von Gelehrten als Ungelehrten sehr stark die Frage getrieben werde, ob und was vor ein Unterscheid zwischen dem Verbesserten und Gregorianischen Calender sey? Denn da sich viele, so von der zu Regenspurg damals vorseyenden Verbesserung und Vereinigung der Calender gehöret, ich weiß nicht was vor eine Verenderung eingebildet, nachmals aber in dem vorjährigen Calender wahrgenommen, daß der Gregorianische Calender unverendert blieben, und gleichwohl nun in beeden Calendern die Monaths-Fest- und Nahmens-Tage, Evangelia, und wodurch etwan sonst die Calender unterschieden waren, gantz übereingefallen, und, dem euserlichen Ansehen nach, sich fast kein anderer Unterscheid zwischen beeden Calendern zeigen wollen, als der Titul, und daß der eine vorn, der andere aber hinten, auf der colmna gedruckt war: So sind die meisten in die Gedancken gerathen, es seye in der That nicht der geringste Unterscheid zwischen dem verbesserten und Gregorianischen Calender, sondern selbiger bestünde nur in dem Nahmen. Ja es wolten auch einige, so lieber bey dem alten geblieben, und diese Neuerung vor eine höchst gefährliche und omineuse Sach hielten, unwillig auf diejenigen Mathematicos werden, so hierinn consulirt worden, und ihre unvorgreiffliche Meinung dem Publico zum besten in Regenspurg entworffen, als ob sie nemlich, wie gut sie es auch vorgegeben, und wie fremd sie sich angestellet, nichts anders gesucht, als den, unsern Vorfahren, 
aus vielen theologicis, politicis und mathematicis rationibus, verhaßten Gregorianischen Calender, unter einem andern Mäntelgen, denen Evangelischen Ständen zu recommendiren, und einzuführen; welches denn sonderlich die Catholischen gern gehöret, und allenthalben frey vorgegeben, die Evangelischen Stände hätten nunmehr den Gregorianischen Calender angenommen; ja, es haben es einige vor ein so gar gutes Zeichen gehalten, daß sie es vor würdig erachtet, deßwegen die Stücke zu lösen, und das Te Deum laudamus zu singen, um dadurch die Freude des Jubel-Jahrs desto grösser zu machen.

Ob nun wohl vieleicht so wenig daran gelegen, oder die Religion wäre touchirt worden, wann die Evangelische Stände aus eigener hoher Bewegnis, gestalten Sachen nach, den von Mathematicis gemachten, vom Pabst Gregorio XIII. aber publicirten, und von Keyserl. Majestät approbirten Calender, so viel das Mathematicum oder die Rechnung betrifft, angenommen, als daß sie vor diesem den von dem Heidnischen Keyser Julio Cæsare publicirten Calender gehabt; immassen die Mathematic weder Catholisch noch Evangelisch ist: Dieweil jedoch vorberührte opinion im Grund falsch, und das hochpreißliche Corpus Evangelicum den Gregorianischen Calender aus wichtigen Ursachen nochmaln verworffen, auch denen Mathematicis dißfals zuviel geschicht, und die wiedrige Meinung bloß dahero entstanden, daß nicht männiglichen bekannt, was hierinn passirt, oder woraus eigentlich ein Calender müsse æstimirt werden; so habe vor gut befunden, diese Sache hier zwar kürtzlich, doch gründlich, zu untersuchen, und darzuthun, daß in der That ein grosser und Hauptunterschied, zwischen dem Verbesserten und Gregorianischen Calender, sey.

Es ist aber zu wissen, das unsere Calender zwey Hauptstück haben. Das eine betrifft die determinirung des Sonnen-Jahrs, und dessen Eintheilung in Monath, Wochen und Tage, so ein pur civilisch Werck ist, womit die Kirche nichts zu thun hat. Das andere concernirt die Anordnung der FestTage, Sonntags Evangelien, und was dem anhänget, welches den öffentlichen Gottesdienst und Kirche mit angehet. Nun sind etliche Feste unbeweglich, die jährlich auf einen gewissen Tag fallen, z. e. Weynachten, das Fest der Offenbahrung, Reinigung Mariä, Johannis «c. andere sind beweglich, und fallen nicht jährlich auf einerley Monath, viel weniger einerley Tag, als da sind Ostern, Pfingsten, Advent 2 . Mit denen unbeweglichen Festen hat es keine difficultät, weil deren Stell schon bekannt. Die beweglichen Festtage dependiren alle mit einander, samt denen Sonntags-Evangelien, von Ostern, als wovon sie gewisse Wochen und Tage abstehen, so daß derjenige, dem 
Ostern bekant, auch alle übrige Feste und Evangelia selbigen Jahrs weiß. Es hat aber das von dem Käyser Constantino M. anno 325. zusammen geruffene Concilium zu Nicæa, wegen der Osterfeyer folgende Verordnung gemacht, und bey Straff des Banns, zu halten geboten: Daß nemlich die Christen ihre Ostern nicht auf den von GOtt denen Juden dazu bestimmten Tag, so da ist der nechste Vollmondstag nach dem Frühlings-Æqquinoctio, sondern erst den Sonntag darauf halten sollen, weil wir Ostern nicht zum Gedächtnis der Creutzigung, so auf der Juden Ostern geschehen, sondern der Aufferstehung Christi, welche den Sonntag darauf erfolget, halten. Welchem Decret nachzuleben biß auf diese Stunde der gesamten Christenheit beständige intention ist.

Hieraus folget so fort unwiedertreiblich, daß man aus dem Zweck nicht urtheilen dörffe, ob der Verbesserte und Gregorianische Calender einerley sey oder nicht. Denn der Zweck ist so wohl im alten als Verbesserten und Gregorischen Calender, vermöge dessen so ietzo erwehnet worden, nothwendig einerley. Sondern es müssen die Calender hauptsächlich æstimirt werden aus der Art und Weiß solchen Zweck zu erlangen, welche gar sehr unterschieden, und eine viel besser seyn kan als die andere. Lasset uns demnach nun sehen, was sich die Evangelischen und Catholischen vor einer Art bedienen. Vor Pabst Gregorii XIII. Zeiten hatten die Christen den Oster-Termin oder Vollmond zu finden, theils aus Mangel guter Mathematicorum, theils der schwehren Rechnung, so sonst dazu gehöret, entübrigt zu seyn, sich viele hundert Jahr einer gewissen kleinen Tabell bedient, darinn auf 19. Jahr nacheinander angesetzet war, auf welchen Tag jedes Jahr der Oster-Vollmond falle, welche Tabell sie wieder von forn anfiengen, so offt 19. Jahr zu Ende waren, und dahero selbige einen Cyclum, einen Creiß, und mit dem Zusatz Cyclum Lunæ, Cyclum Paschalem, Cyclum Decemnovennalem, dessen einzele Jahr aber, wegen dieses so grossen Nutzens, die Güldene Zahlen, nenneten. Da aber Gregorius wahrgenommen, daß dieser Cyclus, so anfangs noch ziemlich mag zugetroffen haben, zu seiner Zeit den Ostervollmond durchgehend über 13. Tage, und manchmal gar über einen völligen Monath zu spät angesetzet, und dadurch verursachet, daß die Christenheit, wider bessers Wissen, Ostern, mit allen übrigen beweglichen Festen, unrecht und wider ihre und des Concilii intention gefeyret; hat er diesen cyclum durch seine Mathematicos endern, oder vielmehr an dessen Stell zwey neue Cyclos substituiren lassen, durch deren Behuff er den Zweck in Zukunfft iedesmal unfehlbar zu treffen hoffete. Die Evangelische Stände hingegen, da sie vermercket, daß diese des 
Gregorii neu erfundene Cycli unterschiedlichen Irrthumern unterworffen, welche so klar, daß auch derselben vornehmster Verfechter, Christoph. Clavius, solche bekennen müssen, und nur dieses vorgeschützet, daß die Natur der Cyclorum also mit sich bringe, und nicht möglich sey einen zu machen, der nicht zuweilen fehlen solte; dabey aber wahrgenommen, daß alle solche Cycli, sie mögen Nahmen haben wie sie wollen, zu ihrem Fundament den scharffen Astronomischen calculum führen, und unmöglich sey, daß einer unter ihnen besser, ja nur so gut, die Ostervollmond und was man immer verlangen kan, anzeige, als ietzt belobter scharffer Astronomischer calculus; so haben sie, an statt eines neuen, aber unvollkommenen, Cycli, so man etwan ausfinden können, anbefohlen, die Fest-Rechnung, und völlige Calender-Arbeit, lieber nach nur besagtem richtigen Fundament selbst einzurichten, und alle cyclos fahren zu lassen.

Wie aber die Astronomische und Cyclische Rechnung gar sehr differiren, also ist nunmehr klar, daß ein grosser Hauptunterscheid, zwischen dem Verbesserten und Gregorianischen Calender, sey. Und hindert nicht, daß gleichwol beede Calender in denen meisten Jahren fast durchgehend zusammen treffen, Denn so lang der Papisten cyclus nicht fehlet, so lang müssen wir nothwendig in der Fest-Rechnung zusammen treffen, weil wir einerley Zweck haben. Es lässet sich aber daraus so wenig schliessen daß die Calender einerley seyn, als wenig ich daraus, wenn z. e. zween Kauffleuthe alle Jahr auf einen Tag und in einem Hause in Leipzig auf der Messe zusammen kommen, urtheilen darff, sie müsten einen Wagen und einen Weg gehabt haben. So offt aber ietztgedachter Cyclus fehlet, und dadurch die Papisten in des Concilii Nicæni Bann verfallen, so offt werden beede Calender um 8. Tage oder gar 4. biß 5. Wochen, in denen beweglichen Festen von einander abweichen. Daß er aber zuweilen fehlen werde, haben auch so gar die vornehmsten Urheber desselben, als oben erwehnet, auf die von denen unserigen geschehene remonstration, gestehen müssen. Und damit solches, und zugleich der Unterscheid zwischen dem Verbesserten und Gregorischen Calender, klärer werde, wollen wir solche Fehler, und daher entstehende discrepanz zwischen beeden Calendern, kürtzlich erzehlen.

Erstlich wird in des Gregorii Cyclis, wider die Wahrheit und Erfahrung, supponirt, daß das Frühlings-Æquinoctium jedesmal auf den 21. Mertz falle, da es doch manchmal fast zwey Tag eher oder langsamer kommt. Wann es sich nun füget, daß z. e. das Æquinoctium auf den 19ten, und der Vollmond auf den 20ten zu Abend fiele, so wäre dieser der wahre Ostervollmond: 
Die Papisten aber müssen solchen vorbey streichen lassen, weil er vor ihrem falsch gesetzten Æqquinoctial-Termin einfället, und Ostern in dem so genanten Mense impurorum, das ist, auf die Zeit, da sonst bey denen Juden diejenige pflegten, so wegen Unreinigkeit Ostern nicht zu rechter Zeit halten können, celebriren. Auf welchen Fall wir 4. biß 5. Wochen in der Festrechnung von einander abweichen, weil wir dem Æquinoctio keinen gewissen Tag gesetzet, sondern dasselbe annehmen, es falle auch worauf es wolle. Gleicher gestalt, wann das ÆEquinoctium auf den 22. Mertz, und der Vollmond den 21ten auf den Abend ist, so nehmen die Papisten diesen Vollmond als den rechten an, weil er nicht vor ihrem ÆEquinoctial-Termin, ob schon vor dem wahren ÆEqunoctio, sich ereignet, dadurch sie denn einen gantzen Monath zu früh kommen, und sich so sehr vergehen, daß sie in einem Jahr zweymal, nemlich im ersten und letzten Monath desselben, Ostern halten, (denn in der Festrechnung fänget das Jahr von dem Neumond an, so dem FrühlingsÆquinoctio am nechsten, und endet sich wieder bey demselben) im andern Jahr aber gar keine Osterfeyr haben. Nicht minder kan es geschehen, daß der Ostervollmond auf einen Sonntag sich begiebet, und er dennoch vom Cyclo auf den Sonnabend angesetzet, dadurch aber verursachet wird, daß die Papisten ihre Ostern 8. Tag zu früh und mit denen Juden zugleich, halten; da doch die Päbste sich ehedessen, und schon vor des Concilii Nicæni Zeiten, nicht gescheuet, deßwegen die Griechische Kirch in den Bann zu thun. Im Gegentheil geschiehet es auch zuweilen, daß der Vollmond auf einen Sonnabend zu stehen kommt, und dennoch vom Cyclo auf den Sonntag verleget, dadurch aber Ostern um 8. Tag verschoben und zu spat gehalten wird. Ob nun wohl an dem, daß dergleichen Fälle sich vorietzo gar selten ereignen, und erst nach Verlauf vieler Seculorum häuffig kommen mögten, so ist doch genug, daß solche aus dem Gebrauch des cycli gewiß entstehen, und hingegen nicht möglich, wo man dem calculo Astronomico folget, daß man wissentlich in solche Irrthümer, so da leichtlich vorher gesehen, und vermieden werden können, verfalle. Daß also der Unterscheid zwischen der Cyclischen und Astronomischen Rechnung, und folglich auch zwischen dem Verbesserten und Gregorischen Calender, hierdurch klärlich am Tage liegt.

Hiezu kommt ferner, daß die Catholischen auf die meiste Sonntage des Jahrs andere Evangelia und Episteln in ihren Calendern ansetzen, als wir. Es ist aber andem, daß in denen wenigsten Calendern bißhero solcher Unterscheid angemercket, sondern denen Papisten durchgehend eben die Evangelia zugeeignet worden, die wir haben. Allein gleichwie die Ordnung der Sonntags- 
Evangelien in unsern Kirchen uns genugsam bekant; also gibt so wohl das Missale als Breviarium Romanum, so nach dem Schluß des Concilii Tridentini, auf Befehl des Pabsts Pii V. heraus kommen, und vom Pabst Clemente VIII. von neuen übersehen worden, klare Maß, wie es bey denen Catholischen dißfals gehalten werde, und wird der Unterscheid aus gegenwärtigem Calender, in gegeneinanderhaltung des Verbesserten und Gregorischen, leichtlich können ersehen werden. Zugeschweigen daß auch in dem Gregorischen Calender weit mehr Festtage stehen als in dem Verbesserten, wie der Augenschein, und die mit roth bezeichnete Tage, weisen.

Bißher haben wir von einem Theil des Calenders, nemlich von der Anordnung der Festtage, Sonntags-Evangelien $2 x$. gehandelt. Was den andern Theil, nemlich die determinirung des Sonnen-Jahrs, und dessen Eintheilung in Monath und Tage, belanget, so hat es Pabst Gregorius XIII. bey des Julii Cæsaris Einrichtung im Hauptwerck bewenden lassen; jedoch weil er gesehen, daß, durch Einschaltung eines gantzen Tages auf alle 4. Jahr, der Sache in etwas, nemlich bey nahe drey vierthel Stund, zu viel geschehe, und damit endlich die Feste so in den Winter gehören, auf den Frühling, und die so in den Frühling gehören, auf den Sommer fallen würden, wann er keine Enderung träffe; So hat er erstlich den 5. Octob. 1582. auf einmal 10. Tage, welche von Zeiten des Concilii Nicæni biß dahin zu viel gezehlet worden, ausgelassen, um damit die Festtage wieder in die vorige Stell zu setzen, darinn sie anfangs gestanden. Nachmals hat er verordnet, daß alle 400. Jahr 3. Schalttag solten ausgelassen werden, und zwar iedesmal bey dem Ende der drey ersten Seculorum, damit die Feste und Zeiten nicht wieder mögten verrücket werden. Die Evangelische Stände hingegen haben verwichenes Jahr, aus eben der Ursach, damit nemlich sie Zeit-Rechnung mit dem Himmels-Lauf und der alten Kirchen Anordnung besser zusamm treffen, und dem notorisch begangenen Fehler abgeholffen werden mögte, nicht 10, sondern 11. Tage, nicht im October, sondern nach dem 18. Februarii, ausgelassen; wegen des Zukünfftigen aber noch keine Verfassung gemacht, sondern ihren Mathematicis anbefohlen, durch fleißiges observiren vorhero den Lauf der Sonnen etwas genauer zu erkundigen, damit man sehen möge, was in Zukunfft wegen Auslassung ein oder des andern Schalttages solle beschlossen werden. Daß also auch hierinn der Unterscheid zwischen dem Verbesserten und Gregorischen Calender offenbar ist.

Solte aber jemand einwenden, wann der Verbesserte und Gregorische Calender in so vielen Stücken differiren, so wäre es auf diese Masse mit der 
so sehr verlangten und versprochenen Vereinigung der Calender schlecht bestellet: So dienet zur Antwort, daß erstlich durch Auswerffung der 11 . Tage, der Einigkeit beederseits Styli auf 100. Jahr prospicirt, und dadurch das jenige, so Handel und Wandel turbirt, auf einmal glücklich gehoben worden. Inzwischen hat man Zeit genug nach genau erkundigtem Sonnenlauf mit denen Catholischen freundlich zu communiciren, und zu versuchen, ob mit allerseits Belieben ein bequemere und bessere Art des Einschaltens könne ausgedacht und eingeführet werden, als bißhero üblich gewesen. Was aber anlanget die Irrthümer so die Catholischen iezuweilen in Ansetzung des Oster-Termins und davon dependirenden beweglichen Festen begehen, und dadurch auf solche Jahr beede Calender in der Fest-Rechnung von einander abweichen; so sind erstlich solche Fälle gar rar. Hiernebst kan man sich auch wohl versichern, weil die Catholische nunmehr uns nichts mehr von dergleichen Fehler vorzuwerfen haben, daß sich über einmal der Fall nicht ereignen darff, da sie sich so sehr verstossen, und in des Concilii Nicæni Bann verfallen, so werden sie sich schämen, daß sie, wider bessers Wissen, und wider ihre eigene ehemal so gar hoch gespannte Regeln, ohne einige Noth, handeln, und von uns den Vorwurff leiden solten, und dahero auf eine Enderung bedacht seyn. Wie man denn Anno 1693, da dergleichen Verstoß geschehen, öffentlich in die Zeitung geschrieben, daß der damalige Pabst auf eine Verbeserung der Calender bedacht wäre. Selbige aber falle aus wie sie wolle, so muß sie in der That mit der unsrigen überein kommen, wo sie nicht an statt der alten Fehler neue substituiren wollen. Die disharmonie in denen Sonntags-Evangelien und Episteln, ingleichen in der Vielheit der Festtage $\mathrm{zu}$ heben, ist theils ohnnötig, weil dem publico nichts daran gelegen, theils unmöglich, weil selbige den Unterscheid der Religionen zum Grund führet. Daß demnach, ungeachtet obgedachten Unterschieds, die Vereinigung beeder Calender so weit geschehen, als es die Wahrheit und bonum publicum erfordert.

\section{Anmerkung}

Das Symbol 2 wurde in Zeiten der Frakturschrift benutzt und entspricht inhaltlich der Abkürzung etc. Da es in heutigen Schriftsätzen kein Äquivalent dafür gibt, wurde dieses Zeichen für oben stehenden Text in seiner ursprünglichen Form übernommen. 
4

\section{Anhang}

\section{Symbole}

$\odot$ Sonne

D Mond

4 Jupiter

o' Mars

§ Merkur

\section{Abkürzungen und Worterläuterungen}

A

abusus (lat.) Missbrauch

a. c. - anni currentis (lat.) des laufenden Jahres 
accepi (lat.) ich habe erhalten

accessio (lat.) Zugabe

accusiren (lat.) beschuldigen, anklagen

ad evitandam invidiam (lat.) um Neid zu vermeiden

ad loci meridianum (lat.) bezüglich des lokalen Meridians

ad palatum (lat.) nach dem Munde

adhibiren (lat.) anwenden, benutzen, sich einer Sache bedienen

adjustiren (lat.) einstellen, ausstatten

adversarius (lat.) Gegner

affection (lat.) Gunst, Wohlwollen

allegiren (lat.) eine Stelle aus einem Buche anführen

Æquinoctium (lat.) Tag-und-Nacht-Gleiche, astronomisch der Schnittpunkt der Ekliptik mit dem Himmelsäquator

Æquinoctium vernum (lat.) Tag-und-Nacht-Gleiche zum Frühlingsanfang

Æquinoctium autumn (lat.) Tag-und-Nacht-Gleiche zu Herbstanfang

agnum Paschalem (lat.) Osterlamm

ex alia causa (lat.) aus irgendeinem anderen Grund

sich anheischig machen, etwas zu tun - sich verpflichten

anhero - jetzt

annoch - darüber hinaus, auch noch, doch noch

ansam carpendi (lat.) Gelegenheit zum Sammeln

in antecessumren (lat.) - im Voraus

application (lat.) Anwendung 
appliciren (lat.) anwenden, anfügen, anpassen

aptiren (lat.) herrichten, auch ausbessern, evtl. reparieren

$\overline{\mathrm{aO}}$ - anno (lat.) im Jahr

aspectus (lat.) ,Anblick ${ }^{6}$, in der Astronomie: bestimmte Stellung der Gestirne zueinander

calculus astronomicus (lat.) Berechnung des Osterdatums gemäß astronomischer Beobachtungsdaten

attribuiren (lat.) zuschreiben

aurei numeri (lat.) goldene Zahl

B

(sich) befahren - befürchten

zum behuff - zum Zwecke

Bene fit beatis manibus. (lat.) Das Gute entsteht durch der Seligen Hände.

Beschimpfung - Kränkung der Ehre eines Menschen. Hier geht sie von der Obrigkeit oder eines Vorgesetzten aus, um wegen eines Vergehens zu bestrafen.

C

calculant,(lat.) derjenige, der die Berechnung ausführt

calculiren (lat.) berechnen

calculus (lat.) Berechnung

calculus astronomicus (lat.) Berechnung des Osterdatums gemäß astronomischer Beobachtungsdaten

Cameralbedienter - vgl. Kammer 
Canon (lat.) Regel

capabel - fähig, im Stande

carmen, carmina (lat.) Gesang, Gesänge

casus (lat.) Fall

ex alia causa (lat.) aus irgendeinem anderen Grund

coeli (lat.) des Himmels

coetus (lat.) Zusammentreffen

rationes Collegiam suadentes (lat.) Überlegungen das Collegium zu empfehlen

Collegæ (lat.) Kollegen

columna (lat.) Spalte

commission - Beauftragung Anderer mit Geschäften

conclusum (lat.) Beschluss

concursam cum Judæis (lat.) Zusammentreffen (des Osterfestes) mit dem (Passahfest) der Juden

conduite (lat.) politisch kluges Verhalten

conferiren (lat.) einwerfen

consideriren (lat.) betrachten, erwägen

Corpus Evangelicorum - Vertretung der evangelischen Reichsstände in Regensburg.

cyclus paschalem (lat.) Methode zur Berechnung des Osterdatums, die im Jahr 525 von einem Römischen Abt eingeführt wurde

communi nomine (lat.) im gemeinsamen Namen

contribuiren (lat.) beitragen, beisteuern

cyclos (lat.) hier: Rechenmethode 


\section{D}

dannenhero - deshalb

decidiren (lat.) entscheiden

decretum (lat.) Beschluss

defendirung (lat.) Verteidigung

desideriren (lat.) vermissen, wünschen

determiniren (lat.) bestimmen, entscheiden

dies (lat.) Tag

die præcantio (lat.) Sitzungstag

differens (lat.) verschieden

discipulus (lat.) Schüler

dissuadiren (lat.) abraten

distinguiren (lat.) unterscheiden, deutlich hervorheben, etwas mit Aufmerksamkeit behandeln

divertiren (frz.) belustigen, ergötzen

divulgiren (frz.) verbreiten, etwas kundtun

dotirung (lat.) Ausstattung

dubium (lat.) Zweifel

$\mathbf{E}$

Eclipsin (lat.) $\odot$ - Sonnenfinsternis

effectus (lat.) Wirkung 
sine effectu (lat.) erfolglos

efficax (lat.) wirksam, erfolgreich

ejusdem (lat.) desselben (Monats)

elaboriren (frz.) ausarbeiten

elenchus (lat.) Verzeichnis

Enenckel - Enkel

emendiren (lat.) berichtigen, verbessern

employe (frz.) Angestellter, hier im Sinne von Anstellung

Ephemeriden - Positionstabellen von Sonne, Mond, Planeten, Kometen oder Fixsternen bezüglich konstanter Zeitabstände

erklecklich - beträchtlich

error (lat.) Fehler, Irrtum

errore calculi (lat.) Rechenfehler

juxta eundem (lat.) nahe desselben

ex alia causa (lat.) aus irgendeinem anderen Grund

e. o. - ex officio (lat.) von Amts wegen, kraft Amtes

ex tempore (lat.) aus dem Stehgreif

exceptio (lat.) Ausnahme

excitiren (lat.) erregen, aufreizen

excusation (lat.) Entschuldigung

exemtio (exemptio) (lat.) Ausnahme

omni exceptione major (lat.) vertrauenswürdig

exequieren (lat.) ausführen, vollstrecken, vollziehen 
exhibiren (lat.) vorzeigen, aushändigen, übergeben

expediens (lat.) Ausweg

exponiren (lat.) herausstellen

expressus order (lat.) ausdrücklicher Befehl

$\mathbf{F}$

facilis (lat.) leicht machbar

febris continua (lat.) fortwährendes Fieber

festum (lat.) Fest(tag), Feier

male fide (lat.) bösen Glaubens, bösgläubig

fiducia (lat.) Vertrauen, Zuversicht, Glauben

non fine opprobrio (lat.) ohne Ende der Schande

fingere (lat.) herausfinden, untersuchen

formiren (lat.) gestalten, bilden, formen, aufstellen

franco (lat.) in Franken

fundirung (lat.) Begründung, Festigung, Stabilisierung

G

general (lat.) allgemein

generös (lat., frz.) großzügig

gloriola (lat.) ein bißchen Ruhm

grandius peccatum (lat.) große Sünde 


\section{$\mathbf{H}$}

H - Abkürzung für ,Herr

honett (frz.) ehrbar, anständig, ehrenhaft, nicht knickerig, rechtschaffen, und dadurch Achtung hervorrufend

honorarium (lat.) Ehren-, hier Vergütung

Hgh $\ell$ - Abkürzung für ,hochgeehrter Herr

Meridianus Hierosolymitano (lat.) Meridian (,Mittagskreis' ${ }^{6}$ von Jerusalem

Hn - Abkürzung für ,Herren`

I

ignoratio (lat.) Unkenntnis

immediatus (lat.) unvermittelt

ob imperfectionem Tabularum (lat.) wegen mangelhafter Tabellen

impingiren (lat.) anstoßen, fehlen, verstoßen

importanz (lat.) Wichtigkeit

impossibilität (lat.) Unmöglichkeit

imputiren (lat.) jemandem für etwas die Schuld geben

in certo casu (lat.) in gewissen Fällen

in ipsum (lat.) an sich

in præsenti (lat.) für den Augenblick

in tempore (lat.) rechtzeitig

incapabel (lat.) unfähig

inclination (lat.) Neigung 
insinuiren (lat.) ,einflüstern', eingeben, einreichen, anzeigen, andeuten

interim (lat.) inzwischen, unterdessen

intraden (lat.) Einkünfte

invitiren (lat.) einladen

ipso exequiarum die (lat.) gerade am Tag des Begräbnisses

\section{$\mathbf{J}$}

judicio (lat.) Beschluss, Urteil

salvo meliori judicio (lat.) vorbehaltlich eines besseren/anderen Urteils

juxta (lat.) nahe

juxta eundem (lat.) nahe desselben

$\mathbf{K}$

Kammer - hier die Verwaltung der Einnahmen und Ausgaben eines Fürsten betreffend

$\mathbf{L}$

laboriren (lat.) herumplagen

lapsus (lat.) Fehler

Lectori (lat.) Leser

Legatos (lat.) Gesandter

leges (lat.) Gesetze

litera (lat.) Aufzeichnungen, Buchstaben, Bücher, Literatur 
littera dominicalisren (lat.) Sonntagsbuchstabe larguer (frz.) hinschmeißen, hinter sich lassen latere (lat.) der Seite, durch die Seite Lufftstreich - erfolglose Bestrebungen

M

omni exceptione major (lat.) vertrauenswürdig male fide (lat.) bösen Glaubens, bösgläubig mathematici Suecici (lat.) die schwedischen Mathematiker mathesis (lat.) Wissenschaft, Mathematik, Astronomie Medicorum (lat.) der Ärzte salvo meliori judicio (lat.) vorbehaltlich eines besseren/anderen Urteils membrum (lat.) Mitglied memorial (lat.) Denkschrift, Eingabe, Gesuch Mercurius (lat.) Merkur meridiano Hierosolymitano (lat.) Meridian (,Mittagskreis ${ }^{6}$ ) von Jerusalem Mhg - Abkürzung für ,Mein hochgeborener' bzw. ,Meine hochgeborenen` Mondjahr - Dauer von 12 Mondmonaten von abwechselnd 30 und 29 Tagen, zählt insgesamt 354 Tage

monitorius (lat.) mahnend, hier Beanstandung

momentorum (lat.) Beweggrund

motus (lat.) Bewegung

motus mediam (lat.) mittlere Bewegung 
motus verum (lat.) wahre Bewegung

$\mathbf{N}$

nepos (lat.) Enkel

communi nomine (lat.) im gemeinsamen Namen

non fine opprobrio (lat.) ohne Ende der Schande

notablis (lat.) bemerkenswert, beachtlich, auffallend

\section{$\mathbf{O}$}

ob imperfectionem Tabularum (lat.) wegen mangelhafter Tabellen

obligant (lat.) verbindlich

Obscuratio maxima (lat.) maximale Verdunklung

observiren (lat.) beobachten, insbesondere astronomische Beobachtungen anstellen

obstruiren (lat.) erschweren, hemmen, verhindern

(sich) occupiren (lat.) stark mit etwas beschäftigt sein

offeriren (lat.) anbieten

officium (lat.) Amt, Beruf, Dienst

omni exceptione major (lat.) vertrauenswürdig

opinio (lat.) Meinung

non fine opprobrio (lat.) ohne Ende der Schande 


\section{$\mathbf{P}$}

Par Amy (frz.) durch einen Freund

papista (lat.) Anhänger des Papstes

participiren (lat.) beteiligt sein

periculo errandiren (lat.) Fehlerrisiko

periculum in mora (lat.) Gefahr im Verzug

permission (lat.) Einverständnis, Erlaubnis, Genehmigung

persona odiosa (lat.) hasserfüllte Person

placitiren (lat.) gut heißen, genehmigen

Plenilunium (lat.) Vollmond

Plenilunium Paschale (lat.) Ostervollmond

post (lat.) nach

post solis occasum (lat.) nach dem Sonnenuntergang

pp - perge, perge (lat.) ,fahre fort, fahre fort' bzw. ,und so fort‘

die præcantio (lat.) Sitzungstag

præsentum (lat.) aktuell, gegenwärtig

prætendiren (lat.) fordern, beanspruchen, auf etwas bestehen

pretium (lat.) Preis, Wert

principaliter (lat.) vorzüglich, hauptsächlich, grundsätzlich, fürstlich, kaiserlich

probi (lat.) anständig, ehrlich, gut, rechtschaffen

projectiren (lat.) entwickeln, planen, entwerfen, vorbereiten

promesse (frz.) Versprechen, Zusage 
propensos (lat.) geneigt, willig

propter (lat.) wegen

prostituiren (lat.) zur Schau stellen, öffentlich feilbieten, preisgeben, beschimpfen

publici (lat.) Öffentlichkeit

Q

Quantitas anni $\mathcal{O}$ et $\mathcal{D}$ (lat.) Länge des Sonnen- und Mondjahres (siehe Sonnenjahr bzw. Mondjahr

quoad mathematica politica et Ecclesiastica (lat.) hinsichtlich Mathematik, Politik und Kirche

quota (lat.) hier Anteil

$\mathbf{R}$

raptim (lat.) eilig

rationes Collegiam suadentes (lat.) Überlegungen das Collegium zu empfehlen

recens (lat.) eben, frisch

recommendiren (lat.) empfehlen

recto (lat.) bezeichnet die Vorderseite eines Blattes Papier

refutation (lat.) Widerlegung (gegenteiliger Argumente)

regardiren (lat.) ansehen, berücksichtigen

Regenspurg - Regensburg. Im Reichssaal des Regensburger Rathauses tagte von 1663 bis 1806 der Immerwährende Reichstag, die Ständevertretung des Heiligen Römischen Reiches. 
Tag der Reinigung Mariæ - Maria Lichtmess

remittiren (lat.) zurücksenden

renasci (lat.) erneuert werden, wiederbelebt werden

res ipsa (lat.) die Sache selbst

res plena invidiæ (lat.) Dinge, voll von Neid

rescribiren (lat.) zurückschreiben, antworten, einen Befehl erlassen

Rescript (lat.) Befehl, schriftlicher Auftrag, schriftliche Antwort auf eine vorausgegangene Anfrage

resolviren (lat.) entschließen, beschließen

restitution (lat.) Rückgabe

resctriction (lat.) Einschränkung

Rudolfinische Tafeln (Tabulæ Rudolphinæ) - Sammlung von Tafeln und Regeln zur Berechnung von Planetenkonstellationen, die auf der Arbeit von Tycho Brahe basiert und von Johannes Kepler herausgegeben wurde [118]. Grundlage astronomischer Berechnungen bis zum 18. Jahrhundert.

\section{$\mathbf{S}$}

salarirung (lat.) Bezahlung

salvo meliori judicio (lat.) vorbehaltlich eines besseren/anderen Urteils

Schedas (lat.) Papiere

scripta (lat.) Schriftstücke

seculum, saeculum (lat.) Jahrhundert, Zeitraum von hundert Jahren

sentiment (lat., frz.) Empfindung, Gefühl, Stimmung

sine effectu (lat.) erfolglos 
sinistre (lat.) böswillig, böse

socer (lat.) Schwiegervater

solennität (lat.) Feierlichkeit

Sonnenjahr - die Zeit, die die Erde für einen Umlauf auf ihrer Bahn um die Sonne benötigt

speciosa argumenta (lat.) großartige Argumente

stabiliren (lat.) bestimmen, befestigen, ansiedeln

statuiren (lat.) feststellen

st. v. - stili veteris (lat.) alten Stils

rationes Collegiam suadentes (lat.) Überlegungen das Collegium zu empfehlen

success (lat.) Erfolg

sugilliren (lat.) schelten, verspotten

supponiren (lat.) unterlegen, voraussetzen

symbola (lat.) Beitrag

$\mathbf{T}$

ob imperfectionem Tabularum (lat.) wegen mangelhafter Tabellen tecto nomine (lat.) mit verheimlichtem Namen

ex tempore (lat.) aus dem Stehgreif

tempus mactandi agnum Paschalem (lat.) Zeit, das Osterlamm zu schlachten torquiren (lat.) quälen, peinigen

T.T. - toto titulo (lat.) ,mit vollständigem Titel' ${ }^{6}$, wurde als formelhafte Wendung bei Weglassen der vollständigen Titulatur benutzt 
tractiren (lat.) behandeln, abhandeln, verhandeln

$\mathbf{U}$

unanimiter (lat.) einmüthig (bei Beschlussfassungen)

Uraniborg (Dänemark) - Standort der Sternwarte Tycho Brahes

urgiren (lat.) auf etwas drängen, etwas immer wieder anregen

universaliter (lat.) im Allgemeinen

Unterschleif - Unterschlagung

unverhalten - Adverb für ,nicht verschwiegen ${ }^{6}$

V

Vale et porro fave (lat.) ,Lebe wohl und sei [mir weiterhin] gewogen', Grußformel am Ende eines Briefs

Vale et salve milliens (lat.) ,Lebe wohl und sei tausfach gegrüßt', Grußformel am Ende eines Briefs

(sich) vergleich - sich einigen, eine gütliche Übereinkunft finden

verso (lat.) bezeichnet die Rückseite eines Blattes Papier

motus verum (lat.) wahre Bewegung

vigiliren (lat.) wachsam sein, auf etwas Acht geben

vitium (lat.) Fehler 


\section{Personenverzeichnis}

Andrea Argoli (1570-1657) italienischer Mathematiker und Astronom, Professor an der Universität Padua, Astologie-Lehrer Wallensteins.

Albrecht (1648-1699) Herzog von Sachsen-Coburg.

August II. siehe Friedrich August I.

Ismael Boulliau (1605-1694) französischer Astronom und Theologe.

Tycho Brahe (1546-1601) war ein bedeutender Astronomen adliger Abstammung. Der dänische König stellte ihm für seine Beobachtungen die Öresundinsel Ven zur Verfügung. Seine dort erbaute Forschungsstätte nannte er nach Urania, der Muse der Sternenkunde, Uraniborg.

Julius Cäsar (100 v. Chr.-44 v. Chr.) römischer Feldherr, Staatsmann und römischer Kaiser.

Giovanni Domenico Cassini (1625-1712) italienisch-französischer Astronom und Mathematiker, Direktor der Sternwarte der Pariser Akademie der Wissenschaften, ausdauernder und akkurater Beobachter. Nach ihm sind die sogenannten Cassinischen Kurven benannt.

Christian V. (1646-1699) 1670-1699 König von Dänemark und Norwegen.

Christopher Clavius (1538-1612) jesuitischer Mathematiker, Professor für Mathematik am Collegium Romanum, verteidigte in seiner 1588 veröffentlichten Schrift den „neuen römischen Kalender“, also den 1582 eingeführten Gregorianischen Kalender gegen Mästlin.

Clemens VIII. (1536-1605) 1592-1605 Papst.

Georg Christoph Eimmart (1638-1705) Nürnberger Mathematiker, Astronom und Kupferstecher, studierte in Jena bei Weigel, begründete in Nürnberg 1678 die erste Nürnberger Sternwarte und öfnete diese auch der interessierten Öffentlichkeit. 
„Bruder Erasmi` Bruder des Daniel Erasmus von Huldenberg.

Georg Philipp Fabricius (1632-1709) aus Gießen stammender Jurist, seit 1674 Gesandter verschiedener Herrschaftshäuser am Immerwährenden Reichstag in Regensburg, vor 1679 Weimarischer Rat, 16821709 Gesandter Sachsen-Weimars und Sachsen-Eisenachs in Regensburg, 1701 Kaiserlicher Rat.

John Flamsteed (1646-1719) englischer Astronom, 1675 Ernennung zum ersten Königlichen Astronom an der Sternwarte der Londoner Royal Society in Greenwich, seine astronomischen Beobachtungsergebnisse besaßen bemerkenswert hohe Genauigkeit und seine Mondbeobachtungen galten als die exaktesten jener Zeit.

August Hermann Francke (1663-1727) Theologe, Hauptvertreter des Pietismus, gründete 1695 eine Armenschule und ein Waisenhaus sowie 1698 die bis heute in Halle bestehenden Franckeschen Stiftungen.

Friedrich I. siehe Friedrich III.

Friedrich II. (1676-1732) Herzog von Sachsen-Gotha und Altenburg.

Friedrich II. (1712-1786) Friedrich der Große/Alter Fritz, 1740/1772-1786 König in/von Preußen und Kurfürst von Brandenburg.

Friedrich III. (1657-1713) 1688-1713 Kurfürst von Brandenburg, als Friedrich I. 1701-1713 König in Preußen.

Friedrich August I. (1670-1733) August der Starke, ab 1694 Kurfürst von Sachsen, ab 1697 König von Polen und als August II. Großfürst von Litauen.

Thomas Fritsch (1666-1726) Leipziger Verleger und Buchhändler, erhielt 1699 ein Kalenderprivileg für das Kurfürstentum Sachsen.

Paul von Fuchs (1640-1704) Staatsmann, Minister des Kurfürsten von Brandenburg, diplomatischer Botschafter in außenpolitischen Angelegenheiten, war an der Gründung der Universität Halle 1694 beteiligt. 
Johannes Gaupp (1667-1738) Mathematiker, Astronom und Theologe, stammt aus Lindau am Bodensee, ab 1685 Studium an der Universität Jena, Schüler Erhard Weigels, 1691/92 Studienreisen und Aufenthalte in London und Oxford, ab 1694 Pfarrer in Lindau, legte 1724 eine Schrift zur „beständigen Richtigkeit des verbesserten Calenders“ vor.

Gregor XIII. (1502-1585) 1572-1585 Papst.

Johannes Hevelius (1611-1687) entstammt einer vermögenden Danziger Familie, war Bierbrauer und Bürgermeister. Seine Leidenschaft galt der Astronomie, die er mit seiner zweiten Frau teilte. Dieser gingen beide in einer auf seinen Häusern errichteten großen Sternwarte nach.

Johann Heinrich Hoffmann (1669-1716) Enkel von Weigels Vorgänger Heinrich Hofmann auf dessen Lehrstuhl an der Universität Jena, Studium an der Universität Jena, Schüler und Assistent Erhard Weigels, ab 1701 Gehilfe Gottfried Kirchs und nach dessen Tod ab 1710 Direktor am Observatorium der Berliner Akademie der Wissenschaften.

Johann Ludwig Hocker (1670-1746) Schüler Erhard Weigels, Respondent bei Hambergers Disputation 1694.

Daniel Erasmus von Huldenberg (1660-1733) Sohn eines preußischen Pastors, Repräsentant des Kurfürsten von Hannover und Gesandter des Königs von England am Wiener Hof.

Johann Ernst (1658-1729) Herzog von Sachsen-Saalfeld.

Johann Ernst III. (1664-1707) Herzog von Sachsen-Weimar.

Johann Wilhelm (1666-1729) Herzog von Sachsen-Eisenach, erteilte Hamberger am 10. April 1700 in Eisenach ein Kalenderprivileg.

Ulrich Junius (1670-1726) Astronom, Mathematiker und Kalenderschreiber, studierte zunächst in Jena, wechselte dann an die Universität Leipzig und wurde dort später Professor. Er publizierte Ephemeriden und führte intensive Briefwechsel. Für das 1699 von Sachsen eingeführte eigenständige Kalendermonopol wurde ihm die Position des zuständigen Kalenderschreibers übertragen. 
Karl XI. (1655-1697) 1660-1697 König von Schweden.

Karl XII. (1682-1718) 1697-1718 König von Schweden.

Johannes Kepler (1571-1630) Astronom, Mathematiker und Physiker, formulierte die drei Keplerschen Gesetze der Planetenbewegung. Er wertete die Aufzeichnungen Tycho Brahes aus und publizierte diese in den Rudolfinischen Tafeln [118]. Er beschrieb darin die Positionen der Planeten mit bis dahin unerreichter Genauigkeit.

Gottfried Kirch (1639-1710) Schulmeister, Astronom und Kalenderschreiber. Seine Kalenderreihen erschienen über mehrere Jahrzehnte, zum Teil auch unter Pseudonymen. Mit Gründung der Berliner Akademie der Wissenschaften wurde er 1700 der erste Direktor des zugehörigen Observatoriums.

Konstantin I. (zwischen 270 und 288-337) 306-337 römischer Kaiser.

Christian Körber (1672-1728) Theologe, 1691-1694 Studium an der Universität Jena, 1696 Diakon und später Superintendent in Lobenstein im Vogtland.

Johannes Kühn (1619-1676) Mathematiker, Studium und akademische Laufbahn an der Leipziger Universität, übernahm 1659 als Nachfolger Philipp Müllers die Professur für Mathematik, erlangte wegen exzessiven Alkoholkonsums und gewalttätiger Ausschreitungen seiner Frau gegenüber traurige Berühmtheit.

Philippe de La Hire (1640-1718) Künstler und Mathematiker, befasste sich mit Geometrie und hier insbesondere mit Kegelschnitten. La Hire wurde 1678 als Mitglied der Pariser Akademie berufen, überraschenderweise in die astronomische Klasse.

Gottfried Wilhelm Leibniz (1646-1716) Philosoph und Wissenschaftler, wird häufig als letzter Universalgelehrter bezeichnet, studierte 1663 bei Erhard Weigel in Jena, verwirklichte mit Gründung der KöniglichPreußischen Akademie der Wissenschaften in Berlin Erhard Weigels Vision des Collegium Artis Consultorum - einschließlich der Finanzierung durch ein Kalendermonopol. 
Leopold I. (1640-1705) 1658-1705 Kaiser des Heiligen Römischen Reiches.

Hiob Ludolf (1649-1711) Erfurter Mathematiker, hatte zunächst Jura studiert, wandte sich dann aber der Mathematik zu, lehrte seit 1683 an der Universität Erfurt und hat sich als Begründer der Lotterie in Deutschland einen Namen gemacht.

Ludwig VI. (1539-1583) Pfalzgraf bei Rhein, ab 1576 Kurfürst von der Pfalz.

Nikolaus Christoph von Lyncker (1643-1726) Kaiserlicher Reichshofrath und Staatsrechtler, war unter anderem Professor der Rechtswissenschaften an der Universität Jena, zugleich Beisitzer des Schöppenstuhles sowie des Hofgerichtes, Geheimrath und Consistorialpräsident in Weimar sowie später Geheimer Rathspräsident mit der Oberaufsicht über die Universität Jena.

Michael Mästlin (1550-1631) Tübinger Mathematiker und Astronom, Lehrer und Freund Johannes Keplers, erkannte das aschgraue Mondlicht richtig als von der Erde reflektiertes Sonnenlicht, spielte eine maßgebliche Rolle in der Polemik gegen die vom Papst verordnete Kalenderreform nach Erscheinen der päpstlichen Bulle „Inter gravissimas" 1582 .

Johannes Meyer (1651-1719) studierte ab 1676 bei Weigel in Jena, ging 1685 als Professor an das evangelische Gymnasium in Regensburg, war in Regensburg zugleich Vertreter Weigels am Immerwährenden Reichstag, als ,Collegii Secretarius' Mitglied des von Weigel geplanten Collegium Artis Consultorum.

Philipp Müller (1640-1713) Theologe, studierte ab 1657 an der Universität Jena, kurzzeitig Pastor in Eisleben, ging 1680 als Probst des Klosters Unser lieben Frauen nach Magdeburg, Professor an der Universität Jena von 1663 bis 1680 sowie von 1702 bis 1713 .

Christoph Nothnagel (1607-1666) Mathematiker und Astronom, Studium in Wittenberg und Königsberg, ab 1634 Mathematikprofessor an der Universität Wittenberg. 
Philolai Pseudonym für Ismael Boulliau.

Pius V. (1504-1572) 1566-1572 Papst.

Kaspar Posner (1626-1700) Physiker, geboren in Gera, Studium in Jena, ab 1654 außerordentlicher und ab 1656 ordentlicher Professor der Physik an der Universität Jena.

Johann Kaspar Posner (1673-1718) Sohn von Kaspar Posner, folgte ihm als Professor der Physik an der Universität Jena.

Conrad Philipp Redeker (1663-1737) Theologe in Blasheim, Responent bei Hambergers Pro-Loco-Disputation 1688 an der Universität Jena.

Samuel Reyher (1635-1714) Mathematiker und Astronom, stammt aus Gotha, studierte in Leipzig und Leyden, wurde 1666 Professor der Mathematik und später der Rechtswissenschaften in Kiel, führte astronomische Beobachtungen durch und reichte in Regensburg einen eigenen Vorschlag zur Kalenderreform ein.

Giovanni Battista Riccioli (1598-1671) italienischer Astronom.

Werner Rolfinck (1599-1673) Mediziner an der Universität Jena.

Ole Christensen Rømer (1644-1710) dänischer Astronom, arbeitete ab 1672 als Mitglied der Pariser Akademie der Wissenschaften bei Giovanni Domenico Cassini an der Sternwarte in Paris, wurde 1676 zum königlich-dänischen Astronomen ernannt und ging 1681 als Professor für Mathematik an die Universität Kopenhagen.

Saul um 1000 v. Chr. erster König Israels.

Johann Andreas Schmidt (1652-1726) lutherischer Theologe und Kirchenhistoriker, Studium an der Universität Jena, Schüler Erhard Weigels, Gehilfe Weigels und später außerordentlicher Professor an der theologischer Fakultät - bis 1695 an der Universität Jena, Professor für Kirchengeschichte an der Universität Helmstedt, stand in enger Korrespondenz mit Leibniz. Schmidt wurde 1701 auf Leibniz' Vorschlag Mitglied der neugegründeten Berliner Akademie. 
Felix Spitz (1641-1717) Schwiegersohn Erhard Weigels und Schwiegervater Georg Albrecht Hambergers. Rechtsgelehrter, gebürtig aus Ronneburg, Studium in Jena und Tübingen, Weimarischer Rat, 1673 Eheschließung mit Anna Katharina Weigel, ab 1685 Professor der Rechtswissenschaften an der Universität Altdorf, ab 1697 Konsulent der Reichsstadt Nürnberg.

Sophia Katharina Spitz (1674-1754) Tochter von Felix Spitz, Enkelin Erhard Weigels, geboren in Jena, 1695 Eheschließung mit Georg Albrecht Hamberger.

David Spleiß (1659-1716) Philosoph, Mediziner, Naturforscher. Sohn von Stephan Spleiß, Stadtarzt und Lehrer am Gymnasium in Schaffhausen.

Johann Jacob Spleiß (1655-1728) Mathematiker. Sohn von Stephan Spleiß und Lehrer am Gymnasium in Schaffhausen.

Johannes Spleiß Buchbinder, Sohn von Stephan Spleiß und Vater von Thomas Spleiß.

Stephan Spleiß (1623-1693) Mathematiker, Pädagoge, Astronom und Rektor am Gymnasium zu Schaffhausen. Vater von David, Johann Jacob und Johannes Spleiß, Großvater von Thomas Spleiß.

Thomas Spleiß (1705-1775) Mathematiker, Physiker und Astronom. Sohn des Buchbinders Johannes Spleiß.

Aegidius Strauch (1632-1682) lutherischer Theologe, arbeitete auch auf dem Gebiet der Mathematik, Studium in Wittenberg und Leipzig, Tätigkeit an der Wittenberger Universität, ging 1669 nach Danzig.

Johann Christoph Sturm (1635-1703) deutscher Astronom und Mathematiker, stammt aus Mittelfranken, hat von 1656 bis 1662 in Jena studiert, war zwischenzeitlich ein Jahr in Leiden und schließlich ab 1669 Professor an der Universität in Altdorf. Gemeinsam mit Georg Albrecht Hamberger und Johannes Meyer hat er nach dem Tod Weigels die Kalenderreform weiter vorangetrieben. 
Gottfried Teuber (1656-1731) aus Zeitz stammender evangelischer Theologe, Hofprediger und Diakon in Zeitz, studierte ab 1677 an der Universität Jena, Schüler Erhard Weigels, war ab 1712 Mitglied der Berliner Akademie der Wissenschaften.

Joachim Tiede (um 1662-1704) Studium an der Universität Kiel, Mitglied der Berliner Akademie der Wissenschaften.

Ernst Heinrich Wedel (1671-1709) Sohn von Georg Wolfgang Wedel, Mediziner, 1695 Doktorwürde an der Universität Jena.

Georg Wolfgang Wedel (1645-1721) Mediziner, stammt aus Golzen bei Merseburg, Studium ab 1661 in Jena, insbesondere bei Werner Rolfinck, war als Mediziner in Halle, Wittenberg und Leipzig sowie als Stadtphysicus in Gotha tätig, seit 1673 als Nachfolger Rolfincks bis zu seinem Lebensende Medizinprofessor an der Universität Jena.

Johann Adolph Wedel (1675-1747) Sohn von Georg Wolfgang Wedel, Mediziner, 1697 Doktorwürde an der Universität Jena, ab 1724 Schwiegervater von Hambergers Sohn Georg Erhard Hamberger.

Anna Katharina Weigel (1654-1710) einzige überlebende Tochter Erhard Weigels, 1673 Eheschließung mit Felix Spitz, Schwiegermutter Georg Albrecht Hambergers.

Erhard Weigel (1625-1699) Mathematiker, Astronom, Philosoph und Pädagoge, gebürtig aus Weiden in der Oberpfalz, Studium ab 1647 in Leipzig, ab 1653 Professor an der Universität Jena.

Margareta Weigel $(* 1618)$ Schwester Erhard Weigels.

Wilhelm Ernst (1662-1728) Herzog von Sachsen-Weimar, erteilte Hamberger am 29. Juli 1700 in Weimar ein Kalenderprivileg.

Vincent Wing (16191668) englischer Mathematiker und Astronom, gab von 1652 bis 1671 Ephemeriden heraus.

John Wing (1662-1726) Neffe von Vincent Wing, Landvermesser, Kalendermacher, veröffentlichte ein Lehrbuch der reinen und angewandten Mathematik für ein breites Publikum [195]. 
Tycho Wing (1696-1750) Sohn von Vincent Wing, Philosoph und Astronom, von 1727 bis 1742 Richter von Rutland, setzte die Ephemeriden seines Vaters fort - bis 1739 unter dem Namen John Wing und dann unter seinem eigenen Namen.

Johann Philipp Wurzelbauer (1651-1725) gelehrter Nürnberger Kaufmann, der sich 1692 eine eigene Sternwarte errichtete und astronomische Beaobachtungen durchführte.

Daniel Zimmermann (1639-1703) Prediger und Konsistorialassessor, studierte in Wittenberg und wurde 1665 in Regensburg ordiniert.

Daniel Zimmermann Sohn des obigen Daniel Zimmermann, 1688 Immatrikulation und 1691 Disputation an der Universität Jena.

Christian Zimmermann $(* 1672)$ Jurist und Ratsherr in Regensburg, Sohn des oben genannten älteren Daniel Zimmermann, 1694 Immatrikulation und 1699 Disputation an der Universität Jena. 


\section{Abbildungsnachweis}

Portrait: Georg Albrecht Hamberger

J. G. Rabener (HrG.): Deutsche Acta eruditorum oder Geschichte der Gelehrten, welche den gegenwärtigen Zustand der Literatur in Europa begreiffen. Bd. 4, Leipzig 1715 [Frontispiz]

Exemplar: Niedersächsische Staats- und Universitätsbibliothek Göttingen 


\section{Literaturverzeichnis}

[1] Bedencken einiger Schwedischen Mathematicorum, von der CalenderVerbesserung de Anno 1700. S. 1332 f. in [135]

[2] Bulle „Inter Gravissimas“. S.13-15 in 31]

[3] Copia Königlichen Dähnischen Rescripti an Herrn Envoye von Luxdoph in Schweden, 8. August. Anno 1696. S. 752 f. in 132

[4] Denen zu Regenspurg/über D. Samuel Reyhers/ und Joach. Tiedens/ Calender-Project, abgefasseten Remarques entgegen gesetzte Beantwortung. Mens. Jun. 1699. 1699 VD17 7:700936M

[5] Edikt des sächsischen Kurfürsten vom 8. (18.) Nov. 1699 (StA Dresden, Landesregierung, Loc. 11 374, Bl.3) und die Aktenvorgänge über Fritschs Privilegierung (ebd., Geheimer Rat, Loc. 7285).

[6] Jahres-Bericht über das Königliche Lyceum und über das K. Gymnasium und die lateinische Schule zu Regensburg für das Studienjahr 1853/54. Stadtamhof 1854

[7] Litterce Responsorice Regice Majestatis Succicae dd. 19. Aug. 1699. Emendationem Fastorum concernentes. S. 181-182 in [157]

[8] Trost-Gedicht über den zwar frühen doch seligen Hintritt Annen Elisabethen, des ... Herrn Erhardi Weigelii ... hertzvielgeliebten Töchterleins. Jena 14. August 1657 VD17 547:632148F

[9] Unvergreifliche Gedancken über die Vorschlage der Herrn Mathematicorum in Schweden, das Calenderwesen betreffend. Zu einem Bericht des Königlich Dänischen Raths Dettleff Niclas von Lewencron vom 5. Oktober 1699. S. 31-37 in [105] 
[10] Kosmos-Himmelsjahr ...: Sonne, Mond und Sterne im Jahreslauf. Stuttgart ISSN 1438-3306

[11] S. R. Acxtelmeier: Monatlicher Staats-Spiegel ... auf den Monat May 1699. Augsburg 1699

[12] S. R. Acxtelmeier: Monatlicher Staats-Spiegel ... auf den Monat Julij 1699. Augsburg 1699

[13] S. R. Acxtelmeier: Monatlicher Staats-Spiegel ... auf den Monat November 1699. Augsburg 1699

[14] S. R. Acxtelmeier: Monatlicher Staats-Spiegel ... auf den Monat December 1699. Augsburg 1699

[15] S. R. AcXtelmeier: Monatlicher Staats-Spiegel ... auf den Monat Julij 1700. Augsburg 1700

[16] A. Argoli: Tabvla Primi Mobilis. Patavii 1667

[17] A. Assmann: Erinnerungsräume - Formen und Wandlungen des kulturellen Gedächtnisses. München 2009

[18] P. Aventinus: Alter und Neuer Historischer Schreib- und HaußCalender / nebst dem Römischen / auff das Schalt-Jahr nach der Heylwärtigen Geburt unsers Heylandes Jesu Christi. MDCLXXII. Gotha 1671 VD1727:713545E

[19] P. Aventinus: Alter und Neuer Historischer Hauß-Calender nebst dem Römischen / auff das Schalt-Jahr nach der heilwärtigen Geburt unsers Heylandes Jesu Christi MDCLXXVI. Gotha 1675 VD1727:714797T

[20] F. W. Bauks: Die evangelischen Pfarrer in Westfalen von der Reformationszeit bis 1945. Bielefeld 1980

[21] G. Betsch, J. Hamel (Hrsg.): Zwischen Copernicus und Kepler - M. Michael Maestlinus Mathematicus Goeppingensis 1550-1631. Frankfurt am Main 2002

[22] J. C. Blasche: Das Leben des Herrn Hofraths und Professors, Georg Erhard Hambergers, nebst einer Nachricht von seinen Schriften, und gelehrten Streitigkeiten. Jena 1758 
[23] I. Boulliau: Ismaelis Bullialdi Astronomia philolaica. Paris 1645

[24] T. BRAHE: Collectanea meteorologica / sub auspiciis Societatis Scientiarum Danicae edita. Appendice: Meteorologiske dagbok - holdt paa Uraniborg for Aarene 1582-1597. Kopenhagen 1876

[25] H.-S. BRATHER: Leibniz und seine Akademie - ausgewählte Quellen zur Geschichte der Berliner Sozietät der Wissenschaften, 1697-1716. Berlin 1993

[26] E. D. Butterfladen: Nach Alt und Neuer Zeit eingerichter Geschichts-Calender / Auf das Jahr 1690. Langensalza 1689 VD1727:712929Q

[27] M. Cantor: Vorlesungen über Geschichte der Mathematik. Bd.3, Leipzig 1901

[28] H. Caselmann, J. J. Herzog: Realencyklopädie für protestantische Theologie und Kirche. Bd. 18, Gotha 1866

[29] G. D. Cassini: Ephemerides Bononienses mediceorum siderum. 1668

[30] C. Clavius: Novi Calendarii romani apologia, adversus Michaelem Maestlinum Gappingensem tribus libris explicata. Rom 1588

[31] C. Clavius: Romani Calendarii A Gregorio XIII. P. M. restitvti explicatio S. D. N. Clementis VIII. P. M. Ivssv edita-accesit confutatio eorum, qui Calendarium aliter instaurandum esse contenderunt. Rom 1603

[32] K. Cramer, G. Patzig: Die Philosophie in Göttingen 1734-1987. S. 86-91 in 163

[33] R. Dick, J. HameL: Beiträge zur Astronomiegeschichte. Band 5, Frankfurt am Main 2002

[34] D. DöRING: Die „Excesse“ des Leipziger Mathematikprofessors Johannes Kühn. S. 321-350 in 133 .

[35] H. DöRING: Die gelehrten Theologen Deutschlands im achtzehnten und neunzehnten Jahrhundert. Band J-M, Neustadt an der Orla 1832 
[36] J. DorschneR: Erhard Weigel in seiner Zeit. S. 11-38 in [161]

[37] J. A. R. von Eisenhart: Nikolaus Christoph Lyncker. Allgemeine Deutsche Biographie 19 (1884), S. 737-740

[38] J. A. R. von Eisenhart: Felix Spitz.

Allgemeine Deutsche Biographie, Band 35 (1893), S. 216-217

[39] B. FABIAN (Hrsg.): Handbuch der historischen Buchbestände in Deutschland. Bd. 19: Thüringen A-G, Hildesheim 1998

[40] B. Fabian (Hrsg.): Handbuch der historischen Buchbestände in Deutschland. Bd. 20: Thüringen H-R, Hildesheim 1999

[41] J. Flamsteed: Lunares Numeri ... London 1673

[42] S. Friedrich: Drehscheibe Regensburg. Das Informations- und Kommunikationssystem des Immerwährenden Reichstags um 1700. Berlin 2007

[43] J. G. Frischmann (Präses), D. Zimmermann (Resp.): Exercitatio De Cultu Imaginum Apud Gentiles. Disputation Universität Jena August/September 1691, VD17 23:330497G \& VD17 12:151102A

[44] G. Fritsch, R. Fritsch: Albert Daniel Mercklein Naturwissenschaftler und/oder Pfarrer in der ersten Hälfte des 18. Jahrhunderts. S. 266-284 in: Medium Mathematik - Anregungen zu einem interdisziplinären Gedankenaustausch. Band 1, Hildesheim \& Berlin 2002

[45] J. M. Fuchs: Einige Notizen zur Schul-Geschichte von Heilsbronn und Ansbach: bekannt gemacht bei der Säkular-Feyer des Ansbacher Gymnasiums am 12. Juni 1837. Brügel 1837

[46] W. FüRnRohr: Das Patriziat der Freien Reichsstadt Regensburg zur Zeit des Immerwährenden Reichstags. Verhandlungen des Historischen Vereins für Oberpfalz und Regensburg, Bd. 93 (1952) S. 153-308

[47] H. GaAB: Zur Biographie von Johann Christoph Sturm (1635-1703). S. $12-85$ in [48]

[48] H. GaAb, P. Leich, G. Löffladt (Hrsg.): Johann Christoph Sturm (1635-1703). Acta Historica Astronomiae, vol. 22. Frankfurt am Main 2004 
[49] N. GÄDEKE: Leibniz lässt sich informieren - Asymmetrien in seinen Korrespondenzbeziehungen. S. 25-46 in [100]

[50] J. Gaupp: Tafeln zur mechanischen Sonnen-Uhr-Kunst, durch welche auff eine gantz leichte Weise alle vorkommende Sonnen-Uhren am allerrichtigsten verzeichnet ... werden können. Lindau 1708

[51] J. Gaupp: Gnomonica oder Mechanische Sonnen-Uhrkunst. Augsburg 1711

[52] J. Gaupp: Gnomonica mechanica continuatio: Fortsetzung der mechanischen Sonnen-Uhr-Kunst. Frankfurt am Main und Leipzig 1720

[53] J. Gaupp: Ausführliche Beschreibung der grossen Sonnen-Finsternuß, welche anno 1715 den 3. May Vormittags in gantz Europa ... zu sehen seyn wird. Augsburg 1715

[54] J. Gaupp: Die Beständige Richtigkeit Des Verbesserten Calenders Derer Evangelischen im Heil. Röm. Reich. Regensburg 1724

[55] J. Grimm, W. Grimm: Deutsches Wörterbuch. online http://woerterbuchnetz.de/DWB/

[56] GÜNTHER: Thomas Spleiß. Allgemeine Deutsche Biographie, Band 35 (1893), S. 233

[57] J. GüNTHER: Lebensskizzen der Professoren der Universität Jena seit 1558 bis 1858. Jena 1858

[58] T. GüNTHER: Goethes Crailsheimer Vorfahren und ihre fränkischthüringische Verwandschaft. Köln 1970

[59] M. Habicht: Nachricht von dem Leben des Herrn Thomas Spleiß. Schaffhausen 1776

[60] F.A. Hallbauer: Friedrich Andreas Hallbauers Sammlung Teutscher auserlesener sinnreicher Inscriptionen. Jena 1732

[61] G. A. Hamberger: Programma De Meritis Germanorum In Mathesin. Quo Orationem Inauguralem Praelectionibus Publicis Solenni Maiorum More Praemittendam Indicit. Jena 10. Juni 1694, VD17 547:690009T 
[62] G. A. Hamberger: Tractatus De Frigore. Jena 1698, VD173:622971N

[63] G. A. Hamberger: Verbesserter und von allem Aberglauben gereinigter Calender. Auf das Jahr nach Christi Geburth MDCCI nach der auf dem Reichstag zu Regenspurg von denen Gesamten Evangelischen Reichsständen beliebten Verfassung. Jena 1700, VD17 27:714901Z

[64] G. A. Hamberger: Anhang Verschiedener zum Calender gehöriger Sachen ... Nebst beygefügter Erörterung der Frage: Ob und was vor ein Unterscheid/zwischen dem Verbesserten und Gregorischen Calender/sey? Anhang zum Kalender 170163 .

[65] G. A. Hamberger: Georg Albrecht Hambergers verbesserter und von allem Aberglauben gereinigter Calender. Jena 1704

[66] G. A. Hamberger: Fasciculus dissertationum academicarum physico-mathematicarum antehac seorsim editarum. Jena 1708

[67] G. A. Hamberger (Präses), G. F. Beer (Resp.): Deum Ex Inspectione Cordis Investigatum. Disputation Universität Jena 15. Oktober 1692, VD17 14:053816G \& VD17 14:053818X

[68] G. A. Hamberger (Präses), A. B. Bernhardi (Resp.): Optica Oculorum Vitia. Disputation Universität Jena Oktober 1696, VD17 3:014740S

[69] G. A. Hamberger (Präses), J. Crüger (Resp.): Dissertatio Academica De Barometris. Disputation Universität Jena 13. März 1701

[70] G. A. Hamberger (Präses), C. F. Fischer (Resp.): Dissertatio Optica De Coloribus. Disputation Universität Jena 1689, VD17 39:150249F

[71] G. A. Hamberger (Präses), M. N. Hanneken (Resp.): Dispvtatio Academica De Ventricvli Per Aestatem Imbecillitate. Disputation Universität Jena 1702

[72] G. A. Hamberger (Präses), J. L. Hassfurter (Resp.): Dissertatio Mathematica De Basi Computi Ecclessiastici. Disputation Universität Jena 1705 
[73] G. A. Hamberger (Präses), V. B. Heuber (Resp.): Methodum Acquirendi Virtutem. Disputation Universität Jena 1690, VD17 12:173952S

[74] G. A. Hamberger (Präses), J. C. Hochstätter (Resp.): De Francis Antiquis Favente Deo. Disputation Universität Jena 1686, VD17 23:302368P \& VD17 14:053886C

[75] G. A. Hamberger (Präses), J. L. Hocker (Resp.): De Usu Matheseos In Theologia. Disputation Universität Jena 19. September 1694, VD17 12:156305F \& VD17 23:623916R

[76] G. A. Hamberger, J. Meyer, J. C. Sturm: Unvorgreiffliches Bedencken wegen vorhabender völliger Calender-Verbesserung. Auf gnädige Veranlassung eines Hochlöblichen Corporis Evangelici unterthänig verfasset von einigen Mathematicis. S. 110-120 in [105]

[77] G. A. Hamberger (Präses), J. C. Müller (Resp.): Dissertatio Academica De Frigore. Disputation Universität Jena 7. September 1698, VD17 3:019259M \& VD17 3:022045M

[78] G. A. Hamberger (Präses), C.P. Redeker (Resp.): De Epochae Christianae Ortu Et Autore. Disputation "pro loco in eadem obtinendo" Universität Jena Dezember 1688, VD17 14:061903C

[79] G. A. Hamberger (Präses), A. Seidel (Resp.): Hydraulicam. Disputation Universität Jena 8. Januar 1698, VD17 14:635216Q

[80] G. A. Hamberger (Präses), C. Seyfried (Resp.): Iridem Diluvii, Gen. IX, 13. seq. Disputation Universität Jena 18. Juli 1696, VD17 12:163442E \& VD17 7:710357C

[81] G. A. Hamberger (Präses), J. P. Strobel (Resp.): $\breve{S} a b \bar{u} a^{c}$ David sive Iusiurandum Davidis I. Sam. XXV, 22. Disputation Universität Jena 1687, VD17 12:145635K

[82] G. A. Hamberger (Präses), C. Wedel (Resp.): Dissertatio Physica De Elatere. Disputation Universität Jena 27. Mai 1699, VD17 14:066448M \& VD17 7:696894H 
[83] G. E. Hamberger: Sendschreiben an T.T. Herrn Hofrath Hallern in Göttingen, Wegen einer in denen Göttingischen gelehrten Zeitungen von 11. Martii a.c. im 27. Stück befindlichen Recension der Hambergerischen Vorrede zu dem Wedelischen Tentamine Botanico. Jena 1748

[84] J. HameL: Erhard Weigel und die Kalenderreform des Jahres 1700. S. 135-156 in 161

[85] J. Hamel: Die Rolle Michael Mästlins in der Polemik um die Kalenderreform von Papst Gregor XIII. S. 33-63 in [21]

[86] J. Hamel: Die Kalenderreform des Jahres 1700 und ihre Durchsetzung in Hessen. Zeitschrift des Vereins für hessische Geschichte, Band 105 (2000) S. 59-74

[87] F. Händel, A. Herrmann (Hrsg.): Das Hausbuch des Apothekers Michael Walburger 1652-1667. Quellenedition zur Kulturgeschichte eines bürgerlichen Hauswesens im 17. Jahrhundert. Hof 1988-1992

[88] A. von Harnack: Geschichte der Königlich Preussischen Akademie der Wissenschaften zu Berlin. Band 2, Berlin 1900

[89] J. Hartung: Galerie der Professoren für Physik und Astronomie der Friedrich-Schiller-Universität Jena. http://www.physik.uni-jena.de/profgalerie/grafik11.pdf

[90] J. Hecker-Stampehl: Ein 30. Februar vor 300 Jahren in Schweden. NordicHistoryBlog - Blogpost vom 29. Februar 2012. http://nordichistoryblog.hypotheses.org/211

[91] P. K. Hentschel, A. D. Wittmann (Hrsg.): The Role of Visual Representations in Astronomy - History and Research Practice. Frankfurt (Main) 2000

[92] K.-D. Herbst: Astronomie um 1700 - Kommentierte Edition des Briefes von Gottfried Kirch an Olaus Römer vom 25. Oktober 1703. Frankfurt am Main 1999

[93] K.-D. HeRBst: Traces to the mechanic's workshop: Gottfried Teuber's copper engraving and woodcut illustrations for Erhard Weigel. S. 53-65 in [91] 
[94] K.-D. Herbst (Hrsg.): Die Korrespondenz des Astronomen und Kalendermachers Gottfried Kirch (1639 - 1710). 3 Bände, Jena 2006

[95] K.-D. HeRBST: Verzeichnis der Schreibkalender des 17. Jahrhunderts. Acta Calendariographica Vol. 1, Jena 2008

[96] K.-D. HeRBst: Der Schreibkalender der Frühen Neuzeit - eine noch wenig genutzte Quelle für die Astronomiegeschichtsschreibung. Sitzungsberichte der Leibniz-Sozietät der Wissenschaften zu Berlin 103 (2009), S. 31-48

[97] K.-D. Herbst: Die Jahreskalender - Ein Medium für gelehrte Kommunikation. S. 189-224 in [100]

[98] K.-D. HeRBst: Die Schreibkalender im Kontext der Frühaufklrung. Acta Calendariographica Vol. 2, Jena 2010

[99] K.-D. HeRBST: Kommentiertes Verzeichnis der Schreibkalender für 1701 bis $1750 \mathrm{im}$ Stadtarchiv Altenburg. Acta Calendariographica Vol. 3, Jena 2011

[100] K.-D. Herbst, S. Kratochwil (Hrsg.): Kommunikation in der Frühen Neuzeit. Frankfurt am Main 2009

[101] N. A. HeRrich: Sammlung aller Conclusorum, Schreiben und anderer Verhandlungen des hochpreißlichen Corporis Evangelicorum vom Jahre 1753 bis 1786. Regensburg 1786

[102] J. Hevelius: Machince Coelestis. Band 2, Rerum uranicorum observationes ... Danzig 1679

[103] F. C. G. Hinsching: Historisch-literarisches Handbuch berühmter und denkwürdiger Personen, welche in dem 18. Jahrhunderte gestorben sind. Band 2, Abth. 2, Leipzig 1796

[104] J. L. Hocker, J. L. Heydenreich: Johann Ludwig Hockers eigene Lebens-Beschreibung. Schwabach 1749

[105] P. Horrebow: Operum mathematico-physicorum: tomus primus [tertius]. Band 2, 1741 
[106] D. V. Hoyt, K. H. Schatten: The Role of the Sun in Climate Change. Oxford University Press 1997

[107] R. Jauernig, G. Steiger: Die Matrikel der Universität Jena. Bd. 2 (1652-1723) Weimar 1961

[108] H. Jaumann: Handbuch Gelehrtenkultur der frühen Neuzeit. Bd.1: Bio-bibliographisches Repertorium. Berlin 2004

[109] C. G. Jöcher, J. C. Adelung, H. W. Rotermund: Allgemeines Gelehrten-Lexicon. Leipzig 1810

[110] K. Junger: Die Fürstenschule zu Heilsbronn. Dissertation Universität Erlangen-Nürnberg 1971

[111] U. Junius: Mercurii In Sole Conspicui Calculus Anno MDCXCVII. D. XXIV. Octobr. ... Leipzig 1697

[112] U. Junius: Mercurius In Sole Videndus Sive Calculus Rari huius Phaenomeni Anno MDCXCVII. D. XXIV. Octobr. .. Leipzig 1697

[113] U. Junius: Unpartheyisches Bedencken Uber die von Tit. Herrn Prof. Weigelio Dem höchst-ansehnlichsten Reichs-Collegio zu Regenspurg proponirte Calender-Vereinigung. Enth. außerdem: Eines unbenandten Authoris Anmerckungen über das unpartheyische Bedencken von Tit. Herrn Prof. Weigelii proponirter Calender-Conciliation nebst einer Beantwortung derselben. Leipzig 1699 VD17 23:686919W, mit abgedruckt in VD17 23:642453U

[114] U. Junius: Novae et accurate motuum coelestium ephemerides ad annum 1701, 1702 \&3 1703 Leipzig 1701, $1702 \& 1703$

[115] W. KAISER: Johann Andreas Segner, der „Vater der Turbine“ Leipzig 1977

[116] J. KePLer: Astronomia Nova. Heidelberg 1609 VD17 23:000587W

[117] J. KePlen: Harmonices mundi libri V. Plancus, Lincii Austriæ 1619 VD17 12:651013V \& VD17 23:231179V

[118] J. KePLER: Tabulce Rudolphinœ, Quibus Astronomicae Scientiae, Temporum longinquitate collapsae Restauratio continetur. Ulm 1627 VD17 12:651552R 
[119] O. Knopf: Die Astronomie an der Universität Jena von der Gründung der Universität im Jahre 1558 bis zur Entpflichtung des Verfassers im Jahre 1927. Fischer 1937

[120] S. Kratochwil: Einige Bemerkungen zum Weigelschen Himmelsglobus im Stadtmuseum Jena. Jenaer Jahrbuch zur Technik- und Industriegeschichte, Band 5 (2003) S. 78-81

[121] S. KratochwiL: Die Himmelsgloben von Erhard Weigel. Jenaer Jahrbuch zur Technik- und Industriegeschichte, Band 6 (2004) S. 41-54

[122] S. Kratochwil (Hrsg.): Philosophia mathematica. Die Philosophie im Werk von Erhard Weigel. Jena 2005

[123] S. Kratochwil: Das Weigel-Projekt: Versuch einer Rekonstruktion des Selbstverständnisses von Erhard Weigel. S. 7-21 in [122]

[124] S. Kratochwil: Der ,Pancosmos' von Erhard Weigel. Der Globusfreund, No. 57/58 (2011, für 2009/2010) S. 11-22

[125] S. Kratochwil: Persönliche Mitteilung.

[126] I. KreKler: Die Autographensammlung des Stuttgarter Konistorialdirektors Friedrich Wilhelm Frommann (1707-1787). Wiesbaden 1992

[127] P. De La Hire: Tabularum Astronomicarum Pars Prior De Motibus Solis Et Lunce. Paris 1687

[128] L. von Lehsten: Die hessischen Reichstagsgesandten im 17. und 18. Jahrhundert. Band 2, Darmstadt 2003

[129] G. W. LeIBNIZ: Sämtliche Schriften und Briefe. Herausgegeben von der Berlin-Brandenburgischen Akademie der Wissenschaften und der Akademie der Wissenschaften in Göttingen. Reihe 4: Politische Schriften, Band 7: 1697-Anfang 1699, 2011

[130] G. W. Leibniz: Sämtliche Schriften und Briefe. Herausgegeben von der Berlin-Brandenburgischen Akademie der Wissenschaften und der Akademie der Wissenschaften in Göttingen. Reihe 1: Allgemeiner politischer und historischer Briefwechsel, Band 17: Mai-Dezember 1699, 2001 
[131] G. W. Leibniz: Sämtliche Schriften und Briefe. Herausgegeben von der Berlin-Brandenburgischen Akademie der Wissenschaften und der Akademie der Wissenschaften in Göttingen. Reihe 1: Allgemeiner politischer und historischer Briefwechsel, Band 18: Januar-August 1700, 2005

[132] C. L. Leucht: Europaischer Staats-Cantzley Vierter Theil ... 1700

[133] H. LüCK, B. SchILDT (Hrsg.): Recht - Idee - Geschichte. Böhlau 2000

[134] H. Ludolf: D. Hiob Ludolffs Math. P.P. zu Erffurt abgenöthigte Wiederlegung Der Von einem Anonymo so intitulirten und in Utopia gedruckten gründlichen und genauen Untersuchung Von dem Anfange des herannahenden Jahr-Hunderts und sothaner Untersuchung beygefügten Schreibens Eines im Gehirne nicht wohlverwahrten Baccalaurei Theologice als betreffend die Streit-Frage: Ob 1700. oder 1701. für das erste Jahr des zukünfftigen Seculi zu halten sey? Jena 1700

[135] J. C. LÜNIG (Hrsg.): Europäische Staats-Consilia oder curieuse Bedencken Band 2, 1715

[136] M. Luther, K.-H. Vanheiden: Die Bibel. Neue evangelistische bersetzung: Das zweite Buch Samuel. http://www.kh-vanheiden.de/NeUe/Bibeltexte/2sam.html

[137] K. Marti-Weissenbach: Stephan Spleiß. Historisches Lexikon der Schweiz online. http://www.hls-dhs-dss.ch/textes/d/D26169.php

[138] P. J. Marperger: Kurtze Beschreibung Des Auff allergnädigste Verordnung Dero Zu Dennemarck Norwegen Kön. Majest. Königs Christiani. V. Von ... Herrn Erhard Weigelio ... verfertigten Und den 4. Octobr. 1696. ... allhier in Copenhagen auff Rosenburg offerirten Pancosmi, oder Groß-Bilds der Welt. Ploen 1697 VD17 14:065342F

[139] M. Mästlin: Altervm Examen Novi Pontificialis Gregoriani Kalendarii. Tübingen 1588

[140] K. MatthäUs: Sturm als Kalendermacher. S. 226-249 in 48]

[141] C. Meiners: Kurze Geschichte und Beschreibung der Stadt Göttingen und der umliegenden Gegend. Haude und Spender 1801 
[142] W. Menn: Pommersche Lebensbilder. Band 4, Stettin 1966

[143] W. Meyer: Verzeichniss der Handschriften im Preussischen Staate. Abt. I: Hannover. Bd. 1: Die Handschriften in Göttingen. Teil 1, Berlin 1893

[144] K. MolL: Zur Frage nach dem Nutzen der Philosophie im Briefwechsel von G. W. Leibniz. S. 155-169 in 100

[145] F. NeEF: Nikolaus Christoph Freiherr von Lyncker. In: Neue Deutsche Biographie, Band 15 (1987), S. 585-586

[146] J.C. PoggendorfF: Biographisch-literarisches Handwrterbuch zur Geschichte der exacten Wissenschaften. Band 1 A-L, Leipzig 1863

[147] J. G. RABener (Hrsg.): Deutsche Acta eruditorum oder Geschichte der Gelehrten, welche den gegenwärtigen Zustand der Literatur in Europa begreiffen. Bd. 4, Leipzig 1715

[148] H.-A.-O. Reichard: Der Passagier auf der Reise in Deutschland, in der Schweiz, zu Paris und Petersburg. Bd. 1, Berlin 1811

[149] S. REyHER: Aller- und Unterthänigster Vorschlag/ Wie die bißhero gebräuchliche Calender also vereiniget werden können/daß/so lange die Welt ... stehen wird/ keine Unrichtigkeit/ noch Verrückung der Feste in der Christl. Kirche/ mehr zu befürchten. Kiel 1699

[150] G. B. Riccioli: Astronomice reformatce. Bonon 1665

[151] G. B. Riccioli: Chronologice reformatce et ad certas conclusiones redactce. Bononiæ 1669

[152] E. F. RössLeR: Die Gründung der Universität Göttingen - Entwürfe, Berichte und Briefe der Zeitgenossen. Göttingen 1855

[153] G. M. Roth, F. Schmitthenner: Anfangsgründe der teutschen Sprachlehre und Orthographie. Gießen 1825

[154] F. RüHL: Chronologie des Mittelalters und der Neuzeit. Berlin 1897

[155] J. J. Scaliger, C. Clavius: Elenchus et castigatio calendarii Gregoriani: a Christophoro Clavio Bambergensi Societatis Jesu castigata. Rom 1595 
[156] J. J. Schalch: Erinnerungen aus der Geschichte der Stadt Schaffhausen, zunächst für derselben Jugend. Band 2, Schaffhausen 1836

[157] C. W. von Schauroth: Vollständige Sammlung aller Conclusorum, Schreiben und anderer übrigen Verhandlungen des hochpreißlichen Corporis Evangelicorum. Band 1, Regensburg 1751

[158] C. SCHAPER: Neue archivalische Forschungen zur Lebensgeschichte von Professor Erhard Weigel (1625-1699). Archiv für Geschichte von Oberfranken. 39 (1959), S. 97-140.

[159] C. Schaper: Aus dem Kreis der Weigel-Schüler in Franken. Archiv für Geschichte von Oberfranken. 39 (1959), S. 141-155.

[160] R. E. SCHIELICKE: Erhard Weigel (1625-1699) und die Armillarsphäre für Eimmarts Observatorium in Nürnberg. S. 274-287 in [199].

[161] R. E. SchiELICKE (Hrsg.): Erhard Weigel - 1625 bis 1699. Barocker Erzvater der deutschen Frühaufklärung. Frankfurt am Main 1999

[162] H. SchlEE: Erhard Weigel und sein süddeutscher Schülerkreis. Heidelberg 1968

[163] H.-G. SchlotTer (Hrsg.): Die Geschichte der Verfassung und der Fachbereiche der Georg-August-Universität zu Göttingen. Göttingen 1994

[164] L. SchnurRer: Georg Hamberger aus Dinkelsbühl Professor der Medizin in Tübingen 1536-1599. Programm zum Jahresbericht der Oberrealschule mit Gymnasium Dinkelsbühl für das Schuljahr 1961/62. Dinkelsbühl 1962

[165] G. Schubart (Präses), C. Zimmermann (Resp.): Meditatio Mortis ex primo iuris obiecto. Disputation Universität Jena Februar 1699 VD17 12:139594Z

[166] H. SchüLING: Erhard Weigel (1625-1699) - Materialien zur Erforschung seines Wirkens. Berichte und Arbeiten aus der Universitätsbibliothek und dem Universitätsarchiv Giessen 18, 1970 
[167] G. H. Schwallenberg: Curieuser Geschichts-Calender, Darinnen alles, was sich in Vor- und Hinter-Pommern von Ao. 1600. Biß 1699. Denckwürdiges begeben, kürtzlich erzehlet wird. Stettin 1700

[168] M. Simon: Ansbachisches Pfarrbuch - die evangelischen-lutherische Geistlichkeit des Fürstentums Brandenburg-Ansbach 1528-1806. Nürnberg 1957

[169] E. SPIEss: Erhard Weigel, weiland Professor der Mathematik und Astronomie zu Jena, der Lehrer von Leibnitz und Pufendorf. Leipzig 1881

[170] D. Spleiss, J. J. Spleiss: Kurzer Bericht von einer newen Erfindung betreffend die Verbesserung und Vereinigung deß Alten und Newen Calenders nach welcher solche auf immer hin ohne Fehler angeordnet werden können. Schaffhausen 1699 VD17 1:085123W

[171] S. Spleiss: Beiläufftiger Bericht Von dem jezigen Cometsternen. Wie solcher In disem zu end lauffenden 1664. Jahr bei anfang deß Christmonats in Schaffhausen und benachbarten Orten beobachtet worden und bei klarem Himmel noch kan gesehen werden. Schaffhausen 1664 VD1723:288135L

[172] D. Steinmetz: Die Gregorianische Kalenderreform von 1582 - Korrektur der christlichen Zeitrechnung in der Frühen Neuzeit. Oftersheim 2011

[173] E. von Steinmeyer: Die Matrikel der Universität Altdorf. Würzburg 1912

[174] S. J. E. Sтоsch: Versuch in richtiger Bestimmung einiger gleichbedeutenden Wörter der deutschen Sprache. Bd. 2, August Mylius, Berlin 1780

[175] B. Studen: Geschichte der physischen Geographie der Schweiz bis 1815. Bern \& Zürich 1863

[176] J. C. Sturm: Collegium Experimentale, Sive Curiosum ... Nürnberg 1676 (Bd. 1) und 1685 (Bd. 2) 
[177] J. TiEdE: Calendarium Novum: Iuxta verissimam anni Solaris quantitatem 365. dier. hor. 47./. 50.//.16 8/37///. mediosque Lunae motus exquisitissimos, cum Sole singulis 592 annis modo perquam mirabili praecise in orbem redeuntes, accurat constructum, ita ut Aequinoctium vernum cum Feriis suis hebdomadicis ... Kiel 1699 VD1714:698332L

[178] G. Wagner: Erhard Weigel, ein Erzieher aus dem XVII. Jahrhunderte. Leipzig 1903

[179] E. Weigel (Präses), C. Vogel (Resp.): De Tempore in genere. Disputation Universität Leipzig 24. Januar 1652. Bauer 1652

[180] E. WeIgel: Speculum Temporis Civilis Das ist Bürgerlicher ZeitSpiegel ... Jena 1664 VD17 23:000473D

[181] E. WeIgel: Pancosmus Aethereus $\& 3$ Sublunaris, hoc est, Nova Globi Coelestis $\&$ Terrestris Adornatio. Jena 1670

[182] E. WeIgel: Ober- und Unter-Welt. das ist/ Eine neue Art der Himmels- und Erd-Kugel. Jena 1670

[183] E. WeIgel: Memoria Temporum, 8 Introductio brevis in Chronometriam. Jena 1677 VD17 3:302355K

[184] E. WeIGEL: Wegweiser zu der Unterweisungs-Kunst/ nicht nur des Verstandes; sondern auch des Willens. Jena 1688 VD17 14:068128R

[185] E. WeIGEL: Extract aus der Himmels-Kunst ... nechst kurtzer Designation der nutzbaren Vortrefflichkeit heraldischer Himmels-Globen .... Jena 1698

[186] E. Weigel: Copia Abermaligen Schreibens des Professoris Weigelii zu Jena an das Evangelische Corpus zu Regenspurg in dem Calenderwesen ... Jena den 10/20. Januarii 1699.

[187] E. Weigel: Brief an Georg Christoph Eimmart in Nürnberg vom 6. März 1699. Nachlass Georg Christoph Eimmart an der Russischen Nationalbibliothek in St. Petersburg, Band 1, Blatt 348.

[188] E. Weigel: Entwurff Der Conciliation, Des Alten und Neuen Calender-Styli, Welcher gestalt solche im Novembr. Ao. 1699. anzustellen ist. 1699 VD17 3:657550B 
[189] E. Weigel: Kurtzer Bericht von der Mathematika. Ediert von S. KRATOCHWIL. S. 123-137 in [122]

[190] E. WeIgel: Unmaßgeblicher Vorschlag wie dem Studio Mathematico auf Teütschen Universiteten zu helfen, und dadurch Des Landes Wohlfahrt zu befördern. Ediert von S. KRATOCHWIL. S. 137-138 in 122.

[191] E. WeigeL: Wienerischer Tugend-Spiegel, darinnen alle Tugenden ... vorgestellet und nebenst einer Mathematischen Demonstration von Gott wider alle Atheisten, zum Grund der Tugenden, beschrieben und mit Kupffern vorgebildet werden. Nürnberg 1687

[192] H. Weigelt: Geschichte des Pietismus in Bayern. Göttingen 2001

[193] G. D. E. Weyer: Samuel Reyher. Chronik der Universität zu Kiel. Kiel 1858

[194] J. E. B. WiedeBURG: Beschreibung der Stadt Jena nach ihrer Topographisch- Politisch- und Akademischen Verfassung. Jena 1785

[195] J. WING: Heptarchia mathematica, or, the seven branches of art. London 1693

[196] V. Wing: Astronomia Britannica. London 1652 \& 1669

[197] R. Wolf: Biographien zur Kulturgeschichte der Schweiz. Band1, Zürich 1858

[198] C. Wolff, H. WutTke: Christian Wolffs eigene Lebensbeschreibung. Leipzig 1841

[199] G. Wolfschmidt (Hrsg.): Astronomie in Nürnberg. Hamburg 2010

[200] J.H. ZEDLER: Grosses vollständiges Universallexikon aller Wissenschaften und Künste. Halle und Leipzig 1732 bis 1754

[201] J. von Zerzog: Beschreibung des Rathauses zu Regensburg. Regensburg 1858

[202] J. C. Zeumer: Vitae professorum theologice, iurisprudentice, medicincet philosophicequi in illustri Academia Ienensi ab ipsius fundatione ad nostra usque tempora vixerunt et adhuc vivunt. Jena 1711 
[203] Ulrich Junius.

http://de.wikipedia.org/wiki/Ulrich_Junius

[204] Melchior Gottlieb Minor.

http://de.wikipedia.org/wiki/Melchior_Gottlieb_Minor

[205] Johann Leonhard Rost.

http://de.wikipedia.org/wiki/Johann_Leonhard_Rost

[206] Johann Konrad Schwarz.

http://de.wikipedia.org/wiki/Johann_Konrad_Schwarz

[207] Johann Kaspar Wetzel.

http://de.wikipedia.org/wiki/Johann_Kaspar_Wetzel

[208] Gian Domenico Cassini.

http://www.britannica.com/EBchecked/topic/98187/...

... Gian-Domenico-Cassini

[209] Daniel Zimmermann. (Portrait in der Regensburger Portraitgalerie) http://rzbvm005.uni-regensburg.de/tut/anzeige.phtml?titel_id=4827

[210] Enormer Aufschwung der Jenaer Medizin. Klinikmagazin 04/2008 http://www.med.uni-jena.de/...

... klinikmagazin/archiv/km408/kmonline/mosaik.htm

[211] Georg Hamberger. (Professorengalerie der Universität Tübingen) http://www.studion.uni-tuebingen.de/mediawiki/index.php/...

...Professorengalerie:_Georg_Hamberger

[212] Währungsrelationen zur Kreuzerzeit in Bayern. http://web.archive.org/web/20070321043643/... ... http://home.fonline.de/rs-ebs/geschichte/gulden/gulden1.htm

[213] Verzeichnis der Globen von Erhard Weigel. http://www.erhard-weigel-gesellschaft.de/...

...Verzeichnis-der-Globen-vo.38.0.html

[214] David Spleiß. Normdatensatz der Deutschen Nationalbibliothek http://d-nb.info/gnd/123879892 
[215] Johann Jacob Spleiß. Normdatensatz der Deutschen Nationalbibliothek http://d-nb.info/gnd/123879868

[216] Lieuwe Willemsz Graaf http://www.gameo.org/encyclopedia/contents/... ... graaf_lieuwe_willemsz_1652_1704

[217] Der 30. Februar - ein Resultat aus der Angst vor verlorener Lebenszeit. Pressemitteilung FH Aachen vom 24. Februar 2012. http://www.fh-aachen.de/fileadmin/org/org_poem/medien_presse... ... mitteilungen/PM_FH_Aachen_Der_30._Februar.pdf

[218] Häufig gestellte Fragen zum Osterdatum - Dokument vom 31. Januar 2007. Ökumenischer Rat der Kirchen.

http://www.oikoumene.org/de/dokumentation/documents/oerk-... ... kommissionen/glauben-und-kirchenverfassung-kommission-fuer/i-. . . ... einheit-die-kirche-und-ihr-auftrag/haeufig-gestellte-fragen-zum-... ... osterdatum.html

[219] Gemeinsam Ostern feiern oder Die bleibende Bedeutung von Nizäa. Catholica Unio der Schweiz. http://www.kath.ch/cus/index.php?\&na $=0,0,0,0, d, 90822,0,0$

[220] Das Kalender-Patent vom 10. Mai 1700. http://www.ari.uni-heidelberg.de/geschichte/kal_patent.html

[221] http://www.goethe-genealogie.de/

[222] http://www.teu-net.de/geschichte/texte/muenze-geld.html 



\section{Register}

Aberglaube, siehe auch Kalenderun- Aventinus, Petrus, 79 fug, $57,60,70,79$

Abner, 58, 59

Albrecht, Herzog von Sachsen-Coburg, 159

Albrecht, Johann Wilhelm, 36

Aleppo, 26

Altdorf, 35, 39, 102, 118, 135

Universität Altdorf, 27, 29, 30, 35, 109,165

Alumni, 33

Amsterdam, 116

Anhalt, 98

Ansbach, 26, 27, 32

Apostel Matthias, 122

Äquinoktium, 22, 23, 26, 46, 84, 88,

90, 96, 100, 107, 123, 128,

$138,140,144$

Argoli, Andrea, 83, 88, 159

Arnisaeus, Jodocus, 79

Asahel, 58, 59

Astrologie, siehe auch Kalenderunfug, 18, 79, 80, 103, 104, 122 ,

159

Astronomischer Calculus, 25, 26, 40,

53, 74, 86, 88, 89, 99, 101,

103, 105, 109, $122,124,127$.

$128,139,140,145$

Aubelin, Barbara, 26

Bayern, 98

von Beichlingen, Wolfgang Dietrich, 119

Berlin, 61, 113, 114, 116

Akademie der Wissenschaften, 20, 39, 41, 112,116, 118 120, 161, 162, 164, 166

Beyer

,- Elisabeth, 35

-, Johann David, 35

Beyerberg, 26, 28

Bibel, Das zweite Buch Samuel, 58

Blasche, Johann Christian, 36

Blasheim, 31, 164

Bodensee, 109, 161

Bohse, August, 79

Boulliau, Ismael, 86, 117, 119, 125. 159, 164

Brahe, Tycho, 11, 80, 99, 125, 130. 156, 158, 159,162

Brandenburg, siehe auch Kurbrandenburg, 41, 116, 118

Braun, Graf von Braun, 95

Braunschweig, 105

Braunschweig-Wolfenbüttel, 98

Breviarium Romanum, 141

Bruder Erasmi, siehe von Huldenberg, Daniel Erasmus 
Bruderkrieg, 58

Buß- und Bettag, 21

Bulle „Inter gravissimas“, 17, 73, 163

Butterfladen, Ernst Dieterich, 79

Cäsar, Julius, römischer Kaiser, 137,

$$
\text { 141, } 159
$$

Cöler

-, Barbara, 26, 28

-, Caspar, 27

-, Johann Achatius, 30

-, Johann Philipp, 27

-, Martin Clemens, 28, 30

-, Philipp Albrecht, 28

Cassini, Giovanni Domenico, 93, 94. 96, 117, 119, 130, 159, 164

Cassinische Kurven, 159

Christentum, 22, 54, 62, 90, 102, 106, 138

Christi Himmelfahrt, 21

Christian V., König von Dänemark und Norwegen, 47, 62, 110 , 159

Clavius, Christopher, 11, 71, 73, 90, 139, 159

Clemens VIII., Papst, 141, 159

Coburg, 30

Collegium Artis Consultorum, 10 , 20, 40, 41, 43, 44, 48, 49. $5157,60,62,67,68,771,72$, $74,76,79,81,83,85,94,96$ 103, 105, 107, 108, 111,113 , 115, 116, 118, 120, 121, 125. 129, 131 135, 146, 155, 157, 162,163

Collegium Jenense, 33, 34

Collegium
- Astronomici, siehe Collegium Artis Consultorum

- Mathematici, siehe Collegium Artis Consultorum

- Mathematicum, siehe Collegium Artis Consultorum

Collegium Romanum, 159

Corpus Evangelicorum, 26, 40, 71. 75. 81, 83, 86, 87, 95, 99 102, 105, 106, 112, 117, 119 $121,124,126,127,129,134$ 137, 146

Crailsheim, 28

Dänemark, 20, 59, 61, 62, 110, 158

Danzig, 94, 99, 116, 161, 165

Datumsgrenze, 88

Deiningen, 29

Disputation, 18, 30, 31, 34, 50, 59. 67, 70, 161, 164

Dreißigjähriger Krieg, 28, 62

Dresden, 114, 117, 120

Ehingen, 26

Eimmart, Georg Christoph, 45, 46, 48, 115, 159

Eisenach, 48, 64, 68, 72

Eisleben, 163

Ekliptik, 144

Endter, Familie, 76, 78, 116

England, 109

Ephemeriden, 83, 84, 86, 87, 89, 93 96, 100, 106,108, 117, 119 . 120, 123, 125, 148, 161, 166

Erfurt, 36, 97, 98, 163

Universität Erfurt, 163

Europa, 47, 62, 70, 98, 106

Fürth, 27 
Fabricius, Georg Philipp, 50, 52, 56, 61, 63, 67, 68, 101, 102, 108 160

Fastnacht, 117

Feuchtwangen, 27

Flamsteed, John, 93, 94, 117, 119, 160

Florin, 98

Francke, August Hermann, 114, 116. 160

Franckesche Stiftungen, 116, 160

Friedrich August I., Kurfürst von Sachsen und König von Polen, 40, 92, 120, 160

Friedrich I., König in Preußen, 160

Friedrich II., Herzog von SachsenGotha und Altenburg, 160

Friedrich II., König von Preußen und Kurfürst von Brandenburg, 26, 160

Friedrich III., Kurfürst von Brandenburg, 41, 108, 113, 116, 160

Fritsch, Thomas, 40, 91, 93, 95, 114 . 160

Fronleichnam, 117

Frühlingsanfang, siehe auch Äquinoktium, 22, 24, 144

Frühlingsvollmond, 22, 24, 26, 46, 88 von Fuchs, Paul, 103, 104,160

Göttingen, 36, 47

Nds. Staats- und Universitätsbibliothek, 9, 12, 74, 168

Städtisches Museum, 11

Universität Göttingen, 34, 36

Gaupp, Johannes, 107, 109, 161

Gera, 110, 164

Gießen, 160
Gnüge, Heinrich Michael, 36

Goethe, Johann Wolfgang, 27

Goldene Zahl, 78, 138, 145

Golzen, 166

Gotha, 44, 49, 76, 78, 79, 108, 164 , 166

Gottesbeweis, 11, 67, 68

Graaf, Lieuwe Willemsz, 116

Greenwich, 11, 88, 160

Meridian von Greenwich, 89

National Maritime Museum, 11

Royal Observatory, 94

Gregor XIII., Papst, 17, 46, 137, 138,

Guben, 116

$$
\text { 141, } 161
$$

Gulden, 98

Halle, 61, 114, 116, 160, 166

Universität Halle, 160

von Haller, Albrecht, 36

Hamberger

-, Anna Catharina, 35

-, Anna Dorothea, 35

-, Clara Elisabetha, 35

-, Georg, 27

-, Georg (Urgroßvater), 26

-, Georg Albrecht, 9, 19, 26, 39, 152, 102, 113, 119, 121, 124

-, Georg Albrecht (Großvater), 26

-, Georg Erhard, 36, 166

-, Georg Friedrich, 27

-, Georg Ludwig (Bruder), 27

-, Georg Ludwig (Vater), 26, 29

-, Georg Philipp, 27

- , Hans Georg, 27

-, Hans Philipp, 27

-, Johann Friedrich, 27 
-, Maria Catharina, 27, 29

-, Maria Salome, 27

-, Maria Sibylla, 27

-, Susanna Hedwig, 36

Familie, 27, 28, 35

Hannover, 112

Heidelberg

Universität Heidelberg, 73

Heilige Drei Könige, 117

Heiliges Römisches Reich, 62, 97 . $122,124,135,155,163$

Heilsbronn, 29, 30

Fürstenschule, 2830

Kloster, 28

Helmstedt, 104, 113,114

Universität Helmstedt, 115, 164

Herbstanfang, 144

Herford, 31

Hertel, Apollonia, 27

Herzog

- von Sachsen-Coburg, 48, 51. 57, 159

- von Sachsen-Eisenach, 41, 48 . 50, 51, 57, 68, 79, 102, 160. 161

- von Sachsen-Gotha und Altenburg, 48, 51, 57, 160

- von Sachsen-Saalfeld, 161

- von Sachsen-Weimar, 33, 36, 41, 48, 50, 51, 57, 79, 102, 160, 161, 166

Hessen-Kassel, 98

Heuber, Veit Benedict, 70

Hevelius, Johannes, 93, 94, 96, 99 . $116,119,161$

Hilpoltstein, 29

Himmelsäquator, 144
Hocker, Johann Ludwig, 32, 161

Hoffmann, Johann Heinrich, 11, 56. $59,61,63,65,67,68,74,75$ 81, 83, 88, $93,107,109,117$. 126,161

Hofmann, Heinrich, 11, 74, 161

Horoskop, 18

Hußwedel, Maria Sophia, 27 von Huldenberg, Daniel Erasmus, 63 65, 95, 111, 114, 118, 160, 161

Infinitesimalrechnung, 35

Israel, Königreich, 58

Jablonski, Daniel Ernst, 112,115

Jahrtausend, 98, 140

Jena, 9, 10, 20, 21, 28, 30, 34, 36, 40, 44, 45, 47, 48, 63, 64, 81, $102,109,110,113,114,126$. 135, 159, 162, 164,166

Collegium Jenense, 33, 34

Sieben Wunder Jenas, 38

Thür. Universitäts- und Landesbibliothek, 34

Universität Jena, 18, 20, 27, 3032, 34,36, 39, 48, 59, 63. 104, 161,164, 166, 167

Jerusalem, 22, 85, 90, 106

Meridian von Jerusalem, 26, 84 88, 106

Johann Ernst, Herzog von SachsenSaalfeld, 161

Johann Wilhelm, Herzog von Sachsen-Eisenach, 161

Juda, Königreich, 58

Julius Cäsar, römischer Kaiser, 137 141, 159 
Junius, Ulrich, 11, 34, 55, 58, 85, 86 , 89, 92, 94, 96, 108, 114, 117 $119,120,126,161$

Kaiser

Heiliges Römisches Reich, 163

Julius Cäsar, 137, 141, 159

Konstantin I., 162

Leopold I., 137

Kalender

Gregorianischer Kalender, 11 , 17, 19, 21, 24, 26, 46, 53, 61, 64, 76, 77, 79, 80, 90, 117. 121, 128, 136, 137, 139, 159

Julianischer Kalender, 17, 20,

$23,25,60,66,70,77$

Schwedischer Kalender, 66

Verbesserter Kalender, 20, 36,

40, 75, 79, 80, 86, 89, 92 109, 121, 122, 127, 136, 137 . 139,161

Kalenderunfug, 18, 62, 64, 79

Karl XI., König von Schweden, 162

Karl XII., König von Schweden, 66, 162

Kepler, Johannes, 25, 40, 93, 95, 119 . 123, 125, 156, 162, 163

Kiel, 50, 164

Universität Kiel, 166

Kirch, Gottfried, 11, 41, 58, 71, 76, $80,83,86,89,91,92,114$ 117, 119, 120, 126, 161, 162

Kloster

Heilsbronn, 28

Unser lieben Frauen, 104, 163

Köhler, Georg Nicolaus, 32

König

- Israels, 164
- in Preußen, 160

- von Dänemark und Norwegen, 110, 159

- von England, 161

- von Polen, 40,160

- von Preußen, 26

- von Schweden, 66, 162

Königsberg, 116, 163

Konstantin I., römischer Kaiser, 23 .

138,162

Kopenhagen, 110

Sternwarte, 110

Universität Kopenhagen, 110 . 164

Körber, Christian, 55, 57, 162

Kraslice, 39

Krebs, Johann Friedrich, 27, 28

Kuhle, Adolph Friedrich, 35

Kühn, Johannes, 19, 162

Kurbrandenburg, 41, 98, 115, 116. 119

Kurfürst

- von Brandenburg, 26, 41, 108,

113, 116, 160

- von Hannover, 161

- von Sachsen, 40, 92, 120, 160

- von der Pfalz, 73, 163

Kursachsen, 40, 91, 93, 95, 98, 108, 160

de La Hire, Philippe, 117, 119,162

Laelius

-, Agnes, 27

-, Lorenz, 27, 28

Landsberg, Philipp, 125

Langensalza, 76, 78, 79, 85, 89

Lehesten, 36

Leibnütz, Friedrich, 20 
Leibniz, Gottfried Wilhelm, 20, 35. 39, 40, 69, 75, 80, 108, 111, $112,114,116,118,120,162$, 164

Leiden, 29,165

Leipzig, 19, 40, 58, 91, 92, 95, 108, 111, 114, 116, 139, 164,166

Leipziger Messe, 139

Universität Leipzig, 18,20, 161. 162

Universitätsbibliothek, 120

Lentersheim, 32

Leopold I., Kaiser, 20, 46, 56, 58, 60. $62,76,79,95,112,113,137$, 163

Leyden, 164

Lindau, 109, 161

von der Lith

-, Heinrich, 32

-, Johann Wilhelm, 32

Lobenstein, 55, 57

London, 161

Royal Society, 93, 109,160

Lotterie, 163

Ludolf, Hiob, 85, 86, 97, 98, 163

Ludwig VI., Pfalzgraf bei Rhein und

Kurfürst von der Pfalz, 73 , 163

Luther, Martin, 25

von Lyncker, Nikolaus Christoph, 61, $63,68,163$

Magdeburg, 103, 104, 108, 163

1. Mai, 21

Mariä Lichtmess, 117

Mariä Reinigung, 117, 137

Mästlin, Michael, 71, 73, 159, 163

Matthias, Apostel, 122
Mercklein, Albert Daniel, 34

Meridian

von Greenwich, 89

von Jerusalem, 26, 84, 88, 106

von Uraniborg, 88, 106, 125

Merseburg, 166

Meyer, Johannes, 9, 39, 45, 50, 52. $57,59,64,65,73,75,80,86$. 98, 102, 110, 111, 113, 118, 121, 124, 163, 165

Mezzavacca, Flaminio, 119

Minor, Melchior Gottlieb, 34

Missale Romanum, 141

Monatlicher Staats-Spiegel, 41, 62. 98, 119

Mond, 23, 24

Mondjahr, 84, 125

Müller, Philipp, 103, 104, 108, 162. 163

Neujahr, 21

Neumond, 22

Nicäa, Konzil von Nicäa, 23, 44, 54 . 73, 84, 90, 105, 106, 109. 125, 128, 138, 139, 141

Nothnagel, Christoph, 19, 163

Nullmeridian, 88

Nürnberg, 11, 45, 47, 48, 50, 61, 73 . 95, 113, 114, 118, 159, 165 . 167

Germanisches Nationalmuseum, 11

Sternwarte, 159

Öfelein, Anna Christina, 27

Ökumenischer Rat der Kirchen, 26

Osterdatum, 9, 22, 26, 46, 61, 63, 64.

71, 73, 74, 76, 84, 86, 90, 91 . 
101, 109, 112, 122, 123, 125, Prognostik, 18, 59, 64, 70, 80, 82,

\section{8,138}

Osterfest, 21, 22, 85, 88, 105, 106 . 137, 146

Osterlamm, 91,144

Osterparadoxon, 24, 46, 53, 110, 140

Ostersonntag, 22, 24, 46, $90,128,138$

Ostervollmond, 96, 99, 100, 106, 107,

Oxford, 161

$$
123,138,140
$$

Padua

Universität Padua, 159

Palästina, 106

Pancosmos, 20, 44, 46, 47, 63, 65, 98

Papst

Clemens VIII., 141, 159

Gregor XIII., 17, 137, 138, 141. 161

Pius V., 141,164

Paris

Akademie der Wissenschaften 93, 94, 106, 159, 162, 164

Sternwarte, 94

Passahfest, 22, 23, 61, 64, 71, 73, 88, 90, 91, 106, 112, 128, 138,

\section{6}

Pfalzgraf bei Rhein, 73,163

Pfingstfest, 21, 137

Philolai (Pseudonym), 86, 117, 164

Pietismus, 116, 160

Pius V., Papst, 141, 164

Plenilunio, siehe Vollmond

Pommern, 83

Posner

-, Johann Kaspar, 109, 110, 164

-, Kaspar, 109, 110, 164

Prag, 63

\section{4, 127}

Rabus

-, Johann Ludwig (der Jüngere), 28

-, Johann Ludwig (der Ältere), 28

-, Ludwig, 26

- , Ursula, 26, 28

Redeker, Conrad Philipp, 31, 164

Reformation, 25

Regensburg, 19, 32, 39, 40, 43, 4547, $49,52,59,61,64,65,72$, 73, 76, 86, 98, 99, 101 103, 108, 111, $113,114,117,118$, $135,136,146,155,163,164$ 167

Immerwährender Reichstag, 1821, 39, 45, 49,51, 57, 98, $102,112,134,155,160,163$

Reichardt

-, Christoph Friedrich, 36

-, Johann August, 36

Remda, 35

Reyher, Samuel, 44, 46, 49, 50, 55, $68,70,80,164$

Riccioli, Giovanni Battista, 90, 91. 93, 95, 117, 119, 164

Rolfinck, Werner, 164, 166

Rømer, Ole Christensen, 106, 108 110, 120, 164

Römisches Reich, 22

Ronneburg, 35, 165

Rose, Christian Gottfried, 36

Rost, Johann Leonhard, 34

Rücker, Johann Michael, 27

Rudolfinische Tafeln, 25, 40, 82, 83, 
86, 88, 96, 98, 101, 111, 112 , 117, 119, 123, 125, 126, 156, 162

Rudolstadt, 35

Rügen, 62

Sachsen, siehe auch Kursachsen, 19 . 161

Sächsischer Landtag, 19

Saul, König Israels, 58, 164

Schöppenstuhl, 163

Schad, Herr von Schad, 44, 49, 56. $60,63,65,86,95$

Schaffhausen, 57, 165

Schaltjahr, 66

Schmidt, 83, $103,105,108$

Schmidt, Johann Andreas, 40, 104. 112, 114, 116, 118, 164

Schumann, Maria, 56, 59, 60, 91, 93

Schwarz, Johann Konrad, 34

Schweden, 20, 59, 61, 62, 66, 70, 110, 122

Schwedisch-Pommern, 62, 66

Sonnenfinsternis, 68, 70, 109

Sonnenjahr, 21, 24, 84, 125, 137, 141

Sonnenuhr, 109

Sonntagsbuchstabe, $75,78,83,85$

Spitz

-, Felix, 35, 44, 45, 60, 65, 72, 86. 91, 95, 114, 118, 165,166

-, Sophia Katharina, 35, 38, 45 , 165

Spleiß

-, David, 55, 57, 165

-, Johann Jacob, 55, 57, 165

-, Johannes, 57, 165

-, Stephan, 55,57

-, Thomas, 57, 165
Stargard, 83

Stettin, 62

Stockholm, 61, 62

Straßburg, 29

Strauch, Aegidius, 19, 165

Sturm, Johann Christoph, 29, 39, 44 46, 54, 57, 60, 72, 76, 78, 83 85, 86, 89, 91, 94, 97, 102. 107, 121, 124, 165

Sulzbach, 48

Syrien, 26

Tübingen, 73, 163,165

Talander, Albert, 79

Teuber, Gottfried, 72, 75, 166

Thüringen, 98

Thür. Hauptstaatsarchiv, 70

Thüringer Wald, 43, 45,47

Theissen, 75

Tiede, Joachim, 49, 50, 55, 166

Trient, Konzil von Trient, 141

Triumviri, 39, 46, 115, 119

Tugendlehre, 67, 69, 70

Tugendschule, 69

Uraniborg, 158, 159

Meridian von Uraniborg, 88 , 106, 125

Ven, 159

Vogel, Christoph, 18

Vollmond, 22, 23, 71, 84, 88, 91, 105. 106, 128

Vorpommern, 62

de Voss, 116

Wahrsagerei, 64, 72, 97

Walburger, Michael, 70

Wallenstein, 159 
Wallis, John, 119

Wedel

-, Ernst Heinrich, 48, 166

-, Georg Wolfgang, 43, 48, 166

-, Johann Adolph, 36, 48, 166

-, Sophia Margaretha, 36

Weiden in der Oberpfalz, 18, 166 Weigel

-, Anna Elisabetha, 35

-, Anna Katharina, 35, 45, 56. 59, 60, 165, 166

-, Erhard, 9, 11, 18, 25, 28, 30 31, 33, 36, 38, 40, $43,48,51$. 56, $58,64,67,70,72,74,76$. 79, 80, 86, 97, 106, 107, 109 . 110, 112, 113, 136, 159, 161 . $162,164,166$

-, Margareta, 61, 63, 166

Weigeliana Domus, 38

Weihnachten, 21, 137

Weimar, 33, 48, 61, 63, 68, 108, 163

Anna Amalia Bibliothek, 38

Thür. Hauptstaatsarchiv, 70

Wendelin, Gottfried, 125

Wenner

-, Barbara, 27, 28

-, Johann, 28

Wetterbeobachtungen, 67, 70, 80, 127

Wetzel, Johann Kaspar, 34

Wien, 20, 44, 47, 49, 56, 59, 60, 63. 65, 95, 97, 161

Wilhelm Ernst, Herzog von Sachsen-

Weimar, 166

Windsheim, 27

Wing

,- John, 119, 166, 167
-, Tycho, 167

-, Vincent, 93, 95, 119, 166

Wittenberg, 32, 163, 165, 166

Universität Wittenberg, 19, 163 , 165

Wolff, Christian, 34, 80

Wurzelbauer, Johann Philipp, 96, 119, 167

Zeit, Lehre von der Zeit, 11, 68

Zeitspiegel, 18, 85, 88, 106

Zeitz, 75, 166

Zimmermann, 32, 49, 50, 65

-, Christian, 55, 59, 167

-, Daniel (Sohn), 55, 59, 167

-, Daniel (Vater), 32, 50, 55, 59 . 60, 91, 93, 167

Zyklischer Calculus, 53, 105, 122. 127, 138, 140

19-Jahre-Zyklus, 23, 24, 138 
Mit der päpstlichen Bulle „Inter Gravissimas“ wurde 1582 der nach Papst Gregor XIII. benannte Gregorianische Kalender eingeführt. In Deutschland wurde dieser Kalender anfangs nur von katholisch regierten Ländern übernommen. Die protestantischen lehnten ihn grundsätzlich - weil vom Papst angeordnet - ab. Das führte zum Paradoxon einer doppelten Kalenderführung in Deutschland während des gesamten 17. Jahrhunderts. Nachdem die Spaltung der Zeitrechnung und des Kalenderwesens in Deutschland über ein Jahrhundert angedauert hatte, wurde von den evangelischen Reichständen auf dem Immerwährenden Reichstag in Regensburg im September 1699 eine Kalenderreform beschlossen und im Jahr 1700 umgesetzt. Die in dieser Edition anlässlich seines 350. Geburtstages veröffentlichten Briefe und Manuskripte des Mathematikers Georg Albrecht Hamberger stammen aus den Jahren 1699 und 1700 und stehen im Zusammenhang mit seinen Aktivitäten im Zuge der Kalenderreform von 1700.

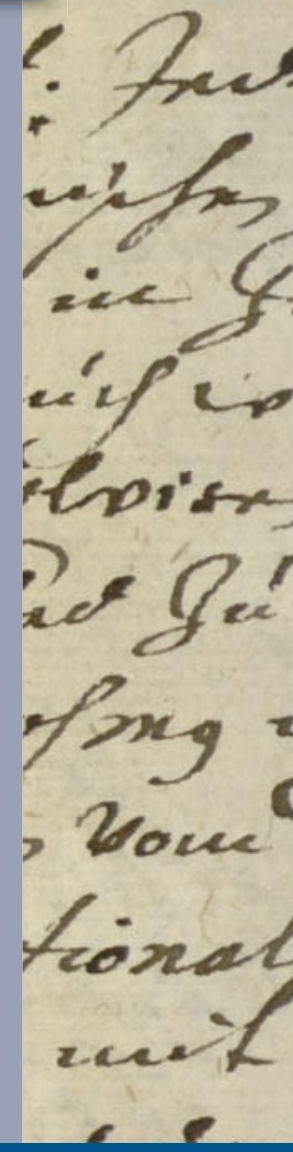

\section{Universitätsverlag Göttingen}

